\title{
De-escalating management of primary and locally recurrent breast cancer
}

Citation for published version (APA):

Poodt, IGM. (2019). De-escalating management of primary and locally recurrent breast cancer. [Doctoral Thesis, Maastricht University]. Maastricht University. https://doi.org/10.26481/dis.20191101ip

Document status and date:

Published: 01/11/2019

DOI:

10.26481/dis.20191101ip

Document Version:

Publisher's PDF, also known as Version of record

\section{Please check the document version of this publication:}

- A submitted manuscript is the version of the article upon submission and before peer-review. There can be important differences between the submitted version and the official published version of record.

People interested in the research are advised to contact the author for the final version of the publication, or visit the DOI to the publisher's website.

- The final author version and the galley proof are versions of the publication after peer review.

- The final published version features the final layout of the paper including the volume, issue and page numbers.

Link to publication

\footnotetext{
General rights rights.

- You may freely distribute the URL identifying the publication in the public portal. please follow below link for the End User Agreement:

www.umlib.nl/taverne-license

Take down policy

If you believe that this document breaches copyright please contact us at:

repository@maastrichtuniversity.nl

providing details and we will investigate your claim.
}

Copyright and moral rights for the publications made accessible in the public portal are retained by the authors and/or other copyright owners and it is a condition of accessing publications that users recognise and abide by the legal requirements associated with these

- Users may download and print one copy of any publication from the public portal for the purpose of private study or research.

- You may not further distribute the material or use it for any profit-making activity or commercial gain

If the publication is distributed under the terms of Article $25 \mathrm{fa}$ of the Dutch Copyright Act, indicated by the "Taverne" license above, 

Copyright 2019 Ingrid Poodt

All rights reserved. No part of this thesis may be reproduced or distributed in any form or by any means, without the prior written permission of the author or publisher.

Layout: Tiny Wouters

Cover: Lisa Bekelaar

Printed by: GVO Drukkers en Vormgevers BV

ISBN: 978-94-6332-567-7

Publication of this thesis was financially supported by Catharina Ziekenhuis Eindhoven, Maastricht University-GROW-School for Oncology \& Development Biology, Integraal Kankercentrum Nederland, Rabobank Eindhoven-Veldhoven, Erbe Nederland, Tromp Medical BV, Chipsoft.

Part of the research described in this thesis was supported by a grant from the Dutch Cancer Society-KWK (Grant number: 2009-4466) 


\section{De-escalating management of primary and}

\section{locally recurrent breast cancer}

\section{PROEFSCHRIFT}

Ter verkrijging van de graad van doctor aan de Universiteit Maastricht, op gezag van Rector Magnificus prof. dr. Rianne M. Letschert volgens het besluit van het College van Decanen,

in het openbaar te verdedigen

op vrijdag 1 november 2019 om 12:00 uur

door

Ingrid Gerdine Marthe Poodt 


\section{Promotor}

Prof. dr. H.J.T Rutten

\section{Copromotores}

Dr. G. A.P. Nieuwenhuijzen, Catharina Ziekenhuis Eindhoven

Dr. R.J. Schipper, Catharina Ziekenhuis Eindhoven / Antoni van Leeuwenhoek Ziekenhuis

Dr. G. Vugts

\section{Beoordelingscommissie}

Prof. dr. V.C.G Tjan-Heijnen, voorzitter

Prof. dr. L.J. Boersma

Prof. dr. J.A. Roukema, Tilburg University

Prof. dr. E.J.Th. Rutgers, Universiteit van Amsterdam

Dr. M.L. Smidt 



\section{TABLE OF CONTENT}

CHAPTER 1 General introduction and outline of the thesis

PART I DE-ESCALATION OF AXILLARY MANAGEMENT IN PRIMARY BREAST CANCER PATIENTS

CHAPTER 2 Trends on axillary surgery in nondistant metastatic breast cancer patients treated between 2011-2015; A Dutch population-based study in the ACOSOG-Z0011 and AMAROS era

CHAPTER 3 The administration of adjuvant chemo(-immuno) therapy in the post ACOSOG-Z0011 Era; A population-based study

CHAPTER 4 The rationale for and long-term outcome of incomplete axillary staging in elderly women with primary breast cancer

\section{PART II PREOPERATIVE DISTANT STAGING AND DE-ESCALATION OF AXILLARY MANAGEMENT IN PATIENTS WITH AN IPSILATERAL BREAST TUMOR RECURRENCE}

CHAPTER 5 Screening for distant metastases in patients with ipsilateral breast tumor recurrence; The impact of different imaging modalities on distant recurrence-free interval

CHAPTER 6 Repeat sentinel lymph node biopsy for ipsilateral breast tumor recurrence; A systematic review of the results and impact on prognosis 
CHAPTER 7 Risk of regional recurrence after negative repeat sentinel lymph in patients with ipsilateral breast tumor recurrence

CHAPTER 8 Low risk of development of a regional recurrence after an unsuccessful repeat sentinel lymph node biopsy in patients with ipsilateral breast tumor recurrence

CHAPTER 9 Prognostic impact of repeat sentinel lymph node biopsy in patients with ipsilateral breast tumor recurrence

PART III

CHAPTER 10 Summary, discussion and recommendations 167 Nederlandse samenvatting, discussie en aanbevelingen

\section{APPENDIX}

Valorisation

List of publications

209

Dankwoord

Curriculum Vitae 



\section{Chapter 1}

General introduction and outline of the thesis 


\section{General introduction}

Since ancient times, the female breast has been a symbol of fertility, femininity, and beauty. ${ }^{1}$ Breast cancer is, worldwide, the most common cancer in women and the second most common cancer overall. ${ }^{2}$ It has challenged and still challenges physicians, because removal by surgery, inevitably, causes disfigurement and has a great impact on the quality of life of breast cancer survivors.

The diagnosis and treatment of breast cancer has changed extensively ${ }^{3}$ due to a better understanding of tumor biology, the development of diagnostic tools, multimodality treatment options and a better perception of the impact of invasive procedures on the quality of life of patients. Ever since axillary nodal involvement has been recognized as an indicator of poor prognosis, axillary management has been a routine component of breast cancer treatment. Consequently, the role and the management of the axillary lymph nodes has been in continous change.

The current chapter consists of an overview of the changes in the management of axillary lymph nodes in patients diagnosed with breast cancer. Among others, it describes the influence of the de-escalation of axillary surgery on the administration of adjuvant chemotherapy and the impact of different imaging modalities used for preoperative staging patients with recurrent breast cancer on the occurrence of distant recurrences after IBTR. Special attention will be given to the de-escalation of axillary surgery in the primary setting and the use of sentinel lymph node biopsy (SLNB) instead of axillary lymph node dissection (ALND) in patients with ipsilateral breast tumor recurrence (IBTR). From this overview, several present challenges concerning axillary lymph node management are being discussed and addressed in this thesis.

\section{Historical perspective on axillary lymph node surgery}

Often thought as a modern disease, breast cancer has afflicted people since ancient times. The management of breast cancer evolved slowly through the centuries up to the Renaissance due to an absence of scientific knowledge of tumor behavior and effective treatments. ${ }^{4}$ Thereby, the practice of medicine was largely stagnant in the middle ages since it was believed that diseases were a punishment of God which only faith could cure. Monotheistic religions prohibited anatomical dissection and putted a ban on the mutilated practice of surgery. ${ }^{4}$ During the Renaissance, characterized by a movement away from the theological influence, medical practice was stimulated and physicians were encouraged to study human anatomy. As a result, the role of breast cancer surgery and axillary lymhp node management evolved. ${ }^{1}$

\section{En bloc clearance of the axilla}

In the $16^{\text {th }}$ century, the French surgeon Ambroise Paré was the first to recognize the spread of breast cancer to regional lymph node basins. Paré described the swelling of 
axillary lymph nodes as follows: "When cancer possesses the breasts it often causes inflammation of the armholes and sends the swelling even to the glandules thereof". 5,6 Soon after, the first surgeons tried to remove enlarged axillary lymph nodes, although, surgical approaches were primitive due to technical issues and the fact that anesthesia was not yet developed for surgical procedures. ${ }^{7}$ Later on, the development of various elements of anesthesiology and intravenous medications, eliminated the pain of surgery. In the $18^{\text {th }}$ century, axillary nodal involvement was recognized as indicative for a worse prognosis and the idea of tumor cell dissemination through the lymphatics was introduced. ${ }^{5}$ From that moment, axillary nodal surgery became a component of breast cancer surgery and surgeons recommended to routinely remove enlarged nodes.

The introduction of microscopic examination in the second half of the $19^{\text {th }}$ century revealed the cellular origin of breast cancer and its patterns of progression. The management of the axillary lymph nodes was radically influenced by the ideas of Rudolf Virchow, the founder of cellular pathology. Virchow considered that regional lymph node metastases represented a temporary barrier to distant disease. Subsequently, for patients with enlarged nodes, a complete ALND was advocated. The American surgeon dr. William Halsted, greatly influenced by Virchow's ideas, set a new standard in the development of breast and axillary surgery; the Halsted mastectomy, also known as the radical mastectomy. ${ }^{8,9}$ He believed that breast cancer had an initial local behavior with a predictable sequential path of cell dissemination, from the breast to the axillary lymph nodes, and only then possibly to distant locations. Halsted developed a technique that would remove the whole tumor in one piece: an "en bloc removal" of the entire breast, pectoralis major muscle and wide resection of the skin and axillary nodes. ${ }^{10}$ Complete ALND was postulated for all patients with breast cancer, regardless of whether the lymph nodes were clinically tumor positive.

In the $20^{\text {th }}$ century, the Halstedian principles dominated and cancer was regarded as a local-regional disease that spread in an orderly fashion based on mechanical considerations. ${ }^{11}$ In addition, the bloodstream was considered to be of little importance in tumor cell dissemination. Both the extent and nuances of surgery were the dominant factors influencing the patient's outcome rather than biological tumor factors. Inadequate surgery was seen as the cause for locoregional recurrences. ${ }^{11}$ Large radical anatomic resections of breast tumors were performed, based on no scientific rationale. Likewise, axillary lymph node surgery was regarded as an important procedure to ensure regional control by removal of all possible tumor cells in the axillary nodes. ${ }^{12}$ For a long time, the goal of an ALND was purely therapeutic and the standard procedure to assess the axillary lymph node status. ALND is an invasive procedure, associated with considerable short- and long-term morbidities. It is prone to disturb the lymph node channels resulting in lymphoedema, as well as seroma, shoulder pain, paraesthesia, and impaired range of motion of the shoulder. ${ }^{13,14}$ These associated morbidities are all known to have a negative impact on the quality of life of breast cancer patients. ${ }^{15,16}$ 


\section{The paradigm shift to a less invasive procedure}

A new surgical era arose when breast cancer surgery began to be influenced by laboratory and clinical research, creating new insights for breast cancer management. ${ }^{11}$ Biological, rather than anatomic factors were found to be responsible for the appearance of metastasis in certain nodes. ${ }^{11}$ Recurrence and survival tended to be independent of the number of axillary nodes removed. ${ }^{17}$ The first clinical trials, i.e. the National Surgical Breast and Bowel Project (NSABP)- $04,{ }^{18}$ showed results justifying less radical surgery. With the introduction of a more biological treatment approach of breast cancer, complete axillary lymph node surgery was no longer considered a solely therapeutic procedure. ALND became a diagnostic staging tool for clinically nodenegative breast cancer patients. ${ }^{12}$ The number of affected nodes in the ALND specimen determined the prognosis and was therefore also an indication for adjuvant treatment. Due to the rapid expansion in medical knowledge, developments were seen in multiple areas of medicine. Besides improvements in surgery, adjuvant therapies were discovered. ${ }^{4}$ In the second half of the $20^{\text {th }}$ century, Bernard Fisher investigated the role of cytotoxic drugs in improving breast cancer treatment, inaugurating the concept of adjuvant treatments. ${ }^{4}$ Further studies followed on the efficacy of chemotherapy and different chemotherapy schedules. ${ }^{19}$ With the availability of these new therapeutic options, physicians started to combine treatment modalities. Partial breast surgeries followed by radiotherapy, chemotherapy and hormonal therapy, when applicable, were performed. Hereby, reducing radical surgery, related morbidities and improving cosmetic outcomes.

Considering, ALND as a diagnostic rather than only therapeutic tool, there was a need for a less invasive axillary lymph node procedure, associated with less morbidity. In only $40 \%$ of the patient who were treated with ALND, metastatic lymph nodes were present. Feasible technological innovations and developments started to play a role and the SLNB was introduced in the early 1990s. The sentinel lymph node(s), are defined as the first node(s) to which cancer cells are most likely to spread from a primary breast tumor. ${ }^{12}$ The technique of sentinel lymph node biopsy rapidly evolved and ultimately an identification rate of $96 \%$ was derived using the combined techniques of lymphoscintigraphy, gamma probe localization, and blue dye. ${ }^{20-22}$ Soon after its introduction, the less invasive SLNB was proven to be a feasible alternative, with considerably less morbidity than $A L N D,{ }^{23-25}$ without compromising the staging accuracy. ${ }^{20,26}$ Therefore, the SLNB replaced ALND for axillary staging and became the standard of care for patients with primary breast cancer and clinical node-negative disease. $^{21,27}$

\section{The omission of extensive axillary node surgery}

In the early years following the introduction of the SLNB, a completion ALND (cALND) was still indicated for patients diagnosed with sentinel lymph node metastases. 
However, only $40 \%$ of those cALNDs contained additional metastasis. ${ }^{28,29}$ Not every sentinel lymph node-positive patient would benefit from axillary clearance and the therapeutic role of a cALND was further questioned. The International Breast Cancer Study Group (IBCSG) 23-01 trial and the Agència d'Avaluació de Tecnologia i Recerca Mèdiques (AATRM) trial, evaluated whether completion ALND was necessary when sentinel nodes only contained micrometastases $(<2 \mathrm{~mm})$. Results showed that omission of CALND was not inferior regarding its impact on regional control and disease-free survival. ${ }^{30,31}$

The additional value of cALND for patients with macrometastases in the sentinel lymph node was first questioned in two randomized controlled trials; the American College of Surgeons Oncology Group (ACOSOG)-Z0011 trial and the After Mapping of the Axilla: Radiotherapy or Surgery (AMAROS) trial. ${ }^{32,33}$ In the ACOSOG-Z0011 study, patients with T1-T2 primary clinical node-negative breast cancer who had 1 or 2 positive sentinel lymph nodes, were randomized between a cALND or no further axillary treatment. ${ }^{32}$ After a ten year follow-up, no significant differences in the ipsilateral locoregional recurrence rate and overall survival were found between the two groups, despite the fact that additional lymph node metastases were found in approximately $30 \%$ of the patients in de ALND group. ${ }^{34}$ Accordingly, not every tumor-involved lymph node will develop into clinically detectible axillary disease. ${ }^{32,35}$ Noted, that $97 \%$ of patients received adjuvant systemic therapy and $89 \%$ of the patients received whole breast irradiation with the use of tangential fields on the axillary basin.

In the search for alternative methods for the axillary treatment in sentinel-node positive breast cancer patients, the use of axillary radiotherapy was investigated in the AMAROS trial. ${ }^{33}$ The AMAROS trial evaluated whether regional control was comparable between CALND and axillary radiation therapy, in sentinel lymph node-positive patients with T1-T2 tumors. Results showed no difference in the 5-year axillary recurrence rate between patients treated with CALND or patients treated with axillary radiotherapy. Besides, axillary radiotherapy was associated with significantly less morbidity. ${ }^{33}$ These results were confirmed by the Optimal Treatment Of the Axilla - Surgery Or Radiotherapy (OTOASOR) trial, showing that axillary radiotherapy, in comparison with ALND, was not inferior in respect to regional control and overall survival. ${ }^{36}$

These study outcomes resulted in a great debate under physicians and hesitations to implement such axillary lymph node-conserving treatment. However, for patients who fulfilled the inclusion criteria of the ACOSOG-Z0011 and AMAROS trials; i.e. cT1-2NO tumors, with either 1 or 2 positive sentinel lymph nodes, mostly treated with whole breast irradiation and adjuvant systemic treatment, the therapeutic effect of ALND on regional tumor control appeared small, while the surgical associated morbidity was still quite high.

The next step in the de-escalation of axillary surgery in primary breast cancer patients was initiated. 


\section{Ipsilateral Breast Tumor Recurrence}

Initially, SLNB was restricted for patients with small, unifocal primary breast tumors and no prior surgery or radiotherapy to breast and/or axilla ${ }^{37}$. The indication for a SLNB rapidly evolved and today's SLNB is also used for patients with multifocal tumors, large T3 and T4 tumors, as well as for patients with an ipsilateral breast tumor recurrence (IBTR) in the breast or chest wall. Within 10 -years, approximately $2-10 \%$ of all breast cancer patients will experience an IBTR, ${ }^{38,39}$ which is associated with an elevated risk of distant metastases and death. ${ }^{40-42}$ Known factors related with increased mortality among patient with IBTR are: an older age, black race (only for primary node-negative breast cancer), estrogen receptor-negative status, an earlier IBTR $(<5$ years after primary breast tumor), and large tumors $(>2 \mathrm{~cm}) .^{40,43,44}$ Still, the impact of nodal involvement on the prognosis of patients with IBTR is unclear.

\section{Repeat sentinel lymph node biopsy}

Currently, no consensus exists in guidelines regarding the optimal management of the regional lymph nodes for patients diagnosed with IBTR. In the recent past, IBTR patients treated with SLNB in the primary setting received an ipsilateral ALND and patients with a previous ALND received no further axillary staging. ${ }^{45,46}$ To spare IBTR patients the additional morbidity of ALND and to improve axillary staging by identifying aberrant drainage pathways, the so-called repeat-SLNB (rSLNB) was introduced as a regional staging option for IBTR patients.

To explore the feasibility and technical aspects of rSLNB in patients with IBTR and no evidence of distant metastatic disease, the Dutch nationwide "Sentinel Node And Recurrent Breast cancer (SNARB)" registration study was conducted. A total of 536 patients, with operable locally recurrent breast cancer and staged with rSLNB, were included in the SNARB study. ${ }^{47} \mathrm{~A}$ repeat sentinel lymph node ( $r S L N$ ) could be identified in $64.3 \%$ of patients. Furthermore, the rSLN appeared to be tumor-negative in $80.1 \%$, with a negative predictive value of $94 \%$, justifying the omission of a cALND after negative rSLNB and sparing those patients its related morbidity. ${ }^{48}$

Scar tissue and fibrosis caused by primary treatments can lead to damage to the lymphatic system, causing lymphatic spread of tumor cells outside of the ipsilateral axilla. Extra-axillary rSLNs or aberrant lymph rSLNs are reported in $54.1 \%$ of patients with a visualized sentinel lymph node, ${ }^{47}$ nodes which would not be noticed with a standard ipsilateral ALND. By identifying rSLNs in aberrant lymph node stations, a more complete regional staging could be achieved which could lead to alterations of adjuvant treatment plans. ${ }^{47}$ Nonetheless, for rSLNB to become an equivalent standard of care in the IBTR setting, it is imperative to ensure high regional disease control and to be informed on its prognostic value. 


\section{Goal of this thesis}

The overall focus of this research is to report on the de-escalation of axillary management in primary breast cancer, and to further reduce invasive lymph node surgery in the local recurrent setting. Thereby diminishing the risk for complications while maintaining regional control and equal overall survival. Furthermore, the impact of these trends on the administration of systemic therapy and the impact of incomplete nodal staging on survival in elderly will be presented. As well as, the impact of different imaging modalities used for pre-operative staging patients with IBTR on the occurrences of distant recurrences after IBTR.

\section{Outline of this thesis}

This thesis consists of two main parts; the first part reports on the implementation and outcome of the de-escalation of axillary management in primary breast cancer patients in the Netherlands. The second part reports on the follow up of patients with an IBTR in whom an rSLNB procedure was performed.

\section{Part I De-escalation of axillary management in primary breast cancer patients}

The first part of this thesis, covering chapters 2, $\mathbf{3}$ and 4, concerns the de-escalation of axillary management in primary breast cancer patients. Chapter $\mathbf{2}$ demonstrates trends in axillary surgery in the post-ACOSOG-Z011 and AMAROS era and identifies factors associated with the omission of CALND in SLN-positive patients. Chapter 3 evaluates the influence of omitting cALND in SLN-positive patients on the administration of adjuvant chemo(-immuno) therapy. Furthermore, the impact of omitting extensive axillary surgery in elderly patients on the overall survival is analyzed in chapter 4 .

\section{PART II Preoperative distant staging and de-escalation of axillary management in patients with an ipsilateral breast tumor recurrence}

Second part of this thesis, consisting of chapters $\mathbf{5}, \mathbf{6}, \mathbf{7}, \mathbf{8}$, and 9 focuses on preoperative distant staging and axillary nodal management of patients with IBTR. Chapter 5 describes the impact of conventional imaging, ${ }^{18} \mathrm{~F}$-FDG PET-CT, compared to no imaging on the distant recurrence-free survival of patients with IBTR. Chapter 6 presents a systematic review evaluating the technical success rate, follow-up assessment, and prognostic value of rSLNB in patients with IBTR. The updated follow-up data of all patients participating in the SNARB-study are presented in chapter $\mathbf{7 , 8}$, and 9. Chapter 7 describes the occurrence of regional recurrence as first event after negative rSLNB in patients treated without CALND. Thereafter, the optimal regional 
treatment options and the impact of an unsuccessful rSLNB procedure (nonvisualization or no successful surgical harvesting of SLNs) on regional disease control are reported in chapter 8. Chapter 9 elucidates the prognostic impact of rSLNB, a negative rSLN versus a positive rSLN versus an unsuccessful rSLNB, on the distant recurrence-free interval of patients with IBTR.

Part III Summary, discussion and recommendations

In chapter 10, the most important findings of this thesis are discussed and recommendations for future research are suggested. 


\section{References}

1. Lakhtakia R. A Brief History of Breast Cancer: Part I: Surgical domination reinvented. Sultan Qaboos Univ Med J. 2014;14(2):e166-169.

2. Bray F, Ferlay J, Soerjomataram I, Siegel RL, Torre LA, Jemal A. Global cancer statistics 2018: GLOBOCAN estimates of incidence and mortality worldwide for 36 cancers in 185 countries. CA Cancer J Clin. 2018.

3. Rescigno J, Zampell JC, Axelrod D. Patterns of axillary surgical care for breast cancer in the era of sentinel lymph node biopsy. Ann Surg Oncol. 2009;16(3):687-696.

4. Ades F, Tryfonidis K, Zardavas D. The past and future of breast cancer treatment-from the papyrus to individualised treatment approaches. Ecancermedicalscience. 2017;11:746.

5. Lewison EF. The surgical treatment of breast cancer: an historical and collective review. Surgery. 1953;34(5):904-953.

6. Cotlar AM, Dubose JJ, Rose DM. History of surgery for breast cancer: radical to the sublime. Curr Surg. 2003;60(3):329-337.

7. Robinson DH, Toledo AH. Historical development of modern anesthesia. J Invest Surg. 2012;25(3):141149.

8. Halsted WS. I. The Results of Operations for the Cure of Cancer of the Breast Performed at the Johns Hopkins Hospital from June, 1889, to January, 1894. Ann Surg. 1894;20(5):497-555.

9. Halsted WS. I. The Results of Radical Operations for the Cure of Carcinoma of the Breast. Ann Surg. 1907;46(1):1-19.

10. Rankin JS. William Stewart Halsted: a lecture by Dr. Peter D. Olch. Ann Surg. 2006;243(3):418-425.

11. Fisher B. Biological research in the evolution of cancer surgery: a personal perspective. Cancer research. 2008;68(24):10007-10020.

12. Kuhn T. Sentinel Lymph Node Biopsy in Early Breast Cancer. Breast Care (Basel). 2011;6(3):185-191.

13. DiSipio $T$, Rye $S$, Newman B, Hayes $S$. Incidence of unilateral arm lymphoedema after breast cancer: a systematic review and meta-analysis. Lancet Oncol. 2013;14(6):500-515.

14. Krag DN, Anderson SJ, Julian TB, Brown AM, Harlow SP, Costantino JP, et al. Sentinel-lymph-node resection compared with conventional axillary-lymph-node dissection in clinically node-negative patients with breast cancer: overall survival findings from the NSABP B-32 randomised phase 3 trial. Lancet Oncol. 2010;11(10):927-933.

15. Peintinger F, Reitsamer R, Stranzl H, Ralph G. Comparison of quality of life and arm complaints after axillary lymph node dissection vs sentinel lymph node biopsy in breast cancer patients. Br J Cancer. 2003;89(4):648-652.

16. Voogd AC, Ververs JM, Vingerhoets AJ, Roumen RM, Coebergh JW, Crommelin MA. Lymphoedema and reduced shoulder function as indicators of quality of life after axillary lymph node dissection for invasive breast cancer. Br J Surg. 2003;90(1):76-81.

17. Fisher B, Slack NH. Number of lymph nodes examined and the prognosis of breast carcinoma. Surg Gynecol Obstet. 1970;131(1):79-88.

18. Fisher B, Montague E, Redmond C, Barton B, Borland D, Fisher ER, et al. Comparison of radical mastectomy with alternative treatments for primary breast cancer. A first report of results from a prospective randomized clinical trial. Cancer. 1977;39(6 Suppl):2827-2839.

19. Early Breast Cancer Trialists' Collaborative G. Effects of chemotherapy and hormonal therapy for early breast cancer on recurrence and 15-year survival: an overview of the randomised trials. Lancet. 2005;365(9472):1687-1717.

20. Cox CE, Bass SS, McCann CR, Ku NN, Berman C, Durand K, et al. Lymphatic mapping and sentinel lymph node biopsy in patients with breast cancer. Annu Rev Med. 2000;51:525-542.

21. Cox CE, Pendas S, Cox JM, Joseph E, Shons AR, Yeatman T, et al. Guidelines for sentinel node biopsy and lymphatic mapping of patients with breast cancer. Ann Surg. 1998;227(5):645-651; discussion 651-643.

22. Kim T, Giuliano AE, Lyman GH. Lymphatic mapping and sentinel lymph node biopsy in early-stage breast carcinoma: a metaanalysis. Cancer. 2006;106(1):4-16.

23. Purushotham AD, Upponi S, Klevesath MB, Bobrow L, Millar K, Myles JP, et al. Morbidity after sentinel lymph node biopsy in primary breast cancer: results from a randomized controlled trial. J Clin Oncol. 2005;23(19):4312-4321. 
24. Schijven MP, Vingerhoets AJ, Rutten HJ, Nieuwenhuijzen GA, Roumen RM, van Bussel ME, et al. Comparison of morbidity between axillary lymph node dissection and sentinel node biopsy. Eur J Surg Oncol. 2003;29(4):341-350.

25. Land SR, Kopec JA, Julian TB, Brown AM, Anderson SJ, Krag DN, et al. Patient-reported outcomes in sentinel node-negative adjuvant breast cancer patients receiving sentinel-node biopsy or axillary dissection: National Surgical Adjuvant Breast and Bowel Project phase III protocol B-32. J Clin Oncol. 2010;28(25):3929-3936.

26. Krag D, Weaver D, Ashikaga T, Moffat F, Klimberg VS, Shriver C, et al. The sentinel node in breast cancer--a multicenter validation study. N Engl J Med. 1998;339(14):941-946.

27. Beek MA, Verheuvel NC, Luiten EJ, Klompenhouwer EG, Rutten HJ, Roumen RM, et al. Two decades of axillary management in breast cancer. Br J Surg. 2015;102(13):1658-1664.

28. Fisher B, Redmond C, Fisher ER, Bauer M, Wolmark N, Wickerham DL, et al. Ten-year results of a randomized clinical trial comparing radical mastectomy and total mastectomy with or without radiation. N Engl J Med. 1985;312(11):674-681.

29. Krag DN, Anderson SJ, Julian TB, Brown AM, Harlow SP, Ashikaga T, et al. Technical outcomes of sentinel-lymph-node resection and conventional axillary-lymph-node dissection in patients with clinically node-negative breast cancer: results from the NSABP B-32 randomised phase III trial. Lancet Oncol. 2007;8(10):881-888.

30. Galimberti V, Cole BF, Zurrida S, Viale G, Luini A, Veronesi P, et al. Axillary dissection versus no axillary dissection in patients with sentinel-node micrometastases (IBCSG 23-01): a phase 3 randomised controlled trial. Lancet Oncol. 2013;14(4):297-305.

31. Sola M, Alberro JA, Fraile M, Santesteban P, Ramos M, Fabregas R, et al. Complete axillary lymph node dissection versus clinical follow-up in breast cancer patients with sentinel node micrometastasis: final results from the multicenter clinical trial AATRM 048/13/2000. Ann Surg Oncol. 2013;20(1):120-127.

32. Giuliano AE, Hunt KK, Ballman KV, Beitsch PD, Whitworth PW, Blumencranz PW, et al. Axillary dissection vs no axillary dissection in women with invasive breast cancer and sentinel node metastasis: a randomized clinical trial. JAMA. 2011;305(6):569-575.

33. Donker M, van Tienhoven G, Straver ME, Meijnen P, van de Velde CJ, Mansel RE, et al. Radiotherapy or surgery of the axilla after a positive sentinel node in breast cancer (EORTC 10981-22023 AMAROS): a randomised, multicentre, open-label, phase 3 non-inferiority trial. Lancet Oncol. 2014;15(12):13031310.

34. Giuliano AE, Ballman KV, McCall L, Beitsch PD, Brennan MB, Kelemen PR, et al. Effect of Axillary Dissection vs No Axillary Dissection on 10-Year Overall Survival Among Women With Invasive Breast Cancer and Sentinel Node Metastasis: The ACOSOG Z0011 (Alliance) Randomized Clinical Trial. JAMA. 2017;318(10):918-926.

35. Giuliano AE, McCall L, Beitsch P, Whitworth PW, Blumencranz P, Leitch AM, et al. Locoregional recurrence after sentinel lymph node dissection with or without axillary dissection in patients with sentinel lymph node metastases: the American College of Surgeons Oncology Group Z0011 randomized trial. Ann Surg. 2010;252(3):426-432; discussion 432-423.

36. Savolt A, Peley G, Polgar C, Udvarhelyi N, Rubovszky G, Kovacs E, et al. Eight-year follow up result of the OTOASOR trial: The Optimal Treatment Of the Axilla - Surgery Or Radiotherapy after positive sentinel lymph node biopsy in early-stage breast cancer: A randomized, single centre, phase III, non-inferiority trial. Eur J Surg Oncol. 2017;43(4):672-679.

37. Roumen RM, Pijpers HJ, Thunnissen FB, Ruers TJ. [Summary of the guideline 'Sentinel node biopsy in breast cancer.' Dutch Work Group 'Sentinel Node Biopsy for Breast Cancer']. Ned Tijdschr Geneeskd. 2000;144(39):1864-1867.

38. Voogd AC, Nielsen M, Peterse JL, Blichert-Toft $M$, Bartelink $H$, Overgaard $M$, et al. Differences in risk factors for local and distant recurrence after breast-conserving therapy or mastectomy for stage I and II breast cancer: pooled results of two large European randomized trials. J Clin Oncol. 2001;19(6):16881697.

39. Veronesi U, Cascinelli N, Mariani L, Greco M, Saccozzi R, Luini A, et al. Twenty-year follow-up of a randomized study comparing breast-conserving surgery with radical mastectomy for early breast cancer. N Engl J Med. 2002;347(16):1227-1232.

40. Anderson SJ, Wapnir I, Dignam JJ, Fisher B, Mamounas EP, Jeong JH, et al. Prognosis after ipsilateral breast tumor recurrence and locoregional recurrences in patients treated by breast-conserving therapy 
in five National Surgical Adjuvant Breast and Bowel Project protocols of node-negative breast cancer. J Clin Oncol. 2009;27(15):2466-2473.

41. Veronesi U, Marubini E, Del Vecchio M, Manzari A, Andreola S, Greco M, et al. Local recurrences and distant metastases after conservative breast cancer treatments: partly independent events. Journal of the National Cancer Institute. 1995;87(1):19-27.

42. Wapnir IL, Aebi S, Geyer CE, Zahrieh D, Gelber RD, Anderson SJ, et al. A randomized clinical trial of adjuvant chemotherapy for radically resected locoregional relapse of breast cancer: IBCSG 27-02, BIG 102, and NSABP B-37. Clin Breast Cancer. 2008;8(3):287-292.

43. Voogd AC, van Oost FJ, Rutgers EJ, Elkhuizen PH, van Geel AN, Scheijmans L, et al. Long-term prognosis of patients with local recurrence after conservative surgery and radiotherapy for early breast cancer. Eur J Cancer. 2005;41(17):2637-2644.

44. Wapnir IL, Anderson SJ, Mamounas EP, Geyer CE, Jr., Jeong JH, Tan-Chiu E, et al. Prognosis after ipsilateral breast tumor recurrence and locoregional recurrences in five National Surgical Adjuvant Breast and Bowel Project node-positive adjuvant breast cancer trials. J Clin Oncol. 2006;24(13):20282037.

45. Nationaal Borstkanker Overleg Nederland (NABON). Richtlijn behandeling van het mammacarcinoom. Accessed 2 March 2012 Available from: http://www.oncoline.nl.

46. Burger AEE, Pain SJ, Peley G. Treatment of recurrent breast cancer following breast conserving surgery. Breast Journal. 2013;19(3):310-318.

47. Vugts G, Maaskant-Braat AJG, Voogd AC, van Riet YEA, Luiten EJT, Rutgers EJT, et al. Repeat sentinel node biopsy should be considered in patients with locally recurrent breast cancer. Breast Cancer Research and Treatment. 2015;153(3):549-556.

48. Vugts G, Maaskant-Braat AJ, Voogd AC, van Riet YE, Luiten EJ, Rutgers EJ, et al. Repeat sentinel node biopsy should be considered in patients with locally recurrent breast cancer. Breast Cancer Res Treat. 2015;153(3):549-556. 



\section{PART}

DE-ESCALATION OF AXILLARY MANAGEMENT IN

PRIMARY BREAST CANCER PATIENTS 



\section{Chapter 2}

\section{Trends on axillary surgery in nondistant metastatic breast cancer patients treated between}

2011 and 2015

A Dutch population-based study in the ACOSOG-Z0011 and

AMAROS era

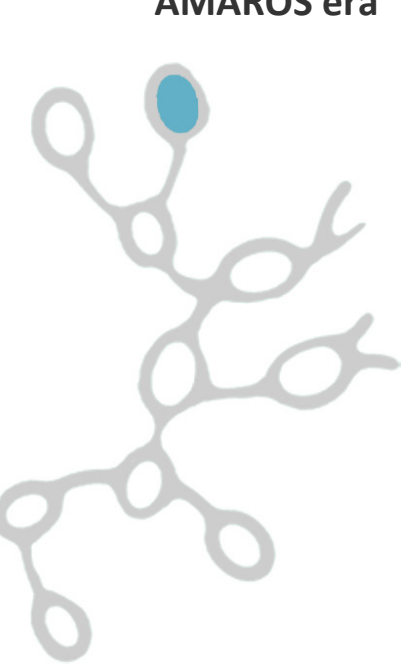

I.G.M. Poodt*, P.E.R. Spronk*, G. Vugts, T. van Dalen, M.T.F.D. Vrancken Peeters, M. Rots, A. Kuijer, G.A.P. Nieuwenhuijzen, R.J. Schipper

* Co-first autorship

Ann Surg 2018;268:1084-1090 


\section{Abstract}

\section{Objectives}

To evaluate patterns of care in axillary surgery for Dutch clinical T1-4NOMO (cT14NOMO) breast cancer patients and to assess the effect of the American College for Surgeons Oncology Group (ACOSOG)-Z0011 and After Mapping of the Axilla: Radiotherapy Or Surgery (AMAROS) trial on axillary surgery patterns in Dutch cT12NOMO sentinel node-positive breast cancer patients.

\section{Background}

Since publication of the ACOSOG-Z0011 and AMAROS trial, omitting a completion axillary lymph node dissection (CALND) in sentinel node-positive breast cancer patients is proposed in selected patients.

\section{Methods}

Data were obtained from the nationwide Nationaal Borstkanker Overleg Nederland (NABON) breast cancer audit. Descriptive analyses were used to demonstrate trends in axillary surgery. Multivariable logistic regression analyses were used to identify factors associated with the omission of CALND in CT1-2NOMO sentinel node-positive breast cancer patients.

\section{Results}

Between 2011 and 2015 in CT1-4NOMO breast cancer patients, the use of sentinel lymph node biopsy as definitive axillary staging increased from $72 \%$ to $93 \%$, and (c)ALND as definitive axillary staging decreased from $24 \%$ to $6 \%(P<0.001)$. The use of CALND decreased from $75 \%$ to $17 \%$ in $\mathrm{CT} 1-2 \mathrm{NO}$ sentinel node-positive patients $(P<0.001)$. Earlier year of diagnosis, lower age, primary mastectomy, invasive lobular subtype, increasing tumor grade, and treatment in a nonteaching hospital were associated with a lower probability of omitting CALND $(P<0.001)$.

\section{Conclusions}

This study shows a trend towards less extensive axillary surgery in Dutch cT1-T4NOMO breast cancer patients; illustrated by an overall increase of sentinel lymph node biopsy and decrease in CALND. Despite this trend, particularly noticed in CT1-2NO sentinel node-positive patients after publication of the ACOSOG-Z0011 and AMAROS trial, variations in patterns of care in axillary surgery are still present. 


\section{Introduction}

Axillary lymph node management in breast cancer patients has changed dramatically during past decades. ${ }^{1}$ Previously, performing an axillary lymph node dissection (ALND) was the standard of care for all nonmetastatic breast cancer patients. In the early $90 \mathrm{~s}$, sentinel lymph node biopsy (SLNB) was introduced as an accurate and less invasive axillary staging procedure, omitting the need for ALND in CT1-2NOMO sentinel lymphnode-negative breast cancer patients. ${ }^{2,3}$ Despite, only small studies investigated accuracy of SLNB in CT3 sentinel lymph node-negative breast cancer patients, SLNB is also widely used in this group of patients. ${ }^{4,5}$ In the early years following the introduction of SLNB, a completion ALND (CALND) was indicated in all patients with a positive sentinel lymph node. ${ }^{6}$

The additional value of CALND was first questioned in two randomized controlled trials; the American College for Surgeons Oncology Group (ACOSOG)-Z0011 trial and the After Mapping of the Axilla: Radiotherapy or Surgery (AMAROS) trial. ${ }^{7,8}$ In the ACOSOG-Z0011 (accrual 1999-2004, published 2011), cT1-2NOMO breast cancer patients with 1 to 2 positive sentinel lymph nodes treated with breast-conserving therapy followed by whole breast radiotherapy were randomized between a cALND or no further axillary treatment. $^{7}$ Ten years cumulative incidence of ipsilateral axillary recurrences was $0.5 \%$ in the ALND group and $1.5 \%$ in the SLNB-alone group, with no significant difference in locoregional recurrence-free survival. ${ }^{9}$ The AMAROS trial (accrual 2001-2010, published 2014) evaluated whether regional control was comparable between cALND and axillary radiation therapy in cT1-2NOMO breast cancer patients with 1 to 2 (and $5 \%>2$ ) positive sentinel lymph nodes, treated with breast-conserving therapy, including whole breast radiotherapy or mastectomy with or without radiotherapy to the chest wall. There was no significant difference in the 5-year axillary recurrence rate between patients treated with cALND or axillary radiotherapy; $0.43 \%$ versus $1.19 \%$. Axillary radiotherapy was associated with significantly less morbidity. ${ }^{8}$ The AMAROS results indicated that in case of a positive sentinel node, both CALND and axillary radiotherapy provide excellent and comparable axillary control disease-free and overall survival for patients with cT1-2N0M0 primary breast cancer.

The first presentation of results of the ACOSOG-Z0011 in 2011 generated great debate under physicians. Some argued that the results should be considered unreliable since patients' accrual was discontinued before the foreseen number of patients was included. In addition, questions were raised regarding the selection of a favorable subgroup of patients; not all patients were treated with whole-breast radiotherapy as planned and lack of consistent documentation of radiation fields. ${ }^{10-14}$ The safety of omitting CALND in sentinel node-positive breast cancer patients was questioned and resulted in hesitations to implement axillary lymph node-conserving treatment. 
This is illustrated by the 2012 Dutch Breast Cancer Guideline, merely suggesting omission of cALND in CT1-2NOMO breast cancer patients with a maximum of two positive sentinel nodes treated with breast-conserving treatment and adjuvant systemic therapy. Based on previous literature and preliminary experience with the AMAROS trial, this guideline also suggested that axillary irradiation could serve as an alternative to CALND in sentinel node-positive patients for whom treatment of the axillary was considered necessary. ${ }^{15}$

The first aim of this study was to demonstrate patterns of care in axillary surgery for all Dutch cT1-4NOMO breast cancer patients diagnosed between 2011 and 2015. The second aim was to evaluate the effects of the ACOSOG-Z0011 and AMAROS trials in Dutch daily clinical practice. Furthermore, this study identified patient, tumor, and hospital-related factors associated with axillary surgery in CT1-2NOMO sentinel nodepositive breast cancer patients.

\section{Methods}

Data were obtained from the Dutch Nationaal Borstkanker Overleg Nederland (NABON) Breast Cancer Audit (NBCA). The NBCA is a multidisciplinary nationwide registry of all diagnostic and treatment modalities of patients who are surgically treated for breast cancer in the Netherlands since 2011. It is facilitated by the Comprehensive Cancer Center Netherlands (IKNL) and the Dutch Institute for Clinical Auditing (DICA). Data are registered directly by the hospital itself or by IKNL data managers. The quality of the Dutch Cancer registry is high and data completeness is estimated to be at least $95 \% .{ }^{16}$

\section{Patients and hospitals}

The current study sample consisted of Dutch patients diagnosed with cT1-4NOMO invasive breast cancer between January 2011 and October 2015. Patients with the following criteria were excluded: $<18$ years of age, those who received neoadjuvant systemic therapy, had any prior surgery of the breast or those of whom information on the axillary surgery was indistinct. Data from 85 different Dutch hospitals (9 academic, 38 teaching and 38 general nonteaching hospitals) were included. Not every hospital is represented in each year due to mergers or acquisitions, resulting in 82 entities in 2011 versus 71 entities in 2015.

\section{Construction of variables}

Hospitals were divided into groups according to their teaching status (general nonteaching, teaching, academic) and surgical hospital volume. Teaching and academic hospitals both provide inhouse surgical training to residents, with distinction that 
academic hospitals are directly connected with a medical faculty of a university. Specialized oncologic hospitals were classified as academic hospitals. Hospital volume was defined as the number of patients who underwent breast cancer surgery per year. Hospitals were divided into low volume ( $<150$ resections), middle volume (150-300 resections) and high volume (>300 resections) on average per year. The cutoff points chosen were based on those reported in a publication of Eusoma, the European Society of Breast Cancer Specialist ${ }^{17}$, and those reported in an article from Greenup et al.. $^{18}$

A positive sentinel node included micrometastases and macrometastases; isolated tumor cells were considered as sentinel node-negative.

Since the NBCA did not register the radiation fields, we could not describe whether or not a patient received radiotherapy on the breast (partial or whole) and/or axilla and/or other regions. Furthermore, we did not have access to information on adjuvant hormonal therapy in all patients.

\section{Statistical analyses}

Descriptive analyses were used to report on the trends in axillary surgery for all cT1-4NOMO breast cancer patients. The outcome of interest was the definitive surgical axillary treatment and was divided into 4 groups: no surgical nodal staging; SLNB-negative; SLNB-positive, no CALND; (c)ALND. The fourth group consisted of patients who were treated with SLNB followed by CALND, and of patients treated with ALND directly.

Univariable and multivariable logistic regression analyses were used to determine the probability to omit a cALND in selected CT1-2N0M0 sentinel node-positive breast cancer patients. A $P$-value of $<0.05$ was considered statistically significant. Data analysis was performed using SPSS version 24 (SPSS Inc, Chicago, IL).

\section{Results}

\section{Patients}

In all, 44,902 patients were diagnosed with cT1-4NOM0 invasive breast cancer between January 2011 and October 2015, and registered in the NBCA. Exclusion of patients $<18$ years of age $(n=14)$, those who received neoadjuvant systemic therapy $(n=3333)$, had any prior surgery of the breast $(n=4014)$, or those of whom information on the axillary surgery was indistinct $(n=21)$, resulted in a study population of 37,520 patients (Figure 2.1, which demonstrates the flowchart of exclusion criteria). Median age was 63 years (19-98); 5335 patients (12\%) were older than 75 years. Most of the patients were diagnosed with a cT1 tumor $(72 \%, n=27,066)$, whereas $26 \%$ of the patients were diagnosed with a cT2 tumor $(n=9575), 2 \%$ with a cT3 tumor $(n=743)$, and $0.4 \%$ with a 
cT4 tumor $(n=136)$ (Table 2.1, which demonstrates the clinical- pathological and hospital characteristics of all cT1-4NOMO patients $(n=37,520)$ and percentages of an ALND).

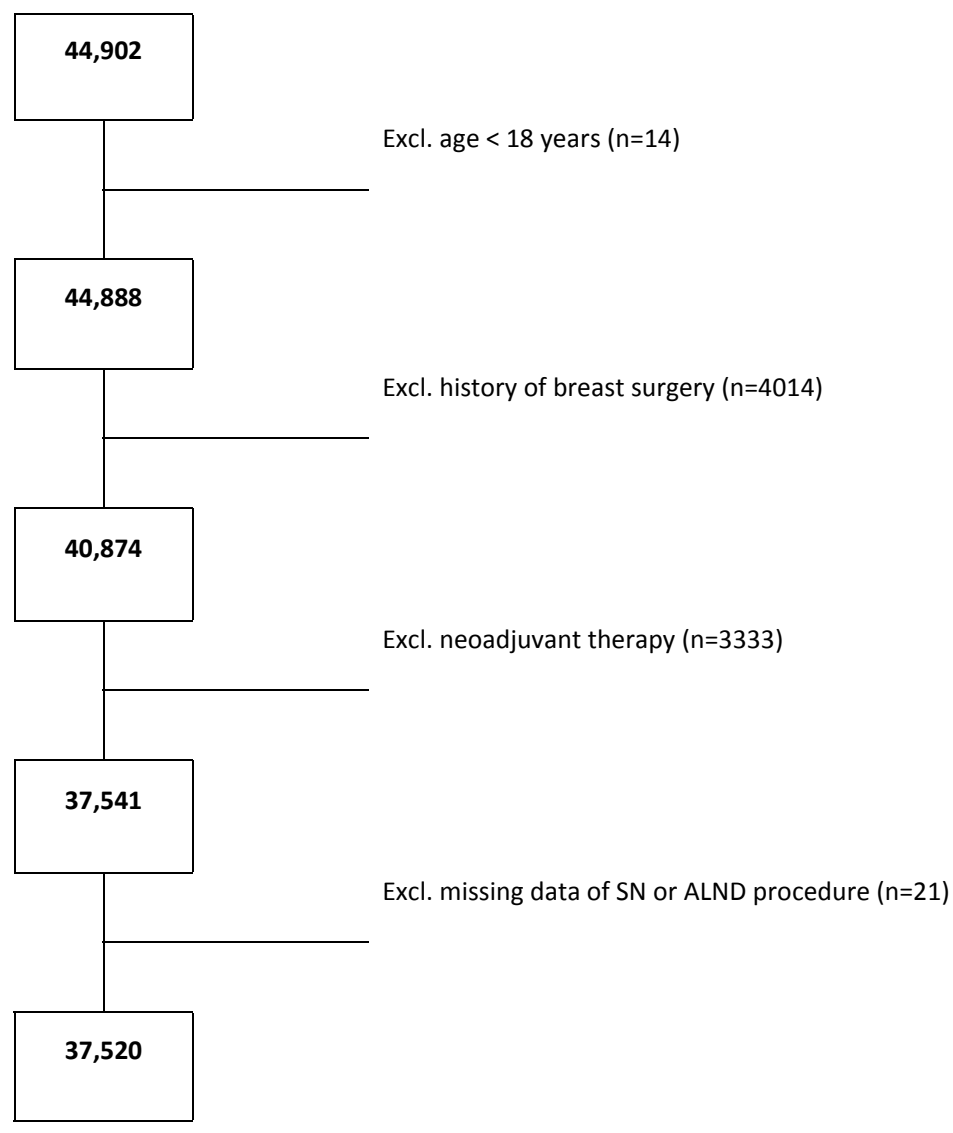

Figure 2.1 Flowchart of exclusion criteria

Excl exclusion, $\mathrm{N}$ number, SN sentinel node, ALND axillary lymph node dissection

\section{Trends in axillary surgery in CT1-4NOMO breast cancer patients}

In 2011, 92\% of all cT1-4NOM0 breast cancer patients were staged using SLNB, increasing to $98 \%$ in 2015 . According to the tumor stage the use of SLNB increased from $93 \%$ to $98 \%$ in cT1 tumors, from $92 \%$ to $98 \%$ in cT2 tumors, from $68 \%$ to $88 \%$ in cT3 tumors, and from $29 \%$ to $70 \%$ in cT4 tumors (Figure 2.2 ). 
Table 2.1 Clinical-pathological and hospital characteristics of all cT1-4NOMO patients ( $n=37,520)$ and percentages of a (completion) axillary lymph node dissection ((c)ALND), 2011 to 2015

\begin{tabular}{|c|c|c|c|c|}
\hline & $\mathbf{N}$ & (c)ALND & & $P$ \\
\hline \multicolumn{5}{|l|}{ Incidence year } \\
\hline 2011 & 4663 & 1100 & $24 \%$ & \multirow[t]{5}{*}{$<0.001$} \\
\hline 2012 & 8097 & 1346 & $17 \%$ & \\
\hline 2013 & 8507 & 1029 & $12 \%$ & \\
\hline 2014 & 8362 & 653 & $8 \%$ & \\
\hline 2015 & 7891 & 444 & $6 \%$ & \\
\hline \multicolumn{5}{|l|}{ Age, yrs } \\
\hline$<40$ & 1135 & 227 & $20 \%$ & \multirow[t]{4}{*}{$<0.001$} \\
\hline $40-50$ & 4615 & 806 & $17 \%$ & \\
\hline $50-75$ & 26435 & 2770 & $10 \%$ & \\
\hline $75+$ & 5335 & 769 & $14 \%$ & \\
\hline \multicolumn{5}{|l|}{ Histologic subtype } \\
\hline Ductal & 32804 & 3793 & $12 \%$ & \multirow[t]{2}{*}{$<0.001$} \\
\hline Lobular & 4716 & 779 & $17 \%$ & \\
\hline \multicolumn{5}{|l|}{ Clinical tumor stage } \\
\hline cT1 & 27066 & 2367 & $9 \%$ & \multirow[t]{4}{*}{$<0.001$} \\
\hline cT2 & 9575 & 1866 & $19 \%$ & \\
\hline cT3 & 743 & 284 & $38 \%$ & \\
\hline cT4 & 136 & 55 & $40 \%$ & \\
\hline \multicolumn{5}{|l|}{ Multifocality } \\
\hline Unifocal & 32919 & 3564 & $11 \%$ & \multirow[t]{2}{*}{$<0.001$} \\
\hline Multifocal & 4601 & 1008 & $22 \%$ & \\
\hline \multicolumn{5}{|l|}{ Receptor status } \\
\hline Triple - & 3323 & 376 & $11 \%$ & \multirow[t]{5}{*}{$<0.001$} \\
\hline HR -, HER2+ & 1024 & 160 & $16 \%$ & \\
\hline $\mathrm{HR}+, \mathrm{HER} 2+$ & 2686 & 356 & $13 \%$ & \\
\hline $\mathrm{HR}+, \mathrm{HER} 2-$ & 28159 & 3320 & $12 \%$ & \\
\hline Unknown & 2328 & 360 & $15 \%$ & \\
\hline \multicolumn{5}{|l|}{ Grade } \\
\hline 1 & 9797 & 818 & $8 \%$ & \multirow[t]{4}{*}{$<0.001$} \\
\hline II & 17528 & 2298 & $13 \%$ & \\
\hline III & 9289 & 1369 & $15 \%$ & \\
\hline Unknown & 904 & 87 & $10 \%$ & \\
\hline \multicolumn{5}{|l|}{ Initial surgery } \\
\hline Mastectomy & 11961 & 2719 & $23 \%$ & \multirow[t]{2}{*}{$<0.001$} \\
\hline Breast-conserving treatment & 25559 & 1853 & $7 \%$ & \\
\hline \multicolumn{5}{|l|}{ Radiotherapy on any region } \\
\hline No & 6183 & 1014 & $16 \%$ & \multirow[t]{3}{*}{$<0.001$} \\
\hline Yes & 26566 & 2373 & $9 \%$ & \\
\hline Unknown & 3419 & 846 & $25 \%$ & \\
\hline \multicolumn{5}{|l|}{ Adjuvant chemotherapy } \\
\hline No & 20958 & 1412 & $7 \%$ & \multirow[t]{3}{*}{$<0.001$} \\
\hline Yes & 12317 & 2670 & $22 \%$ & \\
\hline Unknown & 4242 & 490 & $12 \%$ & \\
\hline Type of hospital & & & & \\
\hline General nonteaching & 13393 & 1971 & $15 \%$ & $<0.001$ \\
\hline Teaching hospital & 21208 & 2372 & $11 \%$ & \\
\hline Academic & 2919 & 229 & $8 \%$ & \\
\hline Hospital surgical volume & & & & \\
\hline$<150$ & 11384 & 1584 & $14 \%$ & $<0.001$ \\
\hline $150-300$ & 13745 & 1606 & $12 \%$ & \\
\hline$>300$ & 9175 & 989 & $11 \%$ & \\
\hline Unknown & 3216 & 393 & $12 \%$ & \\
\hline
\end{tabular}

$\mathrm{N}$ number, (c)ALND (completion) axillary lymph node dissection, CT clinical tumor, HR hormone receptor, HER2 human epidermal growth receptor 2 


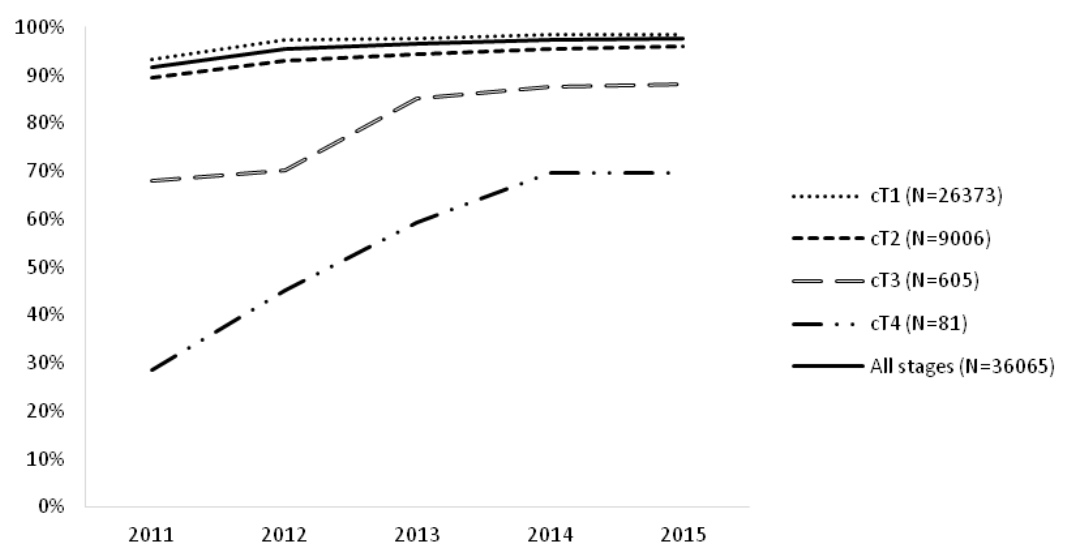

Figure 2.2 Trend in percentages of sentinel lymph node biopsy (SLNB) in cT1-4NOMO breast cancer patients in the Netherlands from 2011 to 2015 according to clinical tumor (cT) stage

In case of a positive SLNB within the group of cT1-4NOMO breast cancer patients $(n=8539)$, the use of a cALND decreased between 2011 and 2015. As shown in Figure 2.3, this decline was noticed in all clinical tumor stages of disease: from $74 \%$ to $13 \%$ for cT1 tumors ( $n=5159$ ) and $77 \%$ to $23 \%$ for cT2 tumors ( $n=3032$ ). Of note, also in cT3 and cT4 tumors, a decreasing trend was observed in the use of a cALND: from $88 \%$ to $27 \%$ in cT3 tumors ( $n=307)$, and from $50 \%$ to $17 \%$ in cT4 tumors $(n=41)$, respectively.

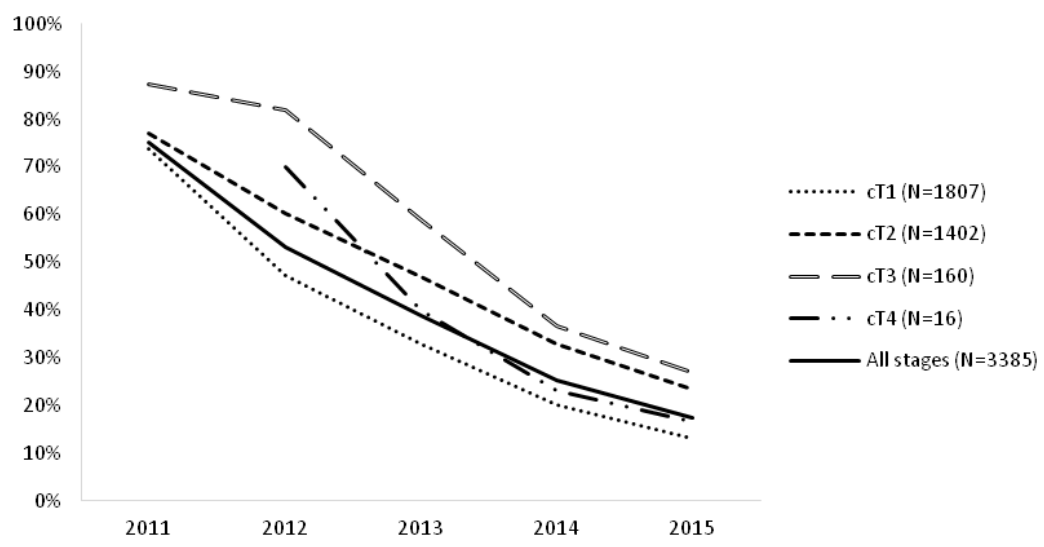

Figure 2.3 Trend in percentages of completion axillary lymph node dissection (cALND) in cT1-4NOM0 sentinel node-positive breast cancer patients in the Netherlands from 2011 to 2015 according to clinical tumor $(\mathrm{cT})$ stage 
Figure 2.4 shows the percentage of patients according to their definitive axillary staging in the period 2011 to 2015 . Hence, these are percentages of the complete group of patients diagnosed with cT1-4NOM0 invasive breast cancer $(n=37,520)$ divided into the following groups: no axillary staging $(n=954)$, SLNB (negative $=27,200$ or positive $=5154$ ) without an ALND and (c)ALND ( $n=4572)$. Obviously, the proportion of patients with a positive SLNB as definitive axillary staging procedure increased from 6\% ( $n=282)$ in 2011 to $18 \%(n=1411)$ in $2015(P<0.001)$. In these cT1-4NOMO sentinel node-positive breast cancer patients, a cALND was omitted. Rarely, in a proportion of patients with a negative SLNB $(n=27,526)$, a cALND was performed $(1 \%, n=326)$. This percentage remains unchanged over the years and was not associated with either age or clinical tumor stage. Apart from this, 861 out of all 37,520 (2.3\%) cT1-4NOMO breast cancer patients received ALND directly, without previous axillary staging. Overall, percentages of SLNB as definitive axillary staging increased from 72\% in 2011 to $93 \%$ in 2015, and percentages of (c)ALND as definitive axillary staging declined from $24 \%$ in 2011 to $6 \%$ in $2015(P<0.001)$.

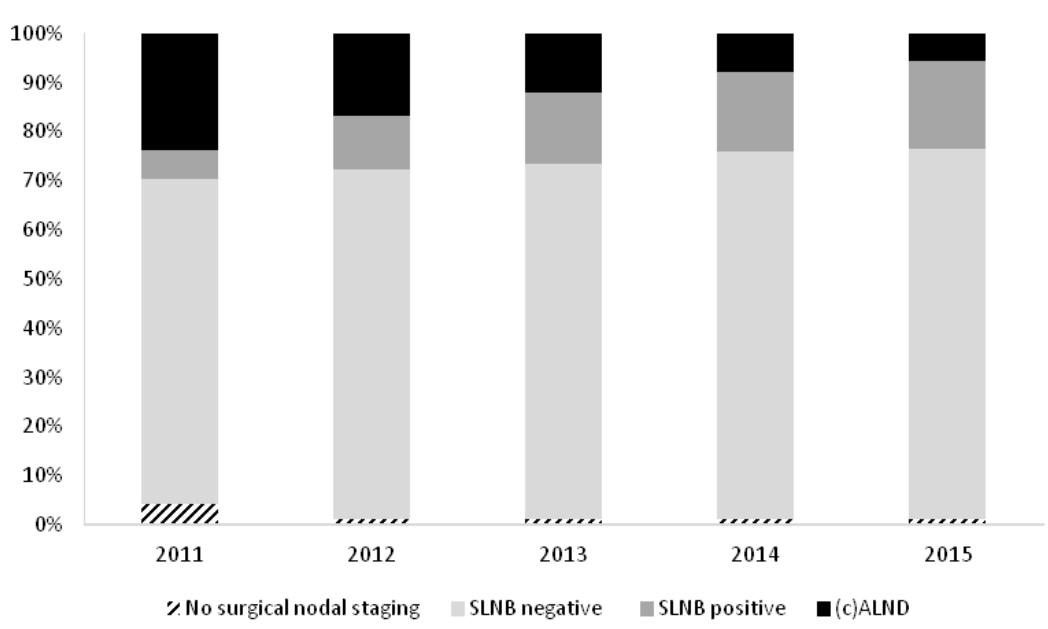

Figure 2.4 Trends in the definitive axillary staging in cT1-4NOMO breast cancer patients in the Netherlands from 2011 to 2015

\section{Trends in axillary surgery in cT1-2N0M0 sentinel node-positive breast cancer patients}

A subgroup analysis was performed in CT1-2NOMO breast cancer patients with 1 to 2 (and $1.8 \%>2$ ) positive sentinel lymph nodes; a group comparable with the ACOSOGZ0011 and AMAROS trial population. A total of 8191 out of 36,641 cT1-2NOMO patients were sentinel node-positive with a median age of 60 years (22-96). The clinical, pathological, and hospital characteristics of this population are shown in Table 2.2. 
Most of these patients underwent breast-conserving surgery $(61 \%, n=4959)$ and were classified with a ductal, unifocal, hormone receptor-positive and human epidermal growth receptor (HER)2-negative breast tumor. The majority $(84 \%, n=5939)$ of the CT1-2NOMO sentinel node-positive patients received radiotherapy on any region and $62 \%(n=4646)$ of the patients received adjuvant chemotherapy.

As shown in Table 2.2, within this subgroup of cT1-2NOM0 sentinel node-positive patients, the performance of a cALND decreased from 75\% in 2011 (ACOZOG-Z0011 published), to $25 \%$ in 2014 (AMOROS published) and 17\% in 2015. In cT1-2NOMO sentinel node-positive breast cancer patients, younger patients were more likely to receive a cALND. Over time, the rate of CALND for patients aged $<40$ decreased from $89.6 \%$ in 2011 to $61.8 \%, 47.0 \%, 37.7 \%$, and $39.6 \%$ in 2012, 2013, 2014, and 2015, respectively. The rate of cALND for patients aged 50 to 75 decreased from $76.4 \%$ in 2011 to $51.1 \%, 37.1 \%, 23.3 \%$, and $15.9 \%$ in 2012, 2013, 2014, and 2015, respectively.

Regarding the receptor status, triple negative patients had a higher probability in receiving CALND. Over time, the rate of CALND in triple negative patients declined from $79.0 \%$ in 2011 to 56.6\%, 50.0\%, 33.7\%, and 25.3\% in 2012, 2013, 2014, and 2015 respectively.

In case of breast-conserving therapy, a cALND was omitted more often (69\%) compared with mastectomy $(48 \%)(P<0.001)$. Figure 2.5 shows the type of primary surgery of cT1-2NOM0 sentinel node-positive patients treated with a cALND from 2011 to 2015. The proportion of patients receiving CALND declined for both types of surgery over the years, but notable is the slower adaption of omitting cALND in the mastectomy group.

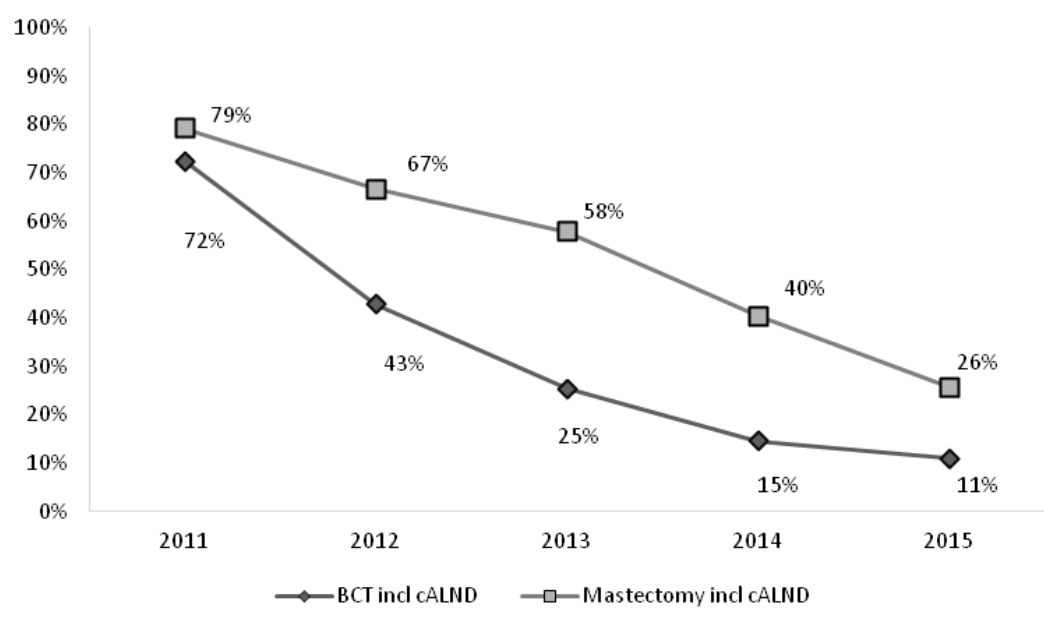

Figure 2.5 Percentages of cT1-2NOM0 sentinel node-positive breast cancer patients in which a completion axillary lymph node dissection (cALND) was performed; breast-conserving therapy versus mastectomy 
Table 2.2 Clinical-pathological and hospital characteristics of cT1-2NOMO sentinel node-positive patients $(n=8191)$ and percentages of completion axillary lymph node dissection (cALND), 2011 to 2015

\begin{tabular}{|c|c|c|c|c|}
\hline & $\mathbf{N}$ & CALND & & $P$ \\
\hline \multicolumn{5}{|l|}{ Incidence year } \\
\hline 2011 & 1111 & 833 & $75 \%$ & \multirow[t]{5}{*}{$<0.001$} \\
\hline 2012 & 1815 & 947 & $52 \%$ & \\
\hline 2013 & 1905 & 723 & $38 \%$ & \\
\hline 2014 & 1730 & 430 & $25 \%$ & \\
\hline 2015 & 1630 & 276 & $17 \%$ & \\
\hline \multicolumn{5}{|l|}{ Age, yrs } \\
\hline$<40$ & 326 & 183 & $56 \%$ & \multirow[t]{4}{*}{$<0.001$} \\
\hline $40-50$ & 1309 & 624 & $48 \%$ & \\
\hline $50-75$ & 5394 & 2035 & $38 \%$ & \\
\hline $75+$ & 1162 & 367 & $32 \%$ & \\
\hline \multicolumn{5}{|l|}{ Histologic subtype } \\
\hline Ductal & 7112 & 2721 & $38 \%$ & \multirow[t]{2}{*}{$<0.001$} \\
\hline Lobular & 1079 & 488 & $45 \%$ & \\
\hline \multicolumn{5}{|l|}{ Clinical tumor stage } \\
\hline cT1 & 5159 & 1807 & $35 \%$ & \multirow[t]{2}{*}{$<0.001$} \\
\hline cT2 & 3032 & 1402 & $46 \%$ & \\
\hline \multicolumn{5}{|l|}{ Multifocality } \\
\hline Unifocal & 6893 & 2583 & $37 \%$ & \multirow[t]{2}{*}{$<0.001$} \\
\hline Multifocal & 1298 & 626 & $48 \%$ & \\
\hline \multicolumn{5}{|l|}{ Receptor status } \\
\hline Triple - & 456 & 225 & $49 \%$ & \multirow[t]{5}{*}{$<0.001$} \\
\hline HR -, HER2+ & 212 & 102 & $48 \%$ & \\
\hline $\mathrm{HR}+, \mathrm{HER} 2+$ & 650 & 267 & $41 \%$ & \\
\hline HR+, HER2- & 6361 & 2374 & $37 \%$ & \\
\hline Unknown & 512 & 241 & $47 \%$ & \\
\hline \multicolumn{5}{|l|}{ Grade } \\
\hline 1 & 1753 & 586 & $33 \%$ & \multirow[t]{4}{*}{$<0.001$} \\
\hline II & 4217 & 1634 & $39 \%$ & \\
\hline III & 2101 & 933 & $44 \%$ & \\
\hline Unknown & 120 & 56 & $47 \%$ & \\
\hline \multicolumn{5}{|l|}{ Initial surgery } \\
\hline Mastectomy & 3232 & 1691 & $52 \%$ & \multirow[t]{2}{*}{$<0.001$} \\
\hline Breast-conserving treatment & 4959 & 1518 & $31 \%$ & \\
\hline \multicolumn{5}{|l|}{ Radiotherapy (on any region) } \\
\hline No & 1138 & 672 & $59 \%$ & \multirow[t]{3}{*}{$<0.001$} \\
\hline Yes & 5939 & 1760 & $30 \%$ & \\
\hline Unknown & 785 & 554 & $71 \%$ & \\
\hline \multicolumn{5}{|l|}{ Adjuvant chemotherapy } \\
\hline No & 2937 & 781 & $27 \%$ & \multirow[t]{3}{*}{$<0.001$} \\
\hline Yes & 4646 & 2135 & $46 \%$ & \\
\hline Unknown & 607 & 293 & $48 \%$ & \\
\hline \multicolumn{5}{|l|}{ Type of hospital } \\
\hline General nonteaching & 2993 & 1353 & $45 \%$ & $<0.001$ \\
\hline Teaching hospital & 4582 & 1684 & $37 \%$ & \\
\hline Academic & 616 & 172 & $28 \%$ & \\
\hline Hospital surgical volume & & & & \\
\hline$<150$ & 2450 & 1076 & $44 \%$ & $<0.001$ \\
\hline $150-300$ & 3060 & 1113 & $36 \%$ & \\
\hline$>300$ & 1988 & 732 & $37 \%$ & \\
\hline Unknown & 693 & 288 & $42 \%$ & \\
\hline
\end{tabular}

$\mathrm{N}$ number, cALND completion axillary lymph node dissection, cT clinical tumor, HR hormone receptor, HER2 human epidermal growth receptor 2 


\section{Prognostic factors omitting a cALND in cT1-2N0M0 sentinel node- positive patients}

A multivariable logistic regression analysis was used to determine independent predictors in omitting cALND (Table 2.3). Apart from an earlier year of diagnosis, lower age and patients being treated with mastectomy, also invasive lobular subtype, increasing tumor grade and being treated in a general nonteaching hospital were independently associated with a lower probability in omitting CALND (all $P<0.001$ ). Hospital surgical volume and receptor status were not independently associated with omitting CALND in multivariable analysis.

\section{Discussion}

This study showed a trend towards less extensive axillary surgery in Dutch cT1-T4NOMO breast cancer patients in the ACOSOG-Z0011 and AMAROS era. Particularly in CT1-T2NOM0 sentinel node-positive invasive breast cancer patients, the performance of a cALND decreased from 75\% in 2011 to $17 \%$ in 2015.

The downward trend observed in the use of cALND in CT1-2NO sentinel-node positive breast cancer patients reflects the implementation of the study concept of the ACOSOG-Z0011 and AMAROS trials in the Netherlands. In these patients, axillary surgery varied between patients treated with breast-conserving therapy and mastectomy. In 2011, the percentage of patients without a cALND was higher in the breast-conserving therapy group (28\%) compared with the mastectomy group (21\%). Only a small percentage of patients (0\% in the ACOSOG-Z0011 and $18 \%$ in the AMAROS trial) were treated with mastectomy, which could be a reason why omitting cALND in mastectomy patients was less likely adopted by surgeons.

As expected, due to the presentation of the results of the ACOSOG-Z0011 trial, a reduction in the number of CALND performed in patients treated with breastconserving therapy was observed. While the results of the AMAROS trial were presented in 2014, a reduction in the percentage of cALND in patients treated with mastectomy was already observed in 2013. This may reflect the confidence of physicians in the concept that not every positive axillary sentinel lymph node will develop into clinical detectable axillary disease.,19 
Table 2.3 Univariable and multivariable analyses for the performance of completion axillary lymph node dissection (cALND) among cT1-2NOMO sentinel node-positive patients ( $n=8191), 2011$ to 2015

\begin{tabular}{|c|c|c|c|c|c|c|}
\hline & \multicolumn{3}{|c|}{ Univariable } & \multicolumn{3}{|c|}{ Multivariable } \\
\hline & Odds ratio & $95 \% \mathrm{Cl}$ & $P$ & Odds ratio & $95 \% \mathrm{Cl}$ & $P$ \\
\hline \multicolumn{7}{|l|}{ Incidence year } \\
\hline 2011 & Ref. & & $<0.001$ & Ref. & & $<0.001$ \\
\hline 2012 & 0.364 & $(0.309-0.429)$ & & 0.359 & $(0.297-0.435)$ & \\
\hline 2013 & 0.204 & $(0.173-0.241)$ & & 0.206 & $(0.17-0.249)$ & \\
\hline 2014 & 0.111 & $(0.093-0.132)$ & & 0.092 & $(0.075-0.113)$ & \\
\hline 2015 & 0.068 & $(0.056-0.082)$ & & 0.059 & $(0.047-0.073)$ & \\
\hline \multicolumn{7}{|l|}{ Age, yrs } \\
\hline$<40$ & Ref. & & $<0.001$ & Ref. & & $<0.001$ \\
\hline $40-50$ & 0.712 & $(0.564-0.918)$ & & 0.723 & $(0.535-0.976)$ & \\
\hline $50-75$ & 0.473 & $(0.383-0.602)$ & & 0.638 & $(0.482-0.845)$ & \\
\hline $75+$ & 0.361 & $(0.284-0.464)$ & & 0.297 & $(0.216-0.407)$ & \\
\hline \multicolumn{7}{|l|}{ Histologic subtype } \\
\hline Ductal & Ref. & & $<0.001$ & Ref. & & 0.023 \\
\hline Lobular & 1.33 & $(1.171-1.516)$ & & 1.214 & $(1.027-1.433)$ & \\
\hline \multicolumn{7}{|l|}{ Clinical tumor stage } \\
\hline cT1 & Ref. & & $<0.001$ & Ref. & & $<0.001$ \\
\hline сT2 & 1.596 & $(1.456-1.748)$ & & 1.303 & $(1.156-1.469)$ & \\
\hline \multicolumn{7}{|l|}{ Multifocality } \\
\hline Unifocal & Ref. & & $<0.001$ & Ref. & & 0.035 \\
\hline Multifocal & 1.554 & $(1.38-1.751)$ & & 1.18 & $(1.012-1.377)$ & \\
\hline \multicolumn{7}{|l|}{ Receptor status } \\
\hline Triple - & Ref. & & $<0.001$ & Ref. & & 0.185 \\
\hline HR -, HER2+ & 0.952 & $(0.687-1.319)$ & & 0.822 & $(0.557-1.213)$ & \\
\hline $\mathrm{HR}+, \mathrm{HER} 2+$ & 0.716 & $(0.562-0.911)$ & & 0.732 & $(0.548-0.978)$ & \\
\hline $\mathrm{HR}+, \mathrm{HER} 2-$ & 0.611 & $(0.505-0.74)$ & & 0.786 & $(0.617-1.001)$ & \\
\hline \multicolumn{7}{|l|}{ Grade } \\
\hline I & Ref. & & $<0.001$ & Ref. & & 0.012 \\
\hline II & 1.968 & $(1.863-2.078)$ & & 1.052 & $(0.91-1.216)$ & \\
\hline III & 2.567 & $(2.425-2.717)$ & & 1.271 & $(1.068-1.513)$ & \\
\hline \multicolumn{7}{|l|}{ Initial surgery } \\
\hline Mastectomy & Ref. & & $<0.001$ & Ref. & & $<0.001$ \\
\hline Breast-conserving treatment & 0.402 & $(0.367-0.441)$ & & 0.335 & $(0.295-0.381)$ & \\
\hline \multicolumn{7}{|l|}{ Type of hospital } \\
\hline General nonteaching & Ref. & & $<0.001$ & Ref. & & $<0.001$ \\
\hline Teaching hospital & 0.704 & $(0.641-0.774)$ & & 0.664 & $(0.566-0.779)$ & \\
\hline Academic & 0.47 & $(0.388-0.568)$ & & 0.335 & $(0.263-0.426)$ & \\
\hline \multicolumn{7}{|l|}{ Hospital surgical volume } \\
\hline$<150$ & Ref. & & $<0.001$ & Ref. & & 0.327 \\
\hline $150-300$ & 0.913 & $(0.876-0.953)$ & & 1.125 & $(0.963-1.315)$ & \\
\hline$>300$ & 0.861 & $(0.822-0.903)$ & & 1.113 & $(0.926-1.337)$ & \\
\hline
\end{tabular}

$\mathrm{Cl}$ confidence interval, Ref reference, $\mathrm{cT}$ clinical tumor, HR hormone receptor, HER2 human epidermal growth receptor 2

In some patients, physicians were still reluctant to omit cALND. As reported in this study, the probability of omitting CALND decreased when patients were younger ( $<40$ years), were treated in a general nonteaching hospital, or had more aggressive tumor biology. The relation of younger age $(<40$ years) to higher cALND rates may 
reflect the hypothesis that treatment of the axilla should be more aggressive in younger patients to optimize overall survival. However, the prognostic relevance of young age on the occurrence of regional recurrences is controversial. ${ }^{20-22}$ Physicians may extrapolate the higher risk of young patients to develop a local recurrence to the regional recurrence risk. Indeed, the occurrence of a local recurrence affects the overall survival of young patients. ${ }^{21,23-25}$ On the contrary, the ACOSOG-Z0011 10-year follow up data showed that the number of regional recurrence is very low in both the ALND group $(0.5 \%)$ and SLNB=only group (1.5\%), and no association of young age $(<50$ years) with loco-regional recurrences was observed. ${ }^{9}$ Hence, it does not seem justified to be reluctant to omit a cALND based only on the age of the patient.

This study reported that triple negative breast cancer patients with a positive SLNB were more likely to receive a cALND compared with hormone receptor-positive patients. This practice may be based on the criticism that in the ACOSOG-Z0011, only small numbers of patients with triple negative breast cancer were included and thus the results were not applicable for triple negative patients. ${ }^{26,27}$ However, several studies do not support such an aggressive approach. Firstly, van Roozendaal et al. questioned in their study whether triple negative patients with a clinically T1-2NO status were more at risk for regional recurrences. Their 5-year follow-up showed a regional and distant recurrence rate of $2.9 \%$ and $12.2 \%$, respectively. It was concluded in this study that triple negative tumors rarely recur regionally and that their diseasefree survival was more threatened by distant recurrence. ${ }^{28}$ Secondly, being at high risk to develop distant metastasis does not necessarily mean being at high risk for axillary nodal recurrence. ${ }^{26}$ Thirdly, a recent follow-up study on the ACOSOG-Z0011 eligible patients was publicized. It was reported that after a median follow-up of 31 months, high risk patients (i.e., triple negative tumors, HER2-positive tumors, and age $<50$ years) compared with average-risk patients had the same risk of regional recurrence, but a higher risk of developing distant metastasis. ${ }^{27}$ Hence, although longer follow-up data are preferable, it does not seem justifiable to perform a cALND based on receptor status only.

We evaluated a significant variation in omitting cALND between different types of hospitals, revealing the presence of early and late adopters. While the first hospitals started omitting CALND in 2011, other hospitals still performed this procedure in 2015, as has been reported by other authors. ${ }^{29-31}$ Steenbergen et al. evaluated in 2010 the implementation of SLNB in the Netherlands and showed that general nonteaching hospitals were late adopters of the SLNB procedure by performing ALND more frequently than other hospitals. ${ }^{29}$ This variation might be explained by the degree of dedication of the multidisciplinary breast cancer treatment teams within a hospital or whether a radiotherapy center was located nearby the treating hospital. Within the current study, there was no information about these possible influencing factors which should be evaluated in future studies. This variation is not favorable, but unfortunately 
the implementation process following the presentation of evidence-based studies and guidelines is seldom monitored and reasons for nonadherence are largely unknown.

Another notable pattern of care was the downward trend of cALND in cT3-4NOMO sentinel node-positive breast cancer patients, which was in line with the decreasing trend in CT1-2NOMO sentinel node-positive breast cancer patients. No randomized trials have been published to justify less extensive axillary surgery in cT3-4NOMO sentinel node-positive breast cancer patients. Nonetheless, the decreasing trend in the numbers of cALNDs performed in all tumor stadia might reflect the growing argument for less extensive surgery in the axilla of breast cancer patients.

In addition, this study revealed an increase in the use of SLNB, especially in cT3 and cT4 patients, from $68 \%$ to $87 \%$ and $29 \%$ to $70 \%$, respectively. This increasing trend in the use of SLNB for nodal staging in breast cancer patients reflects the growing confidence in the concept of this procedure, even in patients with T3 and T4 tumors. The accuracy in performing SLNB in CT3 tumors seems to be comparable to T1 and T2 tumors according to the available literature. Although, the evidence supporting this practice is debatable, since only small studies were published. ${ }^{4,5}$ No conclusive data are available on the accuracy of SLNB in CT4NOMO breast cancer patients.

To our knowledge, this is the largest study demonstrating patterns of care of axillary surgery in breast cancer patients. It shows that trial results of the ACOSOG-Z0011 and AMAROS were progressively implemented in axillary treatment plans of breast cancer patients nowadays. Our study is limited by its retrospective nature and by incomplete information on radiation therapy and fields. Therefore, we could not explore the potential effect of radiation on the axilla. These considerations should be taken into account when discussing axillary treatment options. Excluding neoadjuvant treated patients could result in biased underuse of cALND through the omission of high-stage breast cancer patients who underwent neoadjuvant treatment. Despite the discussion on both trials, we observed a notable early adoption and increasing trend in omitting the use of CALND in sentinel node-positive cT1-2NOMO breast cancer patients, both treated with breast-conserving surgery and mastectomy.

\section{Conclusions}

This study shows a trend towards less extensive axillary surgery in Dutch cT1-T4NOMO breast cancer patients, illustrated by an overall increase of SLNB and decrease in CALND. Despite this decreasing trend particularly noticed in CT1-2NOMO sentinel nodepositive patients after the presentation of the ACOSOG-Z0011 and AMAROS trial, hospital-related variation in axillary surgery is still present. This emphasizes the need for a uniform implementation strategy after the publication of national guidelines which includes an education program for surgeons and patients, to minimize variations in patterns of care in oncologic breast cancer surgery. 


\section{References}

1. Rescigno J, Zampell JC, Axelrod D. Patterns of axillary surgical care for breast cancer in the era of sentinel lymph node biopsy. Ann Surg Oncol. 2009;16(3):687-696.

2. Krag DN, Anderson SJ, Julian TB, et al. Sentinel-lymph-node resection compared with conventional axillary-lymph-node dissection in clinically node-negative patients with breast cancer: overall survival findings from the NSABP B-32 randomised phase 3 trial. Lancet Oncol. 2010;11(10):927-933.

3. Veronesi U, Viale G, Paganelli G, et al. Sentinel lymph node biopsy in breast cancer: ten-year results of a randomized controlled study. Ann Surg. 2010;251(4):595-600.

4. Chung $\mathrm{MH}, \mathrm{Ye} \mathrm{W}$, Giuliano AE. Role for sentinel lymph node dissection in the management of large (> or $=5 \mathrm{~cm}$ ) invasive breast cancer. Ann Surg Oncol. 2001;8(9):688-692.

5. Bedrosian I, Reynolds C, Mick R, et al. Accuracy of sentinel lymph node biopsy in patients with large primary breast tumors. Cancer. 2000;88(11):2540-2545.

6. Lyman $\mathrm{GH}$, Giuliano $\mathrm{AE}$, Somerfield $\mathrm{MR}$, et al. American Society of Clinical Oncology guideline recommendations for sentinel lymph node biopsy in early-stage breast cancer. J Clin Oncol. 2005; 23(30):7703-7720.

7. Giuliano AE, Hunt KK, Ballman KV, et al. Axillary dissection vs no axillary dissection in women with invasive breast cancer and sentinel node metastasis: a randomized clinical trial. JAMA. 2011;305(6):569575.

8. Donker M, van Tienhoven G, Straver ME, et al. Radiotherapy or surgery of the axilla after a positive sentinel node in breast cancer (EORTC 10981-22023 AMAROS): a randomised, multicentre, open-label, phase 3 non-inferiority trial. Lancet Oncol. 2014;15(12):1303-1310.

9. Giuliano AE, Ballman K, McCall L, et al. Locoregional Recurrence After Sentinel Lymph Node Dissection With or Without Axillary Dissection in Patients With Sentinel Lymph Node Metastases: Long-term Follow-up From the American College of Surgeons Oncology Group (Alliance) ACOSOG Z0011 Randomized Trial. Ann Surg. 2016;264(3):413-420.

10. Grube BJ, Giuliano AE. Observation of the breast cancer patient with a tumor-positive sentinel node: implications of the ACOSOG Z0011 trial. Semin Surg Oncol. 2001;20(3):230-237.

11. Shah-Khan M, Boughey JC. Evolution of axillary nodal staging in breast cancer: clinical implications of the ACOSOG Z0011 trial. Cancer Control. 2012;19(4):267-276.

12. Giuliano AE, Morrow M, Duggal S, et al. Should ACOSOG Z0011 change practice with respect to axillary lymph node dissection for a positive sentinel lymph node biopsy in breast cancer? Clin Exp Metastasis. 2012;29(7):687-692.

13. Morrow M, Giuliano AE. To cut is to cure: can we really apply $\mathrm{Z} 11$ in practice? Ann Surg Oncol. 2011;18(9):2413-2415.

14. Guth U, Myrick ME, ViehI CT, et al. The post ACOSOG Z0011 era: does our new understanding of breast cancer really change clinical practice? Eur J Surg Oncol. 2012;38(8):645-650.

15. Nationaal Borstkanker Overleg Nederland (NABON). Richtlijn behandeling van het mammacarcinoom. Accessed 2 March 2012 [Available from: http://www.oncoline.nl.

16. van Bommel AC, Spronk PE, Vrancken Peeters MT, et al. Clinical auditing as an instrument for quality improvement in breast cancer care in the Netherlands: The national NABON Breast Cancer Audit. J Surg Oncol. 2017;115(3):243-249.

17. Wilson AR, Marotti L, Bianchi S, et al. The requirements of a specialist Breast Centre. Eur J Cancer. 2013;49(17):3579-3587.

18. Greenup RA, Obeng-Gyasi $S$, Thomas $S$, et al. The effect of hospital volume on breast cancer mortality. Ann Surg. 2018;267(2):375-381.

19. Fisher $\mathrm{B}$, Jeong $\mathrm{JH}$, Anderson $\mathrm{S}$, et al. Twenty-five-year follow-up of a randomized trial comparing radical mastectomy, total mastectomy, and total mastectomy followed by irradiation. N Engl J Med. 2002;347(8):567-575.

20. Voduc KD, Cheang MC, Tyldesley S, et al. Breast cancer subtypes and the risk of local and regional relapse. J Clin Oncol. 2010;28(10):1684-1691.

21. Botteri E, Bagnardi V, Rotmensz N, et al. Analysis of local and regional recurrences in breast cancer after conservative surgery. Ann Oncol. 2010;21(4):723-728. 
22. Grills IS, Kestin LL, Goldstein N, et al. Risk factors for regional nodal failure after breast-conserving therapy: regional nodal irradiation reduces rate of axillary failure in patients with four or more positive lymph nodes. Int J Radiat Oncol Biol Phys. 2003;56(3):658-670.

23. Arvold ND, Taghian AG, Niemierko A, et al. Age, breast cancer subtype approximation, and local recurrence after breast-conserving therapy. J Clin Oncol. 2011;29(29):3885-3891.

24. Voogd AC, Nielsen M, Peterse JL, et al. Differences in risk factors for local and distant recurrence after breast-conserving therapy or mastectomy for stage I and II breast cancer: pooled results of two large European randomized trials. J Clin Oncol. 2001;19(6):1688-1697.

25. van der Sangen MJ, van de Wiel FM, Poortmans PM, et al. Are breast conservation and mastectomy equally effective in the treatment of young women with early breast cancer? Long-term results of a population-based cohort of 1,451 patients aged $</=40$ years. Breast Cancer Res Treat. 2011;127(1): 207-215.

26. Memorial Sloan Kettering Cancer Center. A new era in axillary management for node-positive women 2016 Available from: https://www.mskcc.org/clinical-updates/new-era-axillary-management-nodepositive-women.

27. Mamtani A, Patil S, Van Zee KJ, et al. Age and Receptor Status Do Not Indicate the Need for Axillary Dissection in Patients with Sentinel Lymph Node Metastases. Ann Surg Oncol. 2016;23(11):3481-3486.

28. van Roozendaal LM, Smit LH, Duijsens GH, et al. Risk of regional recurrence in triple-negative breast cancer patients: a Dutch cohort study. Breast Cancer Res Treat. 2016;156(3):465-472.

29. van Steenbergen LN, van de Poll-Franse LV, Wouters MW, et al. Variation in management of early breast cancer in the Netherlands, 2003-2006. Eur J Surg Oncol. 2010;36 Suppl 1:S36-43.

30. Siesling S, van de Poll-Franse LV, Jobsen JJ, et al. Explanatory factors for variation in the use of breast conserving surgery and radiotherapy in the Netherlands, 1990-2001. Breast. 2007;16(6):606-614.

31. van Steenbergen LN, Voogd AC, Roukema JA, et al. Time trends and inter-hospital variation in treatment and axillary staging of patients with ductal carcinoma in situ of the breast in the era of screening in Southern Netherlands. Breast. 2014;23(1):63-68. 



\section{Chapter}

3

\section{The administration of adjuvant chemo(-immuno) therapy in the post ACOSOG-Z0011 era}

A population-based study

I.G.M. Poodt, M. L. Rots, G. Vugts, T. van Dalen, A. Kuijer, B.E.P.J. Vriens, G.A.P. Nieuwenhuijzen, R.J. Schipper Eur J Surg Oncol 2018;44(8):1151-1156 


\section{Abstract}

\section{Purpose}

The ACOSOG-Z0011-study has resulted in a trend to a more conservative treatment of the axilla for selected sentinel node-positive patients. However, axillary nodal involvement has always been an important factor for tumor staging and tailoring adjuvant chemotherapy plans. This study evaluates the impact of omitting completion axillary lymph node dissection (cALND) on the administration of adjuvant chemo (-immuno)therapy in Dutch clinical T1-2NOMO(cT1-2NOMO) sentinel node-positive breast cancer patients.

\section{Methods}

Data were obtained from the nationwide NABON breast cancer audit. Descriptive analyses were used to demonstrate trends in axillary surgery and adjuvant chemo (-immuno)therapy. Multivariable logistic regression analyses were used to identify factors associated with the prescription of chemo (-immuno)therapy.

\section{Results}

In this cohort of 4331 patients, the omission of a cALND increased from $34 \%$ to $92 \%$, and the administration of chemo (-immuno)therapy decreased from $68 \%$ to $55 \%$, between 2011 and $2015(P<0.001)$. Patients treated with cALND had an OR of 2.2 for receiving adjuvant chemo (-immuno)therapy compared with SLNB only patients. Lower age, a hormone receptor (HR) status other than HR-positive, HER2-negative, increasing tumor grade and stage, and a lymph node status $\geq \mathrm{pN} 2$ were independently associated with a higher probability of chemo (-immuno)therapy $(P<0.05)$.

\section{Conclusions}

This study showed that Dutch CT1-2NOMO sentinel node-positive breast cancer patients treated with cALND had a higher independent probability for receiving adjuvant chemo (-immuno)therapy compared with SLNB only patients, even when corrected for lymph node status and HR-status. Probably, the decisions to administer adjuvant chemo (-immuno)therapy were not only based on guidelines and tumor characteristics, but also on the preferences from physicians and patients. 


\section{Introduction}

After the introduction of the sentinel lymph node biopsy (SLNB), as an accurate and less invasive axillary staging procedure, the performance of an axillary lymph node dissection (ALND) declined, ${ }^{1,2}$ The shift to a more conservative treatment of the axilla for breast cancer patients was introduced first in sentinel lymph node-negative patients only and extended to selected sentinel lymph node-positive patients after the publication of the ACOSOG-Z0011 study. In this study, cT1-2NOMO breast cancer patients with 1 to 2 positive sentinel lymph nodes treated with breast-conserving therapy followed by whole breast radiation, were randomized between a completion ALND (CALND) or no further axillary treatment (in both groups $58 \%$ of the patients received adjuvant chemotherapy). ${ }^{3}$ After a ten-year follow-up period, no significant difference in loco regional recurrence-free survival was found, between the cALND group and the SLNB only group. ${ }^{4}$

Adjuvant systemic therapy is administered for breast cancer patients to reduce the risk of regional recurrences, distant metastases and related death. ${ }^{5}$ One of the most important independent predictor, for these breast cancer related events, is the axillary lymph nodal status. ${ }^{6}$ Particularly, the total number of metastatic axillary lymph nodes is considered a critical factor, as shown by a negative relationship between the number of metastatic nodes and prognostic outcome. ${ }^{6}$ Tumor size and grade, age of the patient, and human epidermal growth receptor (HER)2-overexpression are other factors determining the risk of systemic disease. ${ }^{7,8}$ Furthermore, new prognostic factors that use the tumor genetic profile are emerging as potential determinants for clinical decision making. ${ }^{9,10}$

In the ACOSOG-Z0011 study, metastatic non-sentinel nodes were left behind in about $27 \%$ of the patients after the omission of CALND for sentinel lymph node-positive breast cancer patients. ${ }^{11}$ Although the Dutch Breast Cancer Guidelines recommend adjuvant chemo(-immuno)therapy for all patients (<70 years) with lymph node positive-tumors ${ }^{7}$, recent international guidelines (St. Gallen) recommend chemotherapy for hormone receptor (HR)-positive, HER2-negative tumors (i.e. luminal A-like phenotype) in case of more than 3 metastatic lymph nodes. ${ }^{12}$ Loss of information on the total axillary tumor burden by performing SLNB only, could lead to difficulties in the administration of systemic therapy.

The aim of this study was to evaluate the impact of omitting cALND on the administration of adjuvant chemo(-immuno) therapy for Dutch cT1-2NOMO sentinel lymph node-positive breast cancer patients, treated with breast conserving therapy. 


\section{Methods}

Data were obtained from the Dutch NABON (Nationaal Borstkanker Overleg Nederland) Breast Cancer Audit (NBCA). The NBCA is a multidisciplinary nationwide registry of all diagnostic and treatment modalities of patients who are surgically treated for breast cancer in the Netherlands since 2011. It is facilitated by the Comprehensive Cancer Centre Netherlands (IKNL) and the Dutch Institute for Clinical Auditing (DICA). Data are registered directly by the hospital itself or by IKNL data managers. The quality of the Dutch Cancer registry is high and data completeness is estimated to be at least $95 \% .{ }^{13}$

\section{Patients and hospitals}

The current study sample consisted of Dutch patients diagnosed with cT1-2NOM0 sentinel node-positive invasive breast cancer between January 2011 and October 2015, treated with primary breast conserving therapy. Positive sentinel-node (SN) outcomes included micro- and macro metastases. Isolated tumor cells were classified as $\mathrm{SN}$-negative and were not included in the study.

Patients with the following criteria were excluded: patients that failed to fulfill the inclusion criteria, patients treated with neo-adjuvant treatment, patients $<18$ years of age and those of whom information on axillary surgery or adjuvant chemo(-immuno) therapy was missing. All the patients treated with immunotherapy received trastuzumab. Data from 85 different Dutch hospitals (9 academic, 38 teaching and 38 general non-teaching hospitals) were included.

\section{Construction of variables}

The nominal variable age of patients was constructed according to recommendations in the Dutch Guideline. A supplemental age group (60-69 yrs) was added based on new insights according to the administration of adjuvant(-immuno) therapy for this group. ${ }^{14}$ The axillary lymph node status was divided into 2 groups (pN1 and $\geq p N 2$ ) based on recommendations in the Saint Gallen expert consensus. The consensus discommended to administer adjuvant chemo(-immuno) therapy for patients with low risk disease, HR-positive, HER2-negative cancer (i.e. Luminal A-like), and a pN1 lymph node status. A pN1 lymph node status included micro-metastases and 1-3 positive lymph nodes, in accordance with the TNM classification.

The NBCA did not register exact radiation fields. Therefore, we could not specify whether a patient received radiotherapy on the breast (partial or whole), and/or- the axilla and/or- other regions. Furthermore, we did not have access to information on adjuvant hormonal therapy in all patients. 


\section{Statistical analyses}

Descriptive analyses, using chi-square crosstabs, were used to report on the trends in axillary treatment and the administration of adjuvant chemo(-immuno). The outcome of interests were the percentage of patients in whom a cALND was omitted and the percentage of patients receiving adjuvant chemo(-immuno) therapy. Two-sided $P$-value $<0.05$ was considered statistically significant.

Univariable and multivariable logistic regression analyses were used to determine the probability of adjuvant chemo(-immuno) therapy administrated for selected sentinel node-positive breast cancer patients. All variables included in the univariable analyses were based on their earlier reported effect on the administration of adjuvant chemo(-immuno) therapy ${ }^{7,8}$ and whether the information was registered and could be provided by the NBCA registry. The multivariable model was fitted for all significant univariable factors. Adjuvant radiotherapy was not included in the multivariable regression model, since information regarding radiation fields was missing and almost all patients received radiotherapy (96\%). Hazard ratios and $95 \%$ confidence intervals (Cl) were estimated for each variable compared to the reference group. Two-sided $P$-value $<0.05$ was considered statistically significant. Data analysis was performed using SPSS version 24 (SPSS Inc., Chicago, IL, USA).

\section{Results}

\section{Patients}

Between January 2011 and October 2015, 25700 patients were diagnosed with CT1-2NOM0 invasive breast cancer and treated with primary breast conserving therapy. After exclusion of SN-negative breast cancer patients ( $n=20886), 18.8 \% \quad(n=4818)$ $\mathrm{SN}$-positive patients remained available. Furthermore, exclusion of patients $<18$ years of age $(n=0)$, those of whom information on the axillary surgery was indistinct $(n=0)$ or those of whom information about adjuvant chemotherapy was missing ( $n=483$ ), resulted in a study population of $4331 \mathrm{SN}$-positive breast cancer patients (see flowchart, Figure 3.1).

The median age was 59 years [25-96]; $18.9 \%$ of the patients $(n=817)$ were older than 70 years. Most of the patients were diagnosed with a cT1 tumor (75\%), invasive ductal (92\%), unifocal (92\%) and HR-positive, HER2-negative breast cancer (79\%). The majority of the patients received radiotherapy to any region $(n=4135,96 \%)$. 


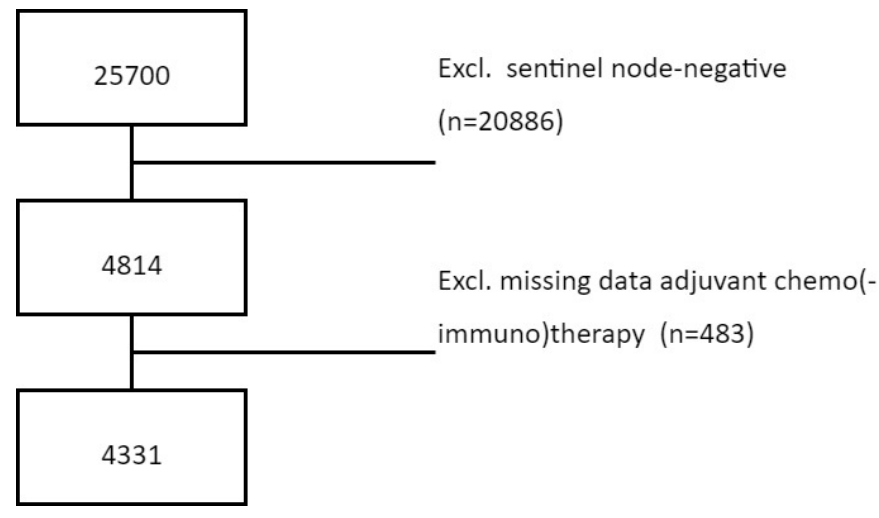

Figure 3.1 Flowchart of exclusion criteria

Overall, $61.6 \%$ ( $n=2668)$ of all patients received adjuvant chemo(-immuno) therapy of whom 10.8\% $(n=288)$ received trastuzumab as well. As shown in Table 3.1, $73.6 \%$ $(n=3186)$ of the patients had undergone SLNB without CALND of whom $56.7 \%(n=1808)$ received adjuvant chemo(-immuno) therapy. The other $26.4 \%(n=1145)$ of the patients had undergone CALND of whom $75.1 \%(n=860)$ were treated with adjuvant chemo(immuno)therapy $(P<0.001)$. Table 3.2 shows the percentages of adjuvant chemo(immuno)therapy divided for $\mathrm{pN} 1-$ and $\geq \mathrm{pN} 2$ lymph node status. Patients treated with cALND diagnosed with $a \geq \mathrm{pN} 2$ status received more often chemo-(immuno)therapy than patients treated with cALND diagnosed with a pN1 status $(P<0.001)$.

\section{Trends in treatment for sentinel node-positive breast cancer patients}

Within this group of cT1-2NOMO sentinel-node positive patients, the omission of a CALND increased from 34\% in 2011, to 92\% in $2015(P<0.001)$. Furthermore, as shown in Figure 3.2, 68\% of the patients received adjuvant chemo(-immuno) therapy in 2011, decreasing to $55 \%$ of the patients in $2015(P<0.001)$. Younger patients were more likely to receive adjuvant chemo(-immuno)therapy compared to older patients. In 2011, the percentage of chemo(-immuno)therapy for patients aged $35-59$ years was $85.1 \%$ and varied to $87.2 \%, 80.8 \%, 79.2 \%$, and $74.5 \%$ in $2012,2013,2014$, and 2015 , respectively $(P<0.001)$. For patients aged 60-69 years, these rates decreased from $62.5 \%$ in 2011 to $62.7 \%, 60.1 \%, 52.3 \%$, and $56.3 \%$ in $2012,2013,2014,2015$, respectively $(P=0.056)$. Regarding the receptor status, HR-positive, HER2-negative patients had a lower probability in receiving adjuvant chemo(-immuno)therapy. Over time the percentage of adjuvant chemo(-immuno)therapy for HR-positive, HER2-negative patients decreased from $67.9 \%$ in 2011 to, $64.1 \%, 59.4 \%, 51.5 \%$, and $51.8 \%$ in 2012, 2013, 2014, and 2015, respectively $(P<0.001)$. The rate of adjuvant chemo(immuno)therapy for triple negative patients remained quite stable with $78.1 \%$ in 2011 to $88.9 \%, 83.7 \%, 81.8 \%$, and $80.5 \%$ in 2012, 2013, 2014, and 2015, respectively $(P=0.635)$. 
Table 3.1 Clinical-pathological and hospital characteristics of cT1-2NOMO sentinel node-positive patients $(\mathrm{N}=4331)$ and percentages of patients receiving adjuvant chemo(-immuno) therapy, 2011 to 2015

\begin{tabular}{|c|c|c|c|c|}
\hline & $\mathrm{N}(4331)$ & Chemotherapy ( $\mathrm{N}=2668)$ & & P-value \\
\hline Incidence year & & & & $<0.001$ \\
\hline 2011 & 727 & 493 & $67.8 \%$ & \\
\hline 2012 & 892 & 597 & $66.9 \%$ & \\
\hline 2013 & 986 & 613 & $62.2 \%$ & \\
\hline 2014 & 999 & 564 & $56.5 \%$ & \\
\hline 2015 & 727 & 401 & $55.2 \%$ & \\
\hline Age, yrs. & & & & $<0.001$ \\
\hline$<35$ & 32 & 30 & $93.8 \%$ & \\
\hline $35-59$ & 2171 & 1744 & $81.7 \%$ & \\
\hline $60-69$ & 1311 & 766 & $58.4 \%$ & \\
\hline $70+$ & 817 & 98 & $12.0 \%$ & \\
\hline Histologic subtype & & & & 0.079 \\
\hline Ductal & 3963 & 2457 & $62.0 \%$ & \\
\hline Lobular & 368 & 211 & $57.3 \%$ & \\
\hline Clinical tumor stage & & & & $<0.001$ \\
\hline cT1 & 3261 & 1941 & $59.5 \%$ & \\
\hline cT2 & 1070 & 727 & $67.9 \%$ & \\
\hline Multifocality & & & & 0.099 \\
\hline Unifocal & 4000 & 2447 & $61.2 \%$ & \\
\hline Multifocal & 315 & 212 & $67.3 \%$ & \\
\hline Unknown & 11 & 7 & $63.6 \%$ & \\
\hline Receptor status & & & & $<0.001$ \\
\hline $\mathrm{HR}+$, Her2- & 3405 & 1982 & $58.2 \%$ & \\
\hline Triple - & 252 & 208 & $82.5 \%$ & \\
\hline HR -, Her2+ & 86 & 79 & $91.9 \%$ & \\
\hline $\mathrm{HR}+$, Her2+ & 313 & 260 & $83.1 \%$ & \\
\hline Unknown & 275 & 139 & $50.0 \%$ & \\
\hline Grade & & & & $<0.001$ \\
\hline 1 & 1090 & 462 & $42.4 \%$ & \\
\hline II & 2138 & 1367 & $63.9 \%$ & \\
\hline III & 1044 & 809 & $77.5 \%$ & \\
\hline Unknown & 59 & 30 & $50.8 \%$ & \\
\hline Axillary Lymph Node dissection & & & & $<0.001$ \\
\hline No & 3186 & 1808 & $56.7 \%$ & \\
\hline Yes & 1145 & 860 & $75.1 \%$ & \\
\hline Lymph node status & & & & $<0.001$ \\
\hline $\mathrm{pN} 1$ & 4146 & 2513 & $60.6 \%$ & \\
\hline$\geq \mathrm{pN} 2$ & 185 & 155 & $83.8 \%$ & \\
\hline Adj. radiotherapy & & & & $<0.001$ \\
\hline No & 64 & 23 & $35.9 \%$ & \\
\hline Yes & 4135 & 2568 & $62.1 \%$ & \\
\hline Unknown & 132 & 77 & $58.3 \%$ & \\
\hline
\end{tabular}

yrs years, cT clinical tumor, HR hormone receptor, Her2 human epidermal growth receptor 2, pN pathologic lymph node status, adj adjuvant 
Table 3.2 Percentages of cT1-2NOMO sentinel node-positive patients ( $\mathrm{N}=4331$ ), treated with adjuvant chemo(-immuno) therapy

\begin{tabular}{lcc}
\hline & SN-positive, without ALND (N=3186) & SN-positive, cALND (N=1145) \\
\hline $\mathrm{pN} 1(\mathrm{~N}=4146)$ & $1808 / 3185(56.8 \%)$ & $705 / 961(73.4 \%)$ \\
$\geq \mathrm{pN} 2(\mathrm{~N}=185)$ & $0 / 1(0 \%)$ & $155 / 184(84.2 \%)$ \\
\hline
\end{tabular}

pN pathologic lymph node status, SN sentinel node, (c)ALND (completion) axillary lymph node dissection

Figure 3.3 presents the percentages of patients receiving adjuvant chemo(-immuno) therapy, divided in a group of SN-positive patients treated with SLNB alone and a group of SN-positive patients treated with CALND. In both groups, the percentages of patients receiving adjuvant chemo(-immuno) therapy varied little over the years 2011-2015.

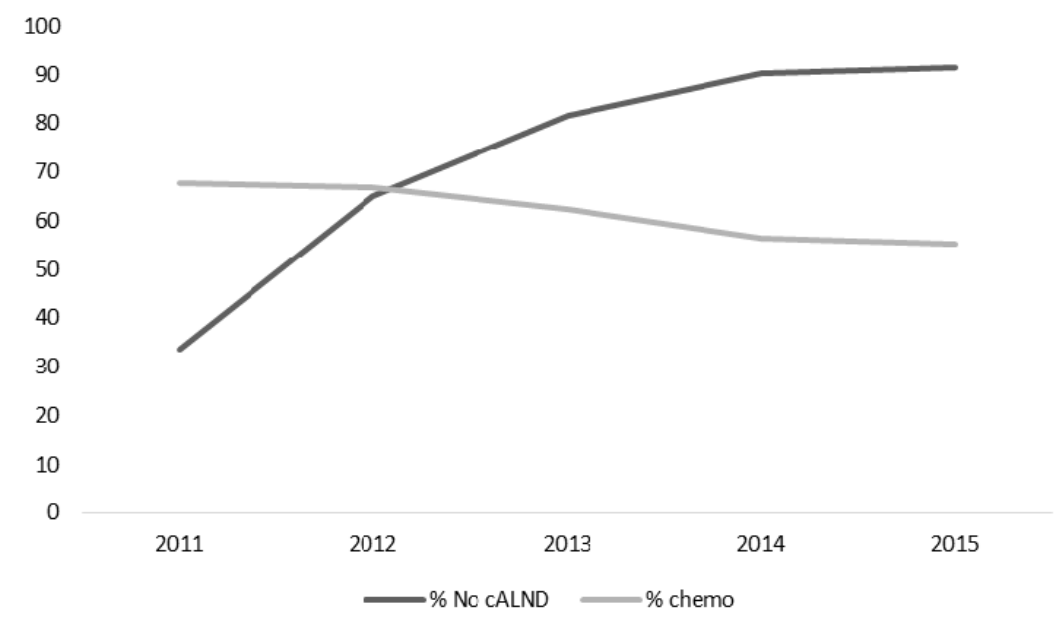

Figure 3.2 Trends in percentages of cT1-2N0M0 sentinel node-positive patients $(n=4331)$ receiving chemo(-immuno) therapy from 2011 to 2015 and percentages of cT1-2NOMO sentinel node positive patients ( $n=4331$ ) without completion axillary lymph node dissection (cALND) from 2011 to 2015

\section{Predictive factors administrating chemo(-immuno) therapy to sentinel node-positive patients}

A multivariable logistic regression analysis was used to determine independent predictors for receiving chemo(-immuno) therapy (Table 3.3). Patients treated with CALND had an OR of 2.2 for receiving chemo(-immuno) therapy compared with SLNB only patients. Apart from a younger age and patients with a hormone status other than HR-positive, HER2-negative, also an increasing tumor grade and tumor stage, as well as $\mathrm{a} \geq \mathrm{pN} 2$ lymph node status were independently associated with the administration of adjuvant chemo(-immuno) therapy (all $P<0.05$ ). 
Table 3.3 Univariable and multivariable logistic regression analyses for receiving chemo(-immuno) therapy among cT1-2NOMO sentinel node-positive patients ( $N=4331$ ), 2011 to 2015

\begin{tabular}{|c|c|c|c|c|c|c|}
\hline & \multicolumn{3}{|c|}{ Univariable } & \multicolumn{3}{|c|}{ Multivariable } \\
\hline & $\begin{array}{l}\text { Odds } \\
\text { ratio }\end{array}$ & $95 \% \mathrm{Cl}$ & P-value & $\begin{array}{l}\text { Odds } \\
\text { ratio }\end{array}$ & $95 \% \mathrm{Cl}$ & P-value \\
\hline \multicolumn{7}{|l|}{ Incidence year } \\
\hline 2011 & Ref. & & $<0.001$ & Ref. & & 0.095 \\
\hline 2012 & 0.961 & $(0.779-1.184)$ & & 1.410 & $(1.069-1.859)$ & \\
\hline 2013 & 0.780 & $(0.637-0.955)$ & & 1.307 & $(0.988-1.729)$ & \\
\hline 2014 & 0.615 & $(0.504-0.751)$ & & 1.144 & $(0.861-1.521)$ & \\
\hline 2015 & 0.548 & $(0.472-0.723)$ & & 1.133 & $(0.839-1.532)$ & \\
\hline \multicolumn{7}{|l|}{ Age, yrs. } \\
\hline$<35$ & 3.357 & $(0.799-14.104)$ & & 1.580 & $(0.358-6.978)$ & \\
\hline $35-59$ & Ref. & & $<0.001$ & Ref. & & $<0.001$ \\
\hline $60-69$ & 0.315 & $(0.269-0.367)$ & & 0.286 & $(0.241-0.339)$ & \\
\hline $70+$ & 0.031 & $(0.024-0.039)$ & & 0.018 & $(0.013-0.023)$ & \\
\hline \multicolumn{7}{|c|}{ Histologic subtype } \\
\hline Ductal & Ref. & & 0.079 & & & \\
\hline Lobular & 0.824 & $(0.664-1.023)$ & & & & \\
\hline \multicolumn{7}{|c|}{ Clinical tumor stage } \\
\hline cT1 & Ref. & & $<0.001$ & Ref. & & 0.002 \\
\hline cT2 & 1.441 & $(1.245-1.668)$ & & 1.372 & $(1.128-1.668)$ & \\
\hline \multicolumn{7}{|l|}{ Multifocality } \\
\hline Unifocal & Ref. & & 0.099 & & & \\
\hline Multifocal & 1.306 & $(1.024-1.667)$ & & & & \\
\hline Unknown & 1.111 & $(0.325-3.800)$ & & & & \\
\hline \multicolumn{7}{|c|}{ Receptor status } \\
\hline $\mathrm{HR}+, \mathrm{Her} 2-$ & Ref. & & $<0.001$ & Ref. & & $<0.001$ \\
\hline Triple - & 3.394 & $(2.434-4.732)$ & & 3.178 & $(2.006-5.034)$ & \\
\hline HR-, Her2+ & 8.103 & $(3.730-17.604)$ & & 5.814 & $(2.307-14.647)$ & \\
\hline $\mathrm{HR}+$, Her2+ & 3.522 & $(2.601-4.769)$ & & 3.246 & $(2.197-4.796)$ & \\
\hline Unknown & 0.734 & $(0.574-0.938)$ & & 0.599 & $(0.433-0.830)$ & \\
\hline \multicolumn{7}{|l|}{ Grade } \\
\hline 1 & 0.415 & $(0.357-0.482)$ & & 0.307 & $(0.256-0.368)$ & \\
\hline II & Ref. & & $<0.001$ & Ref. & & $<0.001$ \\
\hline III & 1.942 & $(1.638-2.301)$ & & 1.937 & $(1.534-2.446)$ & \\
\hline Unknown & 0.583 & $(0.348-0.979)$ & & 0.441 & $(0.235-0.828)$ & \\
\hline \multicolumn{7}{|c|}{ Axillary lymph node dissection } \\
\hline No & Ref. & & $<0.001$ & Ref. & & $<0.001$ \\
\hline Yes & 2.300 & $(1.977-2.675)$ & & 2.243 & $(1.789-2.812)$ & \\
\hline \multicolumn{7}{|c|}{ Lymph node status } \\
\hline $\mathrm{pN} 1$ & Ref. & & $<0.001$ & Ref. & & 0.017 \\
\hline$\geq \mathrm{pN} 2$ & 3.357 & $(2.260-4.988)$ & & 1.901 & $(1.123-3.218)$ & \\
\hline
\end{tabular}

$\mathrm{Cl}$ confidence interval, yrs years, cT clinical tumor, HR hormone receptor, Her2 human epidermal growth receptor 2, pN pathologic lymph node status 


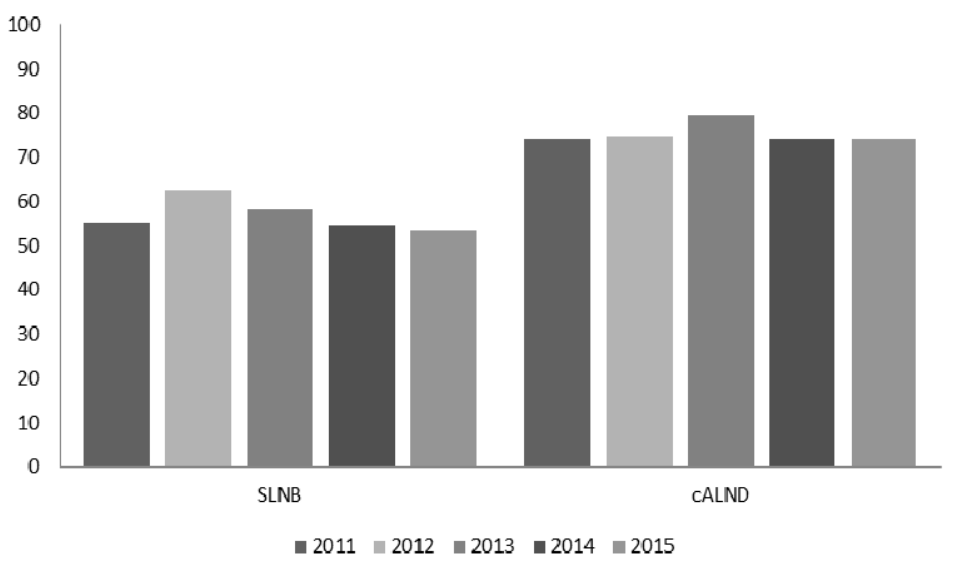

Figure 3.3 Numbers of cT1-2N0M0 sentinel node-positive patients ( $\mathrm{n}=4331$ ) receiving chemo(-immuno) therapy over the years 2011 to 2015, divided per sentinel lymph node biopsy (SLNB) and completion axillary lymph node dissection (cALND)

\section{Discussion}

This study showed an increase for the omission of cALND in Dutch cT1-2NOM0 sentinel node-positive between 2011 and 2015 from 34\% to 92\%, respectively. Patients treated with CALND had a higher independent probability for receiving adjuvant chemo(immuno)therapy compared with SLNB only patients, even when corrected for lymph node status and HR-status.

Recent years, a trend to a more conservative treatment of the axilla in SN-positive patients had been reported, known with a decrease in the performance of CALND. ${ }^{1}$ Nowadays, knowledge on the total axillary tumor burden is more and more missing, which may result in a challenge for multidisciplinary teams recommending adjuvant chemo(-immuno). In contrast to our study, randomized controlled trials, such as the ACOSOG-Z0011 trial (CALND vs. SLNB only), and the AMAROS-trial (cALND vs axillary radiotherapy), as well as the OTOASOR-trial (cALND vs. axillary radiotherapy) ${ }^{4,15-17}$ revealed no difference in the percentage of patients receiving adjuvant chemotherapy between the treatment groups. It was hypothesized, that the absence of the knowledge regarding the final axillary nodal burden, seemed to have no major impact on the administration of adjuvant chemotherapy. Possibly, the knowledge on the tumor burden of the $\mathrm{SN}$ alone rather than the total number of metastatic nodes in the axilla, could be sufficient in clinical decision-making for adjuvant chemotherapy. ${ }^{18}$ In contrast, other studies using blinded mock interdisciplinary tumor boards, based on patient and tumor characteristics as well as information of SLNB or information of CALND, showed that the information of the final nodal status did have a relevant impact on adjuvant 
chemotherapy recommendations. ${ }^{19-21}$ Aigner et al. revealed, only in patients with additional metastatic lymph nodes in a CALND, a previous negative advice on adjuvant chemotherapy would be altered to a positive advice. ${ }^{19}$

Due to a decreasing trend in the performance of CALND in SN-positive patients, others assumed that a growing number of these patients would be treated with adjuvant chemotherapy, in order to manage metastases in remaining non-SNs. ${ }^{9}$ In the current study, $57 \%$ of all patients treated with SLNB alone received chemo(immuno)therapy compared with $75 \%$ of all patients treated with cALND. Furthermore, patients treated with CALND had an OR of 2.2 for receiving chemo(-immuno) therapy compared with SLNB alone patients, even when corrected for lymph nodal status (pN1 and $\geq p N 2$ ), patients age and HR-status. Intriguingly, not only the extent of the total tumor burden seemed to have an impact on the administration of adjuvant chemo(-immuno)therapy, but the performance of a cALND itself seemed to have an even higher impact. Most likely, treatment decisions were influenced by local policies, as well as patient and physician preferences regarding adjuvant chemo(-immuno)therapy.

Last decade, there has been a growing interest in shared decision-making, in which the physicians and patients share treatment preferences together and reach an agreement on the treatment choice. ${ }^{22}$ This patient-centered health care yields a shift from medical paternalism to enhanced autonomy, in which the opinion of patients regarding treatment choice is very important. Multiple comorbidities and fragility might influence patients in their treatment decisions. Several cancer survivors experience the fear of recurrence and develop mental health problems including distress, depression and anxiety. ${ }^{23}$ Patients encountering health-related problems could induce to opt for the most extensive adjuvant treatment plan; including CALND and adjuvant chemo(immuno)therapy, irrespective of final lymph nodal status. A contrary group of patients could opt to refuse such an extensive adjuvant treatment and keeping in mind their health-related quality of life, as well as the possible consequences of adjuvant chemo(immuno) therapy. It is known that, SLNB causes less morbidity compared with CALND, including a lower rate of lymphedema, seromas, pain and sensory changes. ${ }^{24,25}$ Adjuvant chemotherapy is associated with several short- and long-term toxicities, including alopecia, cardiovascular toxicity, peripheral neuropathies, cognitive impairment and fertility. These toxicities may have a negative impact on the healthrelated quality of life of patients. ${ }^{26,27}$ Nowadays, treatment choices are not only based on guidelines and/or patient/tumor characteristics, but are influenced by patients' and/or physicians' opinions regarding comorbidities, fragility and health related quality of life, as well.

Our study is limited by the retrospective nature, reflected by the missing data on possible comorbidities, the administration of hormone therapy and specific information on radiation therapy fields. Therefore, a shift towards the use of adjuvant hormonal therapy could not be analyzed. Yet, in the multivariable analysis the observed 
phenomena were independent for hormone receptor status. Furthermore, information was missing regarding a possible selection of the patients that would not benefit from adjuvant chemo(-immuno) therapy, based on gene-expression profiling (nowadays in The Netherlands, Mammaprint is used in $97 \%$ of the cases when gene profiling is performed). Nonetheless, we don't expect that the use of gene-expressing profiling was already widespread in The Netherlands during the study period, since results from prospective studies were published after $2015^{28}$ and consensus was not yet reached on the prognostic value of these tumor genetic information tools in SN-positive breast cancer patients. ${ }^{10,12}$ These expectations were reflected by a recent publication of Schreuder et al., whom presented that only a small number of node-positive patients received gene expressing profiling. ${ }^{29}$ Excluding neo-adjuvant treated patients could result in a lower percentage of node-positive patients in this study cohort through the omission of high risk patients treated with neoadjuvant therapy. Lastly, a limitation of this study is the potential for residual confounders. ${ }^{30}$ Patients treated with cALND may have differed from SLNB only patients in terms of health status and preferences. These considerations should be taken into account when discussing adjuvant chemo(immuno) therapy options.

To our knowledge, this is the largest study demonstrating trends in axillary surgery and the administration of adjuvant chemo(-immuno) therapy in sentinel-node positive breast cancer patients. A nationwide study, compromising real life data from multiple centers and different hospital types (academic and non-academic), representing daily use practice in the administration of adjuvant chemo(-immuno) therapy in Dutch sentinel node-positive breast cancer patients, primary treated with breast conserving treatment.

\section{Conclusion}

In the post ACOSOG-Z0011 era, which is known for a trend towards less extensive axillary surgery, this study showed that cT1-2NOMO sentinel node-positive patients, treated with a cALND had a higher independent probability for receiving adjuvant chemo(-immuno) therapy compared with SLNB only patients. Probably, the decision to administer adjuvant chemo(-immuno) therapy was not only based on guidelines and/or patient/tumor characteristics, but also on the preferences from physicians and patients. 


\section{References}

1. Poodt IGM, Spronk PER, Vugts G, et al. Trends on axillary surgery in nondistant metastatic breast cancer patients treated between 2011 and 2015: A Dutch population-based study in the ACOSOG-Z0011 and AMAROS Era. Ann Surg. 2018;268(6):1084-1090.

2. Rescigno J, et al. Patterns of axillary surgical care for breast cancer in the era of sentinel lymph node biopsy. Ann Surg Oncol. 2009;16:687-696.

3. Giuliano $A E$, et al. Locoregional recurrence after sentinel lymph node dissection with or without axillary dissection in patients with sentinel lymph node metastases: the American College of Surgeons Oncology Group Z0011 randomized trial. Ann Surg. 2010;252:426-432.

4. Giuliano $A E$, et al. Locoregional Recurrence After Sentinel Lymph Node Dissection With or Without Axillary Dissection in Patients With Sentinel Lymph Node Metastases: Long-term Follow-up From the American College of Surgeons Oncology Group (Alliance) ACOSOG Z0011 Randomized Trial. Ann Surg. 2016;264:413-420.

5. Montemurro F, et al. Controversies in breast cancer: adjuvant and neoadjuvant therapy. Expert Opin Pharmacother. 2005;6:1055-1072.

6. Carter $\mathrm{CL}$, et al. Relation of tumor size, lymph node status, and survival in 24,740 breast cancer cases. Cancer. 1989;63:181-187.

7. Nationaal Borstkanker Overleg Nederland (NABON). Richtlijn behandeling van het mammacarcinoom. Accessed 2 March 2012. Available from: http://www.oncoline.nl.

8. Henry NL, et al. Role of Patient and Disease Factors in Adjuvant Systemic Therapy Decision Making for Early-Stage, Operable Breast Cancer: American Society of Clinical Oncology Endorsement of Cancer Care Ontario Guideline Recommendations. J Clin Oncol 2.016;34:2303-2311.

9. Jatoi I, et al. De-escalation of axillary surgery in early breast cancer. Lancet Oncol. 2016;17:e430-e441.

10. Krop I, et al. Use of Biomarkers to Guide Decisions on Adjuvant Systemic Therapy for Women With Early-Stage Invasive Breast Cancer: American Society of Clinical Oncology Clinical Practice Guideline Focused Update. J Clin Oncol. 2017;35:2838-2847.

11. Giuliano $A E$, et al. Axillary dissection vs no axillary dissection in women with invasive breast cancer and sentinel node metastasis: a randomized clinical trial. JAMA. 2011;305:569-575.

12. Coates AS, et al. Tailoring therapies--improving the management of early breast cancer: St Gallen International Expert Consensus on the Primary Therapy of Early Breast Cancer 2015. Ann Oncol. 2015;26:1533-1546.

13. van Bommel $\mathrm{AC}$, et al. Clinical auditing as an instrument for quality improvement in breast cancer care in the Netherlands: The national NABON Breast Cancer Audit. J Surg Oncol. 2017;115:243-249.

14. Verschoor AM, et al. Adjuvant systemic therapy in early breast cancer: impact of guideline changes and clinicopathological factors associated with nonadherence at a nation-wide level. Breast Cancer Res Treat. 2016;159:357-365.

15. Donker $\mathrm{M}$, et al. Radiotherapy or surgery of the axilla after a positive sentinel node in breast cancer (EORTC 10981-22023 AMAROS): a randomised, multicentre, open-label, phase 3 non-inferiority trial. Lancet Oncol. 2014;15:1303-1310.

16. Straver ME, et al. Role of axillary clearance after a tumor-positive sentinel node in the administration of adjuvant therapy in early breast cancer. J Clin Oncol. 2010;28:731-737.

17. Savolt A, et al. Eight-year follow up result of the OTOASOR trial: The Optimal Treatment Of the Axilla Surgery Or Radiotherapy after positive sentinel lymph node biopsy in early-stage breast cancer: A randomized, single centre, phase III, non-inferiority trial. Eur J Surg Oncol. 2017;43:672-679.

18. Ponzone $\mathrm{R}$, et al. Omission of axillary dissection after a positive sentinel lymph-node: Implications in the multidisciplinary treatment of operable breast cancer. Cancer Treat Rev. 2016;48:1-7.

19. Aigner J, et al. Omission of axillary dissection according to ACOSOG Z0011: impact on adjuvant treatment recommendations. Ann Surg Oncol. 2013;20:1538-1544.

20. Montemurro $\mathrm{F}$, et al. Omission of axillary dissection after a positive sentinel node dissection may influence adjuvant chemotherapy indications in operable breast cancer patients. Ann Surg Oncol. 2012;19:3755-3761.

21. Reimer $\mathrm{T}$, et al. How important is the axillary nodal status for adjuvant treatment decisions at a breast cancer multidisciplinary tumor board? A survival analysis. Ann Surg Oncol. 2008;15:472-477. 
22. Joosten EA, et al. Systematic review of the effects of shared decision-making on patient satisfaction, treatment adherence and health status. Psychother Psychosom. 2008;77:219-226.

23. Runowicz CD, et al. American Cancer Society/American Society of Clinical Oncology Breast Cancer Survivorship Care Guideline. J Clin Oncol. 2016;34:611-635.

24. Peintinger $\mathrm{F}$, et al. Comparison of quality of life and arm complaints after axillary lymph node dissection vs sentinel lymph node biopsy in breast cancer patients. Br J Cancer. 2003;89:648-652.

25. DiSipio $\mathrm{T}$, et al. Incidence of unilateral arm lymphoedema after breast cancer: a systematic review and meta-analysis. Lancet Oncol. 2013;14:500-515.

26. Seretny $M$, et al. Incidence, prevalence, and predictors of chemotherapy-induced peripheral neuropathy: A systematic review and meta-analysis. Pain. 2014;155:2461-2470.

27. Tao JJ, et al. Long term side effects of adjuvant chemotherapy in patients with early breast cancer. Breast. 2015;24 Suppl 2:S149-S153.

28. Cardoso F, et al. 70-Gene Signature as an Aid to Treatment Decisions in Early-Stage Breast Cancer. N Engl J Med. 2016;375:717-729.

29. Schreuder K, et al. Impact of gene-expression profiling in patients with early breast cancer when applied outside the guideline directed indication area. Eur J Cancer. 2017;84:270-277.

30. Skelly AC, et al. Assessing bias: the importance of considering confounding. Evid Based Spine Care J. 2012;3:9-12. 


\section{Chapter 4}

The rationale for and long-term outcome of incomplete axillary staging in elderly women with primary breast cancer

I.G.M. Poodt, R.J. Schipper, G. Vugts, K. Woensdregt, M. van der Sangen, A.C. Voogd, G.A.P. Nieuwenhuijzen 


\section{Abstract}

\section{Background}

The proportion of elderly women diagnosed with breast cancer is rising. Standard treatment, including axillary staging, is often not given to these patients. This study aimed to investigate reasons to omit any surgical axillary staging or to refrain from completion axillary lymph node dissection (CALND) after positive-sentinel lymph node biopsy (SLNB); so-called "incomplete staging". Furthermore, the impact of incomplete staging on regional control and survival in patients aged 75 or older was evaluated.

\section{Methods}

A retrospective cohort study was conducted including all primary breast cancer patients aged 75 or older, diagnosed between 2001 and 2008, and documented by the Netherlands Cancer Registry (NCR). Patients with incomplete staging were compared to patients with complete axillary staging. Survival analyses were used to determine the risk of local, regional and distant recurrence and overall survival.

\section{Results}

In total, 1467 of 2116 (69\%) patients were considered eligible, of whom 258 (17.2\%) had incomplete axillary staging. For 93 patients, diagnosed in 6 of the 10 hospitals in the NCR-area, examination of clinical records revealed that age, comorbidities and patient preferences were the main reason for omitting complete axillary staging. The 10-year axillary recurrence rate in these 93 patients was $5.2 \%(95 \% \mathrm{Cl}, 0.03-10.1)$. Of the 77 patients who had died, 64 (83\%) died of non-breast-cancer-related causes. No significant difference in overall survival was observed between patients with or without complete axillary staging.

\section{Conclusions}

This study demonstrates that the omission of complete axillary staging is common in selected elderly breast cancer patients with $\geq 2$ comorbidities, with no apparent impact on regional control and 10 -year overall survival. 


\section{Introduction}

Breast cancer is the most frequently diagnosed type of cancer in women in the Netherlands. ${ }^{1}$ Due to the rising life expectancy, the proportion of elderly women with breast cancer is increasing. Between 2000 and 2016 the percentage of women aged 75 or older with breast cancer rose from $11 \%$ to $17 \% .^{2}$

Over the last decades, surgical techniques for axillary treatment and staging in primary breast cancer patients have become less extensive and attention has focused on minimizing the risk of morbidity related to surgery. ${ }^{3}$ Presentation of the ACOZOG-Z011 study results in $2011^{4}$ resulted in a downward trend in the use of completion axillary lymph node dissection (cALND) in early breast cancer patients with 1-2 positive sentinel lymph nodes (SLN), treated with breast conserving surgery (BCS) and whole breast irradiation. ${ }^{5}$ However, there is little evidence regarding the optimal axillary treatment in elderly breast cancer patients, since these patients are often excluded from clinical trials. ${ }^{6,7}$ Several studies reported on the differences in treatment in different age groups of breast cancer patients. ${ }^{8-12}$ Compared to their younger counterparts, elderly breast cancer patients less frequently receive what is considered standard treatment. ${ }^{8,13-17}$ They are less likely to undergo surgery and, if treated surgically, are less frequently subjected to BCS and axillary lymph node dissection (ALND). ${ }^{16,18}$ Regarding adjuvant treatment, if treated with BCS, elderly patients are less likely to receive radiotherapy. ${ }^{15,19}$ Adjuvant chemotherapy is rarely used in elderly patients. ${ }^{18,20,21}$ However, physicians use endocrine therapy as an alternative relatively often. ${ }^{21}$

Reasons to apply non-standard treatment in elderly breast cancer patients are patient preferences, a reduced health status, considered fragility and comorbidities. ${ }^{11,21}$ Several studies have demonstrated that both increasing age and the presence of comorbidities are associated with refraining from axillary staging. ${ }^{12,13,17,19}$ Particularly patients suffering from two or more comorbidities have been demonstrated to receive less extensive treatment of the axilla, including less radiotherapy and less frequently completion axillary lymph node dissection (CALND) after positive SLN. ${ }^{13,22}$ Furthermore, risk of dying from other causes increases rapidly with advancing age, thus decreasing the risk an elderly patient has of experiencing a breast cancer relapse during lifetime. ${ }^{3}$

This study was conducted to investigate the reasons for omitting surgical axillary staging or refraining from cALND after prior positive SLNB. The secondary aim was to evaluate the impact of incomplete axillary staging on regional control and overall survival in patients aged 75 or older by presenting the 10-year follow-up data. 


\section{Material and methods}

Data were obtained from the Netherlands Cancer Registry (NCR). The NCR is a multidisciplinary population-based registry of all patients with newly diagnosed breast cancer in the Netherlands. The registry is managed by the Netherlands Comprehensive Cancer Organization (IKNL). Data were registered directly by the hospital itself or by NCR data managers. The quality of the Dutch Cancer Registry is high and data completeness is estimated to be at least $95 \% .^{23}$

According to the Central Committee on Research involving Human Subjects (CCMO), this type of study does not require approval from an ethics committee in the Netherlands.

\section{Patients and hospitals}

The current study sample consisted of Dutch women aged 75 or older, diagnosed with primary breast cancer in the period 2001-2008 in 10 hospitals in the southern part of the Netherlands. Patients who did not receive surgical treatment for the primary breast tumour were excluded, as were patient for whom information on axillary surgery was missing.

For this study, detailed information on recurrence and breast-cancer-related survival was available for the patients of 6 out of the 10 hospitals. Information on overall survival was available for all 10 hospitals.

\section{Treatment-related variables}

According to Dutch guidelines, all patients were preoperative screened with an axillary ultrasound, supplemented with a punction of a suspected node. ${ }^{24}$

A positive sentinel node included micrometastases and macrometastases, isolated tumor cells were considered as sentinel node negative.

The patients were divided into two groups according to the standard of axillary staging during time of diagnosis of primary breast cancer (2001-2008); into the complete and the incomplete axillary staging group. All patients were diagnosed with breast cancer in a period prior presentation of the ACOSOG-Z001 (2011) ${ }^{4}$ and AMAROS study results (2014). ${ }^{25}$ Before publication of these trials, nearly all primary breast cancer patients were staged with SLNB and if positive treated with CALND. ${ }^{26}$ Therefore, the complete axillary staging group (considered to be the control group) existed of early breast cancer patients of whom the SLN was negative and patients who were treated with a CALND in case of positive SLN. The incomplete axillary staging group consisted of women without any surgical axillary staging (neither SLNB nor ALND) and of patients with positive SLN, treated without CALND (deviating from the standard treatment of that time). 
Since the NCR did not register the exact radiation fields, we could not describe whether patients in the control group received radiotherapy on the breast (partial or whole) and/or axilla and/or other regions. Furthermore, we did not have access to information on the hormone receptor status in this group.

Comorbidities were scored according to the Charlson Comorbidity Index (CCI). ${ }^{27}$

\section{Definition of recurrence}

Local recurrence was defined as reappearance of tumour growth in the previously treated breast or overlying skin. Regional recurrence was defined as any evidence of disease found in ipsilateral intramammary nodes, ipsi- and contralateral internal mammary nodes, ipsi- and contralateral axillary nodes, and ipsi- and contralateral infra and supraclavicular nodes. ${ }^{28,29}$ Lymph node recurrences found outside these nodal basins were defined as distant metastatic disease. Distant recurrence was defined as any evidence of disease outside the ipsilateral breast, contralateral breast and regional lymph nodes.

\section{Follow-up}

The clinical records of the patients in the incomplete axillary staging group, diagnosed in 6 out of 10 hospitals in the NCR-area, were reviewed to collect detailed information regarding comorbidities, reasons to omit axillary staging, local and regional recurrence, distant metastasis and date and cause of death. Family physicians and nursing home physicians were contacted in case of missing data.

The general register office provided information on survival of all patients until 31-01-2017. This date was considered as the end of the follow-up period. The date of last follow-up was documented as 31-01-2017, or date of death in case the patient had deceased. Time to death or overall survival was calculated from date of primary surgery until date of last follow-up.

\section{Statistical analysis}

The following variables were compared between the two axillary treatment groups: age at diagnosis of the primary breast cancer, tumour size, nodal status, histological size and grade, type of surgery, number of comorbidities and adjuvant treatment. Statistical significance was tested using Pearson Chi square test and Fisher's exact test for categorical variables. For continuous variables, the Mann-Whitney $U$ test or independent samples $t$ test were used when appropriate. Survival analyses, using the Kaplan-Meier method, were used to calculate overall survival and recurrence-free survival. A two-sided $P$-value of $\leq 0.05$ was considered statistically significant. Data analysis was performed using SPSS version 24 (SPSS Inc., Chicago, IL, USA). 


\section{Results}

In the period 2001-2008, 2116 women aged 75 or older were diagnosed with primary breast cancer in the 10 hospitals in the southern part of the Netherlands and registered by the NCR. Exclusion of patients who were not surgically treated for the primary tumour $(\mathrm{N}=615)$ and those for whom information on the axillary surgery was missing $(\mathrm{N}=34)$ resulted in a study population of 1467 patient. Of this cohort, 1209 (82\%) met the inclusion criteria for the complete staging group (control group) and 258 (18\%) patients those for the incomplete staging group. Detailed information on follow-up of the incomplete axillary staging group, by means of examining clinical records, was derived in 6 out 10 hospitals, resulting in a total group of 93 patients (Figure 4.1).

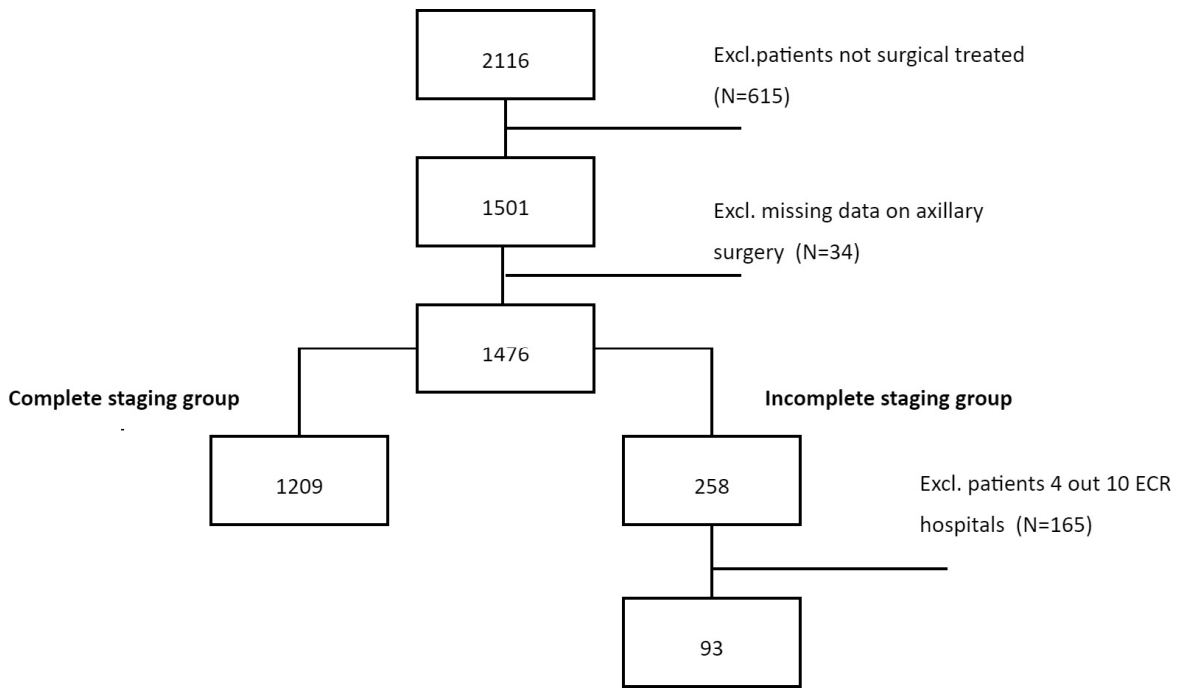

Figure 4.1 Flowchart of patient inclusion

\section{Patient characteristics}

Patient and disease characteristics of all included patients are presented in Table 4.1. In the incomplete axillary staging group, 41/93 (44\%) were proven lymph node positive, treated without CALND. In the other 52 patients (55\%) no axillary staging (neither SLNB nor ALND) besides axillary ultrasound was performed. In the control group, 452/1209 (34\%) patients were proven lymph node positive. By rough estimate, another $17-18$ patients (52 patients with no axillary staging * $34 \%$ ), in the incomplete axillary staging group were probably lymph node positive.

Mean age in the incomplete staging group was 81.7 years compared to 80.1 years in the complete axillary staging group $(P<0.001)$. The percentage of patients with one or 
more comorbidities was significantly higher in the incomplete staging group compared with the complete staging group $(P<0.015)$.

Table 4.1 Patient characteristics of patients subdivided by axillary staging group

\begin{tabular}{|c|c|c|c|c|c|}
\hline \multirow[t]{2}{*}{ Characteristic } & \multicolumn{2}{|c|}{$\begin{array}{l}\text { Incomplete axillary staging } \\
\qquad(\mathrm{N}=93)\end{array}$} & \multicolumn{2}{|c|}{$\begin{array}{l}\text { Complete axillary staging } \\
\qquad(\mathrm{N}=1209)\end{array}$} & \multirow[t]{2}{*}{$P$-value } \\
\hline & $\mathbf{N}$ & $\%$ & $\mathbf{N}$ & $\%$ & \\
\hline Age, mean years & 81.7 & & 80.1 & & $<0.001$ \\
\hline Age, years & & & & & 0.012 \\
\hline $75-79$ & 37 & $(40)$ & 565 & $(46)$ & \\
\hline $80-84$ & 33 & (36) & 480 & (39) & \\
\hline $85+$ & 23 & (25) & 164 & (14) & \\
\hline Clinical nodal status (cN) & & & & & 0.167 \\
\hline cNO & 70 & (75) & 886 & (73) & \\
\hline $\mathrm{cN} 1$ & 10 & (11) & 225 & (19) & \\
\hline $\mathrm{cN} \geq 2$ & 0 & (0) & 6 & $(0.5)$ & \\
\hline Unknown & 13 & (14) & 92 & (8) & \\
\hline Tumour size (pT) & & & & & 0.551 \\
\hline pT1 & 36 & (39) & 494 & $(41)$ & \\
\hline рт2 & 44 & (47) & 580 & (48) & \\
\hline рT3 & 3 & (3) & 48 & (4) & \\
\hline pT4 & 7 & (8) & 72 & (6) & \\
\hline Unknown & 3 & (3) & 15 & (1) & \\
\hline Nodal status (pN) & & & & & $<0.001$ \\
\hline pN negative & 0 & (0) & 719 & $(60)$ & \\
\hline pN positive & 41 & (44) & 452 & (34) & \\
\hline Unknown/ No ax. surgery & 52 & (56) & 79 & (7) & \\
\hline Histological type & & & & & 0.496 \\
\hline Ductal & 74 & $(80)$ & 909 & (75) & \\
\hline Lobular or mixed & 15 & (16) & 212 & (18) & \\
\hline Other & 4 & (4) & 88 & (7) & \\
\hline Histological grade & & & & & 0.082 \\
\hline Good & 27 & (29) & 238 & $(20)$ & \\
\hline Moderate & 39 & (42) & 485 & (40) & \\
\hline Poor & 16 & (17) & 264 & $(22)$ & \\
\hline Unknown & 11 & (12) & 222 & (18) & \\
\hline \multicolumn{6}{|l|}{ Estrogen receptor status } \\
\hline Positive & 76 & $(82)$ & n.a. & & \\
\hline Negative & 14 & (15) & & & \\
\hline Unknown & 3 & (3) & & & \\
\hline \multicolumn{6}{|l|}{ Progesterone receptor status } \\
\hline Positive & 66 & $(72)$ & n.a. & & \\
\hline Negative & 23 & (25) & & & \\
\hline Unknown & 3 & (3) & & & \\
\hline Type of surgery & & & & & $<0.001$ \\
\hline Mastectomy & 44 & $(47)$ & 812 & $(67)$ & \\
\hline Breast-conserving & 49 & (53) & 396 & (33) & \\
\hline Unknown & 0 & (0) & 1 & $(0.1)$ & \\
\hline Radiotherapy & & & & & 0.589 \\
\hline Yes & 39 & $(42)$ & 549 & $(45)$ & \\
\hline No & 54 & (58) & 660 & (55) & \\
\hline
\end{tabular}


Table 4.1 (continued)

\begin{tabular}{|c|c|c|c|c|c|}
\hline \multirow[t]{2}{*}{ Characteristic } & \multicolumn{2}{|c|}{$\begin{array}{l}\text { Incomplete axillary staging } \\
\qquad(\mathrm{N}=93)\end{array}$} & \multicolumn{2}{|c|}{$\begin{array}{l}\text { Complete axillary staging } \\
\qquad(\mathrm{N}=1209)\end{array}$} & \multirow[t]{2}{*}{$P$-value } \\
\hline & $\mathbf{N}$ & $\%$ & $\mathbf{N}$ & $\%$ & \\
\hline Endocrine treatment & & & & & $<0.001$ \\
\hline Yes & 77 & (83) & 586 & (49) & \\
\hline No & 11 & (12) & 623 & (52) & \\
\hline Unknown & 5 & (5) & 0 & $(0)$ & \\
\hline Chemotherapy & & & & & 0.334 \\
\hline Yes & 0 & (0) & 12 & $(1)$ & \\
\hline No & 93 & $(100)$ & 1197 & (99) & \\
\hline Number of comorbidities & & & & & 0.015 \\
\hline 0 & 17 & (18) & 266 & $(22)$ & \\
\hline 1 & 21 & (23) & 349 & (29) & \\
\hline$\geq 2$ & 50 & (54) & 455 & (38) & \\
\hline Unknown & 5 & (5) & 139 & $(12)$ & \\
\hline
\end{tabular}

$\mathrm{N}$ number, \% percentage, pT pathological tumour size, pN pathological nodal status, ax axillary, n.a. not available

\section{Reasons to omit axillary staging}

In $83(89.2 \%)$ of the 93 patients who received incomplete axillary staging, one or more reasons were mentioned and registered in the medical records by the treating surgeon, radiation oncologit or medical oncologist. In 29 patients $(31.2 \%)$, the presence of comorbidities was stated as the main reason for omission of complete axillary staging. In 28 (30.1\%), age was mentioned as the most important decisional factor, followed by the preference of the patient and/or family in 23 patients $(24.7 \%)$. The supposed subsequent morbidity of ALND was the main reason in 13 patients (14\%) to omit the performance of cALND after positive SLNB. Other reasons mentioned for omitting complete axillary staging were physicians' preference, supposed high operation risk for (c)ALND and lastly lack of influence on adjuvant treatment.

\section{Adjuvant therapy}

In the incomplete axillary staging group, 78 patients $(83.9 \%)$ had a positive estrogen and/or progesterone receptor status and 77 (82.8\%) received endocrine therapy with either tamoxifen or an aromatase inhibitor. Incompletely staged patients with positive nodes were more likely to receive endocrine therapy than those who had no axillary staging, $93.0 \%$ versus $74.0 \%$, respectively. In the complete staging group, only 586 patients $(48.5 \%)$ received endocrine therapy $(P<0.001)$. Radiotherapy was administered to a comparable percentage of 39 patients $(40.3 \%)$ in the incomplete staging group and $549(45.4 \%)$ in the complete staging group $(P=0.589)$. Forty-nine patients $(52.7 \%)$ in the incomplete staging group received breast-conserving surgery and only 29 of them (59\%) received adjuvant whole-breast radiotherapy. Ten of the 44 patients treated with mastectomy received adjuvant chest-wall radiotherapy. For 
the patients in the complete staging group, no information was collected on the specific radiation fields.

\section{Prognosis and survival}

The median follow-up time of patients still alive was 10.1 (range 8.1-16.0) years. In the incomplete axillary staging group, 16 patients (17.2\%) developed any recurrence. In four patients $(4.3 \%)$ a local recurrence was diagnosed, regional recurrences were observed in four patients (4.3\%) and eight (8.6\%) developed distant recurrences as first event after primary treatment. The 5 - and 10 -year actuarial regional recurrence rate in the incomplete axillary staging group was $5.2 \%(95 \% \mathrm{Cl}, 0.03-10.1)$. All four patients with a regional recurrence developed clinical palpable nodes in the ipsilateral axilla, after a median time of 2.0 (range 0.2-3.2) years. Two of these patients received primary no axillary staging and two patients had a primary positive rSLNB. After diagnoses of regional recurrence, one of the patients with no primary staging and one of the patient with a primary positive rSLN underwent an ALND, both eventually developed distant metastasis and died due to progressive disease. One patients preferred no further axillary therapy, developed distant metastasis and died as well. The last patient, primary not axillary staged, received regional radiotherapy and died from other, nonbreast-cancer-related causes.

Distant recurrences occurred in 12 patients, after a median time of 1.7 years ( 8 patients as first event, 3 after regional recurrences and 1 after IBTR). Eleven of these patients had hormone-positive tumours and one a triple negative tumour. All these patients died during follow-up, 10 of causes related to their breast cancer and 2 because of cardiac disease.

Ten-year overall survival in the incomplete staging group was $28.5 \%$ ( $95 \% \mathrm{Cl}, 18.9-39.5)$. In this cohort, 10 patients (10.8\%) died of breast cancer, 3 patients $(3.2 \%)$ died from complications after breast-cancer-related treatment, 19 patients (20.4\%) died from cardiovascular disease and 41 (44.1\%) died from other, non-breast-cancer-related causes. In four patients (4.3\%) the cause of death could not be retrieved.

Ten-year overall survival in the complete axillary staging group was $32.7 \%(95 \% \mathrm{Cl}$, 30.5-35.4). The latter was not significantly different from overall survival of patients in the incomplete axillary staging group ( $P$-log rank=0.101) (Figure 4.2). 


\section{Overall Survival}

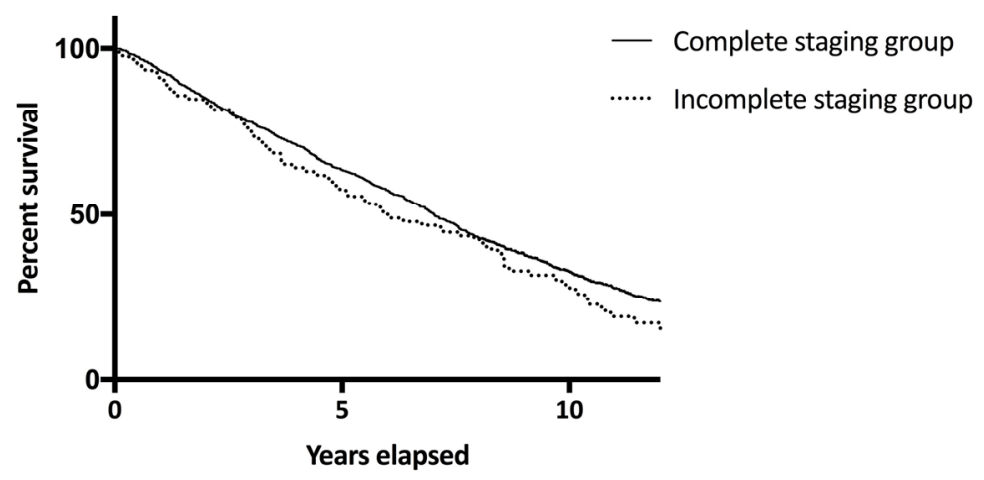

Figure 4.2 Overall survival for patients in the incomplete staging group versus the complete staging group

\section{Discussion}

This study of patients aged 75 or older with primary breast cancer showed that the most common reasons to perform incomplete surgical axillary staging in elderly patients were the presence of two or more comorbidities and the advanced age of the patient, followed by the preference of patients or their family. Furthermore, a 10-year regional recurrence rate of $5.2 \%$ in the incomplete staging group was observed.

Present findings indicate that shared decision-making was common practice during the study period. This is in line with other studies evaluating the need to also involve elderly patients in the decision-making process. ${ }^{30,31}$ Especially in frail elderly patients, shared decision-making plays an important role in tailoring individual treatment plans to these patients. ${ }^{32}$

Similar to this study, a low risk of axillary recurrence has also been presented in a study by Martelli et al. in 2012, which showed a 15-year axillary recurrence rate of $6.0 \%$ in breast cancer patients aged 65 to 80 , treated with breast-conserving therapy and endocrine therapy, without ALND. ${ }^{33}$ Several randomized trials comparing complementary axillary surgery after positive sentinel lymph node biopsy versus no ALND or axillary radiotherapy, such as the ACOSOG-Z0011, AMAROS and OTASOR trials, also showed no difference in axillary recurrence rates between complementary ALND and no ALND or axillary radiotherapy after positive-sentinel lymph node biopsy. ${ }^{4,25,34}$ This was despite the fact that pathologically involved axillary lymph nodes were found in 27-39\% of patients who received ALND. ${ }^{4,25,34}$ These trials studied much younger patients. For example, AMAROS and OTASOR were only eligible for patients younger 
than 75, and in ACOSOG-Z0011 the median age was 54 (25-90) in the SLNB-only group. The results of these trials indicate that only a limited part of all axillary involved lymph nodes have the potential to cause regional problems and that the risk of metastatic spread is mainly determined by the biological behaviour of the primary tumour. ${ }^{35,36}$

Adjuvant endocrine therapy, which had been prescribed to nearly $83 \%$ of the patients in the incomplete staging group, was a possible contributor to the low percentages of axillary recurrence and other breast-cancer-related events. Long-term endocrine treatment is known to suppress growth of cancer cells for many years, if not indefinitely. ${ }^{37}$ Elderly patients tend to develop cancers with a high percentage being hormone responsive ${ }^{38,39}$ (in this study $82 \%$ ), and therefore sensitive for endocrine treatment.

As was expected, most of the patients in this study died from non-breast-cancer-related causes. Compared to younger patients, elderly breast cancer patients die more often with cancer instead of from cancer. ${ }^{40}$ Besides, a balance is needed between the outcome effects of axillary staging and the side effects of axillary staging in terms of morbidity. In the elderly patients, this balance for axillary staging may not result in benefit, especially not for elderly patients with substantial comorbidity. Taking this together with the high mortality unrelated to breast cancer, axillary staging, as addition to local tumour control, seems less important in this population.

The main limitation of this study is the relatively small number of patients in the incomplete axillary staging group and. However, since many clinical trials often exclude elderly patients, the information presented here is useful in filling the gap in evidence regarding optimal axillary treatment of elderly patients. Besides, long time follow-up of elderly patients is hard to achieve, since these patients often withdraw from outpatient clinic visits. Another limitation is the retrospective design of this study, which did not allow us to measure patients' quality of life. In this population, the quality of life may be as important as the outcome rates associated with the different treatment options. Lastly, data is missing regarding the hormone receptor status in the control group. Despite these limitations, this study compiles real-life data from multiple centers, representing daily practice in the axillary treatment of elderly patients.

In summary, axillary surgery, with SLNB and/or (c)ALND, was one of the cornerstones in the management of breast cancer. Rather than their therapeutic potential, the importance mainly concerns their ability to provide prognostic information tailoring adjuvant systemic therapy. Hence, with improved insight regarding tumour biology and the introduction of gene expressing profiling techniques as prognostic tools in clinical practice, the relevance of staging the axillary is decreasing. ${ }^{41}$ Nowadays, interest is raised in foregoing all surgical treatment of the axilla in selected patient groups is. ${ }^{35}$ The present results show that elderly breast cancer patients might be one such group for 
whom the assumed benefits of surgical treatment of the axilla do not outweigh the burden. However, the majority of patients received endocrine treatment and these treatments are associated with several types of side effects as well. ${ }^{42}$ Keeping this in mind, omitting ALND and SLNB spares patients the morbidity related with axillary surgery, and minimizes impact of these treatments on quality of life in this vulnerable group of patients. ${ }^{35}$

\section{Conclusions}

This study demonstrates that the omission of complete axillary staging is common in selected elderly breast cancer patients (mostly treated with endocrine treatment), with $\geq 2$ comorbidities and showed no apparent impact on regional control and 10-year overall survival. Furthermore, a large majority of the patients died from non-breastcancer-related causes. 


\section{References}

1. IKNL. Integraal kankercentrum Nederland. 2018. Nederland. 2018. Available from: https://www.iknl.nl/ oncologische-zorg/tumorteams/borstkanker.

2. IKNL. cijfers over kanker. 2018. Available from: https://www.cijfersoverkanker.nl.

3. Jatoi I, Benson JR, Toi M. De-escalation of axillary surgery in early breast cancer. Lancet Oncol 2016;17:e430-e441.

4. Giuliano AE, Hunt KK, Ballman KV, Beitsch PD, Whitworth PW, Blumencranz PW, et al. Axillary dissection vs no axillary dissection in women with invasive breast cancer and sentinel node metastasis: a randomized clinical trial. JAMA 2011;305:569-575.

5. Poodt IGM, Spronk PER, Vugts G, van Dalen T, Peeters M, Rots ML, et al. Trends on axillary surgery in nondistant metastatic breast cancer patients treated between 2011 and 2015: A Dutch populationbased study in the ACOSOG-Z0011 and AMAROS era. Ann Surg 2018;268(6):1084-1090.

6. Wildiers H, Kunkler I, Biganzoli L, Fracheboud J, Vlastos G, Bernard-Marty C, et al. Management of breast cancer in elderly individuals: recommendations of the International Society of Geriatric Oncology. Lancet Oncol 2007;8:1101-1115.

7. Biganzoli L, Wildiers H, Oakman C, Marotti L, Loibl S, Kunkler I, et al. Management of elderly patients with breast cancer: updated recommendations of the International Society of Geriatric Oncology (SIOG) and European Society of Breast Cancer Specialists (EUSOMA). Lancet Oncol 2012;13:e148-e160.

8. Weggelaar I, Aben KK, Warle MC, Strobbe LJ, van Spronsen DJ. Declined guideline adherence in older breast cancer patients: a population-based study in the Netherlands. Breast J 2011;17:239-245.

9. Hamaker ME, Bastiaannet E, Evers D, Water W, Smorenburg CH, Maartense E, et al. Omission of surgery in elderly patients with early stage breast cancer. Eur J Cancer 2013;49:545-552.

10. Alderman AK, Bynum J, Sutherland J, Birkmeyer N, Collins ED, Birkmeyer J. Surgical treatment of breast cancer among the elderly in the United States. Cancer 2011;117:698-704.

11. Velanovich V, Gabel M, Walker EM, Doyle TJ, O'Bryan RM, Szymanski W, et al. Causes for the undertreatment of elderly breast cancer patients: tailoring treatments to individual patients. J Am Coll Surg 2002;194:8-13.

12. Enger SM, Thwin SS, Buist DS, Field T, Frost F, Geiger AM, et al. Breast cancer treatment of older women in integrated health care settings. J Clin Oncol 2006;24:4377-4383.

13. Louwman WJ, Janssen-Heijnen ML, Houterman S, Voogd AC, van der Sangen MJ, Nieuwenhuijzen GA, et al. Less extensive treatment and inferior prognosis for breast cancer patient with comorbidity: a population-based study. Eur J Cancer 2005;41:779-785.

14. Van Leeuwen BL, Rosenkranz KM, Feng LL, Bedrosian I, Hartmann K, Hunt KK, et al. The effect of undertreatment of breast cancer in women 80 years of age and older. Crit Rev Oncol Hematol 2011;79: 315-320.

15. Lavelle K, Todd C, Moran A, Howell A, Bundred N and Campbell M. Non-standard management of breast cancer increases with age in the UK: a population based cohort of women $>$ or $=65$ years. Br J Cancer 2007;96:1197-1203.

16. Mustacchi G, Cazzaniga ME, Pronzato P, De Matteis A, Di Costanzo F, Floriani I, et al. Breast cancer in elderly women: a different reality? Results from the NORA study. Ann Oncol 2007;18:991-996.

17. Bouchardy C, Rapiti E, Blagojevic S, Vlastos AT, Vlastos G. Older female cancer patients: importance, causes, and consequences of undertreatment. J Clin Oncol 2007;25:1858-1869.

18. Litvak DA, Arora R. Treatment of elderly breast cancer patients in a community hospital setting. Archives of surgery (Chicago, III : 1960) 2006;141:985-990; discussion 90.

19. Bouchardy C, Rapiti E, Fioretta G, Laissue P, Neyroud-Caspar I, Schafer P, et al. Undertreatment strongly decreases prognosis of breast cancer in elderly women. J Clin Oncol 2003;21:3580-3587.

20. Houterman S, Janssen-Heijnen ML, Verheij CD, Louwman WJ, Vreugdenhil G, van der Sangen MJ, et al. Comorbidity has negligible impact on treatment and complications but influences survival in breast cancer patients. Br J Cancer 2004;90:2332-2337.

21. Wyld L, Garg DK, Kumar ID, Brown H, Reed MW. Stage and treatment variation with age in postmenopausal women with breast cancer: compliance with guidelines. $\mathrm{Br}$ J Cancer 2004;90: 1486-1491. 
22. Karam AK, Hsu M, Patil S, Stempel M, Traina TA, Ho AY, et al. Predictors of completion axillary lymph node dissection in patients with positive sentinel lymph nodes. Ann Surg Oncol 2009;16:1952-1958.

23. Schouten LJ, Hoppener P, van den Brandt PA, Knottnerus JA, Jager JJ. Completeness of cancer registration in Limburg, The Netherlands. Int J Epidemiol 1993;22:369-376.

24. Nationaal Borstkanker Overleg Nederland (NABON). Richtlijn behandeling van het mammacarcinoom. Accessed 2 March 2012, Available from: http://www.oncoline.nl.

25. Donker M, van Tienhoven G, Straver ME, Meijnen P, van de Velde CJ, Mansel RE, et al. Radiotherapy or surgery of the axilla after a positive sentinel node in breast cancer (EORTC 10981-22023 AMAROS): a randomised, multicentre, open-label, phase 3 non-inferiority trial. Lancet Oncol 2014;15:1303-1310.

26. Beek MA, Verheuvel NC, Luiten EJ, Klompenhouwer EG, Rutten HJ, Roumen RM, et al. Two decades of axillary management in breast cancer. Br J Surg 2015;102:1658-1664.

27. Charlson ME, Pompei P, Ales KL, MacKenzie CR. A new method of classifying prognostic comorbidity in longitudinal studies: development and validation. J Chronic Dis 1987;40:373-383.

28. Poodt IGM, Vugts G, Maaskant-Braat AJG, Schipper RJ, Voogd AC, Nieuwenhuijzen GAP, et al. Risk of regional recurrence after negative repeat sentinel lymph node biopsy in patients with ipsilateral breast tumor recurrence. Ann Surg Oncol 2018;25(5):1312-1321.

29. Moossdorff M, Vugts G, Maaskant-Braat AJ, Strobbe $U$, Voogd AC, Smidt ML, et al. Contralateral lymph node recurrence in breast cancer: Regional event rather than distant metastatic disease. A systematic review of the literature. Eur J Surg Oncol 2015;41:1128-1136.

30. Hamelinck VC, Bastiaannet E, Pieterse AH, van de Velde $\mathrm{CJH}$, Liefers GJ, Stiggelbout AM. Preferred and perceived participation of younger and older patients in decision making about treatment for early breast cancer: A prospective study. Clin Breast Cancer 2018;18(2):e245-e253.

31. Politi MC, Lewis CL, Frosch DL. Supporting shared decisions when clinical evidence is low. Med Care Res Rev 2013;70:113S-128S.

32. Pinquart $M$, Duberstein PR. Information needs and decision-making processes in older cancer patients. Crit Rev Oncol Hematol 2004;51:69-80.

33. Martelli G, Boracchi P, Ardoino I, Lozza L, Bohm S, Vetrella G, et al. Axillary dissection versus no axillary dissection in older patients with T1NO breast cancer: 15-year results of a randomized controlled trial. Ann Surg 2012;256:920-924.

34. Savolt A, Peley G, Polgar C, Udvarhelyi N, Rubovszky G, Kovacs E, et al. Eight-year follow up result of the OTOASOR trial: The Optimal Treatment Of the Axilla - Surgery Or Radiotherapy after positive sentinel lymph node biopsy in early-stage breast cancer: A randomized, single centre, phase III, non-inferiority trial. Eur J Surg Oncol 2017;43:672-679.

35. Martelli G, Boracchi P, Orenti A, Lozza L, Maugeri I, Vetrella G, et al. Axillary dissection versus no axillary dissection in older T1NO breast cancer patients: 15-year results of trial and out-trial patients. Eur J Surg Oncol 2014;40:805-812.

36. Fisher B, Jeong JH, Anderson S, Bryant J, Fisher ER, Wolmark N. Twenty-five-year follow-up of a randomized trial comparing radical mastectomy, total mastectomy, and total mastectomy followed by irradiation. N Engl J Med 2002;347:567-575.

37. Fowble B, Fein DA, Hanlon AL, Eisenberg BL, Hoffman JP, Sigurdson ER, et al. The impact of tamoxifen on breast recurrence, cosmesis, complications, and survival in estrogen receptor-positive early-stage breast cancer. Int J Radiat Oncol Biol Phys 1996;35:669-677.

38. Syed BM, Green AR, Paish EC, Soria D, Garibaldi J, Morgan L, et al. Biology of primary breast cancer in older women treated by surgery: with correlation with long-term clinical outcome and comparison with their younger counterparts. Br J Cancer 2013;108:1042-1051.

39. Dimitrakopoulos FI, Kottorou A, Antonacopoulou AG, Makatsoris T and Kalofonos HP. Early-Stage Breast Cancer in the Elderly: Confronting an Old Clinical Problem. J Breast Cancer 2015;18:207-217.

40. Bastiaannet E, Portielje JE, van de Velde CJ, de Craen AJ, van der Velde S, Kuppen PJ, et al. Lack of survival gain for elderly women with breast cancer. Oncologist 2011;16:415-423.

41. Gerber B, Heintze K, Stubert J, Dieterich M, Hartmann S, Stachs A, et al. Axillary lymph node dissection in early-stage invasive breast cancer: is it still standard today? Breast Cancer Res Treat 2011;128:613-24.

42. Colleoni M, Giobbie-Hurder A. Benefits and adverse effects of endocrine therapy. Ann Oncol 2010;21 Suppl 7:vii107-111. 




\section{PART II}

PREOPERATIVE DISTANT STAGING AND DE-ESCALATION OF AXILLARY MANAGEMENT IN PATIENTS WITH AN IPSILATERAL BREAST TUMOR

RECURRENCE 



\section{Chapter}

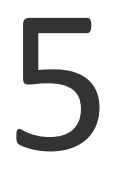

\section{Screening for distant metastases in patients with ipsilateral breast tumor recurrence}

The impact of different imaging modalities on distant recurrence-free interval

I.G.M. Poodt, R.J. Schipper, B.T.A. de Greef, G. Vugts, A.J.G. Maaskant-Braat, F.H. Jansen, D.N.J. Wyndaele, A.C. Voogd, G.A.P. Nieuwenhuijzen On behalf of the Sentinel Node And Recurrent Breast Cancer (SNARB) research group 


\section{Abstract}

\section{Purpose}

In patients with ipsilateral breast tumor recurrence (IBTR), the detection of distant disease determines whether the intention of the treatment is curative or palliative. Therefore, adequate preoperative staging is imperative for optimal treatment planning. The aim of this study is to evaluate the impact of conventional imaging techniques, including chest X-ray and/or CT thorax-(abdomen), liver ultrasonography (US), and skeletal scintigraphy, on the distant recurrence-free interval (DRFI) in patients with IBTR, and to compare conventional imaging with ${ }^{18}$ F-FDG PET-CT or no imaging at all.

\section{Methods}

This study was exclusively based on the information available at time of diagnoses of IBTR. To adjust for differences in baseline characteristics between the three imaging groups, a propensity score (PS) weighted method was used.

\section{Results}

Of the 495 patients included in the study, 229 (46.3\%) were staged with conventional imaging, 89 patients (19.8\%) were staged with ${ }^{18}$ F-FDG PET-CT, and in 168 of the patients $(33.9 \%)$ no imaging was used $(\mathrm{N}=168)$. After a follow-up of approximately 5 years, $14.5 \%$ of all patients developed a distant recurrence as first event after IBTR. After adjusting for the PS weights, the Cox regression analyses showed that the different staging methods had no significant impact on the DRFI.

\section{Conclusions}

This study showed a wide variation in the use of imaging modalities for staging IBTR patients in the Netherlands. After using PS weighting, no statistically significant impact of the different imaging modalities on DRFI was shown. Based on these results, it is not possible to recommend staging for distant metastases using ${ }^{18} \mathrm{~F}$-FDG PET-CT over conventional imaging techniques. 


\section{Introduction}

In patients with ipsilateral breast tumor recurrence (IBTR), adequate preoperative staging is imperative for tailoring optimal treatment plans. The absence or presence, and if so, the extensiveness of distant metastases determines the curative or palliative intent of the treatment of patients with IBTR. ${ }^{1}$ To evaluate for distant metastases at the time of IBTR, preoperative staging is recommended. ${ }^{2-4}$ Conventional imaging, including chest X-ray and/or CT thorax-(abdomen), ultrasonography (US) of the liver, and skeletal scintigraphy, is the standard of care in many hospitals. ${ }^{2-4}$

Besides these conventional imaging techniques, studies have focused on the value of 18-Fluorine-2-Fluoro-2-deoxy-D-Glucose positron emission tomography $\left({ }^{18} \mathrm{~F}\right.$-FDG PET) and ${ }^{18}$ F-FDG PET computer tomography $\left({ }^{18} \mathrm{~F}\right.$-FDG PET-CT) in patients with cancer. ${ }^{5-8}$ The combined ${ }^{18} \mathrm{~F}$-FDG PET and $\mathrm{CT}$ technique provides anatomical and functional information, and has been demonstrated to be an accurate technique in staging patients with IBTR and for the detection of distant metastases. ${ }^{4,9-12}$ In a systematic review, Pennant et al. reported a sensitivity of $96 \%$ and specificity of $89 \%$ for ${ }^{18}$ F-FDG PET-CT. ${ }^{7}$ Furthermore, ${ }^{18}$ F-FDG PET-CT is able to screen the whole body, including regional lymph nodes, in one session and may reduce the need for additional diagnostic procedures often needed to further analyze lesions found on conventional staging images. $^{13}$

However, ${ }^{18}$ F-FDG PET-CT is an expensive procedure and false-positive outcomes, caused for example by inflammatory processes, physiological muscle uptake or old fracture sites, could result in unnecessary additional procedures as well. ${ }^{7}$ False-negative results can occur due to low FDG uptake in some conditions, such as invasive lobular carcinoma, ongoing endocrine therapy, and small highly sclerotic skeletal lesions with low rate of actively replicating cells. ${ }^{14}$ The clinical role of ${ }^{18} \mathrm{~F}$-FDG PET-CT remains controversial, ${ }^{15}$ since there is no evidence of the impact of ${ }^{18}$ F-FDG PET-CT on patients' outcomes. Guidelines are still quite conservative in recommending the use of ${ }^{18} \mathrm{~F}$-FDG PET-CT as first tool for screening distant metastases, in both the primary and recurrent setting.

Theoretically, one could expect that patients screened with a more sensitive screening technique, such as ${ }^{18}$ F-FDG PET-CT, ${ }^{7}$ would experience less distant recurrences during follow-up or would experience these later during follow-up compared to patients screened with conventional imaging or no staging at all. Besides, with a more sensitive screening technique less patients would receive unnecessary curative treatments associated with high morbidity. Therefore, the aim of this study is to evaluate the impact of conventional imaging versus ${ }^{18}$ F-FDG PET-CT versus no imaging, on distant recurrence-free interval in patients diagnosed with IBTR, in order to optimize treatment planning. 


\section{Patients and methods}

\section{SNARB-study design}

The Sentinel Node and Recurrent Breast cancer (SNARB) study is a multicenter national registration study in which 36 Dutch hospitals participated. ${ }^{16,17}$ Patients with clinically apparent ipsilateral or contralateral lymph node metastases and patients with distant metastases at the time of diagnosis of IBTR were excluded. A total of 536 patients with IBTR were included in the SNARB study. No obligatory requirements were formulated in the protocol regarding the use of imaging modalities to stage patients diagnosed with an IBTR.

\section{Patients}

All patients with IBTR, treated with a curative intent, and staged cTxNOMO were considered eligible for inclusion. All included patients were divided into three groups according to the preoperative staging procedure: conventional imaging, ${ }^{18}$ F-FDG PET$\mathrm{CT}$, or no staging at all. Conventional imaging included the use of the following imaging techniques; (1) chest X-ray and/or CT thorax-(abdomen), (2) ultrasonography (US) of the liver or CT thorax-(abdomen), and (3) skeletal scintigraphy. Patients in the conventional imaging group who did not undergo a scan of the thorax, liver and skeletal scintigraphy were excluded.

\section{Definition of recurrences}

Distant recurrences (DR) were defined as any evidence of disease outside the ipsilateral breast, contralateral breast, and regional lymph nodes. A regional recurrence (RR) was defined as any evidence of disease found in ipsilateral intramammary nodes, ipsi- and contralateral internal mammary nodes, ipsi- and contralateral axillary nodes, and ipsiand contralateral infra- and supra-clavicular nodes. ${ }^{18,19}$ Lymph node recurrences found outside these nodal basins were defined as distant metastatic disease. An event in the contralateral breast was defined as a new primary tumor and was not considered a recurrence, unless it could be proven that it was metastatic disease. ${ }^{20}$

\section{Follow-up}

In 2017, follow-up of the 536 patients in the SNARB study was updated. General practitioners were actively contacted for additional follow-up information when hospital records showed no outpatient clinic visits for more than 1 year. Date of last follow-up was documented as last visit to the outpatient clinic, date of last visit to the general practitioner, or date of death in case the patient had deceased. Follow-up time was defined as the time between date of surgery for IBTR and date of last follow-up. 
Distant recurrence-free interval (DRFI) was defined as the time between date of IBTR surgery and date of diagnosis of a DR or date of last follow-up. Only distant recurrences developing as first event after IBTR were recorded as a distant event. Distant recurrences occurring after a local or regional re-recurrence following IBTR were censored.

\section{Statistics}

Only the information available at time of diagnosis of IBTR, so before systemic staging imaging, was used for the analyses. The baseline characteristics were compared between the three staging groups. Categorical variables were tested with a Chi-square statistics or Fisher exact test when necessary and continuous variables were tested with a one-way ANOVA analysis. A 2 -sided $P$ value of $<0.05$ was considered statistically significant.

The effect of the method of staging on the DRFI was analyzed with the use of propensity score (PS) adjustment. A PS was calculated for every patient, based on the possible confounders. Because the outcome of interest was divided in three staging methods groups, multinomial propensity scores were used. The propensity scores were calculated with the MNPS package, an extended version of the TWANG package, in R. To obtain the propensity score weights for multiple staging methods, a generalized boosted model (GBM) regression was used. The GBM was used with 3000 number of trees and different stopping rules were checked: the mean effect size, maximal effect size, mean Kolmogorov-Smirnov, and maximal Kolmogorov-Smirnov. For the specific research question, the average treatment estimation (ATE) comparison was used.

By using the GBM model, the overlaps between the three groups were checked. In practice, overlapping meant that every patient could have received each staging modality and that no values of the covariates occurred only in one of the staging groups. Box plots were used for comparing the distribution of propensity scores and testing the overlap. Generally, standardized mean differences of less than 0.20 were considered small (which is good), 0.40 were considered moderate, and 0.60 were considered large.

Next to the overlap, also the balance of the three groups was assessed. Finally, a combination of the overlap plot, the balance plots, and covariate table were used to assess whether the groups were sufficiently similar to support causal estimation of the primary research question.

After the propensity score weights were calculated, the weights were used in a weighted survival analysis to calculate the effect of the staging method on the DRFI. The effect was investigated with the use of Kaplan-Meier curves and tested with a Cox regression model. When a covariate was still unbalanced after PS weighting, the covariate was included in the Cox regression model to correct for it. ${ }^{21-23}$ 


\section{Results}

\section{Patients}

Of the 536 patients for whom follow-up data were collected, $21(4 \%)$ were lost to follow-up due to emigration, lack of information, or withdrawal of informed consent. Of the $515(96 \%)$ remaining patients, 20 patients were only partly screened for distant metastases and therefore excluded, resulting in a study cohort of 495 patients $(92.4 \%)$.

The median age at the time of IBTR was 64.0 years (range 26-93). The median time from primary surgery to diagnosis of IBTR (DFI) was 10.6 years (range 0.4-32). The majority of the patients had a primary tumor $\leq 2 \mathrm{~cm}(55.4 \%)$, a primary negative nodal status $(72.1 \%$, as determined by sentinel lymph node biopsy and/or axillary lymph node dissection), and hormone receptor-positive, human epidermal growth receptor 2 (HER2)-negative $(67.9 \%)$. The different covariates were divided per staging group are shown in Table 5.1, with the corresponding $p$ values (unadjusted $p$ value). In Table 5.1, it is shown that all variables are statistically significant, except for the median time from primary surgery to IBTR diagnose. In the ${ }^{18} \mathrm{~F}$-FDG PET-CT group, more patients were primary treated with a mastectomy, and more patients had primary positive lymph nodes. In the no-staged group, the patients had a higher mean age at time of IBTR (66 years vs. 63 years in the conventional group and 62.5 years in the ${ }^{18}$ F-FDG PET-CT group). Those patients who received no staging were treated with adjuvant systemic therapy in only $60.7 \%$ of the cases, compared to $73.4 \%$ in patients who were staged. There was no difference in the administration of adjuvant systemic therapy between the conventional imaging staged group and ${ }^{18} \mathrm{~F}$-FDG PET-CT, $74.2 \%$ vs. $71.4 \%$, respectively $(P=0.588)$

\section{Preoperative staging modalities}

Of the 495 patients, 229 patients (46.3\%) underwent preoperative staging with conventional imaging, 89 patients (19.8\%) with ${ }^{18} \mathrm{~F}$-FDG PET-CT, and 168 (33.9\%) received no preoperative staging imaging $(\mathrm{N}=168)$ (Table 5.1). As shown in Figure 5.1, the use of the different imaging procedures changed over time; the use of ${ }^{18}$ F-FDG PETCT increased from $6.5 \%$ in $2008-2010$ to $25.2 \%$ in 2013-2014, while the use of conventional imaging decreased from $58.1 \%$ to $31.7 \%$. In $2008-2010,33.1 \%$ of patients received no preoperative staging imaging, and this percentage fluctuated to $29.8 \%$ in 2010-2011, 29.8\% in 2011-2013 and $43.1 \%$ in $2013-2014$. 


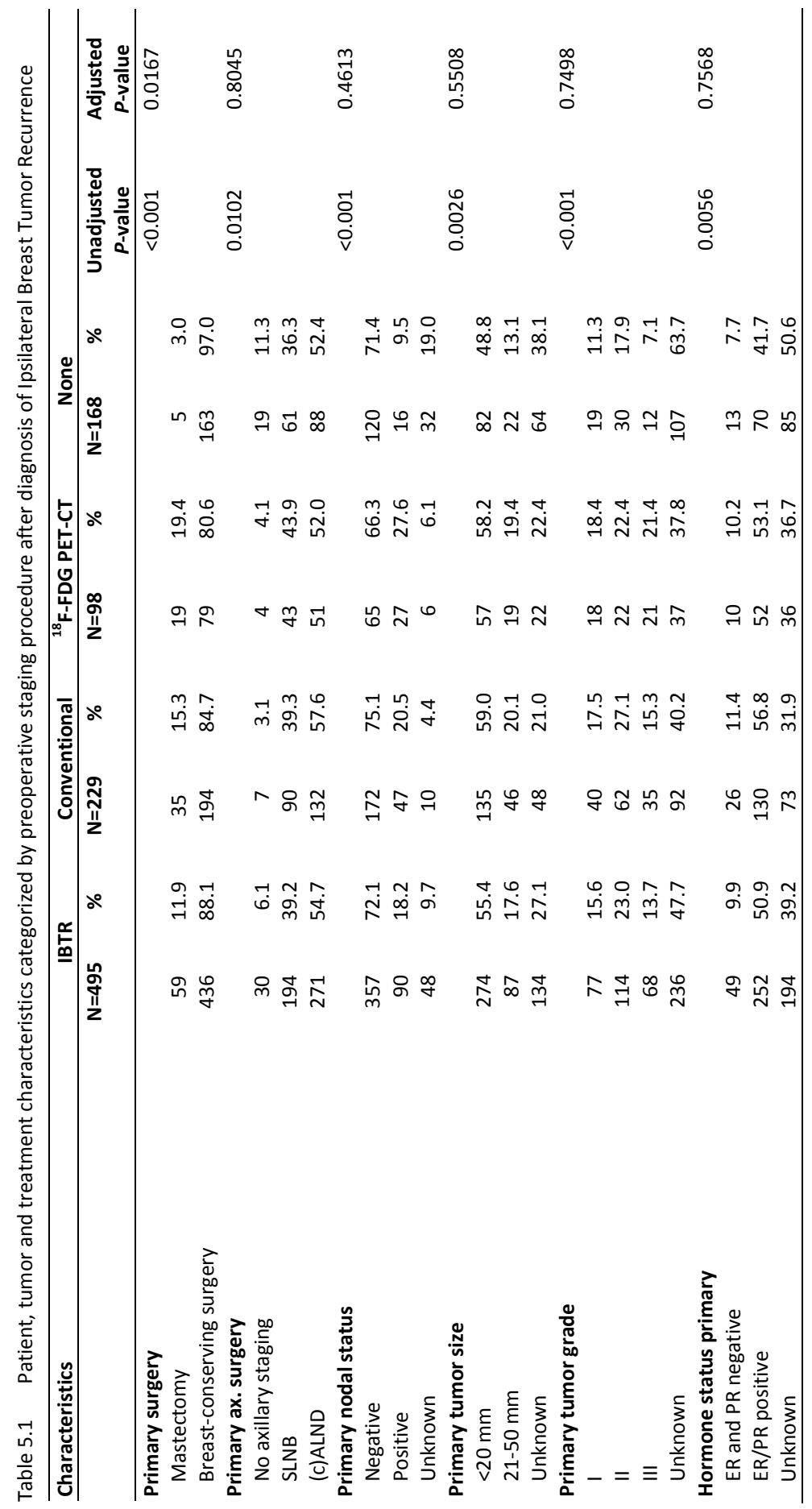




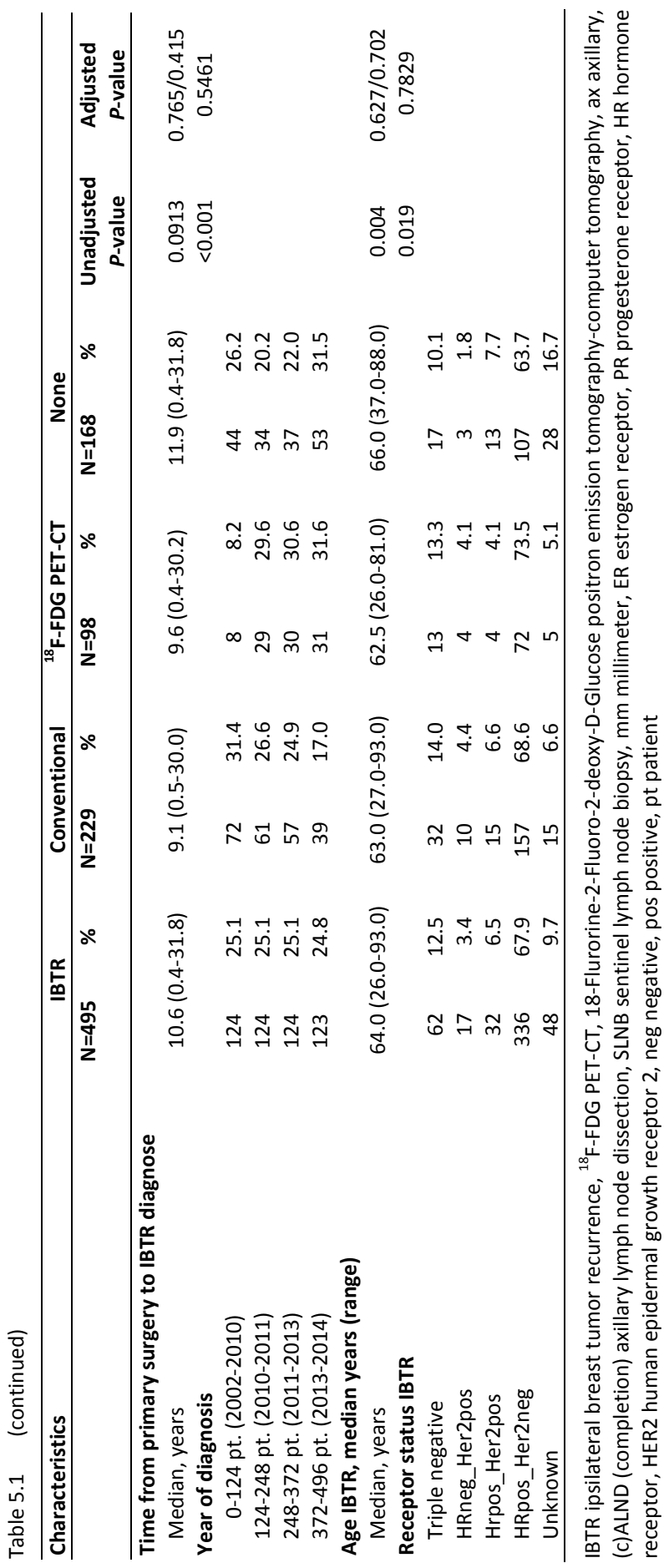




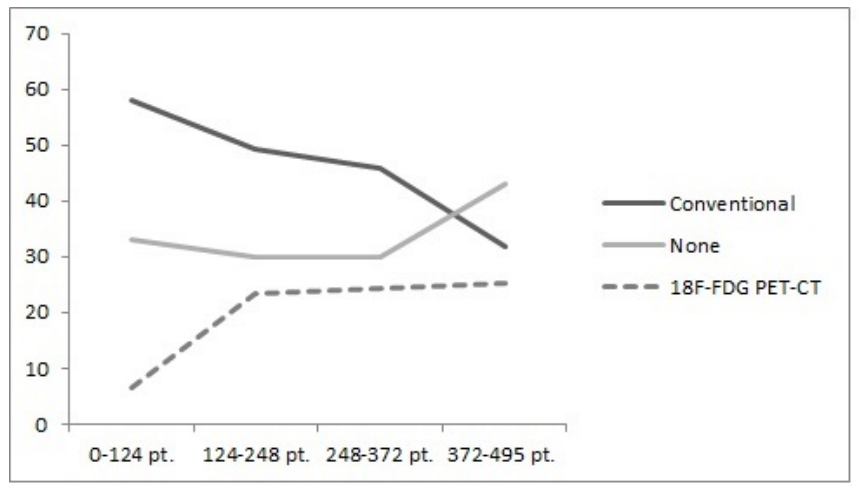

Figure 5.1 Percentages of IBTR patients staged with ${ }^{18}$ F-FDG PET-CT imaging versus conventional imaging versus no imaging over time

The group of 0-124 were the first 124 patient treated for IBTR in 2002-2010, second group of 124 patients: $124-248$ treated in 2010-2011, third group: 248-372 treated in 2011-2013 and 372-495 the last group of patients treated in 2013-2014

\section{Regional recurrences}

Regional recurrences as first event after IBTR occurred in 16 patients after a median time of 2.2 years (range $0.4-7.0)$. In eight patients, the regional recurrence was located in the contralateral axilla $(\mathrm{N}=8)$. The other recurrences were located in the ipsilateral supraclavicular nodal area $(N=2)$, ipsilateral axillary $(N=1)$, parasternal $(N=2)$, or contralateral infraclavicular nodal area $(\mathrm{N}=1)$, or in multiple regional nodal areas $(\mathrm{N}=2)$. The 6-year regional recurrence-free interval was $96.1 \%(\mathrm{Cl}, 94.1 \%-98.1 \%)$. Patients screened with conventional imaging had a 6 -year RR of $96.4 \%$ vs. $96.2 \%$ and $95.3 \%$ for patients with no imaging and ${ }^{18}$ F-FDG PET-CT $(P=0.766)$.

\section{Distant recurrences}

After a median follow-up period of 4.9 years (range $0.3-13.2$ ) after IBTR, 82 (16.5\%) patients had experienced a distant recurrence, and in $10(12.2 \%)$ of these patients a distant recurrence was diagnosed after a local re-recurrence $(\mathrm{N}=4)$ or after a regional re-recurrence $(\mathrm{N}=6)$. Predominant metastatic sites were the bones $(30.6 \% ; \mathrm{N}=22)$, the lungs $(18.1 \% ; \mathrm{N}=13)$, the liver $(12.5 \% ; \mathrm{N}=9)$, the brain $(8.3 \% ; \mathrm{N}=6)$ or to other places (12.5\%; $\mathrm{N}=9)$. In 13 patients, distant recurrences were found in multiple organs $(18.1 \%$ $\mathrm{N}=13$ ). Distant recurrence as first event occurred after a median time of 2.7 years (range, 0.04-8.7) following treatment of IBTR. The mean time of developing a distant recurrence after IBTR did not significantly differ between patients screened with ${ }^{18}$ F-FDG PET-CT, conventional imaging or no imaging $(P=0.648)$. 
Propensity score weighting, check PS weights, overlapping and balance

The GBM was used and the convergence was achieved in all comparisons (Figure 5.2). The overlap between the groups is shown in Table 5.1, but also in the boxplots shown in Figures 5.3 and was good to moderate. Next to the overlap, the balance was also checked and is shown in Figure 5.4. The balance looks sufficient, however the covariate primary surgery (breast-conserving therapy versus mastectomy) was still not balanced correctly after propensity score weighting.
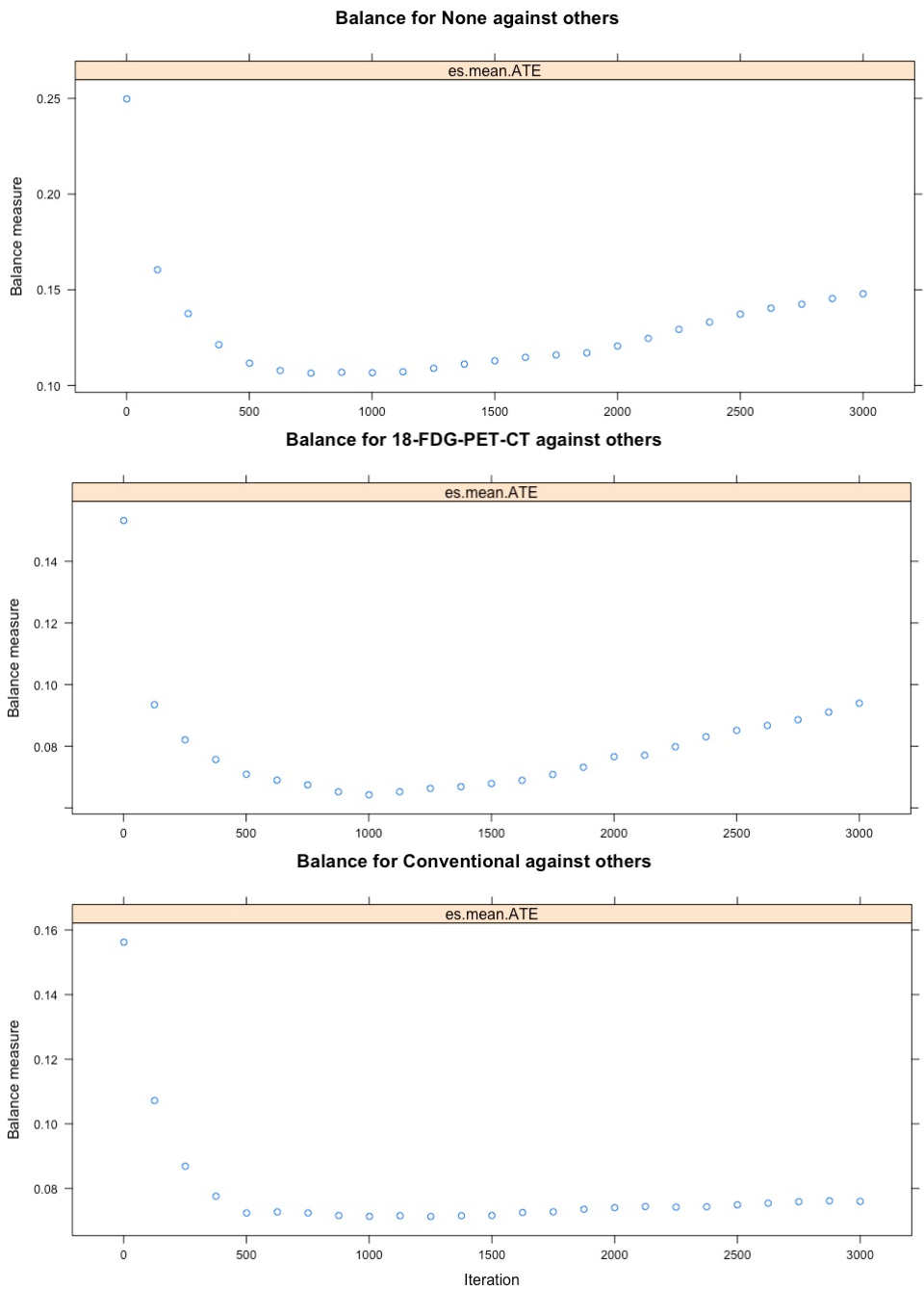

Figure 5.2 Balance assessment. Each panel presents balance measures for one of the staging methods. The top panel presents no staging, the middle panel presents ${ }^{18} \mathrm{~F}$-FDG PET-CT and the bottom panel presents conventional staging 


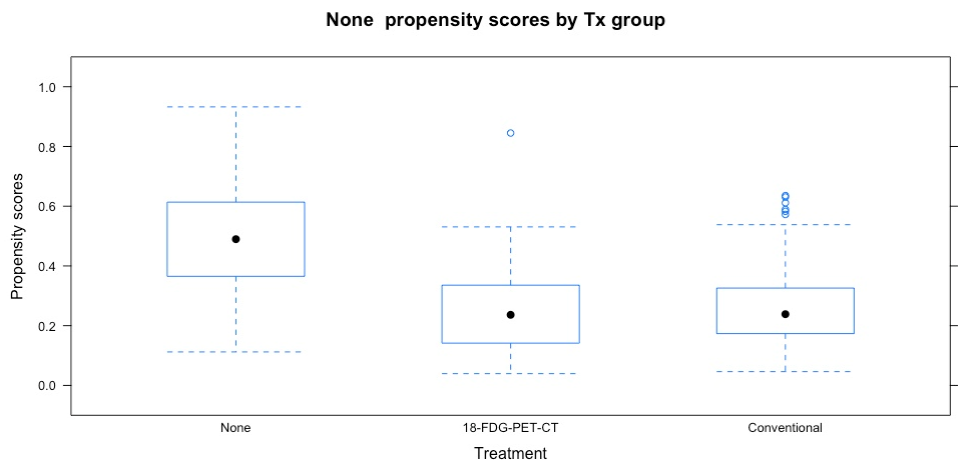

18-FDG-PET-CT propensity scores by Tx group

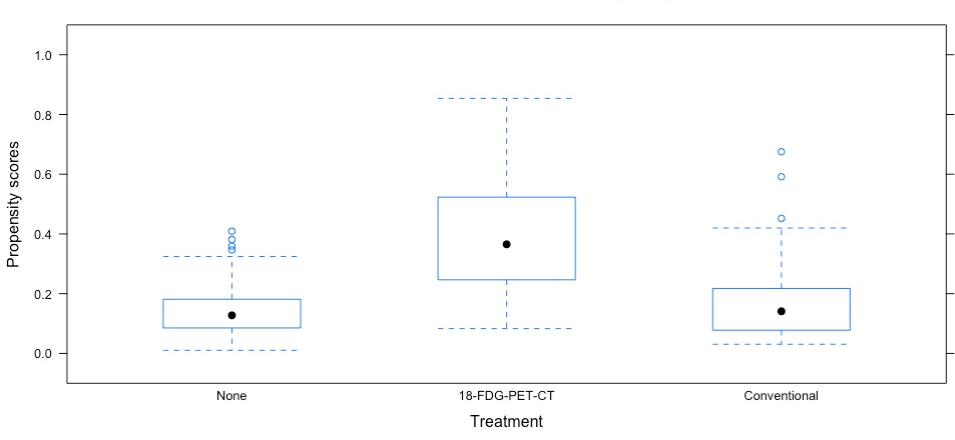

Conventional propensity scores by Tx group

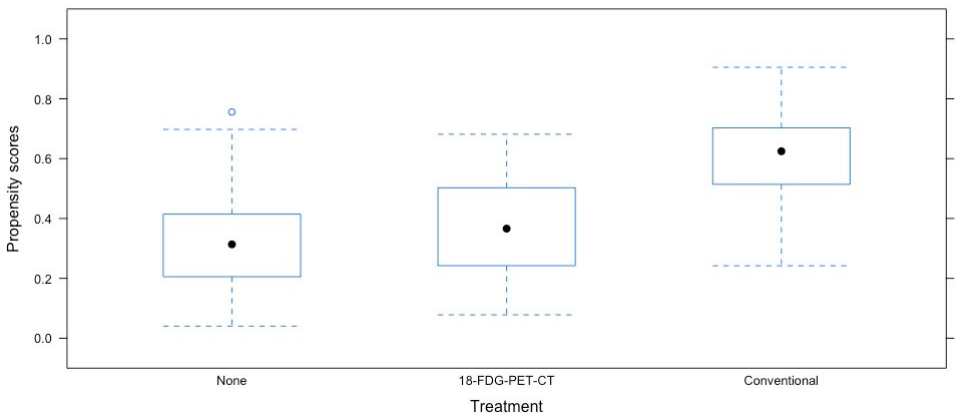

Figure 5.3 Overlap assessment. Each panel presents box plots of the estimated propensity scores for one of the staging methods. The top panel presents no staging, the middle panel presents ${ }^{18} \mathrm{~F}-\mathrm{FDG}$ PET-CT and the bottom panel presents conventional staging

\section{Baseline characteristics after PS weights}

In Table 5.1, the adjusted $p$ values, after adjusting the PS weights to the sample, are shown. After adjusting the PS weights, all the covariates, except for the covariate primary surgery, are no longer statistically significant and therefore balanced between the staging groups. Only the variable 'primary surgery' is taken as a covariate next to the PS weights in the cox regression model. 


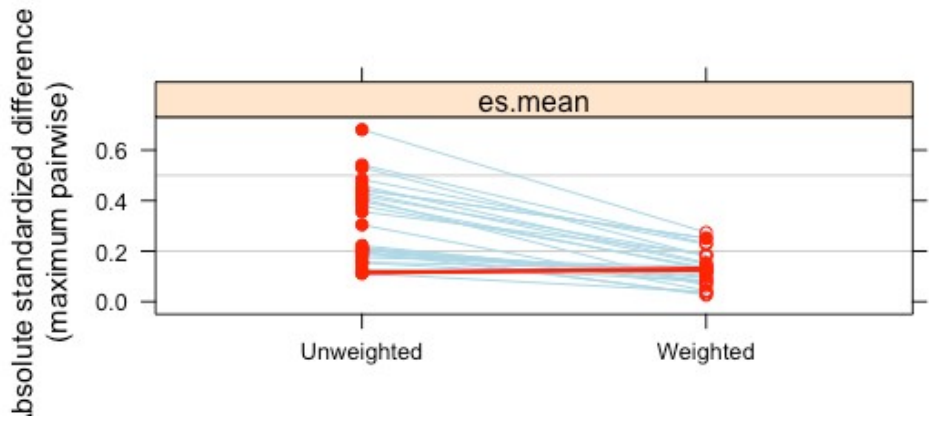

Figure 5.4 Effect size plots for assessing the balance of covariables on patients

A red line identifies a variable for which the standardized bias or effect size increases with weighting; a blue line identifies a variable for which balance improves with weighting

\section{Survival curves of DRFI}

Figure 5.5 presents the Kaplan Meier curves for the three different staging modalities (without correcting for the unbalanced covariate 'primary surgery') and showed no impact of the different imaging groups on the DRFI. Finally, Cox regression analyses were performed with and without the unbalanced covariate 'primary surgery'. The different staging modalities had no significant effect on the DRFI with a HR 0.86 (95\% $\mathrm{Cl}, 0.37-1.98)$ for ${ }^{18} \mathrm{~F}$-FDG PET-CT compared to no imaging and HR 0.96 (95\% Cl, 0.551.67) for conventional imaging compared to no imaging (Table 5.2). By adding the covariate primary surgery to the Cox regression model (because of the imbalance after weighting), the effect of the different imaging groups remained (Table 5.2), however the proportional hazard ( $\mathrm{PH}$ ) assumption became questionable. To assure the $\mathrm{PH}$ assumptions that were made, sensitivity analyses were performed for the primary breast-conserving surgery group and showed no significant effect of the different staging modalities on the DRFI.

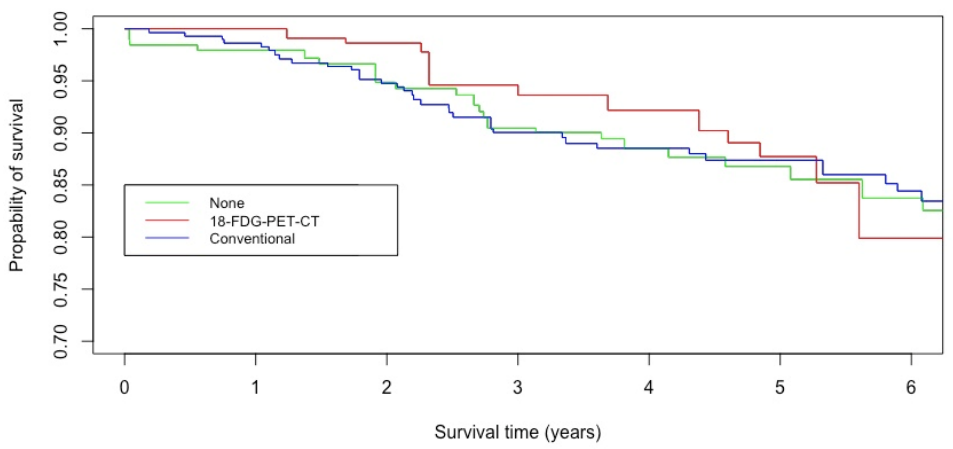

Figure 5.5 Propensity score weighted Kaplan-Meier curves of distant recurrence free interval according to staging method groups 
Table 5.2 Cox regression analyses for distant recurrence-free interval

\begin{tabular}{lcccc}
\hline & Coefficients & Standard error & p-value & Hazard ratio $(95 \% \mathbf{C l})$ \\
\hline $\begin{array}{l}\text { Without covariate } \\
\text { None }\end{array}$ & Ref & & & \\
${ }^{18}$ F-FDG PET-CT & -0.15425 & 0.42637 & 0.718 & $0.8571(0.3716-1.977)$ \\
Conventional & -0.04582 & 0.28627 & 0.873 & $0.9552(0.5450-1.674)$ \\
With covariate & & & & \\
$\quad$ None & Ref & & & \\
${ }^{18}$ F-FDG PET-CT & -0.2523 & 0.4568 & 0.581 & $0.7770(0.3147-1.902)$ \\
Conventional & -0.1398 & 0.3122 & 0.654 & $0.8695(0.4716-1.603)$ \\
Primary surgery & -0.6393 & 0.4219 & 0.130 & $0.5277(0.2308-1.206)$ \\
\hline${ }^{18}$ F-FDG PET-CT & 18-Flurorine-2-Fluoro-2-deoxy-D-Glucose & positron & emission & tomography-computer \\
tomography & & &
\end{tabular}

\section{Discussion}

In this nationwide cohort of 495 patients included in the SNARB study with an ipsilateral breast tumor recurrence, $46.3 \%$ were preoperatively staged with conventional imaging, $19.8 \%$ with ${ }^{18}$ F-FDG PET-CT, and $33.9 \%$ received no preoperative imaging at all to detect distant metastases. Distant recurrences, as a first event after treatment of IBTR, occurred in 72 patients (14.5\%). Propensity score analyses showed no difference in the likelihood of developing distant recurrence, according to the imaging strategy used at time of IBTR.

At baseline, all the covariates differed significantly between the three staging groups, except for the median time from primary surgery to IBTR diagnosis. To correct for these baseline differences, a PS analyses was used, with the aim to reduce or even eliminate confounding. PS methods are particularly appealing when multiple co-variables are studied, and the number of events is rare. ${ }^{24,25}$ After propensity score analyses, we did not find a statistically significant difference in the risk of distant metastases between the three staging groups. This finding is in accordance with the results of a study by Neuman et al., who reported no difference in the risk of developing distant recurrence between patients with imaging versus without imaging at the time of locoregional recurrence. $^{26}$

Historically, IBTR has been considered a risk factor for distant recurrence and thus resulting in a poorer prognosis. ${ }^{26-28}$ Synchronous distant metastases are reported in up to $15-30 \%$ of patients with an IBTR and up to $35 \%$ of patients with isolated lymph node recurrence. ${ }^{26}$ Factors found to be associated with the presence of synchronous metastases are the TNM stage of the primary tumor, with patients with more advanced stages having a higher risk, ${ }^{29}$ and the type of locoregional recurrence, with patients with lymph node recurrences having a higher risk compared to patients with IBTR. ${ }^{26}$ 
Because of this high risk of synchronous distant metastases, the recommendation is to stage all patients diagnosed with an IBTR for distant metastases.

In the current study, we did not observe a difference in the meantime to detection of distant recurrence, nor in the risk of regional recurrences after IBTR, between the different imaging strategies. Although current guidelines recommend the use of chest $\mathrm{X}$-ray, liver ultrasonography or $\mathrm{CT}$, and bone scintigraphy, these imaging modalities have been shown to be less sensitive and specific than ${ }^{18}$ F-FDG PET-CT. ${ }^{13}$ Theoretically, occult metastases could be present at time of diagnosis of IBTR, though too small for detection on conventional imaging modalities. Staging using a more sensitive staging strategy, i.e., ${ }^{18}$ F-FDG PET-CT could prevent false-negative outcomes, by detecting the smaller distant metastasis. Synchronous small metastases missed at time of IBTR could continue to grow, and could become clinical overt during follow-up. Thereby, ${ }^{18}$ F-FDG PET-CT is deemed to be especially valuable in the detection of extra-axillary nodal metastases. ${ }^{13,30}$ In the current study, the lack of difference in time to detection of distant recurrence and in the regional recurrence risk does not support these hypotheses.

Imperative for patients is the impact of distant staging on patients' treatment plan. Changes in treatment plans could include initiation or avoidance of medical treatment such as hormone therapy and chemotherapy, but also surgical treatment of IBTR. ${ }^{7}$ If extensive metastatic disease is diagnosed, patients are generally considered not curable and treatment is aimed to alleviate symptoms and, if possible, prolong survival. ${ }^{5,7}$ Omitting local treatment spares patients the morbidity associated with surgery and/or radiotherapy and minimizes the impact of these treatments on quality of life. Therefore, no staging at time of IBTR may lead to unnecessary exposure to potentially harmful local surgical procedures. ${ }^{31}$ Furthermore, guidelines recommend treating patients with IBTR, especially those with estrogen receptor-negative tumors, with adjuvant chemotherapy, while in the case of synchronous metastasis the standard treatment with adjuvant chemotherapy will be postponed until having symptomatic metastasis. Neuman et al. found that $27 \%$ of 445 patients with a locoregional recurrence had synchronous distant metastases at time of their IBTR. ${ }^{26}$ Hypothetically, choosing not to stage patients with IBTR will lead to overtreatment of up to those $27 \%$ of patients. The impact on patient management and patient's physical as well as mental status underscores the need for accurate staging modalities in this group of IBTR patients who have a variety of treatment options available to them.

Over time, many studies presented the pros and cons of both ${ }^{18} \mathrm{~F}-\mathrm{FDG}$ PET-CT and conventional imaging. ${ }^{18}$ F-FDG PET-CT is able to perform a whole-body evaluation in one session. ${ }^{5}$ This will shorten the time until start of treatment and perhaps will reduce health care-related costs, due a to lower number of hospitals visits, additional diagnostic procedures, and unnecessary curative treatments. ${ }^{13}$ However, further 
studies are needed to investigate the cost-effectiveness of ${ }^{18} \mathrm{~F}$-FDG PET-CT; whether these possible lower costs would indeed outweigh the high costs of ${ }^{18} \mathrm{~F}$-FDG PET-CT. As was shown in this study, the percentage of patients with isolated IBTR screened with ${ }^{18}$ F-FDG PET-CT increased over the years, while the use of conventional imaging decreased. Whether ${ }^{18}$ F-FDG PET-CT should replace conventional imaging in the preoperative staging of patients with IBTR should preferably depend on more aspects besides its diagnostic accuracy and cost-effectiveness, but also on the impact on prognosis and quality of life.

Some caveats apply to this study, because of its retrospective nature, reasons to use conventional imaging, ${ }^{18} \mathrm{~F}-\mathrm{FDG}$ PET-CT, or no imaging for staging were not always reported in the patient files. All patients with IBTR and synchronous metastatic disease were not considered for inclusion and therefore not registered in the database. Data are lacking regarding the numbers of excluded patients and how these synchronous metastasis were detected. Further research is encouraged to evaluate the impact of the different imaging modalities on the prognosis and to determine factors associated with an increased risk of synchronous metastases. Lastly, the diagnostic accuracy of ${ }^{18}$ F-FDG PET-CT and conventional imaging modalities are likely to vary depending on the different techniques used between the different hospitals, regarding length of radioisotope uptake, image acquisition time, and the mode of image interpretation. Nonetheless, the current study is based on the largest cohort of patients with an IBTR, as far as we are aware of. Furthermore, this is a multicenter, nationwide study providing data of different types of hospitals in the Netherlands, representative for IBTR patients in daily practice.

\section{Conclusions}

This study showed a wide variation in the use of imaging modalities for staging of IBTR patients in the Netherlands. After propensity score weighting, no statistically significant impact of the different imaging modalities on the DRFI was shown. Based on these results, it is not possible to recommend staging for distant metastases using ${ }^{18} \mathrm{~F}$-FDG PET-CT over conventional imaging techniques. 


\section{References}

1. Trovo M, Furlan C, Polesel J, Fiorica F, Arcangeli S, Giaj-Levra N, Alongi F, Del Conte A, Militello L, Muraro E, Martorelli D, Spazzapan S, Berretta M. Radical radiation therapy for oligometastatic breast cancer: Results of a prospective phase II trial. Radiother Oncol 2018;126(1):177-180.

2. Cardoso F, Senkus E, Costa A, Papadopoulos E, Aapro M, Andre F, Harbeck N, Aguilar Lopez B, Barrios CH, Bergh J, Biganzoli L, Boers-Doets CB, Cardoso MJ, Carey LA, Cortes J, Curigliano G, Dieras V, El Saghir NS, Eniu A, Fallowfield L, Francis PA, Gelmon K, Johnston SRD, Kaufman B, Koppikar S, Krop IE, Mayer M, Nakigudde G, Offersen BV, Ohno S, Pagani O, Paluch-Shimon S, Penault-Llorca F, Prat A, Rugo HS, Sledge GW, Spence D, Thomssen C, Vorobiof DA, Xu B, Norton L, Winer EP. 4th ESO-ESMO International Consensus Guidelines for Advanced Breast Cancer (ABC 4)dagger. Ann Oncol 2018;29(8):1634-1657.

3. Gradishar WJ, Anderson BO, Balassanian R, Blair SL, Burstein HJ, Cyr A, Elias AD, Farrar WB, Forero A, Giordano SH, Goetz M, Goldstein LJ, Hudis CA, Isakoff SJ, Marcom PK, Mayer IA, McCormick B, Moran M, Patel SA, Pierce L, Reed EC, Salerno KE, Schwartzberg LS, Smith KL, Smith ML, Soliman H, Somlo G, Telli M, Ward JH, Shead DA, Kumar R. Invasive Breast Cancer Version 1.2016, NCCN Clinical Practice Guidelines in Oncology. J Natl Compr Canc Netw 2016;14(3):324-354.

4. Nationaal Borstkanker Overleg Nederland (NABON) (Accessed 2 March 2012) Richtlijn behandeling van het mammacarcinoom. http://www.oncoline.nl.

5. Aukema TS, Rutgers EJ, Vogel WV, Teertstra HJ, Oldenburg HS, Vrancken Peeters MT, Wesseling J, Russell NS, Valdes Olmos RA (2010) The role of FDG PET/CT in patients with locoregional breast cancer recurrence: a comparison to conventional imaging techniques. Eur J Surg Oncol 2010;36(4):387-392.

6. Mahner S, Schirrmacher S, Brenner W, Jenicke L, Habermann CR, Avril N, Dose-Schwarz J. Comparison between positron emission tomography using 2-[fluorine-18]fluoro-2-deoxy-D-glucose, conventional imaging and computed tomography for staging of breast cancer. Ann Oncol 2008;19(7):1249-1254.

7. Pennant M, Takwoingi Y, Pennant L, Davenport C, Fry-Smith A, Eisinga A, Andronis L, Arvanitis T, Deeks J, Hyde C. A systematic review of positron emission tomography (PET) and positron emission tomography/computed tomography (PET/CT) for the diagnosis of breast cancer recurrence. Health Technol Assess 2010;14(50):1-103.

8. Rosen EL, Eubank WB, Mankoff DA. FDG PET, PET/CT, and breast cancer imaging. Radiographics 2007;27 Suppl 1:S215-229.

9. Antoch G, Saoudi N, Kuehl H, Dahmen G, Mueller SP, Beyer T, Bockisch A, Debatin JF, Freudenberg LS. Accuracy of whole-body dual-modality fluorine-18-2-fluoro-2-deoxy-D-glucose positron emission tomography and computed tomography (FDG-PET/CT) for tumor staging in solid tumors: comparison with CT and PET. J Clin Oncol 2004;22(21):4357-4368.

10. Fueger BJ, Weber WA, Quon A, Crawford TL, Allen-Auerbach MS, Halpern BS, Ratib O, Phelps ME, Czernin J. Performance of 2-deoxy-2-[F-18]fluoro-D-glucose positron emission tomography and integrated PET/CT in restaged breast cancer patients. Mol Imaging and Biol 2005;7(5):369-376.

11. Poeppel TD, Krause BJ, Heusner TA, Boy C, Bockisch A, Antoch G. PET/CT for the staging and follow-up of patients with malignancies. Eur J Radiol 2009;70(3):382-392.

12. Czernin J, Satyamurthy N, Schiepers C. Molecular mechanisms of bone 18F-NaF deposition. J Nucl Med 2010;51(12):1826-1829.

13. Jager JJ, Keymeulen K, Beets-Tan RG, Hupperets P, van Kroonenburgh M, Houben R, de Ruysscher D, Lambin P, Boersma LJ. FDG-PET-CT for staging of high-risk breast cancer patients reduces the number of further examinations: A pilot study. Acta Oncol 2010;49(2):185-191.

14. Piva R, Ticconi F, Ceriani V, Scalorbi F, Fiz F, Capitanio S, Bauckneht M, Cittadini G, Sambuceti G, Morbelli S. Comparative diagnostic accuracy of 18F-FDG PET/CT for breast cancer recurrence. Breast Cancer 2017;9:461-471.

15. Krammer J, Schnitzer A, Kaiser CG, Buesing KA, Sperk E, Brade J, Wasgindt S, Suetterlin M, Schoenberg SO, Sutton EJ, Wasser K. (18) F-FDG PET/CT for initial staging in breast cancer patients - Is there a relevant impact on treatment planning compared to conventional staging modalities? Eur Radiol 2015;25(8):2460-2469.

16. Maaskant-Braat AJ, Roumen RM, Voogd AC, Pijpers R, Luiten EJ, Rutgers EJ, Nieuwenhuijzen GA. Sentinel Node and Recurrent Breast Cancer (SNARB): results of a nationwide registration study. Ann Surg Oncol 2013;20(2):620-626. 
17. Vugts G, Maaskant-Braat AJ, Voogd AC, van Riet YE, Luiten EJ, Rutgers EJ, Rutten HJ, Roumen RM, Nieuwenhuijzen GA. Repeat sentinel node biopsy should be considered in patients with locally recurrent breast cancer. Breast Cancer Res Treat 2015;153(3):549-556.

18. Moossdorff M, Vugts G, Maaskant-Braat AJ, Strobbe LJ, Voogd AC, Smidt ML, Nieuwenhuijzen GA. Contralateral lymph node recurrence in breast cancer: Regional event rather than distant metastatic disease. A systematic review of the literature. Eur J Surg Oncol 2015;41(9):1128-1136.

19. Poodt IGM, Vugts G, Maaskant-Braat AJG, Schipper RJ, Voogd AC, Nieuwenhuijzen GAP, Sentinel N, recurrent breast cancer study group. (2018) Risk of regional recurrence after negative repeat sentinel lymph node biopsy in patients with ipsilateral breast tumor recurrence. Ann Surg Oncol. Ann Surg Oncol. 2018;25(5):1312-1321

20. Gourgou-Bourgade S, Cameron D, Poortmans P, Asselain B, Azria D, Cardoso F, A'Hern R, Bliss J, Bogaerts J, Bonnefoi H, Brain E, Cardoso MJ, Chibaudel B, Coleman R, Cufer T, Dal Lago L, Dalenc F, De Azambuja E, Debled M, Delaloge S, Filleron T, Gligorov J, Gutowski M, Jacot W, Kirkove C, MacGrogan G, Michiels S, Negreiros I, Offersen BV, Penault Llorca F, Pruneri G, Roche H, Russell NS, Schmitt F, Servent V, Thurlimann B, Untch M, van der Hage JA, van Tienhoven G, Wildiers H, Yarnold J, Bonnetain F, Mathoulin-Pelissier S, Bellera C, Dabakuyo-Yonli TS. Guidelines for time-to-event end point definitions in breast cancer trials: results of the DATECAN initiative (Definition for the Assessment of Time-to-event Endpoints in CANcer trials). Ann Oncol 2015;26(12):2505-2506.

21. Bang $\mathrm{H}$, Robins JM. Doubly robust estimation in missing data and causal inference models. Biometrics 2005;61(4):962-973.

22. Hullsiek KH, Louis TA. Propensity score modeling strategies for the causal analysis of observational data. Biostatistics 2002;3(2):179-193.

23. Nguyen TL, Collins GS, Spence J, Daures JP, Devereaux PJ, Landais P, Le Manach Y. Double-adjustment in propensity score matching analysis: choosing a threshold for considering residual imbalance. BMC Med Res Methodol 2017;17(1):78.

24. Cepeda MS, Boston R, Farrar JT, Strom BL. Comparison of logistic regression versus propensity score when the number of events is low and there are multiple confounders. Am J Epidemiol 2003; 158(3):280-287.

25. McCaffrey DF, Griffin BA, Almirall D, Slaughter ME, Ramchand R, Burgette LF. A tutorial on propensity score estimation for multiple treatments using generalized boosted models. Stat Med 2013;32(19): 3388-3414.

26. Neuman HB, Schumacher JR, Francescatti AB, Adesoye T, Edge SB, Vanness DJ, Yu M, McKellar D, Winchester DP, Greenberg CC, Alliance/American College of Surgeons Clinical Research Program Cancer Care Delivery Research Breast Cancer Surveillance Working G. Risk of synchronous distant recurrence at time of locoregional recurrence in patients with stage II and III breast cancer (AFT-01). J Clin Oncol 2018;36(10):975-980.

27. Anderson SJ, Wapnir I, Dignam JJ, Fisher B, Mamounas EP, Jeong JH, Geyer CE, Jr., Wickerham DL, Costantino JP, Wolmark N. Prognosis after ipsilateral breast tumor recurrence and locoregional recurrences in patients treated by breast-conserving therapy in five National Surgical Adjuvant Breast and Bowel Project protocols of node-negative breast cancer. J Clin Oncol 2009;27(15):2466-2473.

28. Wapnir IL, Anderson SJ, Mamounas EP, Geyer CE Jr, Jeong JH, Tan-Chiu E, Fisher B, Wolmark N. Prognosis after ipsilateral breast tumor recurrence and locoregional recurrences in five National Surgical Adjuvant Breast and Bowel Project node-positive adjuvant breast cancer trials. J Clin Oncol 2006;24(13):2028-2037.

29. Singletary SE, Allred C, Ashley P, Bassett LW, Berry D, Bland KI, Borgen PI, Clark G, Edge SB, Hayes DF, Hughes LL, Hutter RV, Morrow M, Page DL, Recht A, Theriault RL, Thor A, Weaver DL, Wieand HS, Greene FL. Revision of the American Joint Committee on Cancer staging system for breast cancer. J Clin Oncol 2002;20(17):3628-3636.

30. Eubank WB, Mankoff DA, Takasugi J, Vesselle H, Eary JF, Shanley TJ, Gralow JR, Charlop A, Ellis GK, Lindsley KL, Austin-Seymour MM, Funkhouser CP, Livingston RB. 18fluorodeoxyglucose positron emission tomography to detect mediastinal or internal mammary metastases in breast cancer. J Clin Oncol 2001;19(15):3516-3523.

31. Eubank WB, Mankoff D, Bhattacharya M, Gralow J, Linden H, Ellis G, Lindsley S, Austin-Seymour M, Livingston R. Impact of FDG PET on defining the extent of disease and on the treatment of patients with recurrent or metastatic breast cancer. AJR Am J Roentgenol 2004;183(2):479-486. 



\section{Chapter 6}

\section{Repeat sentinel lymph node biopsy for ipsilateral \\ breast tumor recurrence}

A systematic review of the results and impact on prognosis

I.G.M. Poodt, G. Vugts, R.J. Schipper, G.A.P. Nieuwenhuijzen

Ann of Surg Oncol 2018;25:1329-1339 


\section{Abstract}

\section{Purpose}

During recent years, an increasing number of patients with ipsilateral breast tumor recurrence (IBTR) and previous axillary surgery have undergone repeat sentinel lymph node biopsy ( $r S L N B)$. The influence of axillary nodal status on prognosis for IBTR patients remains unclear. This study aimed to evaluate the technical success rate, follow-up assessment, and prognostic value of rSLNB for patients with IBTR.

\section{Methods}

A systematic search conducted in MEDLINE, Embase and the Cochrane Library up to July 2017 included all studies on rSLNB in IBTR.

\section{Results}

A total of 34 articles describing 1761 patients were identified. A repeat sentinel lymph node ( $r S L N$ ) was successfully harvested from $64.3 \%$ of the patients with IBTR and the rate was significantly higher for the patients who had a previous SLNB than for those who had a previous axillary lymph node dissection (ALND) $(75.7 \%$ vs. $46.1 \% ; P<0.001)$. The rSLN was tumor-positive for $18.2 \%$ of the $\mathrm{rSLNs}, 40 \%$ of which were harvested in basins other than the ipsilateral axilla. The negative predictive value of rSLNB was $96.5 \%$. Overall survival, reported for $21.5 \%$ of the patients, was $95.2 \%$ after a mean follow-up of 29.6 months.

\section{Conclusion}

The prognostic impact of rSLN-positive versus rSLN-negative IBTR remains unclear. Further studies are needed to fill in the gap in the management of lymph nodes for patients with IBTR. However, based on the current evidence, rSLNB is feasible for $64 \%$ of patients, especially after previous SLNB. With a negative predictive value of $96.5 \%$, rSLNB appears to be highly specific, with substantial advantages over ipsilateral ALND in IBTR. 


\section{Introduction}

Ipsilateral breast tumor recurrence (IBTR) for patients previously treated with either breast-conserving surgery (BCS) or mastectomy is reported in approximately $2-10 \%$ of the patients after 10 -year follow-up period. ${ }^{1-3}$ The standard management of IBTR is salvage mastectomy ${ }^{4}$ or second lumpectomy with adjuvant whole-breast radiotherapy depending on the previous treatment. Still, no consensus in guidelines exists regarding the optimal management of lymph nodes in patients with IBTR.

In the recent past, complete axillary clearance was deemed to be necessary for all patients with IBTR regardless of evidence showing axillary nodal involvement. With modern multidisciplinary treatment options such as adjuvant systemic therapy and axillary radiotherapy, as well as improvement in noninvasive diagnostic options such as positron emission tomography-computed tomography (PET-CT), the rationale for performing a standard axillary lymph node dissection (ALND) appears to be waning.

The concept of repeat SLNB (rSLNB) has emerged in recent years, and an increasing number of patients with IBTR and previous axillary staging (SLNB/ALND/none) have undergone this procedure. The repeat sentinel lymph node ( $\mathrm{SLN}$ ) appeared to be tumor-negative in $80.1 \%$ of patients with IBTR, justifying the omission of a completion ALND and sparing those patients from its related morbidity. ${ }^{5}$ Furthermore, by identifying rSLNs in aberrant lymph node stations, a more complete regional staging could be achieved, potentially leading to alterations of adjuvant treatment plans.

The impact of nodal involvement on the prognosis of patients with IBTR still is unclear. Based on an unfavorable prognostic impact of nodal involvement in the primary setting, it is hypothesized that a positive rSLNB also would have an unfavorable impact in the recurrent setting. However, it is possible that nodal involvement in recurrent breast cancer does not have the same prognostic implications as in primary breast cancer.

Several case series and studies regarding rSLNB for patients with IBTR have been published, and the procedure currently is adopted as treatment option by many physicians. This growing confidence was illustrated by mention of the rSLNB in the Dutch Breast Cancer Guidelines ${ }^{6}$ and in the American Society of Clinical Oncology Clinical Practice Guideline update. ${ }^{7}$ This systematic review aimed to provide an update of data on rSLNB and to evaluate the technical success rate, follow-up data, and prognostic impact of rSLNB on patients with IBTR. 


\section{Material and methods}

\section{Search}

A literature search was performed using PubMed (MEDLINE), Embase and the Cochrane Library databases to find all original articles and case reports on patients with IBTR and rSLNB who have no clinical evidence of lymph node metastases. The following search terms were used: "recurrent breast cancer", "ipsilateral breast tumor recurrence", "locally recurrent breast cancer", "sentinel lymph node biopsy", "sentinel lymph node biopsy (MESH)", "lymphatic mapping", "repeat and re-operative" (see Appendix 6.1). Furthermore, references of the selected articles were searched by hand. The final search was performed on 21 July 2017.

\section{Selection and data extraction}

The selection process for the selected articles is summarized in Figure 6.1. Articles describing rSLNB for patients with IBTR were included in the review. Only articles published in the English language were included irrespective of the number of patients, the completeness of data, and quality. The exclusion criteria ruled out studies that failed to fulfil the inclusion criteria, articles with unavailable, review articles, duplicate publications, comments, editorials and letters to the editor. The search and screening of the articles were performed independently by two authors (I.P. and G.V.). Data extraction was performed independently by the same two authors (I.P. and G.V.). Discrepancies were resolved by discussion (see Information Data Extraction, in the Supporting Information). With the extracted data, an attempt was made to answer the Review Questions in the Supporting Information).

\section{Construction of variables}

The disease-free interval (DFI) indicated the time in months between the primary breast cancer treatment and the diagnoses of IBTR. The follow-up time was the time reported after treatment of IBTR. The technical success rate yielded the percentage of rSLNs surgically harvested successfully, including nodes found with blue dye during surgery and not seen on lymphoscintigram.

Positive rSLNB outcomes (pN1) included micro-metastasis $(>0.2 \mathrm{~mm}$ and/or $>200$ cells, but none larger than $2 \mathrm{~mm}$ ) and 1-3 macro-metastases (>2 $\mathrm{mm}$ ) in accordance with the TNM Classification, $7^{\text {th }}$ edition. Isolated tumor cells (ITCS) (small clusters of cells $<0.2$ $\mathrm{mm}$ and/or $<200$ cells) were classified as node-negative (pNO). 


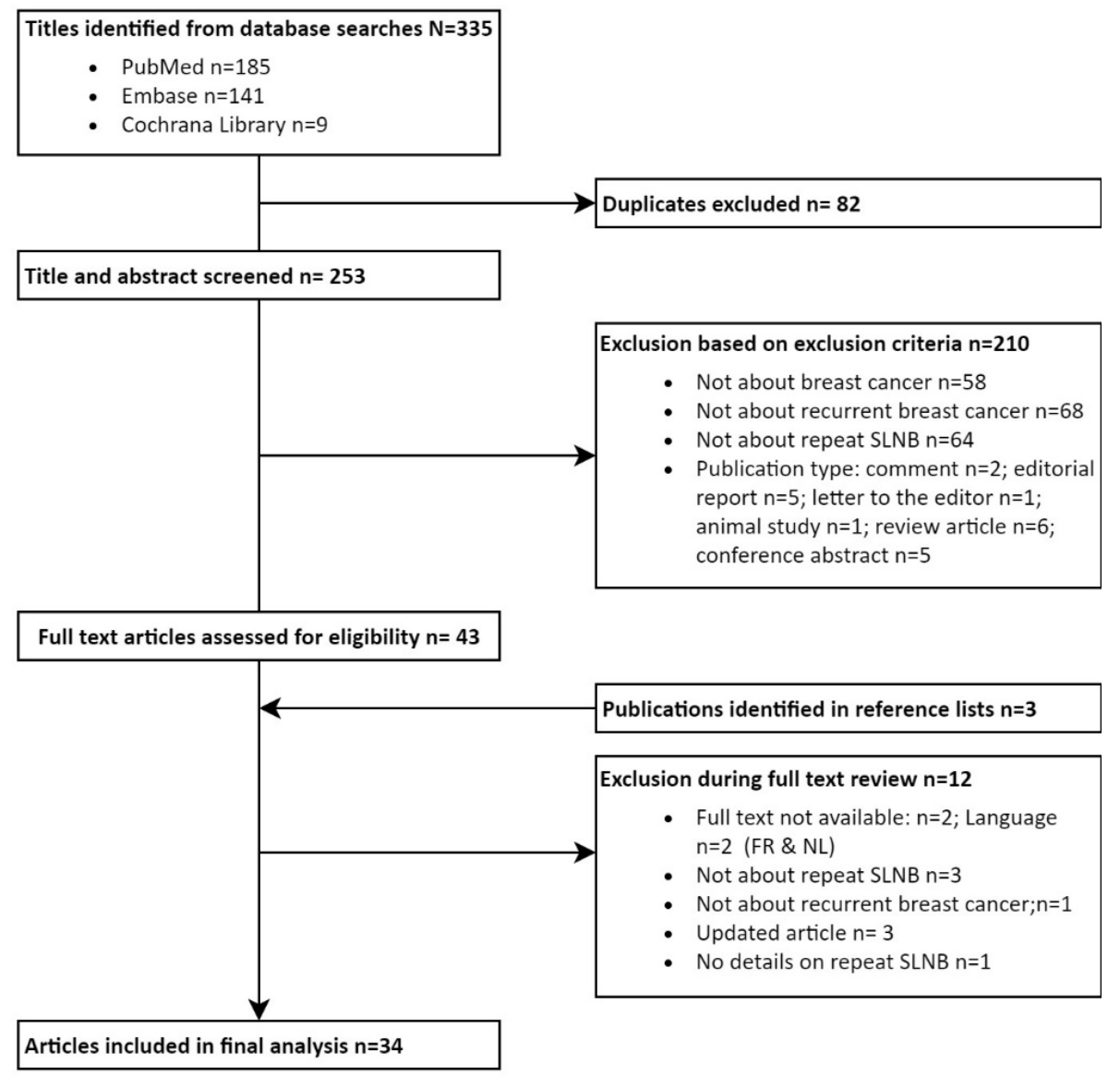

Figure 6.1 Flowchart of search strategy

A regional recurrence was defined as any evidence of disease found in the ipsilateral intramammary nodes, ipsi- and contralateral internal mammary nodes, ipsi- and contralateral axillary nodes, and ipsi- and contralateral infra- and supra-clavicular nodes. Lymph node recurrences found outside these nodal basins were defined as distant metastatic disease. In the recently published Maastricht Delphi Consensus statement on the definition of regional events, only ipsilateral nodal recurrences (either axillary or in other ipsilateral nodal basins) are considered regional recurrences. ${ }^{8}$ Based on earlier rSLNB studies ${ }^{5,9}$, we state that the definition of a regional recurrence after IBTR should be broadened and should include contralateral basins because lymphatic drainage towards these basins is common. ${ }^{10-12}$ Therefore, we considered contralateral events as regional recurrences. Distant recurrence was defined as any evidence of disease at any site other than the ipsilateral and contralateral breast or regional lymph nodes. 
The selected articles did not specify exact radiation fields. Therefore, we could not differentiate whether a patient received radiotherapy on the breast (partial or whole) and/or the axilla and/or other regions.

\section{Information Data-extraction}

The following information was collected:

1. Number of patients with locally recurrent breast cancer

2. Primary breast treatment: mastectomy or breast-conserving therapy/lumpectomy

3. Primary axillary treatment: sentinel lymph node biopsy (SLNB), axillary lymph node dissection (ALND), or none

4. Adjuvant radiotherapy after primary event

5. Disease free interval (DFI)

6. Secondary breast treatment: salvage mastectomy or second lumpectomy

7. Lymphatic mapping and repeat SLNB (rSLNB) technical success rate

8. Aberrant drainage patterns

9. Number of aberrant lymph nodes with metastases

10. Pathologic outcome rSLNB

11. Completion ALND and pathologic outcome

12. Adjuvant treatment after recurrence

13. Follow-up time in months

14. Regional recurrence rate

15. Distant recurrence rate

16. Survival

\section{Review Questions}

With the extracted data, an attempt was made to answer the following questions:

1. What is the identification rate for a $\mathrm{rSLN}$ on preoperative lymphoscintigraphy?

2. What is the technical success rate for the rSLNB procedure?

3. What is the location and pathologic outcome of the rSLN?

4. What is the influence of the previous axillary staging method (SLNB, ALND, no axillary staging) on the identification rate of a rSLN on preoperative lymphoscintigraphy, the technical success rate of rSLNB, and aberrant drainage patterns?

5. What is the false-negative rate and what is the negative predictive value of rSLNB?

6. What is the probability of additional metastatic lymph nodes after a positive rSLN in CALND?

7. Which adjuvant treatment plans were described after treatment of IBTR, and which adjuvant treatment plans were changed based on the outcome of the rSLNB procedure?

8. What percentage of patients are experiencing local, regional and/or distant recurrences after $r S L N B$ ?

9. Is the pathological lymph node status of patients with IBTR a prognostic factor? 


\section{Statistical analyses}

Derived data were pooled to calculate weighed estimates and corresponding 95\% confidence intervals $(\mathrm{Cl})$ of the identification rate for preoperative lymphoscintigraphy, the technical success rate of the rSLNB procedure, and aberrant drainage patterns. Furthermore, data were stratified according to previous axillary procedure (no axillary staging, SLNB, ALND), primary breast treatment (mastectomy or lumpectomy), and primary treatment with or without adjuvant radiotherapy. These patients were compared with respect to the identification rate for preoperative lymphoscintigraphy, the technical success rate of the rSLNB procedure, and aberrant drainage patterns using the Chi square test. A two-sided $P$ value lower than 0.05 was considered statistically significant. Data analysis was performed using SPSS version 24 (SPSS Inc, Chicago, IL, USA).

\section{Results}

The selection process is presented in Figure 6.1. The search strategy resulted in 335 abstracts. Of these 355 abstracts, 210 abstracts were excluded based on the predefined exclusion criteria, and another 82 abstracts were excluded because they were duplicates. The text of the remaining 43 articles was fully reviewed, and 9 were excluded. Another three studies were updates of previously published studies consisting of the same patient group. The latest updates of these studies were included, resulting in 31 eligible articles after full-text review.

Furthermore, screening of reference lists and related citations resulted in the identification of three additional articles. Finally, this search strategy resulted in 34 eligible articles and case reports on patients with ipsilateral breast cancer recurrence who underwent rSLNB. All the selected articles were published between 2004 and 2016 (Table $6.1^{5,9,13-44}$.

\section{Characteristics of patients with IBTR}

A total 1761 eligible patients with IBTR were described. The patients per article ranged from 1 to 536 patients (Table 6.1. All the patients, with a mean age of 56 years (range 41-69 years), had a history of breast cancer. Initial breast cancer treatment was not mentioned in $3.2 \%$ of the patients $(n=56)$, whereas $86.0 \%$ had been treated previously with breast-conserving therapy or lumpectomy $(n=1515)$ and $10.8 \%$ with mastectomy $(n=190)$. 


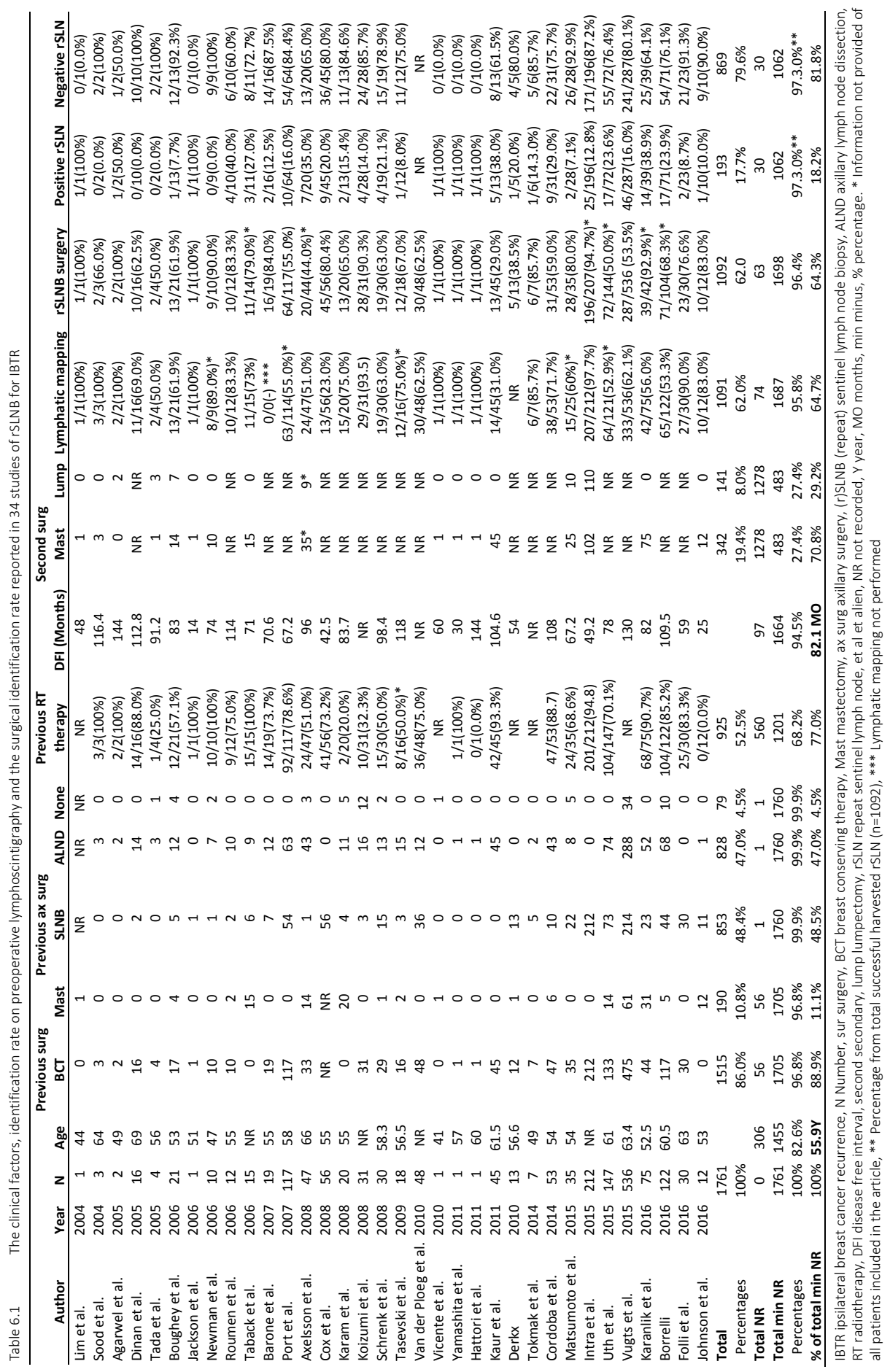


Furthermore, $4.5 \%$ of the patients $(n=79)$ had not received previous axillary surgery, whereas $47.0 \%(n=828)$ previously undergone ALND, $48.4 \% \quad(n=853)$ previously undergone SLNB alone, and $0.06 \%(n=1)$ had no previous axillary treatment specified. The majority of the patients $(77 \%)$ had primary treatment with adjuvant radiotherapy. The mean DFI was 82.1 months (range 14-144 months).

\section{Identification rate for preoperative lymphoscintigraphy}

Data on sentinel node identification with preoperative lymphoscintigraphy were provided by 33 articles comprising 1687 patients. A sentinel node was identified in 1091 of these 1687 patients, resulting in a rSLN identification rate of $64.7 \%$ for preoperative lymphoscintigraphy (Figure 6.2). The rSLN identification rates for preoperative lymphoscintigraphy according to previous axillary procedure are shown in Table 6.2. Of 627 patients with report of a previous ALND, 357 (56.9\%; 95\% Cl, 53.1-60.8\%) had rSLN identified via preoperative lymphoscintigraphy, which is significantly fewer than those who had previous SLNB (77.2\%; 95\% Cl, 74.0-80.1\%) $(P<0.001)$ (Table 6.2a).

The exact location of the rSLN on lymphoscintigraphy was described for 1048 patients, with $39.2 \%$ showing drainage to aberrant lymph node basins $(n=411)$ and $60.8 \%$ showing drainage to the ipsilateral axilla $(n=637)$. Stratified according to primary axillary procedure, aberrant drainage patterns were detected in 100 of the reported 504 patients with successful mapping after SLNB (19.8\%; 95\% Cl, 16.4-23.3\%) and in 254 of 350 patients reported to have successful mapping after ALND (72.6\%; 95\% Cl, 67.9-77.3\%) $(P<0.001)$ (Table 6.2a).

\section{Technical success of rSLNB}

Most articles described the use of a dual-mapping method, including injection of a radiotracer (usually technetium-99 $\mathrm{m}$ ) and blue dye preoperatively. Data on the surgically harvested sentinel node was provided by 33 articles comprising 1698 patients. A rSLN was surgically retrieved in 1092 patients, resulting in a mean success rate of $64.3 \%$, with a range of $29-100 \%$ per article. For $82.1 \%$ of these patients, surgical harvesting of the rSLN was performed after identification of the rSLN using lymphoscintigraphy, with or without the use of blue dye ( $n=896)$ (Figure 6.2).

Stratifying of the data showed that a rSLN was successfully retrieved surgically from 608 of 803 reported patients after a previous SLNB (75.7\%; 95\% Cl, 72.7-78.7\%) and from 329 of 714 reported patients after a previous ALND (46.1\%; 95\% Cl, 42.4-49.7\%) $(P<0.001)$. Furthermore, a rSLN was retrieved from 56 of 66 reported patients after no axillary staging (84.9\%; 95\% Cl, 76.0-93.7\%) (Table 6.2a). 
Table 6.2 Identification rate for preoperative lymphoscintigraphy, technical success rate fot repeat sentinel node biopsy, and risk for aberrant drainage in patients with ipsilateral breast tumor recurrence

A. Stratified according to primary axillary procedure

\begin{tabular}{|c|c|c|c|c|}
\hline \multirow[t]{2}{*}{ Outcome } & \multicolumn{3}{|c|}{ Primary axillary procedure } & \multirow[b]{2}{*}{$P$ value } \\
\hline & SLNB & ALND & None & \\
\hline Preoperative lymphoscintigraphy & & & & $\leq 0.001$ \\
\hline Identification rate (proportion) & $507 / 657$ & $357 / 627$ & $49 / 58$ & \\
\hline Percentage (\%) & $77.2 \%$ & $56.9 \%$ & $84.5 \%$ & \\
\hline $95 \% \mathrm{Cl}$ & $74.0-80.1$ & $53.1-60.8$ & 74.9-94.1 & \\
\hline Repeat sentinel node biopsy & & & & $\leq 0.001$ \\
\hline Technical success rate (proportion) & $608 / 803$ & $329 / 714$ & $56 / 66$ & \\
\hline Percentage (\%) & $75.7 \%$ & $46.1 \%$ & $84.9 \%$ & \\
\hline $95 \% \mathrm{Cl}$ & 72.7-78.7 & $42.4-49.7$ & $76.0-93.7$ & \\
\hline Aberrant drainage lymphoscintigram & & & & $\leq 0.001$ \\
\hline Proportion & $100 / 504$ & $254 / 350$ & $8 / 45$ & \\
\hline Percentage (\%) & $19.8 \%$ & $72.6 \%$ & $17.8 \%$ & \\
\hline $95 \% \mathrm{Cl}$ & $16.4-23.3$ & $67.9-77.3$ & $6.2-29.4$ & \\
\hline Aberrant Sentinel node retrieved & & & & $\leq 0.001$ \\
\hline Proportion & $43 / 357$ & $61 / 109$ & $4 / 18$ & \\
\hline Percentage (\%) & $12.0 \%$ & $56.0 \%$ & $22.2 \%$ & \\
\hline $95 \% \mathrm{Cl}$ & $8.7-15.4$ & $46.5-65.4$ & $1.0-43.5$ & \\
\hline
\end{tabular}

B. Stratified according to primary treatment with adjuvant radiotherapy

\begin{tabular}{lccc}
\hline Outcome & \multicolumn{2}{c}{ Primary adjuvant radiotherapy } \\
\cline { 2 - 4 } & RT & No RT & $\boldsymbol{P}$ value \\
\hline Preoperative lymphoscintigraphy & & & 0.988 \\
$\quad$ Identification rate (proportion) & $45 / 62$ & $24 / 33$ & \\
Percentage (\%) & $72.6 \%$ & $72.7 \%$ & \\
$95 \% \mathrm{Cl}$ & $61.2-84.0$ & $56.7-88.8$ & 0.096 \\
Repeat sentinel node biopsy & & & \\
Technical success rate (proportion) & $81 / 111$ & $149 / 233$ & 0.042 \\
Percentage (\%) & $64.0 \%$ & $73.0 \%$ & \\
95\% Cl & $57.7-70.2$ & $64.6-81.4$ & \\
Aberrant drainage lymphoscintigram & & & 0.049 \\
Proportion & $27 / 37$ & $5 / 13$ & \\
Percentage (\%) & $70.3 \%$ & $38.5 \%$ & \\
95\% Cl & $54.8-85.7$ & $7.9-69.1$ & \\
Aberrant Sentinel node retrieved & & & \\
Proportion & $25 / 36$ & $5 / 13$ & \\
Percentage (\%) & $69.4 \%$ & $38.5 \%$ & \\
95\% Cl & $53.6-71.6$ & $7.9-69.1$ & \\
\hline
\end{tabular}

C. Technical success rate for repeat sentinel node biopsy from patients with ipsilateral breast tumor recurrence stratified according to previous breast procedure

\begin{tabular}{lccc}
\hline Outcome & \multicolumn{2}{c}{ Primary breast procedure } \\
\cline { 2 - 4 } & Mastectomy & Lump./BCT & $\boldsymbol{P}$ value \\
\hline Repeat sentinel node biopsy & & & 0.050 \\
Technical success rate (proportion) & $109 / 161$ & $760 / 1273$ & \\
Percentage (\%) & $67.7 \%$ & $59.7 \%$ & \\
$95 \% \mathrm{Cl}$ & $60.4-75.0$ & $57.0-62.4$ \\
\hline
\end{tabular}

SLNB sentinel lymph node biopsy, ALND axillary lymph node dissection, $\mathrm{Cl}$ confidence interval, RT radiotherapy, $\mathrm{BCT}$ breast-conserving therapy 


\section{Pathological outcome}

Pathologic outcomes showed $18.2 \%$ positive sentinel nodes $(n=193)$ and $81.8 \%$ negative sentinel nodes $(n=869)$. A total of 78 positive sentinel nodes were harvested in aberrant basins ( $40.4 \%$ of the total positive SLNs), 34 (17.6\% of the total positive SLNs) of which were retrieved in a contralateral basin (Figure 6.3). For $74.1 \%$ of the patients with a positive sentinel node, completion ALND (CALND) was performed. Additional non-sentinel node metastases were found in $16.1 \%(n=23)$ (Figure 6.4).

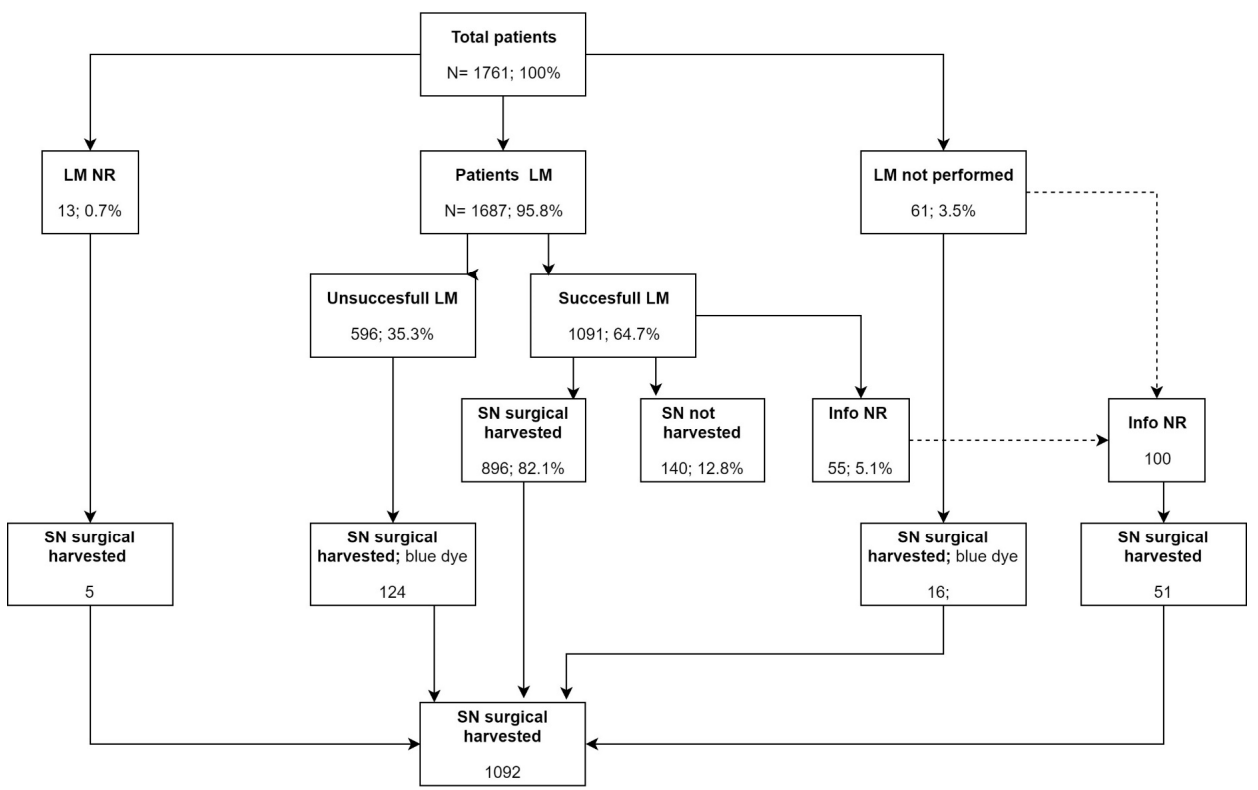

Figure 6.2 Flowchart preoperative lymphoscintigraphy and surgical harvested repeat sentinel node LM lymphoscintigram; SN sentinel node, NR not reported

\section{False-negative rate/diagnostic performance of rSLNB}

Of the 869 patients with a negative ipsilateral rSLN, 144 underwent a confirmation ipsilateral ALND, 139 of which were node-negative. In five patients, positive nonsentinel nodes were found, resulting in a negative predictive value of $96.5 \%$ (Figure 6.4). Furthermore, in these studies, 117 rSLN-positive patients were reported. Adding these together with the five false-negative patients resulted in a total number of 122 node-positive patients, yielding a false negative rate of $4.1 \%$ (5 false-negative/122 node-positive). 


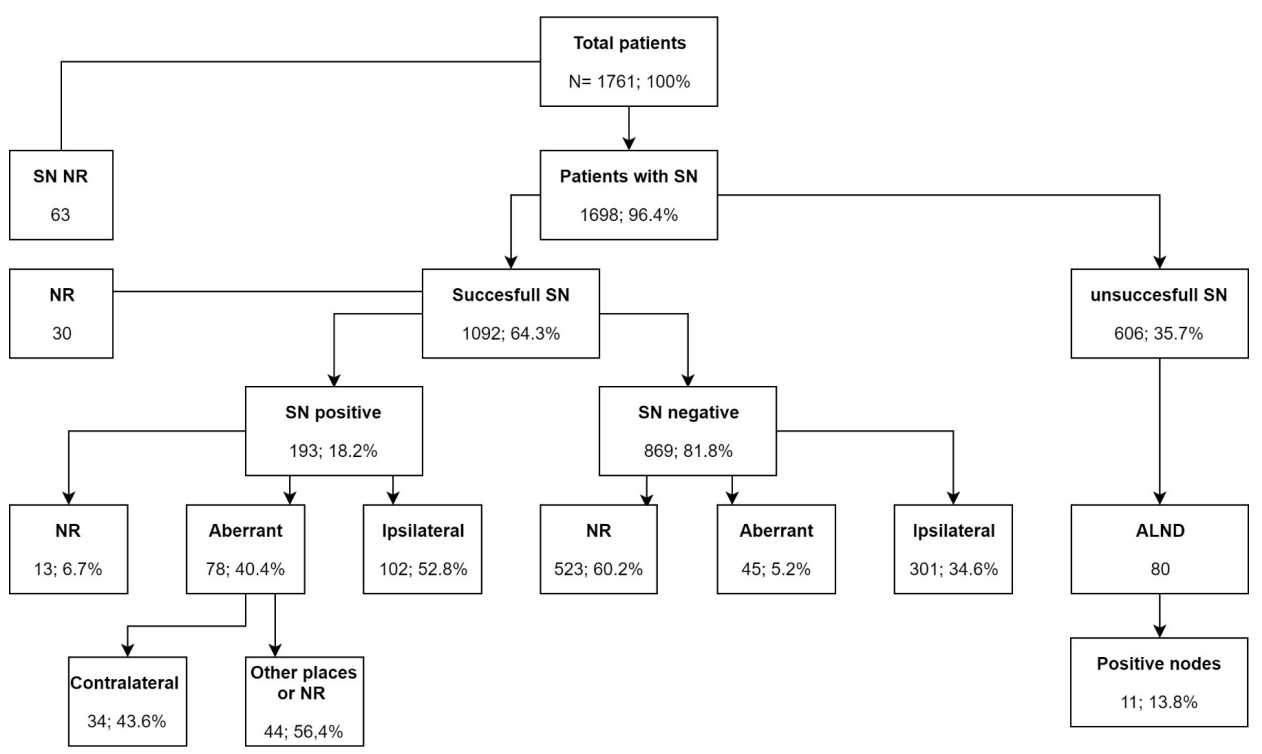

Figure 6.3 Flowchart of surgically harversted repeat sentinel node: location and outcome SN sentinel node, NR not reported, ALND axillary lymph node dissection

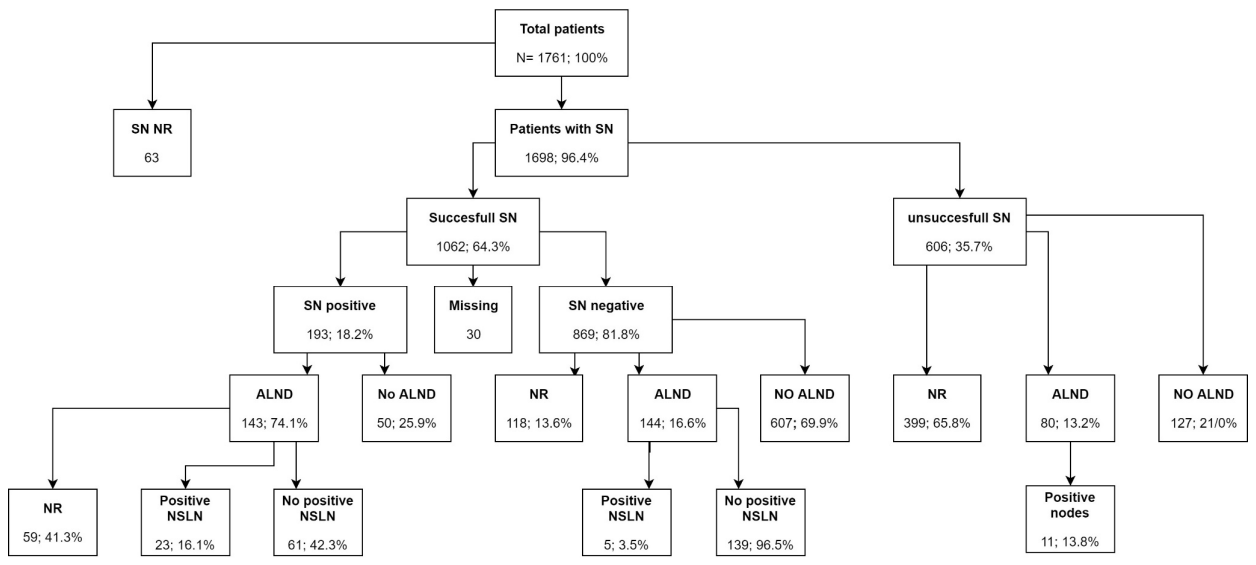

Figure 6.4 Flowchart of outcome (completion) axillary lymph node dissection (ALND)

SN sentinel node, NR not reported, NSLN non-sentinel lymph nodes, ALND axillary lymph node dissection

\section{Adjuvant treatment after IBTR}

Information on adjuvant systemic treatment strategies was provided only in 12 articles ( $n=296$ patients). Adjuvant chemotherapy was administered to $37 \%$ if the patients $(n=109)$ and endocrine therapy to $47 \%$ (123 of 238 reported patients). Radiotherapy to 
the breast or chest wall was provided to $29.5 \%$ of the patients ( $n=87$ of 295 reported cases).

Overall, for $63.8 \%$ of patients (74 out of 116 reported patients) with a tumor-positive rSLN, the adjuvant treatment plans were changed. These alterations varied from administration of adjuvant systemic therapy $(n=18)$, to adjuvant radiotherapy on the internal mammary chain, the ipsilateral or contralateral axilla, or the periclavicular region $(n=20)$, or both systemic and radiation treatment $(n=18)$, to a contralateral ALND because of metastases in the contralateral SLN ( $n=19)$.

For six patients, adjuvant treatment plans were changed because of unsuccessful rSLNB to adjuvant chemotherapy $(n=1)$ and adjuvant radiotherapy $(n=5)$.

\section{Follow-up Assessment and Outcomes}

For $48.2 \%$ of the total cohort $(n=849)$, data on regional node recurrences were provided. During a mean follow-up period of 31.7 months (range 13-60 months), $1.30 \%$ of the patients $(n=11)$ experienced a regional lymph node recurrence. For 2 of the 11 patients, the regional recurrence was located in the ipsilateral axilla (1 negative rSLN and 1 unsuccessful rSLNB). For one patient, it was observed in the internal mammary node (IMN) after a negative rSLN in the ipsilateral axilla. For the remaining eight patients, the location was not mentioned. The reported disease-free survival in these 849 patients was $98.7 \%$ during a mean follow-up period of 31.7 months (Table 6.3).

Data on distant recurrences were reported in 496 patients. In this relatively small subgroup, distant recurrences were diagnosed in $4.64 \%(n=23)$ during a mean follow-up period of 30.4 months (range 16-60 months), resulting in a disease-free survival of $95.4 \%$. Of the 23 patients, 14 died because of metastatic disease, 3 were living 16 months after IBTR, and 6 had this information was missing. The overall survival rate was $95.2 \%$ during a mean follow-up period of 29.6 months (range 16-60 months). However this was reported only in $21.5 \%$ of the patients (Table 6.3 ).

Table 6.3 Follow-up assessment and survival after ipsilateral breast tumor recurrence (IBTR)

\begin{tabular}{|c|c|c|c|c|c|}
\hline & Follow-up & $\begin{array}{l}\text { Regional } \\
\text { recurrence }\end{array}$ & $\begin{array}{c}\text { Distant } \\
\text { metastases }\end{array}$ & Death & $\begin{array}{c}\text { Cancer-related } \\
\text { deaths }\end{array}$ \\
\hline Articles describing FU & 20 & 19 & 11 & 10 & 10 \\
\hline Patients with FU data available & 902 & 849 & 496 & 379 & 379 \\
\hline$\%$ of total of patients & $51.2 \%$ & $48.2 \%$ & $28.2 \%$ & $21.5 \%$ & $21.5 \%$ \\
\hline Mean FU after IBTR (months) & 31.9 & 31.7 & 30.4 & 29.6 & 29.6 \\
\hline Range & $(13-60)$ & $(13-60)$ & $(16-60)$ & $(16-60)$ & $(16-60)$ \\
\hline NO. of events reported & & 11 & 23 & 18 & 14 \\
\hline Disease free last FU (n) & - & 838 & 473 & - & - \\
\hline Percentage (\%) & & $98.7 \%$ & $95.4 \%$ & & \\
\hline $95 \% \mathrm{Cl}$ & & (98.8-98.9) & $(95.2-95.6)$ & & \\
\hline Survival at last FU (n) & - & 849 & 482 & 361 & 365 \\
\hline Percentage (\%) & & $100 \%$ & $97.2 \%$ & $95.2 \%$ & $96.3 \%$ \\
\hline $95 \% \mathrm{Cl}$ & & & (96.9-97.5) & $(94.8-95.6)$ & $(96.3-96.6)$ \\
\hline
\end{tabular}

IBTR ipsilateral breast cancer recurrence, FU follow-up, \% percentage, $\mathrm{Cl}$ confidence interval, $\mathrm{n}$ number 


\section{Prognostic Value of rSLN}

Of the 11 patients reported to have regional recurrences, the $r S L N$ was negative for two patients, unsuccessful for one patient, and not available for the remaining eight patients. Of the 23 patients with a diagnosis of distant recurrences, pathologic outcome of the rSLN was described for only 7 patients (node-negative in 4, node-positive in 2, non-identification in 1). Overall, data required to elucidate the impact of a positive/negative/unsuccessful rSLN on regional or distant recurrences and survival were missing.

\section{Discussion}

This systematic review aimed to evaluate the technical success rate, follow-up assessment, and prognostic value of rSLNB for patients with IBTR. A rSLNB is feasible for $64 \%$ of the patients with IBTR, especially after SLNB. With a negative predictive value of $96.5 \%, r S L N B$ appears to be an accurate procedure. In this study, the overall survival, reported for $21.5 \%$ of the patients, was $95.2 \%$ after a mean follow-up period of 29.6 months. Unfortunately, data required to elucidate the prognostic value of rSLNB were missing.

Within 10 years, $2-10 \%$ of patients treated for breast cancer will experience IBTR. ${ }^{1-3}$ IBTR, which is associated with an elevated risk of distant metastasis ${ }^{45-47}$ and death for patients treated with either mastectomy or breast-conserving therapy. ${ }^{48} \mathrm{~A} 10$-year survival rate of $39 \%$ after IBTR was reported by Voogd et al., with $64 \%$ of patients ultimately experiencing distant metastasis, mainly within the first 5 years after IBTR. ${ }^{49}$ Notably, only $4 \%$ of the patients received systemic therapy adjuvant to IBTR.

Other factors associated with an increased mortality among patients with IBTR were evaluated in the National Surgical Adjuvant Breast and Bowel protocols (NSABP) of node-negative primary disease (i.e., B-13, B-14, B-19, B-20, and B-23) and node-positive primary disease (i.e., B-15, B-16, B-18, B-22, and B-25). Earlier IBTR ( $<5$ years after primary breast tumor), older age, black race (only in primary node-negative breast cancer), higher body mass index, estrogen receptor (ER)-negative status, and larger tumors $\left(>2 \mathrm{~cm}\right.$ ) were associated with a decreased survival. ${ }^{48,50}$ The influence of axillary nodal involvement in the setting of IBTR was not reported.

In the current review, comparable with earlier published reviews ${ }^{12,51,52}$, the mean identification rate for rSLNB detected on preoperative lymphoscintigraphy was $64.7 \%$, with $39 \%$ showing drainage to aberrant lymph node basins. This review showed that a rSLN was successfully harvested from $64.3 \%$ of the patients, whereas this percentage ranged between 65 and $83 \%$ in earlier published reviews. ${ }^{12,51,52}$ The presented identification rate in this study is lower than in studies elucidating sentinel node surgery 
for primary breast cancer. First, earlier published rSLNB studies showed several technical aspects of the procedure that influenced the identification rate. In both primary breast cancer and IBTR, injection of a higher amount of technetium-99 led to a higher SLN identification rate. ${ }^{53,54}$ Therefore, technical adjustments in the rSLNB procedure are expected to yield higher identification rates in the future. Second, as reported in this study, it should be kept in mind that previous surgery in the axilla and/or radiotherapy appeared to have a pronounced negative influence on rSLN identification. ${ }^{53}$

Although cALND had not been performed for all rSLN-negative patients, the negative predictive value was $96.5 \%$. This rate seems to justify the accuracy of this procedure with a minimal risk of understaging and treatment.

The results of this review imply the usefulness of rSLNB. Nevertheless, other studies have questioned the need for this procedure. Firstly, two NSABP-trials described the prognosis after locoregional failure in primary node-positive and node-negative patients. The 5-year distant-disease-free-survival (DDFS) was $67 \%$ for node-negative primary breast cancer patients and $51 \%$ for node-positive patients, with a corresponding 5-year overall survival (OS) of 77 and 60\%, respectively. ${ }^{48,50}$ The risk of mortality appeared to justify the need for systemic therapy for all patients with IBTR regardless of nodal involvement. ${ }^{55}$ Second, the CALOR (chemotherapy for isolated loco regional breast cancer) trial found a significantly better 5 -year disease free survival and OS for IBTR patients treated with chemotherapy than for patients treated without chemotherapy ( $69 \%$ vs. $57 \%$ and $88 \%$ vs. $76 \%$, respectively). ${ }^{56}$ The benefit was substantially greater for estrogen receptor (ER)-negative patients than for the ERpositive patients. Therefore, the CALOR trial recommended adjuvant chemotherapy for all patients with IBTR, particularly ER-negative patients, irrespective of nodal involvement. $^{56}$

On the other hand, not all patients with IBTR will progress to systemic disease. Considering the risk for distant recurrences, it is valuable to predict which patients will benefit from adjuvant chemotherapy, radiotherapy or axillary surgery. Furthermore, by visualization of aberrant lymphatic pathways, a more complete regional staging could be achieved. The rSLNB can possibly stratify risk among patients with IBTR and therefore the usefulness of modifying future adjuvant treatment plans.

Unfortunately, due to a lack of information, it was not possible to determine the impact of node-negative rSLNB versus node-positive rSLNB versus unsuccessful rSLNB on the outcome for patients with IBTR. Other limitations of this study were heterogeneity of the selected studies, the underreporting of survival data, and the missing data about dissemination studies investigating the patients with IBTR. The follow-up period was too short or not mentioned in the selected studies, and breast-cancer related events were not scored systematically in most publications. Ideally, follow-up results should be 
published in larger cohort studies, with exact follow-up time reported as well as events during the follow-up period.

Despite these limitations, the current review is unique in that it presented data on the largest cohort of patients with IBTR and rSLNB. A feasibility rate of $64 \%$ of the procedure was confirmed, as well as the advantages of rSLNB over ipsilateral ALND, the presence of aberrant pathways, and possible treatment changes.

\section{Conclusion}

The prognostic impact of rSLN-positive versus rSLN-negative IBTR remains unclear, and further studies are needed to fill in the gap in the management of lymph nodes in patients with IBTR. However, based on current evidence, rSLNB is feasible for $64 \%$ of patients, especially after previous SLNB. With a negative predictive value of $96.5 \%$, rSLNB appears to be highly specific, with substantial advantages over ipsilateral ALND in IBTR. 


\section{References}

1. Veronesi U, Cascinelli N, Mariani L, et al. Twenty-year follow-up of a randomized study comparing breast-conserving surgery with radical mastectomy for early breast cancer. N Engl J Med. 2002;347(16):1227-1232.

2. Houssami N, Macaskill P, Marinovich ML, Morrow M. The association of surgical margins and local recurrence in women with early-stage invasive breast cancer treated with breast-conserving therapy: a meta-analysis. Ann Surg Oncol. 2014;21(3):717-730.

3. Arriagada R, Le MG, Guinebretiere JM, Dunant A, Rochard F, Tursz T. Late local recurrences in a randomised trial comparing conservative treatment with total mastectomy in early breast cancer patients. Ann Oncol. 2003;14(11):1617-1622.

4. Burger AE, Pain SJ, Peley G. Treatment of recurrent breast cancer following breast conserving surgery. The breast journal. 2013;19(3):310-318.

5. Vugts G, Maaskant-Braat AJ, Voogd AC, et al. Repeat sentinel node biopsy should be considered in patients with locally recurrent breast cancer. Breast Cancer Res Treat. 2015;153(3):549-556.

6. Nationaal Borstkanker Overleg Nederland (NABON). Richtlijn behandeling van het mammacarcinoom. Accessed 2 March 2012; http://www.oncoline.nl.

7. Lyman GH, Somerfield MR, Bosserman LD, Perkins CL, Weaver DL, Giuliano AE. Sentinel lymph node biopsy for patients with early-stage breast cancer: American Society of Clinical Oncology Clinical Practice Guideline Update. J Clin Oncol. 2016;35(5):561-564.

8. Moossdorff M, van Roozendaal LM, Strobbe LJ, et al. Maastricht Delphi consensus on event definitions for classification of recurrence in breast cancer research. J Natl Cancer Inst. 2014;106(12):pii dju288.

9. Intra M, Viale G, Vila J, et al. Second axillary sentinel lymph node biopsy for breast tumor recurrence: experience of the European Institute of Oncology. Ann Surg Oncol. 215;22(7):2372-2377.

10. Moossdorff M, Vugts G, Maaskant-Braat AJ, et al. Contralateral lymph node recurrence in breast cancer: Regional event rather than distant metastatic disease. A systematic review of the literature. Eur J Surg Oncol. 2015;41(9):1128-1136.

11. Morcos B, Jaradat I, El-Ghanem M. Characteristics of and therapeutic options for contralateral axillary lymph node metastasis in breast cancer. Eur J Surg Oncol. 2011;37(5):418-421.

12. Maaskant-Braat AJ, Voogd AC, Roumen RM, Nieuwenhuijzen GA. Repeat sentinel node biopsy in patients with locally recurrent breast cancer: a systematic review and meta-analysis of the literature. Breast Cancer Res Treat. 2013;138(1):13-20.

13. Lim I, Shim J, Goyenechea M, Kim CK, Krynyckyi BR. Drainage across midline to sentinel nodes in the contralateral axilla in breast cancer. Clin Nucl Med. 2004;29(6):346-347.

14. Sood A, Youssef IM, Heiba SI, et al. Alternative lymphatic pathway after previous axillary node dissection in recurrent/primary breast cancer. Clin Nucl Med. 2004;29(11):698-702.

15. Agarwal A, Heron DE, Sumkin J, Falk J. Contralateral uptake and metastases in sentinel lymph node mapping for recurrent breast cancer. J Surg Oncol. 2005;92(1):4-8.

16. Dinan D, Nagle CE, Pettinga J. Lymphatic mapping and sentinel node biopsy in women with an ipsilateral second breast carcinoma and a history of breast and axillary surgery. Am J Surg. 2005;190(4):614-617.

17. Tada K, Nishimura S, Miyagi Y, et al. The effect of an old surgical scar on sentinel node mapping in patients with breast cancer: a report of five cases. Eur J Surg Oncol. 2005;31(8):840-844.

18. Boughey JC, Ross MI, Babiera GV, et al. Sentinel lymph node surgery in locally recurrent breast cancer. Clin Breast Cancer. 2006;7(3):248-253.

19. Jackson BM, Kim S, Davidson R, Schuchter L, Acs G, Czerniecki BJ. Repeat operative sentinel lymph node biopsy. Clin Breast Cancer. 2006;6(6):530-534.

20. Newman EA, Cimmino VM, Sabel MS, et al. Lymphatic mapping and sentinel lymph node biopsy for patients with local recurrence after breast-conservation therapy. Ann Surg Oncol. 2006;13(1):52-57.

21. Roumen RMH, Kuijt GP, Liem IH. Lymphatic mapping and sentinel node harvesting in patients with recurrent breast cancer. Eur J Surg Oncol. 2006;32(10):1076-1081.

22. Taback B, Nguyen P, Hansen N, Edwards GK, Conway K, Giuliano AE. Sentinel lymph node biopsy for local recurrence of breast cancer after breast-conserving therapy. Ann Surg Oncol. 2006;13(8): 1099-1104. 
23. Barone JL, Feldman SM, Estabrook A, Tartter PI, Rosenbaum Smith SM, Boolbol SK. Reoperative sentinel lymph node biopsy in patients with locally recurrent breast cancer. Am J Surg. 2007;194(4):491-493.

24. Port ER, Garcia-Etienne CA, Park J, Fey J, Borgen PI, Cody IHS. Reoperative sentinel lymph node biopsy: A new frontier in the management of ipsilateral breast tumor recurrence. Ann Surg Oncol. 2007;14(8): 2209-2214.

25. Axelsson CK, Jonsson PE. Sentinel lymph node biopsy in operations for recurrent breast cancer. Eur J Surg Oncol. 2008;34(6):626-630.

26. Cox CE, Furman BT, Kiluk JV, et al. Use of reoperative sentinel lymph node biopsy in breast cancer patients. J Am Coll Surg. 2008;207(1):57-61.

27. Karam A, Stempel M, Cody HS, 3rd, Port ER. Reoperative sentinel lymph node biopsy after previous mastectomy. J Am Coll Surg. 2008;207(4):543-548.

28. Koizumi M, Koyama M, Tada K, et al. The feasibility of sentinel node biopsy in the previously treated breast. Eur J Surg Oncol. 2008;34(4):365-368.

29. Schrenk P, Tausch C, Wayand W. Lymphatic mapping in patients with primary or recurrent breast cancer following previous axillary surgery. Eur J Surg Oncol. 2008;34(8):851-856.

30. Tasevski R, Gogos AJ, Mann GB. Reoperative sentinel lymph node biopsy in ipsilateral breast cancer relapse. Breast. 2009;18(5):322-326.

31. van der Ploeg IM, Oldenburg HS, Rutgers EJ, et al. Lymphatic drainage patterns from the treated breast. Ann Surg Oncol. 2010;17(4):1069-1075.

32. Vicente DA, Henry LR, Hahm G, Soballe PW, Smart D. Axillary sentinel lymph node biopsy after mastectomy: A case report. World J Surg Oncol. 2010;8:59.

33. Derkx F, Maaskant-Braat AJ, van der Sangen MJ, et al. Staging and management of axillary lymph nodes in patients with local recurrence in the breast or chest wall after a previous negative sentinel node procedure. Eur J Surg Oncol. 2010;36(7):646-651.

34. Yamashita T, Fujita T, Hayashi $\mathrm{H}$, et al. Detection of parasternal metastatic lymph nodes by sentinel lymph node methods in a patient with recurrence in the conserved breast. Breast Cancer (Tokyo, Japan). 2014;21(2):246-248.

35. Hattori M, Nishimura S, Tada K, et al. Reoperative sentinel lymph node biopsy for ipsilateral breast tumor recurrence after previous axillary lymph node dissection: Report of a case. Surg Today. 2011; 41(2):247-250.

36. Kaur P, Kiluk JV, Meade $\mathrm{T}$, et al. Sentinel lymph node biopsy in patients with previous ipsilateral complete axillary lymph node dissection. Ann Surg Oncol. 2011;18(3):727-732.

37. Tokmak H, Kaban K, Muslumanoglu M, Demirel M, Aktan S. Management of sentinel node re-mapping in patients who have second or recurrent breast cancer and had previous axillary procedures. World J Surg Oncol. 2014;12(1);205.

38. Cordoba O, Perez-Ceresuela F, Espinosa-Bravo M, et al. Detection of sentinel lymph node in breast cancer recurrence may change adjuvant treatment decision in patients with breast cancer recurrence and previous axillary surgery. Breast. 2014;23(4):460-465.

39. Matsumoto A, Jinno H, Takahashi M, Hayashida T, Kitagawa Y. Technical feasibility and validity of sentinel lymph node biopsy after ipsilateral breast tumor recurrence. Eur J Surg Oncol. 2016;42(9):S132.

40. Uth $\mathrm{CC}$, Christensen $\mathrm{MH}$, Oldenbourg $\mathrm{MH}$, et al. Sentinel lymph node dissection in locally recurrent breastcCancer. Ann Surg Oncol. 2015;22(8):2526-2531.

41. Karanlik H, Ozgur I, Kilic B, et al. Sentinel lymph node biopsy and aberrant lymphatic drainage in recurrent breast cancer: Findings likely to change treatment decisions. J Surg Oncol. 2016;114(7): 796-802.

42. Borrelli P, Donswijk ML, Stokkel MP, et al. Contribution of SPECT/CT for sentinel node localization in patients with ipsilateral breast cancer relapse. Eur J Nucl Med Mol Imaging. 2017;44(4):630-637.

43. Folli S, Falco G, Mingozzi $M$, et al. Repeat sentinel lymph node biopsy in patients with ipsilateral recurrent breast cancer after breast-conserving therapy and negative sentinel lymph node biopsy: a prospective study. Minerva Chir. 2016;71(2):73-79.

44. Johnson J, Esserman L, Ewing C, Alvarado M, Park C, Fowble B. Sentinel lymph node mapping in postmastectomy chest wall recurrences: Influence on radiation treatment fields and outcome. Ann Surg Oncol. 2016;23(3):715-721.

45. Fisher B, Anderson S, Fisher ER, et al. Significance of ipsilateral breast tumour recurrence after lumpectomy. Lancet. 1991;338(8763):327-331. 
46. Veronesi $U$, Marubini $E$, Del Vecchio $M$, et al. Local recurrences and distant metastases after conservative breast cancer treatments: partly independent events. J Natl Cancer Inst. 1995;87(1):19-27.

47. Wapnir IL, Aebi S, Geyer CE, et al. A randomized clinical trial of adjuvant chemotherapy for radically resected locoregional relapse of breast cancer: IBCSG 27-02, BIG 1-02, and NSABP B-37. Clin Breast Cancer. 2008;8(3):287-292.

48. Anderson SJ, Wapnir I, Dignam JJ, et al. Prognosis after ipsilateral breast tumor recurrence and locoregional recurrences in patients treated by breast-conserving therapy in five National Surgical Adjuvant Breast and Bowel Project protocols of node-negative breast cancer. J Clin Oncol. 2009; 27(15):2466-2473.

49. Voogd AC, van Oost FJ, Rutgers EJ, et al. Long-term prognosis of patients with local recurrence after conservative surgery and radiotherapy for early breast cancer. Eur J Cancer. 2005;41(17):2637-2644.

50. Wapnir IL, Anderson SJ, Mamounas EP, et al. Prognosis after ipsilateral breast tumor recurrence and locoregional recurrences in five National surgical adjuvant Breast and bowel project node-positive adjuvant breast cancer trials. J Clin Oncol. 2006;24(13):2028-2037.

51. Kothari MS, Rusby JE, Agusti AA, MacNeill FA. Sentinel lymph node biopsy after previous axillary surgery: A review. Eur J Surg Oncol. 2012;38(1):8-15.

52. Ikeda T. Re-sentinel node biopsy after previous breast and axillary surgery. Surg Today. 2014;44(11): 2015-2021.

53. Vugts G, Maaskant-Braat AJ, Voogd AC, et al. Improving the success rate of repeat sentinel node biopsy in recurrent breast cancer. Ann Surg Oncol. 2015;22 Suppl 3:S529-535.

54. Valdes-Olmos RA, Jansen L, Hoefnagel CA, et al. Evaluation of mammary lymphoscintigraphy by a single intratumoral injection for sentinel node identification. J Nucl Med. 2000;41(9):1500-1506.

55. Ugras S, Matsen C, Eaton A, Stempel M, Morrow M, Cody HS. Reoperative sentinel lymph node biopsy is feasible for locally recurrent breast cancer, But is it worthwhile? Ann Surg Oncol. 2016;23(3):744-748.

56. Aebi S, Gelber S, Anderson SJ, et al. Chemotherapy for isolated locoregional recurrence of breast cancer (CALOR): a randomised trial. Lancet Oncol. 2014;15(2):156-163. 


\section{Appendix 6.1}

\section{Search terms}

PubMed/MEDLINE(()((ipsilateral breast tumor recurrence) OR locally recurrent breast cancer) OR recurrent breast cancer)) AND ((("Sentinel Lymph Node Biopsy”[Mesh]) OR sentinel lymph node biopsy) OR lymphatic mapping $))$ OR (((((“Sentinel Lymph Node Biopsy"[Mesh]) OR sentinel lymph node biopsy) OR lymphatic mapping)) AND ((repeat) OR re-operative)).

Embase (( (sentinel lymph node biopsy/ OR sentinel lymph node biopsy.af. OR lymphatic mapping.af.) AND (recurrent breast cancer.af. OR ipsilateral breast tumor recurrence.af. OR locally recurrent breast cancer.af.)) OR ((sentinel lymph node biopsy/ OR sentinel lymph node biopsy.af. OR lymphatic mapping.af.) AND (repeat.af. OR reoperative.af.))).

Cochrane ((MeSH descriptor: [Sentinel Lymph Node Biopsy] explode all trees) OR "lymphatic mapping" OR "sentinel lymph node biopsy") AND ("ipsilateral breast tumor recurrence" OR "recurrent breast cancer" OR "locally recurrent breast cancer")) OR ((MeSH descriptor: [Sentinel Lymph Node Biopsy] explode all trees) OR "lymphatic mapping" OR "sentinel lymph node biopsy") AND ("repeat" OR "re-operative")) 


\section{Chapter 7}

\section{Risk of regional recurrence after negative repeat sentinel lymph node biopsy in patients with ipsilateral breast tumor recurrence}

I.G.M. Poodt, G. Vugts, A.J.G. Maaskant-Braat, R.J. Schipper, A.C. Voogd, G.A.P. Nieuwenhuijzen On behalf of the Sentinel Node and Recurrent Breast Cancer (SNARB) study group 


\section{Abstract}

\section{Background}

Repeat sentinel lymph node biopsy ( $r S L N B$ ) has increasingly been used in patients with ipsilateral breast tumor recurrence (IBTR). The safety in terms of regional disease control after this procedure remains unclear. This study evaluates the occurrence of regional recurrences as first event in patients with IBTR and negative rSLNB, treated without additional lymph node dissection.

\section{Patients and methods}

Data were obtained from the Sentinel Node and Recurrent Breast Cancer (SNARB) study. In 201 patients, tumor-negative rSLNB was obtained without performing additional lymph node dissections.

\section{Results}

With median follow-up of 4.7 (range 0.9-12.7) years, regional recurrence occurred after median time of 3.0 (range 0.4-6.7) years in $4.5 \%(\mathrm{~N}=9)$ of patients as first event after IBTR and rSLNB. In four of these nine patients, the site of recurrence was in concordance with the anatomical location of rSLNB. Two of the nine recurrences were reported in the ipsilateral axilla, resulting in an ipsilateral axillary regional recurrence rate of $1.0 \%$. In the other seven patients, regional recurrence occurred in aberrant basins. Univariable analysis showed that triple-negative IBTR and lower amount of radioactive-labeled tracer ( ${ }^{99 \mathrm{~m}}$ technetium) used during rSLNB were associated with developing regional recurrence as first event after a negative $\operatorname{rSLNB}(P<0.05)$.

\section{Conclusions}

The risk of developing regional recurrence after negative rSLNB is low. The low relapse rate supports the safety of rSLNB as primary nodal staging tool in IBTR. The time has come for clinical guidelines to adopt rSLNB as axillary staging tool in patients with IBTR. 


\section{Introduction}

During recent decades, sentinel lymph node biopsy (SLNB) has emerged and is currently accepted as the new standard practice for axillary staging in patients with primary breast cancer. ${ }^{1}$ Following the growing confidence in the efficacy of SLNB, questions were raised regarding use of this procedure in patients with ipsilateral breast tumor recurrence (IBTR). To date, there is no standard practice regarding axillary staging in $\mathrm{IBTR}^{2}$, hence several studies have evaluated repeat SLNB (rSLNB) in the recurrent setting. These studies showed feasibility of repeat sentinel node in approximately $65 \%$ of cases and revealed a role of this procedure in tailoring adjuvant treatment plans. ${ }^{3,4}$ However, safety in terms of regional disease control and regional lymph node recurrence after rSLNB in patients with IBTR remains unclear.

In primary breast cancer, regional disease control after SLNB without completion axillary lymph node dissection (cALND) has been investigated critically. False-negative rates of approximately $5 \%$, very low regional recurrence rates, and survival rates comparable to those following ALND justified the conclusion that ALND could be safely omitted in sentinel lymph node-negative patients ${ }^{1,5-7}$, thereby sparing patients with primary breast cancer the morbidity associated with $A L N D^{8,9}$.

For patients with IBTR and a tumor-negative rSLNB, clinically relevant treatment changes were also observed. With a negative predictive value of $94 \%$, omission of additional lymph node dissection was assumed to be safe. ${ }^{3}$ Nonetheless, long term follow-up data on regional recurrence after negative rSLNB have not yet been published. For rSLNB to become an equivalent standard of care in the IBTR setting as well, it is imperative to ensure high regional disease control. Therefore, the aim of this study is to evaluate occurrence of regional recurrence as first event after negative rSNLB in patients with nonmetastatic IBTR, treated with curative intent and without CALND.

\section{Methods}

\section{SNARB-study design}

The SNARB study is a multicenter national registration study in which 36 Dutch hospitals participated. In the period from February 2008 to July 2011, data of 150 patients with recurrent breast cancer were prospectively entered into the database. $^{10}$ Subsequently, from August 2011 to December 2014, data from 386 additional patients were retrospectively entered into the database. The additional data were derived from 29 of the 36 initial participating hospitals. Patients with clinically apparent ipsilateral or contralateral lymph node metastases and patients with distant metastases were excluded. ${ }^{3}$ A total of 536 patients, over 18 years old with operable locally recurrent breast cancer and staged with rSLNB, were included. During 
rSLNB, the dual-mapping technique with both ${ }^{99 m}$ techneticum and blue dye was used. From January 2017 to July 2017, follow-up data of the 536 included SNARB patients were collected and entered into the database.

\section{Patients}

Patients with IBTR and successful rSLNB were considered eligible for inclusion. Patients who underwent additional axillary lymph node dissection as validation procedure after detection of a negative sentinel lymph node were excluded. Patients with either microor macrometastases in their sentinel lymph nodes were excluded. Sentinel lymph nodes containing isolated tumor cells (ITC) (small clusters of cells $<0.2 \mathrm{~mm}$ and/or fewer than 200 cells) were classified as node negative.

\section{Regional recurrence}

The primary endpoint of this study was regional lymph node recurrence as first event after curative treatment of IBTR. Regional recurrence was defined as any evidence of disease found in ipsilateral intramammary nodes, ipsi- and contralateral internal mammary nodes, ipsi- and contralateral axillary nodes, and ipsi- and contralateral infraand supraclavicular nodes. Lymph node recurrences found outside these nodal basins were defined as distant metastatic disease. In the recently published Maastricht Delphi Consensus statement on the definition of regional events, only ipsilateral nodal recurrences (either axillary or in other ipsilateral nodal basins) were considered as regional recurrences. ${ }^{11}$ Based on earlier rSLNB studies ${ }^{3,12}$, we state that the definition of a regional recurrence after IBTR should be broadened and should also include contralateral nodes, since lymphatic drainage towards these basins is common. ${ }^{4,13,14}$ Therefore, we considered contralateral events as regional recurrences.

Regional recurrences were registered if they occurred as a first event after negative rSLNB or when diagnosed concurrent with local recurrences in the previous treated breast. Patients with regional recurrence coincident with or after the diagnosis of distant disease were not reported as having regional recurrence as first event. In patients with second IBTR or newly diagnosed contralateral breast tumor as first event without clinically (i.e., physical examination or after imaging studies) relevant regional lymph node metastases, possible lymph node metastases found during a second rSLNB were not regarded as regional recurrence.

\section{Follow-Up}

General practitioners were actively contacted for additional follow-up information when hospital records showed no outpatient clinic visits for more than 1 year. Date of last follow-up was documented as last visit to the outpatient clinic, date of visit to the general practitioner, or date of death in case the patient had deceased. 
Follow-up time was defined as time between date of surgery for initial IBTR to date of last follow-up. Time to regional recurrence was defined as time between treatment of IBTR and date of diagnosis of regional recurrence as first event after IBTR.

\section{Statistics}

The variables used (see Supporting information) were compared between patients with regional recurrence as first event and patients with no regional recurrence. Statistical significance was tested using Pearson Chi square test and Fisher exact test for categorical variables. For continuous variables, Mann-Whitney $U$ test or independent Sample $t$ test was used when appropriate. Two-sided $P$-value $<0.05$ was considered statistically significant. Survival analysis, using the Kaplan-Meier method, was performed to calculate the 5-year risk of regional recurrences after IBTR. Data analysis were performed using SPSS version 24 (SPSS Inc., Chicago, IL, USA).

\section{Results}

\section{Patients}

Follow-up data were collected of 536 patients. As 21 patients were lost to follow-up due to file loss, emigration, and loss of informed consent, 515 patients remained available for analysis. Of these 515 patients, 230 patients had a successful negative rSLNB, of whom 29 patients were excluded since they underwent additional lymph node dissection. The median age of the remaining 201 patients at time of IBTR was 63.5 (range 34-87) years. The median time from primary surgery to diagnosis of IBTR was 8.5 (range 0.4-30) years. After treatment of IBTR, $22.4 \%$ of patients underwent (re)irradiation to the chest wall or regional lymph node basins $(\mathrm{N}=45)$. Of all patients, $63.2 \%$ received adjuvant systemic treatment $(\mathrm{N}=127)$. Adjuvant endocrine therapy was administered in $56.7 \%(\mathrm{~N}=114)$ and adjuvant chemotherapy in $16.9 \%$ of the patients $(\mathrm{N}=34)$. Patient characteristics are summarized in Table 7.1.

\section{Regional recurrence}

With median follow-up of 4.7 (range 0.9-12.7) years from IBTR, nine patients were diagnosed with regional recurrence as first event after negative rSLNB (4.5\%). These nine regional recurrences occurred after median time of 3.0 (range 0.4-6.7) years. Therefore, the overall regional recurrence rate as first event was $4.5 \%$, with 5 -year regional recurrence-free rate of $95.4 \%$ (95\% confidence interval (CI) 91.9\%-98.9\%). Of the nine patients with regional recurrence, two patients experienced a regional recurrence in the ipsilateral axilla, resulting in an ipsilateral axillary recurrence rate of 1\% (Table 7.2). 
Within the nine patients with regional recurrence, six recurrences were symptomatic (i.e., patients visited the outpatient clinic with lymph node swelling or other localized complaints in an interval between planned follow-up points). The other three recurrences were detected during routine follow-up: two patients during scheduled echography and one patient during scheduled positron emission tomography scan (Table 7.2).

Table 7.1 Clinicopathological characteristics of all patients with IBTR and negative repeat sentinel lymph node biopsy, without additional lymph node dissection ( $N=201)$

\begin{tabular}{|c|c|c|c|c|}
\hline & $\begin{array}{l}\text { Total group } \\
(\mathrm{N}=\mathbf{2 0 1})\end{array}$ & $\begin{array}{c}\text { Regional } \\
\text { recurrence } \\
(\mathrm{N}=9)\end{array}$ & $\begin{array}{l}\text { No regional } \\
\text { recurrence } \\
(\mathrm{N}=192)\end{array}$ & $P$-value \\
\hline Age primary tumor, median years (range) & $51.0(26-80)$ & $49.0(40-69)$ & $51.0(26-80)$ & 0.758 \\
\hline Age primary tumor, years & & & & 0.719 \\
\hline$<35$ & $8(4.0 \%)$ & - & $8(4.2 \%)$ & \\
\hline $35-59$ & $137(68.5 \%)$ & $6(66.7 \%)$ & $131(68.6 \%)$ & \\
\hline $60-69$ & $45(22.5 \%)$ & $3(33.3 \%)$ & $42(22.0 \%)$ & \\
\hline$\geq 70$ & $10(5.0 \%)$ & - & $10(5.2 \%)$ & \\
\hline Primary surgery & & & & 0.679 \\
\hline Mastectomy & $38(18.9 \%)$ & $2(22.2 \%)$ & $36(18.8 \%)$ & \\
\hline Breast-conserving surgery & $163(81.1 \%)$ & $7(77.8 \%)$ & $156(81.3 \%)$ & \\
\hline Primary SN & & & & 0.411 \\
\hline Negative & $88(43.8 \%)$ & $2(22.2 \%)$ & $86(44.8 \%)$ & \\
\hline Positive & $16(8.0 \%)$ & $1(11.1 \%)$ & $15(7.8 \%)$ & \\
\hline No SN & $97(48.3 \%)$ & $6(66.7 \%)$ & $91(47.4 \%)$ & \\
\hline Primary axillary surgery & & & & 0.512 \\
\hline No axillary staging & $18(9.0 \%)$ & $2(22.2 \%)$ & $16(8.3 \%)$ & \\
\hline SN negative & $86(42.8 \%)$ & $2(22.2 \%)$ & $84(43.8 \%)$ & \\
\hline SN positive, CALND & $13(6.4 \%)$ & $1(11.1 \%)$ & $12(6.3 \%)$ & \\
\hline SN positive, no cALND & $3(1.5 \%)$ & - & $3(1.6 \%)$ & \\
\hline ALND & $81(40.1 \%)$ & $4(44.4 \%)$ & $77(40.1 \%)$ & \\
\hline Primary nodal status & & & & 0.645 \\
\hline Negative & $145(72.1 \%)$ & $6(66.7 \%)$ & 139 (72.4\%) & \\
\hline Positive & $31(15.4 \%)$ & $1(11.1 \%)$ & $30(15.6 \%)$ & \\
\hline Unknown & $25(12.4 \%)$ & $2(22.2 \%)$ & $23(12.0 \%)$ & \\
\hline Primary tumor size & & & & 0.110 \\
\hline$<20 \mathrm{~mm}$ & $116(57.7 \%)$ & $5(55.6 \%)$ & $111(57.8 \%)$ & \\
\hline $21-50 \mathrm{~mm}$ & $33(16.4 \%)$ & $1(11.1 \%)$ & $32(16.7 \%)$ & \\
\hline$>50 \mathrm{~mm}$ & $3(1.5 \%)$ & $1(11.1 \%)$ & $2(1.0 \%)$ & \\
\hline Unknown & 49 (24.4\%) & $2(22.2 \%)$ & 47 (24.5\%) & \\
\hline Primary tumor grade & & & & 0.071 \\
\hline 1 & $38(18.9 \%)$ & - & $38(19.8 \%)$ & \\
\hline II & $47(23.4 \%)$ & - & 47 (24.5\%) & \\
\hline III & 30 (14.9\%) & $2(22.2 \%)$ & $28(14.6 \%)$ & \\
\hline Unknown & $86(42.8 \%)$ & $7(77.8 \%)$ & $79(41.1 \%)$ & \\
\hline Receptor status of primary tumor & & & & 0.017 \\
\hline Triple negative & $8(4.0 \%)$ & $1(11.1 \%)$ & $7(3.6 \%)$ & \\
\hline HR- Her2+ & $2(1.0 \%)$ & $1(11.1 \%$ & $1(0.5 \%)$ & \\
\hline $\mathrm{HR}+\mathrm{Her} 2+$ & $3(1.5 \%)$ & - & $3(1.6 \%)$ & \\
\hline $\mathrm{HR}+\mathrm{Her} 2-$ & $58(28.9 \%)$ & $1(11.1 \%)$ & $57(29.7 \%)$ & \\
\hline Unknown & $130(64.7 \%)$ & $6(66.7 \%)$ & $124(64.6 \%)$ & \\
\hline
\end{tabular}


Table 7.1 (continued)

\begin{tabular}{|c|c|c|c|c|}
\hline & $\begin{array}{l}\text { Total group } \\
\qquad(\mathrm{N}=\mathbf{2 0 1})\end{array}$ & $\begin{array}{l}\text { Regional } \\
\text { recurrence } \\
(\mathrm{N}=9)\end{array}$ & $\begin{array}{l}\text { No regional } \\
\text { recurrence } \\
(\mathrm{N}=192)\end{array}$ & $P$-value \\
\hline Hormone status primary tumor & & & & 0.270 \\
\hline ER and PR negative & $18(9.0 \%)$ & $2(22.2 \%)$ & $16(8.3 \%)$ & \\
\hline ER/PR positive & $106(52.7 \%)$ & $3(33.3 \%)$ & $103(53.6 \%)$ & \\
\hline Unknown & 77 (38.3\%) & $4(44.4 \%)$ & $73(38.0 \%)$ & \\
\hline \multicolumn{5}{|l|}{$\begin{array}{l}\text { Time from primary surgery to IBTR } \\
\text { diagnose }\end{array}$} \\
\hline Median, months (range) & $106.5(4-361)$ & $143.0(15-213)$ & $105.0(4-361)$ & 0.902 \\
\hline Median, years (range) & $8.5(0-30)$ & $11.0(1-17)$ & $8.0(0-30)$ & 0.940 \\
\hline$<2$ years & $19(9.5 \%)$ & $2(22.2 \%)$ & $17(8.9 \%)$ & 0.414 \\
\hline $2.1-5$ years & $39(19.4 \%)$ & $1(11.1 \%)$ & $38(19.8 \%)$ & \\
\hline $5.1-10$ years & $50(24.9 \%)$ & $1(11.1 \%)$ & $49(25.5 \%)$ & \\
\hline$>10$ years & $92(45.8 \%)$ & $5(55.6 \%)$ & $87(45.3 \%)$ & \\
\hline Age IBTR, median years (range) & $63.5(34-87)$ & $65.0(41-76)$ & $63.0(34-87)$ & 0.658 \\
\hline Age IBTR, years & & & & 0.951 \\
\hline$<35$ & $1(0.5 \%)$ & - & $1(0.5 \%)$ & \\
\hline $35-59$ & $72(35.8 \%)$ & $4(44.4 \%)$ & $68(35.4 \%)$ & \\
\hline $60-69$ & $74(36.8 \%)$ & $3(33.3 \%)$ & $71(37.0 \%)$ & \\
\hline$\geq 70$ & $54(26.9 \%)$ & $2(22.2 \%)$ & $52(27.1 \%)$ & \\
\hline Location IBTR & & & & 0.679 \\
\hline Breast & $163(81.1 \%)$ & $7(77.8 \%)$ & $156(81.3 \%)$ & \\
\hline Mastectomy scar or chest wall & $38(18.9 \%)$ & $2(22.2 \%)$ & $36(18.8 \%)$ & \\
\hline Repeat SN aberrant & & & & 0.873 \\
\hline Yes & $97(48.3 \%)$ & $5(55.6 \%)$ & $92(47.9 \%)$ & \\
\hline No & $102(50.7 \%)$ & $4(44.4 \%)$ & $98(51.0 \%)$ & \\
\hline Unknown & $2(1.0 \%)$ & - & $2(1.0 \%)$ & \\
\hline $\begin{array}{l}\text { Repeat SN tracer amount, MBq median } \\
\text { (range) }\end{array}$ & $109(20.0-385.0)$ & $80.0(30.0-117.0)$ & $110.0(20.0-385.0)$ & 0.044 \\
\hline Tumor size IBTR & & & & 0.663 \\
\hline$<20 \mathrm{~mm}$ & $145(72.1 \%)$ & $8(88.9 \%)$ & $137(71.4 \%)$ & \\
\hline $21-50 \mathrm{~mm}$ & $34(16.9 \%)$ & $1(11.1 \%)$ & $33(17.2 \%)$ & \\
\hline$>50 \mathrm{~mm}$ & $2(1.0 \%)$ & - & $2(1.0 \%)$ & \\
\hline Unknown & $20(10.0 \%)$ & - & $20(10.4 \%)$ & \\
\hline Tumor grade IBTR & & & & 0.035 \\
\hline 1 & $40(19.9 \%)$ & - & $40(20.8 \%)$ & \\
\hline II & $85(42.3 \%)$ & $2(22.2 \%)$ & $83(43.2 \%)$ & \\
\hline III & $64(31.8 \%)$ & $5(55.6 \%)$ & $59(30.7 \%)$ & \\
\hline Unknown & $12(6.0 \%)$ & $2(22.2 \%)$ & $10(5.2 \%)$ & \\
\hline Receptor status IBTR & & & & 0.002 \\
\hline Triple negative & $25(12.4 \%)$ & $5(55.6 \%)$ & $20(10.4 \%)$ & \\
\hline HR-Her2+ & $6(3.0 \%)$ & - & $6(3.1 \%)$ & \\
\hline HR+ Her2+ & $11(5.5 \%)$ & - & $11(5.7 \%)$ & \\
\hline HR+ Her2- & $129(64.2 \%)$ & $4(44.4 \%)$ & $125(65.1 \%)$ & \\
\hline Unknown & 30 (14.9\%) & - & $30(15.6 \%)$ & \\
\hline Radiotherapy IBTR & & & & 1.000 \\
\hline Yes & $45(22.4 \%)$ & $2(22.2 \%)$ & $43(22.4 \%)$ & \\
\hline No & $156(77.6 \%)$ & $7(77.8 \%)$ & $149(77.6 \%)$ & \\
\hline Systemic therapy IBTR & & & & 0.728 \\
\hline Yes & $127(63.2 \%)$ & $5(55.6 \%)$ & $122(63.5 \%)$ & \\
\hline No & $74(36.8 \%)$ & $4(44.4 \%)$ & $70(36.5 \%)$ & \\
\hline
\end{tabular}


Table $7.1 \quad$ (continued)

\begin{tabular}{|c|c|c|c|c|}
\hline & $\begin{array}{l}\text { Total group } \\
\qquad(\mathrm{N}=\mathbf{2 0 1})\end{array}$ & $\begin{array}{l}\text { Regional } \\
\text { recurrence } \\
(\mathrm{N}=9)\end{array}$ & $\begin{array}{c}\text { No regional } \\
\text { recurrence } \\
(\mathrm{N}=192)\end{array}$ & $P$-value \\
\hline \multicolumn{5}{|l|}{ Endocrine therapy IBTR } \\
\hline Yes & $114(56.7 \%)$ & $5(55.6 \%)$ & $110(57.3 \%)$ & 0.505 \\
\hline No & $87(43.3 \%)$ & $4(44.4 \%)$ & $82(42.7 \%)$ & \\
\hline Chemotherapy IBTR & & & & 1.000 \\
\hline Yes & 34 (16.9\%) & $1(11.1 \%)$ & $33(17.2 \%)$ & \\
\hline No & 167 (83.1\%) & $8(88.9 \%)$ & $159(82.8 \%)$ & \\
\hline
\end{tabular}

Univariable analyses compared patients with regional recurrence $(\mathrm{N}=9)$ and patients without regional recurrence ( $\mathrm{N}=192)$. IBTR: ipsilateral breast tumor recurrence; ALND axillary lymph node dissection, cALND completion axillary lymph node dissection, $S N$ sentinel node, $\mathrm{mm}$ millimeter, HR hormone receptor, ER estrogen, PR progesterone, MBq meg becquerel, Her2 human epidermal growth receptor 2

\section{Location of regional recurrence}

Two patients experienced ipsilateral axillary recurrence. One of these patients underwent breast surgery alone (without SLNB or ALND) at the time of the primary breast tumor. During treatment for IBTR, the negative rSLNB was located in the ipsilateral axilla and completion ALND was omitted. Thus, this patient had a relatively intact ipsilateral axilla and developed an ipsilateral axillary recurrence 59 months after treatment for IBTR. The other patient received ALND during primarily treatment. At the time of IBTR, the negative rSLNB was located in the contralateral axilla. Forty-three months after IBTR, an ipsilateral axillary recurrence, localized near the subscapular muscle, was diagnosed.

The remaining seven patients developed nodal recurrence outside of the ipsilateral axilla: three in the ipsilateral supraclavicular basin, one in the ipsilateral internal mammary chain and three in the contralateral axilla. In four of the nine patients $(44.4 \%)$, the site of regional recurrence was in concordance with the site of the rSLNB on lymphoscintigraphy and during rSLNB surgery (one ipsilateral axilla, one ipsilateral internal mammary chain and two contralateral axilla).

\section{Adjuvant radiotherapy to the regional lymph node basins}

Of all patients, $88.1 \%(\mathrm{~N}=177)$ were primarily treated with adjuvant radiotherapy (for detailed information on location of radiotherapy, see Supporting Information). After treatment of IBTR, 22.4\% ( $\mathrm{N}=45)$ of patients underwent (re)irradiation, of whom 35 patients received radiotherapy to the chest wall, seven patients to the breast, and one to the chest wall and infraclavicular region because of an aberrant node on lymphoscintigram, while in two patients the region was unknown. Two of the nine patients diagnosed with regional recurrence after IBTR received radiotherapy to the chest wall (Table 7.2). 
Table 7.2 Regional recurrence after negative repeat sentinel lymph node biopsy, without additional lymph node dissection

\begin{tabular}{|c|c|c|c|c|c|c|c|}
\hline $\begin{array}{l}\text { Regional } \\
\text { recurrence }\end{array}$ & $\begin{array}{c}\text { Follow- } \\
\text { up IBTR } \\
\text { (Months) }\end{array}$ & rSN location LM & $\begin{array}{l}\text { rSN location } \\
\text { surgical } \\
\text { harvested }\end{array}$ & $\begin{array}{l}\text { DFI } 1^{\text {st- }} 2^{\text {nd }} \\
\text { tumor } \\
\text { (Months) }\end{array}$ & $\begin{array}{l}\text { Primary } \\
\text { axillary } \\
\text { staging }\end{array}$ & $\begin{array}{l}\text { Primary } \\
\text { adjuvant } \\
\text { (RT, CT, } \\
\text { HT) }\end{array}$ & $\begin{array}{l}\text { Secondary } \\
\text { adjuvant } \\
\text { (CT, RT, HT) }\end{array}$ \\
\hline $\begin{array}{l}\text { Ipsilateral } \\
\text { axilla }\end{array}$ & 59 & Ipsilateral axilla & Ipsilateral axilla & 61 & None & RT breast & HT \\
\hline $\begin{array}{l}\text { Ipsilateral } \\
\text { axilla }\end{array}$ & 43 & $\begin{array}{l}\text { Contralateral } \\
\text { axilla }\end{array}$ & $\begin{array}{l}\text { Contralateral } \\
\text { axilla }\end{array}$ & 19 & $\begin{array}{l}\text { SN+, } \\
\text { cALND }\end{array}$ & $\begin{array}{l}\text { RT breast, } \\
\text { RT axilla } \\
\text { n.a., CT }\end{array}$ & None \\
\hline $\begin{array}{l}\text { Ipsilateral } \\
\text { supraclavicular }\end{array}$ & 40 & $\begin{array}{l}\text { Ipsilateral } \\
\text { internal } \\
\text { mammary chain/ } \\
\text { intramammary }\end{array}$ & Ipsilateral axilla & 143 & ALND & None & RT chest, HT \\
\hline $\begin{array}{l}\text { Ipsilateral } \\
\text { supraclavicular }\end{array}$ & 65 & $\begin{array}{l}\text { Ipsilateral } \\
\text { internal } \\
\text { mammary chain } \\
\text { /intramammary }\end{array}$ & $\begin{array}{l}\text { Ipsilateral } \\
\text { internal } \\
\text { mammary } \\
\text { chain }\end{array}$ & 187 & ALND & RT breast & $\mathrm{HT}$ \\
\hline $\begin{array}{l}\text { Ipsilateral } \\
\text { supraclavicular }\end{array}$ & 9 & Ipsilateral axilla & Ipsilateral axilla & 15 & SN- & None & RT chest \\
\hline $\begin{array}{l}\text { Ipsilateral } \\
\text { internal } \\
\text { mammary } \\
\text { chain }\end{array}$ & 4 & $\begin{array}{l}\text { Ipsilateral } \\
\text { internal } \\
\text { mammary chain } \\
\text { /intramammary }\end{array}$ & $\begin{array}{l}\text { Ipsilateral } \\
\text { internal } \\
\text { mammary } \\
\text { chain }\end{array}$ & 196 & None & $\mathrm{RT}$ breast & None \\
\hline $\begin{array}{l}\text { Contralateral } \\
\text { axilla }\end{array}$ & 80 & $\begin{array}{l}\text { Contralateral } \\
\text { axilla }\end{array}$ & $\begin{array}{l}\text { Contralateral } \\
\text { axilla }\end{array}$ & 213 & ALND & $\begin{array}{l}\text { RT breast, } \\
\text { RT axilla } \\
\text { n.a. }\end{array}$ & CT \\
\hline $\begin{array}{l}\text { Contralateral } \\
\text { axilla }\end{array}$ & 15 & Ipsilateral axilla & Ipsilateral axilla & 30 & SN- & $\begin{array}{l}\text { RT breast, } \\
\text { HT }\end{array}$ & HT \\
\hline $\begin{array}{l}\text { Contralateral } \\
\text { axilla }\end{array}$ & 9 & $\begin{array}{l}\text { Contralateral } \\
\text { axilla }\end{array}$ & $\begin{array}{l}\text { Contralateral } \\
\text { axilla }\end{array}$ & 180 & ALND & RT breast & None \\
\hline
\end{tabular}

DFI disease free interval, IBTR ipsilateral breast tumor recurrence, $r S N$ repeat sentinel node, LM lymphoscintigram, RT radiotherapy, CT chemotherapy, HT hormone therapy, SN+ sentinel node positive, cALND completion axillary lymph node dissection, ALND axillary lymph node dissection, SN- sentinel node negative, n.a. not available

\section{Comparison of variables between patients with and without regional recurrences as first event after IBTR.}

Comparing patients who developed regional recurrence and those who did not, we did not find significant differences between the groups regarding disease-free interval (DFI), age or tumor size during primary and recurrent breast cancer (Table 7.1). Likewise, there were no significant differences in administration of adjuvant therapy following IBTR between the two patient cohorts.

Of the nine patients with regional recurrence as first event after a negative rSLNB, $55.4 \%$ had a triple-negative recurrent tumor compared with $10.4 \%$ of the patients without regional recurrence as first event $(P=0.002)$. Furthermore, grade III IBTR was found in $55.6 \%$ of patients with regional recurrence compared with $30.7 \%$ of the 
patients without regional recurrence $(P=0.035)$. Lastly, patients with regional recurrence as first event were injected with a significantly lower amount of radioactively labeled tracer $\left({ }^{99 \mathrm{~m}}\right.$ technetium) during rSLNB (median $80.0 \mathrm{MBq}$ ) compared with patients without regional recurrence as first event (median $110.0 \mathrm{MBq})(P=0.044)$ (Table 7.1).

\section{Discussion}

Data from this study showed that the risk of developing regional recurrence after negative rSLNB in patients with IBTR is low. The low relapse rate supports the safety of rSLNB as nodal staging procedure in the IBTR setting.

After median follow-up of 4.7 (range 0.9-12.7) years, regional recurrence occurred in $4.5 \%$ of patients after negative rSLNB. To date, other studies reporting on regional recurrence after negative $\mathrm{rSLNB}$, other than ipsilateral axillary recurrences only, are limited $^{2,12,15-27}$ (Table 7.3). As shown in Table 7.3, the number of patients in all these studies were relatively small; moreover, definitions of regional recurrence could not be deduced from the articles. Therefore, comparison of these results with our regional recurrence rate of $4.5 \%$ could not be made.

In the primary setting, the highest incidence of axillary recurrence occurred between 24 and 42 months. ${ }^{28}$ Recently, Geurts et al. published data about first and second recurrences after curative treatment of primary breast cancer, reporting that the maximum risk of regional recurrence after IBTR was reached within the first year following treatment. ${ }^{29}$ In this study with a median follow-up of 4.7 years, sufficient time has elapsed to assume that, after a relative long follow-up period, the risk of developing regional recurrence after negative rSLNB is low.

In the recent past, performance of ipsilateral ALND in the setting of IBTR was considered as standard care for optimal regional disease control. Therefore, the very low rate of ipsilateral axillary recurrence (1.0\%) after negative rSLNB in this study is most interesting. As shown in Table $7.3,{ }^{2,12,15-27}$ other studies reporting on ipsilateral axillary recurrence after negative rSLNB showed results to vary between $0 \%$ and $9 \%$. Intra et al. published a study on rSLNB with a relatively large number of patients. In that study, an ipsilateral axillary recurrence rate of $3.9 \%$ was described, during median follow-up of 5 years ${ }^{12}$. However, that rate was observed in a cohort of patients with negative repeat sentinel lymph nodes and positive repeat sentinel lymph nodes followed by the performance of CALND.

During introduction of the SLNB procedure in the primary setting, an ipsilateral axillary recurrence rate of $5 \%$ was accepted to replace CALND by SLNB as standard axillary staging tool. ${ }^{30}$ Later on, Wely et al. reported an even lower ipsilateral axillary recurrence rate of $1.6 \%$ after median follow-up of 77 months. ${ }^{28}$ Analogue to these 
percentages, it seems acceptable that the 1.0\% ipsilateral axillary recurrences rate reported herein justifies replacement of ipsilateral ALND by rSLNB in case of clinically node-negative IBTR.

After radiotherapy and surgery of the breast and/or axilla, drainage in rSLNB outside the ipsilateral axilla is described in $18-70 \%$ of patients. ${ }^{3,23,31}$ In this cohort of patients, $48.3 \%$ of the rSLNBs were located in an aberrant lymph node station. With the visualization of aberrant lymph drainage in IBTR patients, it is assumed that rSLNB is a more accurate staging method than an ipsilateral ALND. ${ }^{3}$ Hence, for at least $48 \%$ of our patients, ipsilateral ALND would not have been an accurate staging tool and the aberrant rSNs would have remained unnoticed in absence of rSLNB. With $56 \%$ of patients with regional recurrence having an aberrant $r S N$, it could be hypothesized that one should (re)irradiate aberrant basins on a preventive basis, despite the nodenegative outcome. However, this seems to be overtreatment, since the aberrant regional recurrence rate is very low.

Table 7.3 Articles describing regional recurrence in patients with IBTR and negative repeat sentinel lymph node biopsy, without additional lymph node dissection

\begin{tabular}{|c|c|c|c|c|}
\hline Author & Patients (N) & $\begin{array}{c}\text { Follow-up after IBTR } \\
\text { (Months) }\end{array}$ & $\begin{array}{c}\text { Regional } \\
\text { recurrence }\end{array}$ & $\begin{array}{c}\text { Ipsilateral axillary } \\
\text { recurrence }\end{array}$ \\
\hline Agarwal et al. ${ }^{15}$ & 1 & 25 & $0(0 \%)$ & $0(0 \%)$ \\
\hline Boughey et al. ${ }^{17}$ & 8 & Median 13 (of 13 patients) & - & $0(0 \%)$ \\
\hline Roumen et al. ${ }^{24}$ & 2 & Mean 14 & $0(0 \%)$ & $0(0 \%)$ \\
\hline Barone et al. ${ }^{16}$ & 14 & Mean 15 (of 19 patients) & - & $0(0 \%)$ \\
\hline Port et al. ${ }^{23}$ & 31 & Mean 26.4 (of 115 patients) & - & $0(0 \%)$ \\
\hline Cox et al. ${ }^{18}$ & 36 & Mean 26 (of 56 patients) & - & $0(0 \%)$ \\
\hline Karam et al. ${ }^{20}$ & 7 & Mean 33.3 (of 11 patients) & - & $1 / 7(14.3 \%)$ \\
\hline Kaur et al. ${ }^{22}$ & 3 & Mean 21.6 (of 45 patients) & - & $0(0 \%)$ \\
\hline Derkx et al. $^{2}$ & 2 & Mean 12 & $0(0 \%)$ & $0(0 \%)$ \\
\hline Tokmak et al . ${ }^{25}$ & 5 & Mean 27 (of 6 patients) & $0(0 \%)$ & $0(0 \%)$ \\
\hline Matsumoto et al. ${ }^{27}$ & 26 & Median 40.3 (of 28 patients) & - & $0(0 \%)$ \\
\hline Intra et al. ${ }^{12}$ & 171 & All 60 (of 196 patients) & - & $8 / 212(3.9 \%)^{a}$ \\
\hline Uth et al. ${ }^{26}$ & 47 & Median 38 (of 144 patients) & - & $0(0 \%)$ \\
\hline Karanlik et al. $^{21}$ & 15 & Mean 36 (of 39 patients) & $0(0 \%)$ & $0(0 \%)$ \\
\hline Johnson et al. ${ }^{19}$ & 8 & Median 55.5 (of 12 patients) & $1 / 8(12.5 \%)^{b}$ & $0(0 \%)$ \\
\hline 15 articles & 376 patients & Range $12-60$ (1-3 years) & $1 / 33(3.0 \%)$ & $9 / 376(2.4 \%)$ \\
\hline
\end{tabular}

DFI disease free interval, IBTR ipsilateral breast tumor recurrence. ${ }^{a}$ Intra et. al. including 25 positive rSLNB

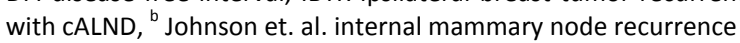

Only the $1 \%$ of patients with ipsilateral axillary recurrence after rSLNB could have had a possible benefit from ALND. The other seven (3.5\%) regional recurrences were found outside the ipsilateral axilla. These aberrant sites of recurrence were in concordance with the site of the harvested rSLNB in three cases. For these patients, the histologic outcome of rSLNB was possibly false negative. In four other patients, the regional recurrence was not concordant with the location of the rSLNB. One explanation could be that rSLNB in IBTR is a technically challenging procedure. As published before, 
injection with a larger amount of tracer leads to a higher identification rate. ${ }^{32}$ In this study, patients with regional recurrence had a significantly lower amount of tracer injected. Injection of a higher tracer dose might have led to the identification of repeat sentinel lymph nodes in additional basins. It could also be hypothesized that lymph drainage of the IBTR might have been multi-directional, and the rSLNB identified only one basin.

In this study, $55.4 \%$ of patients with regional re-recurrences had triple-negative IBTR. Therefore, triple-negative disease seems to be a risk factor for developing regional rerecurrence. Although the numbers are small, these findings are comparable to identified risk factors for regional recurrence after primary SLNB. ${ }^{33,34}$ Patients with estrogen receptor (ER)-negative tumors (in particular, triple-negative tumors) have increased risk of developing regional recurrence after primary SLNB. ${ }^{33,34}$ Clinicians could opt for more aggressive treatment in patients with triple-negative IBTR. In this study, only $17 \%$ of patients with IBTR were treated with adjuvant chemotherapy, while the CALOR trial provided evidence of a beneficial effect of adjuvant systemic treatment on overall and disease-free survival for IBTR, especially ER-negative IBTR. ${ }^{35}$

Some caveats have to be considered regarding this study. Given the small number of regional events, multivariable analyses were inappropriate and limited statistical conclusions could be made. Furthermore, a randomized controlled trial comparing rSLNB with ALND would have been preferable. On the other hand, such a trial would most probably be underpowered due to the low incidence of recurrent breast cancer and regional recurrence after recurrent breast cancer. Despite these limitations, the present study is unique in the fact that follow-up data were available for a large cohort of patients with IBTR and negative rSLNB. No other studies on regional recurrence after negative rSLNB have included such a large patient population. Furthermore, this is a multicenter study, including data from different types of hospital in the Netherlands with different breast cancer volumes. Going forward, further research is encouraged in the field of rSLNB to optimize the prognostic value of this procedure, but on the basis of present evidence, cALND can be safely omitted after negative rSLNB.

\section{Conclusion}

The 5-year risk of developing regional recurrence after negative rSLNB without subsequent ALND in patients with IBTR is less than $5 \%$, with only $1 \%$ being located in the ipsilateral axilla. This low relapse rate provides further evidence that rSLNB is a safe primary staging method in IBTR, in terms of regional recurrence. Based on these data, we suggest to adopt rSLNB as standard of care in IBTR and to omit ipsilateral ALND. 


\section{References}

1. Naik AM, Fey J, Gemignani M, et al. The risk of axillary relapse after sentinel lymph node biopsy for breast cancer is comparable with that of axillary lymph node dissection: a follow-up study of 4008 procedures. Ann Surg. 2004;240(3):462-468; discussion 468-471.

2. Derkx F, Maaskant-Braat AJ, van der Sangen MJ, et al. Staging and management of axillary lymph nodes in patients with local recurrence in the breast or chest wall after a previous negative sentinel node procedure. Eur J Surg Oncol. 2010;36(7):646-651.

3. Vugts G, Maaskant-Braat AJ, Voogd AC, et al. Repeat sentinel node biopsy should be considered in patients with locally recurrent breast cancer. Breast Cancer Res Treat. 2015;153(3):549-556.

4. Maaskant-Braat AJ, Voogd AC, Roumen RM, Nieuwenhuijzen GA. Repeat sentinel node biopsy in patients with locally recurrent breast cancer: a systematic review and meta-analysis of the literature. Breast Cancer Res Treat. 2013;138(1):13-20.

5. Veronesi U, Galimberti V, Paganelli G, et al. Axillary metastases in breast cancer patients with negative sentinel nodes: a follow-up of 3548 cases. Eur J Cancer. 2009;45(8):1381-1388.

6. Veronesi U, Viale G, Paganelli G, et al. Sentinel lymph node biopsy in breast cancer: ten-year results of a randomized controlled study. Ann Surg. 2010;251(4):595-600.

7. Krag DN, Anderson SJ, Julian TB, et al. Sentinel-lymph-node resection compared with conventional axillary-lymph-node dissection in clinically node-negative patients with breast cancer: overall survival findings from the NSABP B-32 randomised phase 3 trial. Lancet Oncol. 2010;11(10):927-933.

8. DiSipio T, Rye $S$, Newman B, Hayes $S$. Incidence of unilateral arm lymphoedema after breast cancer: a systematic review and meta-analysis. Lancet Oncol. 2013;14(6):500-515.

9. Peintinger F, Reitsamer R, Stranzl H, Ralph G. Comparison of quality of life and arm complaints after axillary lymph node dissection vs sentinel lymph node biopsy in breast cancer patients. Br J Cancer. 2003;89(4):648-652.

10. Maaskant-Braat AJ, Roumen RM, Voogd AC, et al. Sentinel Node and Recurrent Breast Cancer (SNARB): results of a nationwide registration study. Ann Surg Oncol. 2013;20(2):620-626.

11. Moossdorff M, van Roozendaal LM, Strobbe LJ, et al. Maastricht Delphi consensus on event definitions for classification of recurrence in breast cancer research. J Natl Cancer Inst. 2014;106(12).

12. Intra M, Viale G, Vila J, et al. Second Axillary Sentinel Lymph Node Biopsy for Breast Tumor Recurrence: Experience of the European Institute of Oncology. Ann Surg Oncol. 2015;22(7):2372-2377.

13. Moossdorff M, Vugts G, Maaskant-Braat AJ, et al. Contralateral lymph node recurrence in breast cancer: Regional event rather than distant metastatic disease. A systematic review of the literature. Eur J Surg Oncol. 2015;41(9):1128-1136.

14. Morcos B, Jaradat I, El-Ghanem M. Characteristics of and therapeutic options for contralateral axillary lymph node metastasis in breast cancer. Eur J Surg Oncol. 2011;37(5):418-421.

15. Agarwal A, Heron DE, Sumkin J, Falk J. Contralateral uptake and metastases in sentinel lymph node mapping for recurrent breast cancer. J Surg Oncol. 2005;92(1):4-8.

16. Barone JL, Feldman SM, Estabrook A, Tartter PI, Rosenbaum Smith SM, Boolbol SK. Reoperative sentinel lymph node biopsy in patients with locally recurrent breast cancer. Am J Surg. 2007;194(4):491-493.

17. Boughey JC, Ross MI, Babiera GV, et al. Sentinel lymph node surgery in locally recurrent breast cancer. Clin Breast Cancer. 2006;7(3):248-253.

18. Cox CE, Furman BT, Kiluk JV, et al. Use of reoperative sentinel lymph node biopsy in breast cancer patients. J Am Coll Surg. 2008;207(1):57-61.

19. Johnson J, Esserman L, Ewing C, Alvarado M, Park C, Fowble B. Sentinel Lymph Node Mapping in PostMastectomy Chest Wall Recurrences: Influence on Radiation Treatment Fields and Outcome. Ann Surg Oncol. 2016;23(3):715-721.

20. Karam A, Stempel M, Cody HS, 3rd, Port ER. Reoperative sentinel lymph node biopsy after previous mastectomy. J Am Coll Surg. 2008;207(4):543-548.

21. Karanlik H, Ozgur I, Kilic B, et al. Sentinel lymph node biopsy and aberrant lymphatic drainage in recurrent breast cancer: Findings likely to change treatment decisions. J Surg Oncol. 2016;114(7): 796-802.

22. Kaur P, Kiluk JV, Meade T, et al. Sentinel lymph node biopsy in patients with previous ipsilateral complete axillary lymph node dissection. Ann Surg Oncol. 2011;18(3):727-732. 
23. Port ER, Garcia-Etienne CA, Park J, Fey J, Borgen PI, Cody IHS. Reoperative sentinel lymph node biopsy: A new frontier in the management of ipsilateral breast tumor recurrence. Ann Surg Oncol. 2007; 14(8):2209-2214.

24. Roumen $\mathrm{RMH}$, Kuijt GP, Liem IH. Lymphatic mapping and sentinel node harvesting in patients with recurrent breast cancer. Eur J Surg Oncol. 2006;32(10):1076-1081.

25. Tokmak H, Kaban K, Muslumanoglu M, Demirel M, Aktan S. Management of sentinel node re-mapping in patients who have second or recurrent breast cancer and had previous axillary procedures. World J Surg Oncol. 2014;12:205.

26. Uth CC, Christensen MH, Oldenbourg MH, et al. Sentinel Lymph Node Dissection in Locally Recurrent Breast Cancer. Ann Surg Oncol. 2015;22(8):2526-2531.

27. Matsumoto A, Jinno H, Nakamura T, et al. Technical feasibility of sentinel lymph node biopsy in patients with ipsilateral breast tumor recurrence and previous axillary surgery. Int J Surg. 2015;22:28-31.

28. van Wely BJ, van den Wildenberg FJ, Gobardhan P, et al. "Axillary recurrences after sentinel lymph node biopsy: a multicentre analysis and follow-up of sentinel lymph node negative breast cancer patients". Eur J Surg Oncol. 2012;38(10):925-931.

29. Geurts YM, Witteveen A, Bretveld R, et al. Patterns and predictors of first and subsequent recurrence in women with early breast cancer. Breast Cancer Res Treat. 2017;165(3):709-720.

30. de Kanter AY, Menke-Pluymers MM, Wouters MW, Burgmans I, van Geel AN, Eggermont AM. 5-Year follow-up of sentinel node negative breast cancer patients. Eur J Surg Oncol. 2006;32(3):282-286.

31. Maaskant-Braat AJ, de Bruijn SZ, Woensdregt K, Pijpers H, Voogd AC, Nieuwenhuijzen GA. Lymphatic mapping after previous breast surgery. Breast. 2012;21(4):444-448.

32. Vugts G, Maaskant-Braat AJ, Voogd AC, et al. Improving the Success Rate of Repeat Sentinel Node Biopsy in Recurrent Breast Cancer. Ann Surg Oncol. 2015;22 Suppl 3:S529-535.

33. Linnaus $M E$, Dueck AC, Kosiorek HE, et al. Regional recurrence in the era of sentinel lymph node biopsy. Am J Surg. 2015;210(6):1155-1160; discussion 1160-1151.

34. Wang J, Xie X, Wang $X$, et al. Locoregional and distant recurrences after breast conserving therapy in patients with triple-negative breast cancer: a meta-analysis. Surgical oncology. 2013;22(4):247-255.

35. Aebi S, Gelber S, Anderson SJ, et al. Chemotherapy for isolated locoregional recurrence of breast cancer (CALOR): a randomised trial. Lancet Oncol. 2014;15(2):156-163. 


\section{Chapter 8}

Low risk of development of a regional recurrence after an unsuccessful repeat sentinel lymph node biopsy in patients with ipsilateral breast tumor recurrence

I.G.M. Poodt, C.J.E.F. Walstra, G. Vugts, A.J.G. Maaskant-Braat, A.C. Voogd, R.J. Schipper, G.A.P. Nieuwenhuijzen On behalf of the Sentinel Node And Recurrent Breast Cancer (SNARB) study group. 


\section{Abstract}

\section{Background}

Unlike sentinel lymph node biopsy (SLNB) in the primary setting, the repeat SLNB (rSLNB) in patients with ipsilateral breast tumor recurrence(IBTR) is challenging, because it is difficult to visualize and/or harvest a sentinel lymph node in every patient. Regional treatments options and safety in terms of regional disease control after such an unsuccessful rSLNB remain unclear. This study assesses factors associated with the performance of axillary lymph node dissection (ALND) after unsuccessful rSLNB and evaluates the occurrence of regional recurrences.

\section{Methods}

Data were obtained from the Sentinel Node and Recurrent Breast Cancer (SNARB) study. In 239 patients, the rSLNB was unsuccessful, of whom 60 patients underwent ipsilateral ALND.

\section{Results}

A shorter time interval between primary treatment and IBTR, and a primary negative SLNB were significantly associated with a higher probability to be treated with ALND after unsuccessful rSLNB $(P<0.001)$.

The 5-year regional-recurrence rate was $0.0 \%$ in the ALND group compared with $3.7 \%$ in the group treated without ALND $(P=0.113)$. Of the 179 patients treated without ALND, after a median follow-up of 5.1 years (range 0.3-13.2), 7 (3.9\%) developed a regional recurrence as first event after unsuccessful rSLNB. None of the seven recurrences occurred in the ipsilateral axilla. Univariable analysis showed no factors associated with regional recurrence as first event after unsuccessful rSLNB $(P>0.05)$.

\section{Conclusions}

The present study demonstrates that the risk of regional recurrence in patients with an IBTR and an unsuccessful rSLNB is negligible, irrespective of the use of ALND. This suggests that there is no need for additional treatment of the axilla after an unsuccessful rSLNB. 


\section{Introduction}

In recent years, repeat sentinel lymph node biopsy (rSLNB) emerged as an axillary staging procedure in patients with ipsilateral breast tumor recurrence (IBTR). Unlike sentinel node biopsy in the primary setting, the procedure in patients with IBTR is challenging. Repeat sentinel node ( $r S N)$ identification is reported to vary between 53 and $93 \%{ }^{1,2}$, with a mean percentage of $63 \%{ }^{3}$ For the remaining patients rSLNB was unsuccessful, which means that no sentinel lymph node could be visualized and/or harvested. Previous treatments of the breast and axilla with surgery and/or radiotherapy have been associated with a more difficult identification of rSLNB. ${ }^{1}$ Scar tissue and post irradiation fibrosis may change the anatomy of breast and axillary lymphatics, whereby lymph vessels may be totally blocked or disrupted ${ }^{4,5}$, increasing the risk of unsuccessful rSLNB procedures. The optimal regional treatment options after an unsuccessful rSLNB are unclear, as its impact on regional disease control.

Previously, in a cohort of IBTR patients who were all successfully staged with a negative rSLNB, safety with respect to regional control was investigated. The 5-year risk of developing regional recurrences after a negative rSLNB without subsequent ALND was less than $5 \%$, and only $1 \%$ was located in the ipsilateral axilla. These low regional relapse rates justified the recommendation to replace ipsilateral ALND by rSLNB in case of a clinically node negative IBTR. ${ }^{6}$ Going forward, Ugras et al. investigated whether the promises of rLSNB, such as improved regional control and better survival, were fulfilled by comparing a group of IBTR patients who had axillary staging versus a group of patients who did not. ${ }^{7}$ No difference in tumor characteristics or treatment of IBTR were observed, and low rates of axillary failure occurred in both groups. Although their sample size was insufficient to exclude small differences particularly in nodal recurrences, they concluded that restaging of the axilla in patients with IBTR is of limited value and that further research in larger cohorts is needed. ${ }^{7}$

Hence, uncertainty exists on the need for and extent of regional treatments, necessary for patients with an unsuccessful rSLNB procedure. Some advocate to perform an ipsilateral ALND or recommend extensive radiotherapy to the closest lymph node basin. This study was designed to assess factors associated with the decision to perform an ALND after unsuccessful rSLNB and to evaluate the risk of regional recurrences as first event after an unsuccessful rSLNB in patients with IBTR, treated with curative intent.

\section{Methods}

\section{SNARB study design}

The Sentinel Node and Recurrent Breast Cancer (SNARB) study is a multicenter national registration study in which 36 Dutch hospitals participated. ${ }^{8,9}$ Patients with clinically apparent (clinical exam and axillary ultrasound) ipsilateral or contralateral axillary 
lymph node metastases and patients with distant metastases at the time of diagnosis of IBTR were excluded. A total of 536 patients with operable locally recurrent breast cancer were staged with rSLNB and included in the SNARB study. ${ }^{8}$ The dual-mapping technique with both ${ }^{99 m}$ techneticum and blue dye was used for all rSLNB procedures. Technical specifications have been reported in detail earlier. ${ }^{1}$

\section{Patients}

A rSLNB was defined as unsuccessful when the sentinel node could not be surgically harvested. All patients with IBTR, breast or chest wall, and an unsuccessful rSLNB were considered eligible for inclusion.

\section{Aims}

First, to explore specific patient and tumor characteristics predictive for the performance of an ALND after unsuccessful rSLNB, a subgroup analysis was done comparing patients who underwent ALND after unsuccessful rSLNB compared with patients who did not undergo ALND. Second, in patients with unsuccessful rSLNB treated with an ALND, factors related to metastatic lymph nodes were evaluated. Third, the occurrence of regional recurrences as first event in patients with unsuccessful rSLNB was investigated between patients treated with and without ALND. Finally, in patients with unsuccessful rSLNB treated without ALND, factors related to regional recurrences as first event after IBTR were explored.

\section{Follow-up}

In 2017, follow-up data of the 536 patients in the SNARB study were collected and entered into the database. General practitioners were actively contacted for additional follow-up information when hospital records showed no outpatient clinic visits for more than 1 year. Date of last follow-up was documented as last visit to the outpatient clinic, date of last visit to the general practitioner or date of death in case the patient had deceased. Follow-up time was defined as the time between date of surgery for IBTR and date of last follow-up. Time to regional recurrence was defined as time between treatment of IBTR and date of diagnosis of regional recurrence as first event after IBTR. Twenty-one patients (4\%) for whom follow-up data were not available due to emigration, lack of information, or withdrawal of informed consent were excluded; 515 patients $(96 \%)$ remained available for analysis.

\section{Definition of regional recurrence}

The primary endpoint of this study was regional lymph node recurrence as first event after curative treatment of an IBTR. A regional recurrence (RR) was defined as any evidence of disease found in ipsilateral intramammary nodes, ipsi- and contralateral 
internal mammary nodes, ipsi- and contralateral axillary nodes, and ipsi- and contralateral infra- and supra-clavicular nodes. ${ }^{6,10}$ In the recently published Maastricht Delphi Consensus statement on the definition of regional events, only ipsilateral nodal recurrences (either axillary or in other ipsilateral nodal basins) were considered as regional recurrences. ${ }^{11}$ Based on earlier rSLNB studies ${ }^{8,12}$, we state that the definition of a regional recurrence after IBTR should be broadened and should also include contralateral nodes, since lymphatic drainage towards these basins is common. ${ }^{2,10,13}$ Therefore, we considered contralateral events as regional recurrences. Lymph node recurrences found outside these nodal basins were defined as distant metastatic disease.

Regional recurrences diagnosed at the same time as or after the appearance of distant recurrences were not recorded, as distant metastatic disease is considered to be the most unfavorable site of relapse, according to a hierarchy of prognosis. ${ }^{14}$ In case of synchronous $L R$ and $R R$, the recurrence was registered as a RR.

\section{Statistics}

The following variables were compared between patients with ALND and without ALND following an unsuccessful rSLNB: age, tumor and axillary surgery, nodal classification, tumor stage, receptor status and adjuvant therapy of primary tumor and IBTR; time interval from primary surgery to IBTR; repeat SN tracer amount. Statistical significance was tested using Pearson Chi square test and Fisher exact test for categorical variables when appropriate. For continuous variables, Mann-Whitney $U$ test or independent samples $t$ test was used when appropriate. The multivariable model was fitted for all significant univariable factors. A two-sided $P$ value of $<0.05$ was considered statistically significant. Survival analysis, using the Kaplan-Meier method, was performed to calculate the 5-year risk of regional recurrences after curative treatment for IBTR, either with or without ALND. Differences were analyzed using the log-rank test. Data analysis was performed using SPSS version 24 (SPSS Inc., Chicago, IL).

\section{Results}

Of the included 515 patients, 239 (46\%) had an unsuccessful rSLNB, of which 60 (25\%) patients underwent ipsilateral ALND. The median age at time of IBTR was 65.0 years (range 29-93). After treatment of IBTR, 160 patients (66.9\%) received adjuvant systemic treatment. Adjuvant endocrine therapy was administered in 140 patients (58.6\%) and adjuvant chemotherapy in 55 (23.0\%) patients. 
Factors related to the performance of ALND in patients with an unsuccessful rSLNB

Table 8.1 presents patient, tumor, and treatment characteristics categorized by patients treated with an ALND and without an ALND after an unsuccessful rSLNB. In univariable analysis, time between primary treatment and diagnosis of IBTR was significantly shorter for patients treated with ALND compared with patients treated without ALND, with a median of 5.2 years versus 14.0 years, respectively $(P<0.001)$. Furthermore, patients treated with ALND were significantly more often staged with a primary negative sentinel lymph node $(P<0.001)$. No significant differences were observed between the groups regarding size, grade or receptor status of the IBTR, nor in the adjuvant treatments following curative treatment of IBTR.

Table 8.1 Clinical-pathological characteristics of all patients with ipsilateral breast tumor recurrence and unsuccessful repeat sentinel lymph node biopsy ( $\mathrm{N}=239)$

\begin{tabular}{|c|c|c|c|c|}
\hline & $\begin{array}{l}\text { Total group: } \\
\text { (N=239) }\end{array}$ & $\begin{array}{l}\text { Additional } \\
\text { lymph node } \\
\text { dissection } \\
(\mathrm{N}=60)\end{array}$ & $\begin{array}{l}\text { No additional } \\
\text { lymph node } \\
\text { dissection } \\
(\mathrm{N}=179)\end{array}$ & $P$ value \\
\hline Age primary tumor, median years (range) & $52.0(25-88)$ & $56.0(33-88)$ & $51.0(27-87)$ & 0.005 \\
\hline Age primary tumor, years & & & & 0.002 \\
\hline$<35$ & $18(7.5 \%)$ & $4(6.7 \%)$ & $14(7.8 \%)$ & \\
\hline $35-59$ & $155(64.9 \%)$ & $29(48.3 \%)$ & $126(70.4 \%)$ & \\
\hline $60-69$ & $54(22.6 \%)$ & $20(33.3 \%)$ & $34(19.0 \%)$ & \\
\hline$\geq 70$ & $12(5.0 \%)$ & $7(11.7 \%)$ & $5(2.8 \%)$ & \\
\hline Primary Surgery & & & & 1.000 \\
\hline Mastectomy & $12(5.0 \%)$ & $3(5.0 \%)$ & $9(5.0 \%)$ & \\
\hline Breast-conserving surgery & $227(95.0 \%)$ & $57(95.0 \%)$ & $170(95.0 \%)$ & \\
\hline Primary SN & & & & $<0.001$ \\
\hline Negative & $74(31.0 \%)$ & $50(83.3 \%)$ & $24(13.4 \%)$ & \\
\hline Positive & $14(5.9 \%)$ & $3(5.0 \%)$ & $11(6.1 \%)$ & \\
\hline No SN & $151(63.2 \%)$ & $7(11.7 \%)$ & $144(80.4 \%)$ & \\
\hline Primary axillary surgery & & & & $<0.001$ \\
\hline No axillary staging & $6(2.5 \%)$ & $2(3.3 \%)$ & $4(2.2 \%)$ & \\
\hline SN-negative & $72(30.1 \%)$ & $50(83.3 \%)$ & $22(12.3 \%)$ & \\
\hline SN-negative, cALND & $2(0.8 \%)$ & $0(0.0 \%)$ & $2(1.1 \%)$ & \\
\hline SN-positive, cALND & $12(5.0 \%)$ & $1(1.7 \%)$ & $11(6.1 \%)$ & \\
\hline SN-positive, no cALND & $2(0.8 \%)$ & $2(3.3 \%)$ & $0(0.0 \%)$ & \\
\hline ALND & $145(60.7 \%)$ & $5(8.3 \%)$ & $140(78.2)$ & \\
\hline Primary nodal status & & & & 0.001 \\
\hline Negative & $172(72.0 \%)$ & $54(90.0 \%)$ & $118(65.9 \%)$ & \\
\hline Positive & $51(21.3 \%)$ & $4(6.7 \%)$ & $47(26.3 \%)$ & \\
\hline Unknown & $16(6.7 \%)$ & $2(3.3 \%)$ & $14(7.8 \%)$ & \\
\hline Primary tumor size (mm) & & & & 0.066 \\
\hline$<20$ & $131(54.8 \%)$ & $39(65.0 \%)$ & $92(51.4 \%)$ & \\
\hline $21-50$ & $39(16.3 \%)$ & $6(10.0 \%)$ & $33(18.4 \%)$ & \\
\hline$>50$ & $1(0.4 \%)$ & $1(1.7 \%)$ & $0(0.0 \%)$ & \\
\hline Unknown & $68(28.5 \%)$ & $14(23.3 \%)$ & $54(30.2 \%)$ & \\
\hline
\end{tabular}


Table $8.1 \quad$ (continued)

\begin{tabular}{|c|c|c|c|c|}
\hline & $\begin{array}{l}\text { Total group: } \\
(\mathrm{N}=239)\end{array}$ & $\begin{array}{l}\text { Additional } \\
\text { lymph node } \\
\text { dissection } \\
(\mathrm{N}=60)\end{array}$ & $\begin{array}{l}\text { No additional } \\
\text { lymph node } \\
\text { dissection } \\
(\mathrm{N}=179)\end{array}$ & $P$ value \\
\hline Primary tumor grade & & & & 0.007 \\
\hline 1 & $35(14.6 \%)$ & $14(23.3 \%)$ & $21(11.7 \%)$ & \\
\hline II & $45(18.8 \%)$ & $17(28.3 \%)$ & $28(15.6 \%)$ & \\
\hline III & $30(12.6 \%)$ & $6(10.0 \%)$ & $24(13.4 \%)$ & \\
\hline Unknown & $129(54.0 \%)$ & $23(38.3 \%)$ & $106(59.2 \%)$ & \\
\hline Receptor status of primary tumor & & & & 0.004 \\
\hline Triple negative & $16(6.7 \%)$ & $5(8.3 \%)$ & $11(6.1 \%)$ & \\
\hline HRneg_Her2pos & $3(1.3 \%)$ & $0(0.0 \%)$ & $3(1.7 \%)$ & \\
\hline Hrpos_Her2pos & $5(2.1 \%)$ & $1(1.7 \%)$ & $4(2.2 \%)$ & \\
\hline HRpos_Her2neg & $45(18.8 \%)$ & $21(35.0 \%)$ & $24(13.4 \%)$ & \\
\hline Unknown & $170(71.1 \%)$ & $33(55.0 \%)$ & $137(76.5 \%)$ & \\
\hline Hormone status primary tumor & & & & 0.002 \\
\hline ER and PR negative & $26(10.9 \%)$ & $8(13.3 \%)$ & $18(10.1 \%)$ & \\
\hline ER/PR positive & $110(46.0 \%)$ & $38(63.3 \%)$ & $72(40.2 \%)$ & \\
\hline Unknown & $103(43.1 \%)$ & $14(23.3 \%)$ & $89(49.7 \%)$ & \\
\hline \multicolumn{5}{|l|}{ Time from primary surgery to IBTR diagnose } \\
\hline Median, months (range) & $146(5-360)$ & $62.0(8-330)$ & $167(5-360)$ & $<0.001$ \\
\hline Median, years (range) & $12.2(0.42-30.0)$ & $6.0(0.7-27.5)$ & $14.0(0.42-30.0)$ & $<0.001$ \\
\hline$<2$ & $14(5.9 \%)$ & $5(8.3 \%)$ & $9(5.0 \%)$ & $<0.001$ \\
\hline $2.1-5$ & $37(15.5 \%)$ & $21(35.0 \%)$ & $26(8.9 \%)$ & \\
\hline $5.1-10$ & $44(18.4 \%)$ & $21(35.0 \%)$ & $23(73.2 \%)$ & \\
\hline$>10$ & $144(60.3 \%)$ & $13(21.7 \%)$ & $131(73.2 \%)$ & \\
\hline Preoperative staging imaging modalities & & & & 0.289 \\
\hline None & $85(35.6 \%)$ & $17(28.3 \%)$ & $68(38.0 \%)$ & \\
\hline Conventional imaging & $115(48.1 \%)$ & $34(56.7 \%)$ & $81(45.3 \%)$ & \\
\hline${ }^{18}$ F-FDG PET-CT & $39(16.3 \%)$ & $9(15.0 \%)$ & $30(16.8 \%)$ & \\
\hline Age IBTR, median years (range) & $65.0(29-93)$ & $64.5(36-93)$ & $66.0(29-92)$ & 0.257 \\
\hline Age IBTR, years & & & & 0.991 \\
\hline$<35$ & $4(1.7 \%)$ & $1(1.7 \%)$ & $3(1.7 \%)$ & \\
\hline $35-59$ & $72(30.1 \%)$ & $19(31.7 \%)$ & $53(29.6 \%)$ & \\
\hline $60-69$ & $80(33.5 \%)$ & $20(33.3 \%)$ & $60(33.5 \%)$ & \\
\hline$\geq 70$ & $83(34.7 \%)$ & $20(33.3 \%)$ & $63(35.2 \%)$ & \\
\hline Location IBTR & & & & 1.000 \\
\hline Breast & 227 (95.0\%) & $57(95.0 \%)$ & $170(95.0 \%)$ & \\
\hline Mastectomy scar or chest wall & $12(5.0 \%)$ & $3(5.0 \%)$ & $9(5.0 \%)$ & \\
\hline Repeat SN aberrant LM & & & & 0.062 \\
\hline Yes & $39(16.3 \%)$ & $4(6.7 \%)$ & 35 (19.6\%) & \\
\hline No & $23(9.6 \%)$ & $7(11.7 \%)$ & $16(8.9 \%)$ & \\
\hline No successful LM & $177(74.1 \%)$ & $49(81.7 \%)$ & $128(71.5 \%)$ & \\
\hline $\begin{array}{l}\text { Repeat SN tracer amount, MBq median } \\
\text { (range) }\end{array}$ & $100.0(19-219)$ & $100.5(20-177)$ & $100(19-219)$ & 0.656 \\
\hline Tumor size IBTR (mm) & & & & 0.464 \\
\hline$<20$ & $163(68.2 \%)$ & $41(68.3 \%)$ & $122(68.2 \%)$ & \\
\hline $21-50$ & $59(24.7 \%)$ & $17(28.3 \%)$ & $42(23.5 \%)$ & \\
\hline$>50$ & $5(2.1 \%)$ & $0(0.0 \%)$ & $5(2.8 \%)$ & \\
\hline Unknown & $12(5.0 \%)$ & $2(3.3 \%)$ & $10(5.6 \%)$ & \\
\hline
\end{tabular}


Table $8.1 \quad$ (continued)

\begin{tabular}{|c|c|c|c|c|}
\hline & $\begin{array}{l}\text { Total group: } \\
(\mathrm{N}=239)\end{array}$ & $\begin{array}{l}\text { Additional } \\
\text { lymph node } \\
\text { dissection } \\
(\mathrm{N}=60)\end{array}$ & $\begin{array}{l}\text { No additional } \\
\text { lymph node } \\
\text { dissection } \\
(\mathrm{N}=179)\end{array}$ & $P$ value \\
\hline Tumor grade IBTR & & & & 0.320 \\
\hline 1 & $52(21.8 \%)$ & $9(15.0 \%)$ & $43(24.0 \%)$ & \\
\hline II & $107(44.8 \%)$ & $26(43.3 \%)$ & $81(45.3 \%)$ & \\
\hline III & $69(28.9 \%)$ & $21(35.0 \%)$ & $48(26.8 \%)$ & \\
\hline Unknown & $11(4.6 \%)$ & $4(6.7 \%)$ & $7(3.9 \%)$ & \\
\hline Receptor status IBTR & & & & 0.904 \\
\hline Triple negative & $36(15.1 \%)$ & 9 (15.0\%) & $27(15.1 \%)$ & \\
\hline HRneg_Her2pos & $9(3.8 \%)$ & $3(5.0 \%)$ & $6(3.4 \%)$ & \\
\hline Hrpos_Her2pos & $15(6.3 \%)$ & $4(6.7 \%)$ & $11(6.1 \%)$ & \\
\hline HRpos_Her2neg & $161(67.4 \%)$ & $41(68.3 \%)$ & $120(67.0 \%)$ & \\
\hline Unknown & $18(7.5 \%)$ & $3(5.0 \%)$ & $15(8.4 \%)$ & \\
\hline Radiotherapy IBTR & & & & 0.553 \\
\hline Yes & $41(17.2 \%)$ & $12(20.0 \%)$ & $29(16.2 \%)$ & \\
\hline No & $198(82.8 \%)$ & $48(80.0 \%)$ & $150(83.8 \%)$ & \\
\hline Systemic therapy IBTR & & & & 0.875 \\
\hline Yes & $160(66.9 \%)$ & $19(31.7 \%)$ & $60(33.5 \%)$ & \\
\hline No & 79 (33.1\%) & $41(68.3 \%)$ & 119 (66.5\%) & \\
\hline Endocrine therapy IBTR & & & & 0.547 \\
\hline Yes & $140(58.6 \%)$ & 33 (55.0\%) & 107 (59.8\%) & \\
\hline No & 99 (41.4\%) & 27 (45.0\%) & $72(40.2 \%)$ & \\
\hline Chemotherapy IBTR & & & & 0.724 \\
\hline Yes & $55(23.0 \%)$ & $15(25.0 \%)$ & $40(22.3 \%)$ & \\
\hline No & $184(770 \%)$ & $45(75.0 \%)$ & $139(77.7 \%)$ & \\
\hline
\end{tabular}

Univariable analysis compared patients with ipsilateral axillary lymph node dissection $(\mathrm{N}=60)$ and patients with no axillary lymph node dissection ( $\mathrm{N}=179$ ). IBTR ipsilateral breast tumor recurrence, ALND axillary lymph node dissection, calmed completion axillary lymph node dissection, $\mathrm{SN}$ sentinel node, mm millimeter, HR hormone receptor, ER estrogen, PR progesterone, MBq mega becquerel, Her2 human epidermal growth receptor 2 , neg negative, pos positive

Factors related to metastatic lymph nodes in patients with unsuccessful rSLNB treated with an ALND

In $52(87 \%)$ of the 60 patients, ALND revealed no involved lymph nodes. In the other eight patients (13\%) macrometastases were found in one or more lymph nodes. Univariable analysis showed no significant differences between the groups with or without positive lymph nodes regarding patient and tumor characteristics. Patients with positive lymph nodes were treated more often with radiotherapy compared to patients with negative lymph nodes: $50.0 \%$ versus $15.4 \%$, respectively $(P=0.043)$. Adjuvant chemotherapy was administered to $50.0 \%$ of the patients with positive lymph nodes versus $21.2 \%$ to patients with negative lymph nodes ( $P=0.098$ ) (Table 8.2 ). 
Table 8.2 Clinical-pathological characteristics of all patients with an ipsilateral breast tumor recurrence and unsuccessful repeat sentinel lymph node biopsy who all underwent axillary lymph node dissection $(\mathrm{N}=60)$. Univariable analysis compared patients with node-positive axillary lymph node dissection $(\mathrm{N}=8)$ and patients with node-negative axillary lymph node dissection $(\mathrm{N}=52)$

\begin{tabular}{|c|c|c|c|c|}
\hline & $\begin{array}{l}\text { Total group: } \\
(\mathrm{N}=60)\end{array}$ & $\begin{array}{c}\text { Node positive } \\
\text { ALND }(\mathrm{N}=8)\end{array}$ & $\begin{array}{l}\text { Node negative } \\
\text { ALND }(\mathrm{N}=52)\end{array}$ & $P$-value \\
\hline Age primary tumor, median years (range) & $56.0(33-88)$ & $50.0(35-60)$ & $59.5(25-88)$ & 0.080 \\
\hline Age primary tumor, years & & & & 0.120 \\
\hline$<35$ & $4(6.7 \%)$ & $0(0.0 \%)$ & $4(7.7 \%)$ & \\
\hline $35-59$ & $29(48.3 \%)$ & $7(87.5 \%)$ & $22(42.3 \%)$ & \\
\hline $60-69$ & $20(33.3 \%)$ & $1(12.5 \%)$ & $19(36.5 \%)$ & \\
\hline$\geq 70$ & $7(11.7 \%)$ & $0(0.0 \%)$ & $7(13.5 \%)$ & \\
\hline Primary Surgery & & & & 1.000 \\
\hline Mastectomy & $3(5.0 \%)$ & $0(0.0 \%)$ & $3(5.8 \%)$ & \\
\hline Breast-conserving surgery & $57(95.0 \%)$ & $8(100 \%)$ & $49(94.2 \%)$ & \\
\hline Primary SN & & & & 0.378 \\
\hline Negative & $50(83.3 \%)$ & $6(75.0 \%)$ & $44(84.6 \%)$ & \\
\hline Positive & $3(5.0 \%)$ & $0(0.0 \%)$ & $3(5.8 \%)$ & \\
\hline No SN & $7(11.7 \%)$ & $2(25.0 \%)$ & $5(9.6 \%)$ & \\
\hline Primary axillary surgery & & & & 0.548 \\
\hline No axillary staging & $2(3.3 \%)$ & $1(12.5 \%)$ & $1(1.9 \%)$ & \\
\hline SN-negative & $44(73.3 \%)$ & $0(0.0 \%)$ & $44(84.6 \%)$ & \\
\hline SN-negative, cALND & $6(10.0 \%)$ & $6(75.0 \%)$ & $0(0.0 \%)$ & \\
\hline SN-positive, cALND & $1(1.7 \%)$ & $0(0.0 \%)$ & $1(1.9 \%)$ & \\
\hline SN-positive, no cALND & $2(3.3 \%)$ & $0(0.0 \%)$ & $2(3.8 \%)$ & \\
\hline ALND & $5(8.3 \%)$ & $1(12.5 \%)$ & $4(7.7 \%)$ & \\
\hline Primary nodal status & & & & 0.229 \\
\hline Negative & $54(90.0 \%)$ & $7(87.5 \%)$ & $47(90.4 \%)$ & \\
\hline Positive & $4(6.7 \%)$ & $0(0.0 \%)$ & $4(7.7 \%)$ & \\
\hline Unknown & $2(3.3 \%)$ & $1(12.5 \%)$ & $1(1.9 \%)$ & \\
\hline Primary tumor size & & & & 0.723 \\
\hline$<20 \mathrm{~mm}$ & $39(65.0 \%)$ & $4(50.0 \%)$ & $35(67.3 \%)$ & \\
\hline $21-50 \mathrm{~mm}$ & $6(10.0 \%)$ & $1(12.5 \%)$ & $5(9.6 \%)$ & \\
\hline$>50 \mathrm{~mm}$ & $1(1.7 \%)$ & $0(0.0 \%)$ & $1(1.9 \%)$ & \\
\hline Unknown & $14(23.3 \%)$ & $3(37.5 \%)$ & $11(21.2 \%)$ & \\
\hline Primary tumor grade & & & & 0.730 \\
\hline I & $14(23.3 \%)$ & $2(25.0 \%)$ & $12(23.1 \%)$ & \\
\hline II & $17(28.3 \%)$ & $2(25.0 \%)$ & $15(28.8 \%)$ & \\
\hline III & $6(10.0 \%)$ & $0(0.0 \%)$ & $6(11.5 \%)$ & \\
\hline Unknown & $23(38.3 \%)$ & $4(50.0 \%)$ & $19(36.5 \%)$ & \\
\hline Receptor status of primary tumor & & & & 0.602 \\
\hline Triple negative & $5(8.3 \%)$ & $0(0.0 \%)$ & $5(9.5 \%)$ & \\
\hline HRneg_Her2pos & $0(0.0 \%)$ & $0(0.0 \%)$ & $0(0.0 \%)$ & \\
\hline Hrpos_Her2pos & $1(1.7 \%)$ & $0(0.0 \%)$ & $1(1.9 \%)$ & \\
\hline HRpos_Her2neg & $21(35.0 \%)$ & $2(25.0 \%)$ & $19(36.5 \%)$ & \\
\hline Unknown & $33(55.0 \%)$ & $6(75 \%)$ & $27(51.9 \%)$ & \\
\hline Hormone status primary tumor & & & & 0.363 \\
\hline ER and PR negative & $8(13.3 \%)$ & $0(0.0 \%)$ & $8(15.4 \%)$ & \\
\hline ER/PR positive & $38(63.3 \%)$ & $5(62.5 \%)$ & $33(63.5 \%)$ & \\
\hline Unknown & $14(23.3 \%)$ & $3(37.5 \%)$ & $11(21.2 \%)$ & \\
\hline
\end{tabular}


Table 8.2 (continued)

\begin{tabular}{|c|c|c|c|c|}
\hline & $\begin{array}{l}\text { Total group: } \\
(\mathrm{N}=60)\end{array}$ & $\begin{array}{l}\text { Node positive } \\
\text { ALND }(\mathrm{N}=8)\end{array}$ & $\begin{array}{l}\text { Node negative } \\
\text { ALND }(\mathrm{N}=52)\end{array}$ & $P$-value \\
\hline \multicolumn{5}{|l|}{$\begin{array}{l}\text { Time from primary surgery to IBTR } \\
\text { diagnose }\end{array}$} \\
\hline Median, months (range) & $62.0(8-330)$ & $60.0(8-330)$ & $96.5(50-226)$ & 0.094 \\
\hline Median, years (range) & $6.0(0.7-27.5)$ & $5.02(0.7-27.5)$ & $8.06(4.2-18.9)$ & 0.094 \\
\hline$<2$ years & $5(8.3 \%)$ & $0(0.0 \%)$ & $5(9.6 \%)$ & 0.083 \\
\hline 2.1- 5 years & $21(35.0 \%)$ & $1(12.5 \%)$ & $20(38.5 \%)$ & \\
\hline $5.1-10$ years & $21(35.0 \%)$ & $6(75.0 \%)$ & $15(28.8 \%)$ & \\
\hline$>10$ years & $13(21.7 \%)$ & $1(12.5 \%)$ & $12(23.1 \%)$ & \\
\hline Age IBTR, median years (range) & $64.5(36-93)$ & $66.5(26-93)$ & $59.5(44-70)$ & 0.219 \\
\hline Age IBTR, years & & & & 0.497 \\
\hline$<35$ & $1(1.7 \%)$ & $0(0.0 \%)$ & $1(1.9 \%)$ & \\
\hline $35-59$ & $19(31.7 \%)$ & $4(50.0 \%)$ & $15(28.8 \%)$ & \\
\hline $60-69$ & $20(33.3 \%)$ & $3(37.5 \%)$ & $17(32.7 \%)$ & \\
\hline$\geq 70$ & $20(33.3 \%)$ & $1(12.5 \%)$ & $19(36.5 \%)$ & \\
\hline Location IBTR & & & & 1.000 \\
\hline Breast & $57(95.0 \%)$ & $8(100.0 \%)$ & $49(94.2 \%)$ & \\
\hline Mastectomy scar or chest wall & $3(5.0 \%)$ & $0(0.0 \%)$ & $3(5.8 \%)$ & \\
\hline Repeat SN aberrant LM & & & & 0.355 \\
\hline Yes & $4(6.7 \%)$ & $0(0.0 \%)$ & $4(7.7 \%)$ & \\
\hline No & $7(11.7 \%)$ & $2(25.0 \%)$ & $5(9.6 \%)$ & \\
\hline No successful LM & $49(81.7 \%)$ & $6(75.0 \%)$ & $43(82.7 \%)$ & \\
\hline Repeat SN tracer amount, MBq median (range) & $100.5(20-177)$ & $110.5(46.8-177.0)$ & $100.0(20.0-172.0)$ & 0.458 \\
\hline Tumor size IBTR & & & & 0.318 \\
\hline$<20 \mathrm{~mm}$ & $41(68.3 \%)$ & $4(50.0 \%)$ & $37(71.2 \%)$ & \\
\hline $21-50 \mathrm{~mm}$ & $17(28.3 \%)$ & $4(50.0 \%)$ & $13(25.0 \%)$ & \\
\hline$>50 \mathrm{~mm}$ & $0(0.0 \%)$ & $0(0.0 \%)$ & $0(0.0 \%)$ & \\
\hline Unknown & $2(3.3 \%)$ & $0(0.0 \%)$ & $2(3.8 \%)$ & \\
\hline Tumor grade IBTR & & & & 0.295 \\
\hline 1 & $9(15.0 \%)$ & $2(50.0 \%)$ & $7(13.5 \%)$ & \\
\hline II & $26(43.3 \%)$ & $1(12.5 \%)$ & $25(48.1 \%)$ & \\
\hline III & $21(35.0 \%)$ & $4(50.0 \%)$ & $17(32.7 \%)$ & \\
\hline Unknown & $4(6.7 \%)$ & $1(12.5 \%)$ & $3(5.8 \%)$ & \\
\hline Receptor status IBTR & & & & 0.696 \\
\hline Triple negative & $9(15.0 \%)$ & $1(12.5 \%)$ & $8(15.4 \%)$ & \\
\hline HRneg_Her2pos & $3(5.0 \%)$ & $1(12.5 \%)$ & $2(3.8 \%)$ & \\
\hline Hrpos_Her2pos & $4(6.7 \%)$ & $0(0.0 \%)$ & $4(7.7 \%)$ & \\
\hline HRpos_Her2neg & $41(68.3 \%)$ & $6(75.0 \%)$ & $35(67.3 \%)$ & \\
\hline Unknown & $3(5.0 \%)$ & $0(0.0 \%)$ & $3(5.8 \%)$ & \\
\hline Radiotherapy IBTR & & & & 0.043 \\
\hline Yes & $12(20.0 \%)$ & $4(50.0 \%)$ & $8(15.4 \%)$ & \\
\hline No & $48(80.0 \%)$ & $4(50.0 \%)$ & $44(84.6 \%)$ & \\
\hline Systemic therapy IBTR & & & & 0.416 \\
\hline Yes & $19(31.7 \%)$ & $7(87.5 \%)$ & $34(65.4 \%)$ & \\
\hline No & $41(68.3 \%)$ & $1(12.5 \%)$ & $18(36.4 \%)$ & \\
\hline
\end{tabular}


Table 8.2 (continued)

\begin{tabular}{|c|c|c|c|c|}
\hline & $\begin{array}{l}\text { Total group: } \\
\quad(\mathrm{N}=60)\end{array}$ & $\begin{array}{l}\text { Node positive } \\
\text { ALND }(\mathrm{N}=8)\end{array}$ & $\begin{array}{l}\text { Node negative } \\
\text { ALND }(\mathrm{N}=52)\end{array}$ & $P$-value \\
\hline Endocrine therapy IBTR & & & & 0.719 \\
\hline Yes & $33(55.0 \%)$ & $5(62.5 \%)$ & $28(53.8 \%)$ & \\
\hline No & $27(45.0 \%)$ & $3(37.5 \%)$ & $24(46.2 \%)$ & \\
\hline Chemotherapy IBTR & & & & 0.098 \\
\hline Yes & $15(25.0 \%)$ & $4(50.0 \%)$ & $11(21.2 \%)$ & \\
\hline No & $45(75.0 \%)$ & $4(50.0 \%)$ & $41(78.8 \%)$ & \\
\hline
\end{tabular}

IBTR ipsilateral breast tumor recurrence, ALND axillary lymph node dissection, cALND completion axillary lymph node dissection, $\mathrm{SN}$ sentinel node, $\mathrm{mm}$ millimeter, HR hormone receptor, ER estrogen, PR progesterone, MBq mega becquerel, Her2 human epidermal growth receptor 2, neg negative, pos positive

\section{Regional recurrences in patients treated with ALND and patients treated without ALND after unsuccessful rSLNB}

With a median follow-up of 5.1 (range 0.3-13.2) years from IBTR, none of the patients treated with ALND after unsuccessful rSLNB experienced regional recurrence as first event after IBTR compared with seven patients (3.9\%) in the group of patients treated with no ALND after unsuccessful rSLNB. The 5-year actuarial regional recurrence rate was $0.0 \%$ in the ALND group compared with $3.7 \%$ (95\% confidence interval $(\mathrm{Cl})$ 0.6-7.4) in the group treated without ALND $(P=0.113)$. Furthermore, the 5-year disease free survival was $90.8 \%(95 \% \mathrm{Cl} 85.9-95.7)$ in the ALND group compared with $91.1 \%(95 \% \mathrm{Cl}$ 83.7-98.5) in the group treated without ALND ( $P=0.980)$

Of the seven patients with regional recurrence, none experienced regional recurrence in the ipsilateral axilla, resulting in an ipsilateral axillary recurrence rate of $0.0 \%$. Five patients experienced regional recurrences in the contralateral axilla: one patient in the contralateral infraclavicular basin, and in one patient regional recurrences were found in multiple basins (bilaterally supra- and infraclavicular) (Table 8.3). In one patient, the occurrence of the contralateral regional recurrence was in concordance with the site of rSLNB on lymphoscintigraphy. At time of IBTR, a contralateral ALND was not performed due to the age of the patient and more than two comorbidities. In the other six patients, no lymph nodes were visualized during lymphoscintigraphy. 
Table 8.3 Regional recurrences after an unsuccessful repeat sentinel lymph node biopsy, without additional lymph node dissection.

\begin{tabular}{|c|c|c|c|c|c|c|}
\hline $\begin{array}{l}\text { Regional } \\
\text { recurrence }\end{array}$ & $\begin{array}{l}\text { Follow-up } \\
\text { IBTR } \\
\text { (Months) } \\
\end{array}$ & rSN location LM & $\begin{array}{l}\text { DFI } 1^{\text {st- }} 2^{\text {nd }} \\
\text { tumor } \\
\text { (Months) } \\
\end{array}$ & $\begin{array}{l}\text { Primary } \\
\text { axillary } \\
\text { staging } \\
\end{array}$ & $\begin{array}{c}\text { Primary } \\
\text { adjuvant (RT, } \\
\mathrm{CT}, \mathrm{HT} \text { ) } \\
\end{array}$ & $\begin{array}{c}\text { IBTR } \\
\text { adjuvant (CT, } \\
\text { RT, HT) } \\
\end{array}$ \\
\hline $\begin{array}{l}\text { Contralateral } \\
\text { axilla }\end{array}$ & 15 & No LM & 6 & $\mathrm{SN}+, \mathrm{cALND}$ & $\mathrm{RT}, \mathrm{HT}$ & HT \\
\hline $\begin{array}{l}\text { Contralateral } \\
\text { axilla }\end{array}$ & 61 & $\begin{array}{c}\text { Contralateral } \\
\text { axilla }\end{array}$ & 19 & ALND & RT & HT \\
\hline $\begin{array}{l}\text { Contralateral } \\
\text { axilla }\end{array}$ & 26 & No LM & 13 & ALND & RT & None \\
\hline $\begin{array}{l}\text { Contralateral } \\
\text { axilla }\end{array}$ & 32 & No LM & 24 & ALND & $\begin{array}{l}\text { RT (unknown } \\
\text { region), } \\
\text { unknown CT, } \\
\text { HT }\end{array}$ & HT \\
\hline $\begin{array}{l}\text { Contralateral } \\
\text { axilla }\end{array}$ & 17 & No LM & 18 & ALND & $\mathrm{RT}$ & HT \\
\hline $\begin{array}{l}\text { Contralateral } \\
\text { infraclavicular }\end{array}$ & 25 & No LM & 14 & No staging & $\begin{array}{l}\text { RT (ipsilateral } \\
\text { axillar) }\end{array}$ & None \\
\hline $\begin{array}{l}\text { Contralateral, } \\
\text { ipsilateral infra / } \\
\text { supraclavicular }\end{array}$ & 25 & No LM & 19 & ALND & RT, HT & CT \\
\hline
\end{tabular}

DFI disease free interval, IBTR ipsilateral breast tumor recurrence, $r S N$ repeat sentinel node, LM lymphoscintigram, RT radiotherapy, CT chemotherapy, HT hormone therapy, SN+ sentinel node positive, CALND completion axillary lymph node dissection, ALND axillary lymph node dissection, SN- sentinel node negative, n.a. not available

Four of the seven regional recurrence patients presented with a symptomatic RR (i.e., patients visited the outpatient clinic with lymph node swelling or other localized complaints in an interval between planned follow-up moments or after follow-up was already terminated). The other three recurrences were detected during routine followup; one patient during scheduled echography, one patient during scheduled breast magnetic resonance imaging, and one patient during scheduled positron emission tomography scan.

All seven patients with a regional recurrence received adjuvant radiotherapy during the treatment of their primary breast cancer (five to the breast only, one to the ipsilateral axilla, and for one patient the extension of adjuvant radiotherapy was unknown), and none of them received re-irradiation after IBTR. The patient treated with adjuvant radiotherapy to the ipsilateral axilla experienced a regional recurrence in the contralateral axilla (Table 8.3).

\section{Adjuvant radiotherapy for patients with unsuccessful rSLNB treated without ALND}

Of all patients with an unsuccessful rSLNB treated without ALND, 167 (93.3\%) were primarily treated with adjuvant radiotherapy and for two patients (1.1\%) information regarding primary adjuvant radiotherapy was unknown. Besides radiotherapy to the 
breast, 10 patients were also treated with adjuvant radiotherapy to the axilla and/or regional basins of which eight patients to the ipsilateral axilla and supraclavicular region, one to the supraclavicular region and one to the ipsilateral axilla. Information of adjuvant radiotherapy to the regional basins was unknown in 76 patients, of which one experienced a regional recurrence after IBTR (Table 8.4).

Table 8.4 Clinical-pathological characteristics of all patients with ipsilateral breast tumor recurrence and unsuccessful repeat sentinel lymph node biopsy, without additional lymph node dissection $(\mathrm{N}=179)$

\begin{tabular}{|c|c|c|c|c|}
\hline & $\begin{array}{l}\text { Total group: } \\
\qquad(\mathrm{N}=179)\end{array}$ & $\begin{array}{l}\text { Regional } \\
\text { recurrence } \\
(\mathrm{N}=7)\end{array}$ & $\begin{array}{l}\text { No regional } \\
\text { recurrence } \\
(\mathrm{N}=172)\end{array}$ & $P$ value \\
\hline Age primary tumor, median years (range) & $51.0(27-87)$ & $54.0(37-67)$ & $51.0(27-87)$ & 0.598 \\
\hline Age primary tumor, years & & & & 0.777 \\
\hline$<35$ & $14(7.8 \%)$ & $0(0.0 \%)$ & $14(8.1 \%)$ & \\
\hline $35-59$ & $126(70.4 \%)$ & $6(85.7 \%)$ & $120(69.8 \%)$ & \\
\hline $60-69$ & $34(19.0 \%)$ & $1(14.3 \%)$ & $33(19.2 \%)$ & \\
\hline$\geq 70$ & $5(2.8 \%)$ & $0(0.0 \%)$ & $5(2.9 \%)$ & \\
\hline Primary Surgery & & & & 1.000 \\
\hline Mastectomy & $9(5.0 \%)$ & $0(0.0 \%)$ & $9(5.2 \%)$ & \\
\hline Breast-conserving surgery & $170(95.0 \%)$ & $7(100.0 \%)$ & $163(94.8 \%)$ & \\
\hline Primary SN & & & & 0.409 \\
\hline Negative & $24(13.4 \%)$ & $0(0.0 \%)$ & $24(14.0 \%)$ & \\
\hline Positive & $11(6.1 \%)$ & $1(14.3 \%)$ & $10(5.8 \%)$ & \\
\hline No SN & $144(80.4 \%)$ & $6(85.7 \%)$ & $138(80.2 \%)$ & \\
\hline Primary axillary surgery & & & & 0.162 \\
\hline No axillary staging & $4(2.2 \%)$ & $1(14.3 \%)$ & $3(1.7 \%)$ & \\
\hline SN-negative & $22(12.3 \%)$ & $0(0.0 \%)$ & $22(12.8 \%)$ & \\
\hline SN-negative, cALND & $2(1.1 \%)$ & $0(0.0 \%)$ & $2(1.2 \%)$ & \\
\hline SN-positive, cALND & $11(6.1 \%)$ & $1(14.3 \%)$ & $10(5.8 \%)$ & \\
\hline SN-positive, no cALND & $0(0.0 \%)$ & $0(0.0 \%)$ & $0(0.0 \%)$ & \\
\hline ALND & $140(78.2)$ & $5(71.4 \%)$ & $135(78.5 \%)$ & \\
\hline Primary nodal status & & & & 0.106 \\
\hline Negative & $118(65.9 \%)$ & $4(57.1 \%)$ & $114(66.3 \%)$ & \\
\hline Positive & $47(26.3 \%)$ & $1(14.3 \%)$ & $46(26.7 \%)$ & \\
\hline Unknown & $14(7.8 \%)$ & $2(28.6 \%)$ & $12(7.0 \%)$ & \\
\hline Primary tumor size (mm) & & & & 0.941 \\
\hline$<20$ & $92(51.4 \%)$ & $4(57.1 \%)$ & $80(51.2 \%)$ & \\
\hline $21-50$ & $33(18.4 \%)$ & $1(14.3 \%)$ & $32(18.6 \%)$ & \\
\hline$>50$ & $0(0.0 \%)$ & $0(0.0 \%)$ & $0(0.0 \%)$ & \\
\hline Unknown & $54(30.2 \%)$ & $2(28.6 \%)$ & $52(30.2 \%)$ & \\
\hline Primary tumor grade & & & & 0.425 \\
\hline 1 & $21(11.7 \%)$ & $0(0.0 \%)$ & $21(12.2 \%)$ & \\
\hline II & $28(15.6 \%)$ & $2(28.6 \%)$ & $26(15.1 \%)$ & \\
\hline III & $24(13.4 \%)$ & $0(0.0 \%)$ & $24(14.0 \%)$ & \\
\hline Unknown & $106(59.2 \%)$ & $5(71.4 \%)$ & $101(58.7 \%)$ & \\
\hline Receptor status of primary tumor & & & & 0.894 \\
\hline Triple negative & $11(6.1 \%)$ & $1(14.3 \%)$ & $10(5.8 \%)$ & \\
\hline HRneg_Her2pos & $3(1.7 \%)$ & $0(0.0 \%)$ & $3(1.7 \%)$ & \\
\hline Hrpos_Her2pos & $4(2.2 \%)$ & $0(0.0 \%)$ & $4(2.3 \%)$ & \\
\hline HRpos_Her2neg & $24(13.4 \%)$ & $1(14.3 \%)$ & $23(13.4 \%)$ & \\
\hline Unknown & $137(76.5 \%)$ & $5(71.4 \%)$ & $132(76.7 \%)$ & \\
\hline
\end{tabular}


Table 8.4 (continued)

\begin{tabular}{|c|c|c|c|c|}
\hline & $\begin{array}{l}\text { Total group: } \\
\qquad(\mathrm{N}=179)\end{array}$ & $\begin{array}{l}\text { Regional } \\
\text { recurrence } \\
(\mathrm{N}=7)\end{array}$ & $\begin{array}{l}\text { No regional } \\
\text { recurrence } \\
(\mathrm{N}=\mathbf{1 7 2})\end{array}$ & $P$ value \\
\hline Hormone status primary tumor & & & & 0.361 \\
\hline ER and PR negative & $18(10.1 \%)$ & $1(14.3 \%)$ & $17(9,9 \%)$ & \\
\hline ER/PR positive & $72(40.2 \%)$ & $1(14.3 \%)$ & $71(41.3 \%)$ & \\
\hline Unknown & 89 (49.7\%) & $5(71.4 \%)$ & $84(48.8 \%)$ & \\
\hline \multicolumn{5}{|l|}{ Time from primary surgery to IBTR diagnose } \\
\hline Median, months (range) & $167(5-360)$ & $165(68-284)$ & $170(5-360)$ & 0.376 \\
\hline Median, years (range) & $14.0(0.42-30.0)$ & $13.8(5.7-23.8)$ & $14.2(0.42-30.0)$ & 0374 \\
\hline$<2$ & $9(5.0 \%)$ & $0(0.0 \%)$ & $9(5.2 \%)$ & 0.754 \\
\hline $2.1-5$ & $26(8.9 \%)$ & $0(0.0 \%)$ & $16(9.3 \%)$ & \\
\hline $5.1-10$ & $23(73.2 \%)$ & $1(14.3 \%)$ & $22(12.8 \%)$ & \\
\hline$>10$ & $131(73.2 \%)$ & $6(85.7 \%)$ & $125(72.7 \%)$ & \\
\hline Age IBTR, median years (range) & $66.0(29-92)$ & $68.1(60-75)$ & $66.0(29-92)$ & 0.209 \\
\hline Age IBTR, years & & & & 0.325 \\
\hline$<35$ & $3(1.7 \%)$ & $0(0.0)$ & $3(1.7 \%)$ & \\
\hline $35-59$ & $53(29.6 \%)$ & $0(0.0 \%)$ & $53(30.8 \%)$ & \\
\hline $60-69$ & $60(33.5 \%)$ & $3(42.9 \%)$ & $57(33.1 \%)$ & \\
\hline$\geq 70$ & $63(35.2 \%)$ & $4(57.1 \%)$ & $59(34.3 \%)$ & \\
\hline Location IBTR & & & & 1.000 \\
\hline Breast & $170(95 \%)$ & $7(100.0 \%)$ & $163(94.8 \%)$ & \\
\hline Mastectomy scar or chest wall & $9(5.0 \%)$ & $0(0.0 \%)$ & $9(5.2 \%)$ & \\
\hline Repeat SN aberrant LM & & & & 0.619 \\
\hline Yes & 35 (19.6\%) & $1(14.3 \%)$ & $34(19.8 \%)$ & \\
\hline No & $16(8.9 \%)$ & $0(0.0 \%)$ & $16(9.3 \%)$ & \\
\hline No successful LM & $128(71.5 \%)$ & $6(85.7 \%)$ & $122(70.9 \%)$ & \\
\hline Repeat SN tracer amount, MBq median (range) & $100(19-219)$ & $100.0(21-198)$ & $100.0(19-219)$ & 0.827 \\
\hline Tumor size IBTR (mm) & & & & 0.255 \\
\hline$<20$ & $122(68.2 \%)$ & $4(57.1 \%)$ & $118(68.6 \%)$ & \\
\hline $21-50$ & $42(23.5 \%)$ & $2(28.6 \%)$ & $40(23.3 \%)$ & \\
\hline 50 & $5(2.8 \%)$ & $1(14.3 \%)$ & $4(2.3 \%)$ & \\
\hline Unknown & $10(5.6 \%)$ & $0(0.0 \%)$ & $10(5.8 \%)$ & \\
\hline Tumor grade IBTR & & & & 0.734 \\
\hline 1 & $43(24.0 \%)$ & $1(14.3 \%)$ & $42(24.4 \%)$ & \\
\hline II & $81(45.3 \%)$ & $3(42.9 \%)$ & $78(45.3 \%)$ & \\
\hline III & $48(26.8 \%)$ & $3(42.9 \%)$ & $45(26.2 \%)$ & \\
\hline Unknown & $7(3.9 \%)$ & $0(0.0 \%)$ & $7(4.1 \%)$ & \\
\hline Receptor status IBTR & & & & 0.794 \\
\hline Triple negative & 27 (15.1\%) & $1(14.3 \%)$ & $26(15.1 \%)$ & \\
\hline HRneg_Her2pos & $6(3.4 \%)$ & $0(0.0 \%)$ & $6(3.5 \%)$ & \\
\hline Hrpos_Her2pos & $11(6.1 \%)$ & $0(0.0 \%)$ & $11(6.4 \%)$ & \\
\hline HRpos_Her2neg & $120(67.0 \%)$ & $6(85.7 \%)$ & $114(66.3 \%)$ & \\
\hline Unknown & $15(8.4 \%)$ & $0(0.0 \%)$ & $15(8.7 \%)$ & \\
\hline Radiotherapy IBTR & & & & 0.600 \\
\hline Yes & $29(16.2 \%)$ & $0(0 \%)$ & $29(16.9 \%)$ & \\
\hline No & $150(83.8 \%)$ & $7(100.0 \%)$ & $143(83.1 \%)$ & \\
\hline Systemic therapy IBTR & & & & 1.000 \\
\hline Yes & $119(66.5 \%)$ & $5(71.4 \%)$ & $114(66.3 \%)$ & \\
\hline No & $60(33.5 \%)$ & $228.6 \%)$ & $58(33.7 \%)$ & \\
\hline
\end{tabular}


Table 8.4 (continued)

\begin{tabular}{lcccc}
\hline & Total group: & $\begin{array}{c}\text { Regional } \\
\text { recurrence } \\
(\mathbf{N}=\mathbf{7})\end{array}$ & $\begin{array}{c}\text { No regional } \\
\text { recurrence } \\
(\mathbf{N}=\mathbf{1 7 2})\end{array}$ & $P$ value \\
\hline $\begin{array}{l}\text { Endocrine therapy IBTR } \\
\text { Yes }\end{array}$ & $107(59.8 \%)$ & $4(57.1 \%)$ & $103(59.9 \%)$ & 1.000 \\
No & $72(40.2 \%)$ & $3(42.9 \%)$ & $69(40.1 \%)$ & 1.000 \\
$\begin{array}{l}\text { Chemotherapy IBTR } \\
\text { Yes }\end{array}$ & $40(22.3 \%)$ & $1(14.3 \%)$ & $39(22.7 \%)$ & \\
No & $139(77.7 \%)$ & $6(85.7 \%)$ & $133(77.3 \%)$ & \\
\hline
\end{tabular}

Univariable analysis compared patients with regional recurrences $(\mathrm{N}=7)$ and patients without regional recurrences ( $\mathrm{N}=172)$. IBTR ipsilateral breast tumor recurrence, ALND axillary lymph node dissection, cALND completion axillary lymph node dissection, $\mathrm{SN}$ sentinel node, $\mathrm{mm}$ millimeter, HR hormone receptor, ER estrogen, PR progesterone, MBq mega becquerel, Her2 human epidermal growth receptor 2, neg negative, pos positive

After treatment of IBTR, 29 (16.2\%) of patients underwent (re)-irradiation, of which 18 patients to the chest wall, four to the breast (these were treated with a relumpectomy) and regional lymph nodes, four only to the regional lymph node basins and in three patients the location was unknown. None of these patients experienced a regional recurrence.

\section{Comparison of variables among patients with and without regional recurrences as first event after IBTR}

Comparing the patients who developed regional recurrences and those who did not, we found no significant differences between the groups regarding DFI, age and tumor characteristics during primary and recurrent breast cancer (Table 8.4). Likewise, there were no significant differences in the administration of adjuvant therapy following IBTR between the two patient cohorts.

\section{Discussion}

Data from this study showed that the risk of developing regional recurrences after an unsuccessful rSLNB in patients with IBTR is low. The low relapse rate supports the hypothesis that there is no need for additional axillary treatment after an unsuccessful rSLNB in the IBTR setting.

In the past, the performance of an ipsilateral ALND in the setting of IBTR was considered as standard care for an optimal regional disease control. In this study, $25 \%$ of the patients with an unsuccessful rSLNB received an additional ALND. Because the regional recurrences were found in aberrant basins in all cases, most patients would not have had a theoretical benefit from ipsilateral ALND.

The present finding that patients treated with ALND after an unsuccessful rSLNB had a much shorter DFI compared with patients not treated with ALND is in accordance with 
the findings from previous studies, which observed a shorter DFI as an indicator for poor prognosis. ${ }^{14-16}$ Nevertheless, none of the regional recurrences in this study occurred in the ipsilateral axilla, and thus an ALND would not have prevented those regional events. Obviously, uncertainty exists on regional treatment options for patients with an unsuccessful rSLNB. The percentage of patients receiving adjuvant radiotherapy did not differ between patients treated with or without ALND. And since the regional recurrence rate was low in both groups, there is no indication for adjuvant axillary radiotherapy in the setting of an unsuccessful rSLNB procedure as well. Regarding the use of adjuvant chemotherapy, it is supported in all IBTR patients, especially in the estrogen receptor negative subgroup. ${ }^{17}$

In $13 \%$ of the patients treated with an ALND after an unsuccessful rSLNB, metastatic lymph nodes were found. This is a remarkably high percentage, considering the fact that not a single ipsilateral axillary recurrence occurred - not even in patients who did not undergo cALND. Randomized trials comparing complementary axillary surgery after positive sentinel lymph node biopsy versus no ALND or axillary radiotherapy in the primary setting, such as the ACOSOG-Z0011, AMAROS and OTASOR trials, found comparable regional recurrence rates between those groups, whereas pathologically involved axillary lymph nodes were found in $27-39 \%$ of patients who received ALND ${ }^{18-20}$, an even higher percentage compared to the $13 \%$ found in this study. These results strengthen the available evidence that only a limited part of the involved lymph nodes have the potential to progress into clinically detectable axillary disease and confirm the hypothesis that a standard ALND after an unsuccessful rSLNB is not useful.

The 5-year actual regional recurrence rate was $3.7 \%$ in the group of patients treated without ALND after an unsuccessful rSLNB. Until now, other studies evaluating rSLNB focused mainly on the successfully harvested $\mathrm{rSN}^{\prime} \mathrm{s}^{3,12}$ Hence, no data are available to compare our findings regarding the impact of an unsuccessful rSLNB on the outcome for IBTR. In a cohort of 201 IBTR patients, all staged with a negative rSLNB, a 5-year regional recurrence rate of $4.5 \%$ was found, with an ipsilateral recurrence rate of $1.0 \%{ }^{6}$ One could speculate that in patients with an unsuccessful rSLNB, positive sentinel nodes may have been left behind, which could develop into clinically detectable disease. However, in the current study, the recurrence rate in patients with an unsuccessful rSLNB turned out to be similar to the recurrence rate in the group of patients with successfully harvested negative lymph nodes.

Furthermore, this study showed no significant differences in tumor and patient characteristics between patients developing regional recurrence and those who did not. Although the event numbers are small, based on these results, we cannot distinguish patients with an unsuccessful rSLNB being more at risk for regional recurrence. Recently Ugras et al. questioned whether axillary staging by rSLNB is even worthwhile and found a comparable regional recurrence rate between patients staged with rSLNB and patients without axillary staging. ${ }^{7}$ The low regional recurrence rate 
reported is in line with the results of Ugras et al. and with their conclusion that restaging of clinically node-negative patients may be of limited value. ${ }^{7}$ Furthermore, with improving non-invasive diagnostic options as positron emission tomographycomputed tomography (PET-CT), the rationale seems to be even more weaning.

Axillary surgery, with SLNB and/or (c)ALND, has been one of the cornerstones in the management of breast cancer. With the potential therapeutic impact of rSLNB and the possible ability to provide prognostic information tailoring adjuvant systemic therapy, rSLNB gained credibility in the setting of IBTR. ${ }^{8}$ However, the need for axillary surgery as a staging procedure is diminishing due to the improved knowledge of tumor biology, the development of more effective adjuvant therapies and the increasing use of biomarkers and genomic tests as prognostic tools in clinical practice. Hence, in the primary treatment setting trials such as SOUND, POSNOC and BOOG, are currently exploring differences in outcome between patients staged with SLNB compared to no axillary surgery. ${ }^{21-23}$ Results are awaited, but it is clear that the questions addressed in these trials are similar to the questions raised in the IBTR setting. Our IBTR patients with an unsuccessful rSLNB, most probably, will be different from patients with no axillary staging (no rSLNB or (c)ALND) at all. However, the 5-year regional recurrence rate in the unsuccessful rSLNB was less than $5 \%$, and no recurrences were found in the ipsilateral axilla, even though no lymph nodes were removed. These findings may indicate that the omission of any surgical lymph node staging in patients with IBTR without clinical manifest lymph node metastases can be justified in the future.

This study is limited by its retrospective nature, because a randomized controlled trial comparing unsuccessful rSLNB patients treated with ALND and without ALND would have been preferable. On the other hand, such a trial would most probably be underpowered due to the low incidence of recurrent breast cancer and regional recurrence after recurrent breast cancer. Given the small number of regional recurrences, multivariable analysis to determine independent risk factors were not feasible. These considerations should be taken into account when discussing treatment options after an unsuccessful rSLNB. Despite these limitations, the present study is unique by presenting follow-up data of a large cohort of patients with IBTR and unsuccessful rSLNB. The SNARB-study is a multicenter Dutch study providing data of different types of hospitals and therefore representative for patients with unsuccessful rSLNB in daily practice.

\section{Conclusion}

The present study shows that the risk of regional recurrence in the ipsilateral axilla in patients with an IBTR and an unsuccessful rSLNB is negligible, irrespective of the use of ALND. This suggests that there is no need for additional treatment of the axilla after an unsuccessful rSLNB. These results may trigger the discussion on the impact of any surgical axillary staging in the IBTR setting. 


\section{References}

1. Vugts G, Maaskant-Braat AJG, Voogd AC et al. Improving the success rate of repeat sentinel node biopsy in recurrent breast cancer. Ann Surg Oncol 2015;22:529-535.

2. Maaskant-Braat AJ, Voogd AC, Roumen RM, Nieuwenhuijzen GA. Repeat sentinel node biopsy in patients with locally recurrent breast cancer: a systematic review and meta-analysis of the literature. Breast Cancer Res Treat 2013;138:13-20.

3. Poodt IGM, Vugts G, Schipper RJ, Nieuwenhuijzen GAP. Repeat sentinel lymph node biopsy for ipsilateral breast tumor recurrence: A systematic review of the results and impact on prognosis. Ann Surg Oncol 2018;25(5):1329-1339.

4. Borger JH, Kemperman $\mathrm{H}$, Smitt HS et al. Dose and volume effects on fibrosis after breast conservation therapy. Int J Radiat Oncol Biol Phys 1994;30:1073-1081.

5. Mukesh MB, Harris E, Collette $S$ et al. Normal tissue complication probability (NTCP) parameters for breast fibrosis: pooled results from two randomised trials. Radiother Oncol 2013;108:293-298.

6. Poodt IGM, Vugts G, Maaskant-Braat AJG et al. Risk of regional recurrence after negative repeat sentinel lymph node biopsy in patients with ipsilateral breast tumor recurrence. Ann Surg Oncol 2018; 25(5):1312-1321.

7. Ugras S, Matsen C, Eaton A et al. Reoperative Sentinel Lymph Node Biopsy is Feasible for Locally Recurrent Breast Cancer, But is it Worthwhile? Ann Surg Oncol 2016;23:744-748.

8. Vugts G, Maaskant-Braat AJG, Voogd AC et al. Repeat sentinel node biopsy should be considered in patients with locally recurrent breast cancer. Breast Cancer Res Treat 2015;153:549-556.

9. Maaskant-Braat AJG, Roumen RMH, Voogd AC et al. Sentinel node and recurrent breast cancer (SNARB): Results of a nationwide registration study. Ann Surg Oncol 2013;20:620-626.

10. Moossdorff M, Vugts G, Maaskant-Braat AJ et al. Contralateral lymph node recurrence in breast cancer: Regional event rather than distant metastatic disease. A systematic review of the literature. Eur J Surg Oncol 2015;41:1128-1136.

11. Moossdorff M, van Roozendaal LM, Strobbe $L$ et al. Maastricht Delphi consensus on event definitions for classification of recurrence in breast cancer research. J Natl Cancer Inst 2014;106.

12. Intra M, Viale G, Vila J et al. Second Axillary Sentinel Lymph Node Biopsy for Breast Tumor Recurrence: Experience of the European Institute of Oncology. Ann Surg Oncol 2015;22:2372-2377.

13. Morcos B, Jaradat I, El-Ghanem M. Characteristics of and therapeutic options for contralateral axillary lymph node metastasis in breast cancer. Eur J Surg Oncol 2011;37:418-421.

14. Hudis CA, Barlow WE, Costantino JP et al. Proposal for standardized definitions for efficacy end points in adjuvant breast cancer trials: the STEEP system. J Clin Oncol 2007;25:2127-2132.

15. Aebi S, Gelber S, Anderson SJ et al. Chemotherapy for isolated locoregional recurrence of breast cancer (CALOR): a randomised trial. Lancet Oncol 2014;15:156-163.

16. Geurts YM, Witteveen A, Bretveld $R$ et al. Patterns and predictors of first and subsequent recurrence in women with early breast cancer. Breast Cancer Res Treat 2017;165(3):709-720.

17. Wapnir IL, Price KN, Anderson SJ et al. Efficacy of Chemotherapy for ER-Negative and ER-Positive Isolated Locoregional Recurrence of Breast Cancer: Final Analysis of the CALOR Trial. J Clin Oncol 2018; JCO2017765719.

18. Savolt A, Peley G, Polgar C et al. Eight-year follow up result of the OTOASOR trial: The Optimal Treatment Of the Axilla - Surgery Or Radiotherapy after positive sentinel lymph node biopsy in earlystage breast cancer: A randomized, single centre, phase III, non-inferiority trial. Eur J Surg Oncol 2017; 43:672-679.

19. Donker M, van Tienhoven G, Straver ME et al. Radiotherapy or surgery of the axilla after a positive sentinel node in breast cancer (EORTC 10981-22023 AMAROS): a randomised, multicentre, open-label, phase 3 non-inferiority trial. Lancet Oncol 2014;15:1303-1310.

20. Giuliano AE, Hunt KK, Ballman KV et al. Axillary dissection vs no axillary dissection in women with invasive breast cancer and sentinel node metastasis: a randomized clinical trial. JAMA 2011;305: 569-575.

21. Gentilini O, Veronesi U. Abandoning sentinel lymph node biopsy in early breast cancer? A new trial in progress at the European Institute of Oncology of Milan (SOUND: Sentinel node vs Observation after axillary UltraSouND). Breast 2012;21:678-681. 
22. Goyal A, Dodwell D. POSNOC: A Randomised Trial Looking at Axillary Treatment in Women with One or Two Sentinel Nodes with Macrometastases. Clin Oncol (R Coll Radiol) 2015;27:692-695.

23. van Roozendaal LM, Vane MLG, van Dalen $T$ et al. Clinically node negative breast cancer patients undergoing breast conserving therapy, sentinel lymph node procedure versus follow-up: a Dutch randomized controlled multicentre trial (BOOG 2013-08). BMC Cancer 2017;17:459. 



\section{Chapter}

\section{Prognostic impact of repeat sentinel lymph node biopsy in patients with ipsilateral breast tumour}

I.G.M. Poodt, G. Vugts, R.J. Schipper, R.M.H. Roumen, H.J.T. Rutten, A.J.G. Maaskant-Braat, A.C. Voogd, G.A.P. Nieuwenhuijzen On behalf of the Sentinel Node and Recurrent Breast Cancer (SNARB) study group 


\section{Abstract}

\section{Background}

Ipsilateral breast tumour recurrence (IBTR) has an unfavourable prognosis, with a significant risk of subsequent distant recurrence. Repeat SLNB (rSLNB) has recently been demonstrated to be technically feasible and useful in tailoring adjuvant treatment plans in patients with IBTR. The prognostic impact of rSLNB in patients with IBTR remains unclear. This study analysed the risk of distant recurrence after IBTR, and evaluated the prognostic impact of rSLNB and other patient and tumour characteristics on distant recurrence-free survival.

\section{Methods}

Data were obtained from the SNARB (Sentinel Node and Recurrent Breast Cancer) study. Cox-proportional hazards analyses were performed to assess the prognostic effect of tumour, patient and treatment factors on distant recurrence-free survival.

\section{Results}

Of the 515 included patients, $230(44.7 \& \%)$ had a tumour-negative rSLNB and 46 (8.9\%) had a tumour-positive rSLNB. In 239 patients (46.4\%) the rSLNB was unsuccessful. After a median follow-up of 5.1 years, 115 patients (22.3\%) had developed a recurrence. The overall 5-year distant recurrence-free survival was $84.2 \%$ (95\% C.I. 80.7 to 87.7 ). An interval of less than 2 years between primary breast cancer treatment and ipsilateral recurrence $(P=0.018)$, triple negative IBTR $(P=0.045)$ and absence of adjuvant chemotherapy after IBTR $(P=0.010)$ were independently associated with poor distant recurrence-free survival. The association between the outcome of rSLNB and distant recurrence-free survival was not statistically significant $(P=0.682)$.

\section{Conclusion}

The outcome of rSLNB is not an important prognostic factor for distant recurrence, and its value as a staging tool in patients with IBTR seems disputable. 


\section{Introduction}

Ipsilateral breast tumour recurrence (IBTR) has an unfavourable prognosis, with a significant risk of subsequent local, regional and distant recurrence as well as poor survival. ${ }^{1-4}$ The 5 -year overall survival for patients with IBTR ranges between 45 and $80 \%{ }^{5-7}$ Primary nodal status, size of IBTR, and the disease-free interval (DFI) between primary breast cancer and IBTR diagnosis are known prognostic factors for the development of further recurrences ${ }^{8,9}$. Fortunately, as a result of increasing knowledge of tumour behaviour and enhanced treatment options, the percentage of patients developing an IBTR has decreased significantly over the years. ${ }^{8,10}$ Nevertheless, because the incidence of breast cancer is high, IBTR still occurs in a considerable number of patients. Improvements in treatment strategies for patients with IBTR are therefore needed to increase the cure rate.

Patients with IBTR without evidence of distant metastasis are treated with curative intent, aiming for local disease control through wide local excision or mastectomy, combined with selective use of (re)irradiation depending on previous treatments. ${ }^{11,12}$ Although lymph node staging is an integral component of primary breast cancer treatment, the optimal management of the lymph nodes in patients with IBTR has not been standardized. Until recently, ipsilateral axillary lymph node dissection (ALND) was a standard procedure in patients with IBTR, aiming to achieve maximum locoregional disease control. The rationale for performing an ipsilateral ALND has become questionable for several reasons. The prognostic impact of nodal status at the time of IBTR is unclear. Moreover, the staging accuracy of ipsilateral ALND is debatable, because aberrant lymphatic drainage patterns are frequently found in patients with $\mathrm{IBTR}^{13}$, and exposing patients to the risks of ALND-associated morbidity is disputed. Several studies ${ }^{14-16}$ have assessed repeat sentinel lymph node biopsy (rSLNB) in patients with IBTR, and reported that it is technically feasible and useful in tailoring in adjuvant treatment plans. Regional relapse rates after negative-rSLNB without completion ALND in patients with recurrent breast cancer are very low. ${ }^{17}$ However, detailed information on distant relapse rates is lacking and so the prognostic value of rSLNB remains unclear. $^{13}$

The aim of this study was to describe the incidence of subsequent breast cancer-related events in patients with IBTR who have undergone rSLNB, and to determine the prognostic value of rSLNB and other patient and tumour characteristics on distant recurrence-free survival (DRFS).

\section{Methods}

The SNARB study is a multicentre national registry study in which 36 Dutch hospitals participated. Patients with clinically apparent ipsilateral or contralateral lymph node metastases and patients with distant metastasis at the time of diagnosis of IBTR were 
excluded. Patients with operable locally recurrent breast cancer were staged with rSLNB and included in this study. ${ }^{15}$ The dual mapping technique with both ${ }^{99 \mathrm{~m}}$ Techneticum and blue dye was used for rSLNB procedure. Technical specifications and determinants of successful rSLNB have been reported in detail elsewhere. ${ }^{15,18}$

\section{Pathological lymph node status}

A positive sentinel lymph node (SLN) at rSLNB was defined as a lymph node containing either macrometastases (larger than $2.0 \mathrm{~mm}$ ) and/or micrometastases (over $0.2 \mathrm{~mm}$ and/or more than 200 cells, but none larger than $2.0 \mathrm{~mm}$ ) in accordance with the TNM classification, seventh edition. ${ }^{19}$ Isolated tumour cells (small clusters of cells no larger than $0.2 \mathrm{~mm}$ and/or fewer than 200 cells) in the SLNs were classified as node-negative. In patients with an unsuccessful rSLNB, a sentinel node could not be visualized and/or harvested because of an unsuccessful procedure. In these patients, injection of a second dose of radiolabeled tracer was allowed, or the physician could act in accordance with the local protocol. ${ }^{18}$ There was no requirement to perform an ALND in patients with an unsuccessful rSLNB.

\section{Follow-up}

In 2017, follow-up data on patients in the SNARB study were collected and entered into the database. General practitioners were contacted for additional follow-up information when hospital records showed no outpatient clinic visits for more than 1 year. Last follow-up was documented as date of last visit to the outpatient clinic, date of last visit to the general practitioner or date of death. Follow-up time was defined as the interval between date of surgery for IBTR and date of last follow-up. Patients for whom follow-up data were not available, owing to emigration, lack of information or withdrawal of informed consent, were excluded.

\section{Definition of recurrence}

A local re-recurrence (LRR) after a previously treated IBTR was defined as reappearance of tumour growth in the treated breast or overlying skin. A regional recurrence (RR) was defined as any evidence of disease in ipsilateral intramammary nodes, ipsilateral and contralateral internal mammary nodes, ipsilateral and contralateral axillary nodes, and ipsilateral and contralateral infraclavicular and supraclavicular nodes. ${ }^{17,20}$ Lymph node recurrences found outside these nodal basins were considered as distant metastatic disease. An event in the contralateral breast was defined as a new primary tumour and was not considered as a recurrence, unless it could be proven that it was metastatic disease. ${ }^{21}$

Distant recurrences (DRs) were defined as any evidence of disease outside the ipsilateral breast, contralateral breast and regional lymph nodes. LRR and/or RR diagnosed at the same time as, or after the appearance of, DR were not recorded 
because distant metastatic disease is considered to be the worst site according to a hierarchy of prognosis from worst to best. ${ }^{22}$ In the event of synchronous LRR and RR, the recurrence was registered as a RR.

\section{Study endpoints}

The clinical events to be included in the definitions of time-to-event endpoints were selected according to the DATECAN and STEEP guidelines. ${ }^{21,22}$ Recurrence-free interval was defined as the interval from date of surgery of the IBTR to detection of the first recurrence ( $L R R, R R, D R$ ) or date of last follow-up. Distant recurrence-free interval (DRFI) was defined as the interval between date of surgery of the IBTR and date of diagnosis of a DR or date of last follow-up. The occurrence of DR after IBTR and breast cancer-related death were included in the DRFI. ${ }^{21,22}$ Breast cancer-specific survival was censored in patients who died from other causes.

\section{Statistical analysis}

Patient, tumour and treatment characteristics were compared between groups using Pearson's $X^{2}$ or Fisher's exact test, as appropriate, for categorical data; Mann-Whitney $U$ test or independent-samples $t$ test was used for continuous variables depending on the normality of the distribution. Survival analyses were undertaken, using the KaplanMeier method to calculate the prognosis of patients after curative treatment for IBTR. DRFS rates were calculated based on the DRFI defined above. The 5-year DRFS was calculated for tumour, patient and treatment variables, and compared between strata using the two-tailed log-rank test. To assess the independent prognostic effect of the variables, a multivariable analysis was performed using Cox proportional hazards model. The multivariable model was fitted for factors that were statistically significant in the univariable analyses, prespecified prognostic factors according to the CALOR (Chemotherapy as Adjuvant LOcally Recurrent Breast Cancer) study ${ }^{23}$ (DFI, location and receptor status of IBTR and use of adjuvant chemotherapy for IBTR), size of IBTR and the outcome of rSLNB (positive, negative or unsuccessful). Hazard ratios and $95 \%$ confidence intervals were estimated for each variable compared with the reference group. Two-sided $P<0.05$ was considered statistically significant. Data analysis was done using SPSS ${ }^{\circledR}$ version 24 (IBM, Armonk, New York, USA).

\section{Results}

Follow-up data were collected of 536 patients included in the SNARB study. Twenty-one patients were lost to follow-up, and 515 patients (96.1 per cent) remained for analysis. 


\section{Successful versus unsuccessful repeat sentinel node biopsy}

Of the 515 patients, 276 patients (53.6\%) had an rSLNB with successful harvesting of the SLN, and in 239 patients (46.4\%) the SLN could not be visualized and/or harvested because of an unsuccessful procedure. Patient and tumour characteristics categorized by successful and unsuccessful rSLNB procedure are summarized in Table 9.1. Patients who had undergone ALND during treatment of theprimary breast cancer were significantly less likely to have a successful rSLNB, owing to a lower rSLN identification rate. The median time from primary breast cancer surgery to diagnosis of IBTR was significantly longer in the unsuccessful group. No differences in adjuvant treatment regimens were observed between both groups.

Table 9.1 Patient, tumour and treatment characteristics of patients with ipsilateral breast tumour recurrence according to a successful or unsuccessful repeat sentinel node biopsy

\begin{tabular}{|c|c|c|c|c|}
\hline & $\begin{array}{l}\text { All patients } \\
\qquad(\mathrm{N}=515)\end{array}$ & $\begin{array}{c}\text { rSLNB } \\
\text { successful } \\
(\mathrm{N}=\mathbf{2 7 6}) \\
\end{array}$ & $\begin{array}{c}\text { rSLNB } \\
\text { unsuccessful } \\
(\mathrm{N}=239) \\
\end{array}$ & $P$-value ${ }^{\dagger}$ \\
\hline Final status of primary axillary surgery* & & & & $<0.001$ \\
\hline No axillary staging & $34(6.6 \%)$ & $18(10.1 \%)$ & $6(2.5 \%)$ & \\
\hline SLNB & $203(39.4 \%)$ & $129(46.7 \%)$ & $74(31.0 \%)$ & \\
\hline (c)ALND & $278(54.0 \%)$ & 119 (43.1\%) & $159(66.5 \%)$ & \\
\hline Primary nodal status * & & & & 0.014 \\
\hline Negative & $372(72.2 \%)$ & $200(72.5 \%)$ & $172(72.0 \%)$ & \\
\hline Positive & $91(17.7 \%)$ & $40(14.5 \%)$ & $51(21.3 \%)$ & \\
\hline Unknown & $52(10.1 \%)$ & $36(13.0 \%)$ & $16(6.7 \%)$ & \\
\hline \multicolumn{5}{|l|}{$\begin{array}{l}\text { Time from primary surgery to IBTR } \\
\text { diagnose (years) * }\end{array}$} \\
\hline Median (range) & $10.5(0.4-31.8)$ & $8.6(0.4-31.8)$ & $11.8(0.4-30.0)$ & $<0.001^{\ddagger}$ \\
\hline$<2$ years & $38(7.4 \%)$ & $24(8.7 \%)$ & $14(5.9 \%)$ & 0.003 \\
\hline$\geq 2.0,<5.0$ & $94(18.3 \%)$ & $57(20.7 \%)$ & $37(15.5 \%)$ & \\
\hline$\geq 5.0,<10.0$ & $117(22.8 \%)$ & $73(26.5 \%)$ & $44(18.4 \%)$ & \\
\hline$\geq 10.0$ & $265(51.6 \%)$ & $121(44.0 \%)$ & $144(60.3 \%)$ & \\
\hline \multicolumn{5}{|l|}{ Unknown } \\
\hline \multicolumn{5}{|l|}{ Age at IBTR (years) } \\
\hline Median (range) & $64.0(26-93)$ & $63.0(27-89)$ & $65.0(26-93)$ & $0.048^{\ddagger}$ \\
\hline$<35$ & $6(1.2 \%)$ & $2(0.7 \%)$ & $4(1.7 \%)$ & 0.091 \\
\hline $35-59$ & $176(34.2 \%)$ & $104(37.7 \%)$ & $72(30.1 \%)$ & \\
\hline $60-69$ & $178(34.6 \%)$ & $98(35.5 \%)$ & $80(33.5 \%)$ & \\
\hline$\geq 70$ & $155(30.1 \%)$ & $72(26.1 \%)$ & $83(34.7 \%)$ & \\
\hline Location of IBTR & & & & $<0.001$ \\
\hline Breast & $454(88.2 \%)$ & $227(82.2 \%)$ & $227(95.0 \%)$ & \\
\hline Mastectomy scar or chest wall & $61(11.8 \%)$ & 49 (17.8\%) & $12(5.0 \%)$ & \\
\hline Aberrant location of SLN at rSLNB & & & & $<0.001$ \\
\hline Yes & $126(24.5 \%)$ & $126(45.7 \%)$ & $0(0.0 \%)$ & \\
\hline No & $148(28.7 \%)$ & $148(53.6 \%)$ & $0(0.0 \%)$ & \\
\hline Unknown & $2(0.4 \%)$ & $2(0.7 \%)$ & $0(0.0 \%)$ & \\
\hline Unsuccessful rSLNB & $239(46.4 \%)$ & $0(0.0 \%)$ & $239(100 \%)$ & \\
\hline
\end{tabular}


Table 9.1 (continued)

\begin{tabular}{|c|c|c|c|c|}
\hline & $\begin{array}{l}\text { All patients } \\
(\mathrm{N}=515)\end{array}$ & $\begin{array}{c}\text { rSLNB } \\
\text { successful } \\
(\mathrm{N}=276)\end{array}$ & $\begin{array}{c}\text { rSLNB } \\
\text { unsuccessful } \\
(\mathrm{N}=239)\end{array}$ & $P$-value ${ }^{\dagger}$ \\
\hline Final axillary surgery at IBTR & & & & $<0.001$ \\
\hline Unsuccessful rSLNB & $179(34.8 \%)$ & $0(0.0 \%)$ & 179 (74.9\%) & \\
\hline (c)ALND & $104(20.2 \%)$ & $44(15.9 \%)$ & $60(25.1 \%)$ & \\
\hline rSLNB & $232(45.0 \%)$ & $232(84.1 \%)$ & $0(0.0 \%)$ & \\
\hline Lesion size of IBTR (cm) & & & & 0.140 \\
\hline$\leq 2$ & $362(70.3 \%)$ & $199(72.1 \%)$ & $163(68.2 \%)$ & \\
\hline$>2$ & $120(23.3 \%)$ & $56(20.3 \%)$ & $64(26.8 \%)$ & \\
\hline Unknown & $33(6.4 \%)$ & $21(7.6 \%)$ & $12(5.0 \%)$ & \\
\hline Tumour grade of IBTR & & & & 0.703 \\
\hline 1 & $104(20.2 \%)$ & $52(18.8 \%)$ & $52(21.8 \%)$ & \\
\hline II & 231 (44.9\%) & $124(44.9 \%)$ & 107 (44.8\%) & \\
\hline III & $151(29.3 \%)$ & $82(29.7 \%)$ & $69(28.9 \%)$ & \\
\hline Unknown & $29(5.6 \%)$ & $18(6.5 \%)$ & $11(4.6 \%)$ & \\
\hline Receptor status of IBTR & & & & 0.346 \\
\hline Triple-negative & 67 (13.0\%) & $31(11.2 \%)$ & $36(15.1 \%)$ & \\
\hline HR-, HER-2+ & $18(3.5 \%)$ & $9(3.3 \%)$ & $9(3.8 \%)$ & \\
\hline HR+,HER-2+ & $33(6.4 \%)$ & $18(6.5 \%)$ & $15(6.3 \%)$ & \\
\hline HR+, HER-2- & $345(67.0 \%)$ & $184(66.7 \%)$ & $161(67.4 \%)$ & \\
\hline Unknown & $52(10.1 \%)$ & $34(12.3 \%)$ & $18(7.5 \%)$ & \\
\hline Systemic therapy after IBTR & & & & 0.446 \\
\hline Yes & $354(68.7 \%)$ & $194(70.3 \%)$ & 160 (66.9\%) & \\
\hline No & $161(31.3 \%)$ & $82(29.7 \%)$ & $79(33.1 \%)$ & \\
\hline Endocrine therapy after IBTR & & & & 0.277 \\
\hline Yes & $315(61.2 \%)$ & $175(63.4 \%)$ & $140(58.6 \%)$ & \\
\hline No & $200(38.8 \%)$ & $101(36.6 \%)$ & $99(41.4 \%)$ & \\
\hline Chemotherapy recurrent after IBTR & & & & 0.606 \\
\hline Yes & $125(24.3 \%)$ & $70(25.4 \%)$ & $55(23.0 \%)$ & \\
\hline No & $390(75.7 \%)$ & $206(74.6 \%)$ & $184(77.0 \%)$ & \\
\hline
\end{tabular}

Values in parentheses are percentages unless indicated otherwise. * Primary refers to the time of primary breast cancer treatment before the recurrence. (r)SLNB (repeat) sentinel lymph node biopsy, (c)ALND (completion) axillary lymph node dissection, IBTR ipsilateral breast tumour recurrence, SLN sentinel lymph node, HR hormone receptor, HER-2 human epidermal growth receptor 2 . + Pearson $\chi 2$ test, except $¥$ MannWhitney U test

\section{Positive and negative versus unsuccessful repeat sentinel node biopsy}

Of the 515 patients, 230 patients (44.7\%) had a successful negative rSLNB, 46 patients (8.9\%) had a successful positive rSLNB; the rSLNB procedure was unsuccessful in the remaining 239 patients (46.4\%). Patient and tumour characteristics categorized by outcome of the rSLNB after IBTR are summarized in Table 9.2. The majority of the patients had an IBTR no larger than $2 \mathrm{~cm}$ (70.3\%), grade II disease (44.9\%), and hormone receptor (HR)-positive, human epidermal growth receptor (HER)2-negative breast cancer (67.0\%). After surgical treatment for IBTR, 315 patients (61.2\%) received adjuvant endocrine therapy. Adjuvant chemotherapy was administered to 125 patients (24.3\%). In total, 354 patients (68.7\%) received adjuvant endocrine and/or 
chemotherapy. Adjuvant endocrine therapy and/or adjuvant chemotherapy were administered significantly more often in patients with a positive rSLNB than in those with a negative or unsuccessful rSLNB $(P<0.001)$.

Table 9.2 Patient, tumour and treatment characteristics of patients with ipsilateral breast tumour recurrence according to outcome of repeat sentinel node biopsy

\begin{tabular}{|c|c|c|c|c|c|}
\hline & $\begin{array}{l}\text { All patients } \\
\qquad(\mathrm{N}=515)\end{array}$ & $\begin{array}{l}\text { rSLNB- } \\
\text { positive } \\
(\mathrm{N}=46)\end{array}$ & $\begin{array}{c}\text { rSLNB- } \\
\text { negative } \\
(\mathrm{N}=\mathbf{2 3 0})\end{array}$ & $\begin{array}{c}\text { rSLNB } \\
\text { unsuccessful } \\
(\mathrm{N}=239)\end{array}$ & $P$-value ${ }^{\dagger}$ \\
\hline $\begin{array}{l}\text { Final status of primary axillary } \\
\text { surgery* }\end{array}$ & & & & & $<0.001$ \\
\hline No axillary staging & $34(6.6 \%)$ & $7(15.2 \%)$ & $21(9.1 \%)$ & $6(2.5 \%)$ & \\
\hline SLNB & 203 (39.4\%) & $14(30.4 \%)$ & $115(50.0 \%)$ & 74 (31.0\%) & \\
\hline (c)ALND & $278(54.0 \%)$ & $25(54.3 \%)$ & $94(40.9 \%)$ & $159(66.5 \%)$ & \\
\hline Primary nodal status* & & & & & 0.037 \\
\hline Negative & $372(72.2 \%)$ & $30(65.2 \%)$ & 170 (73.9\%) & $172(72.0 \%)$ & \\
\hline Positive & $91(17.7 \%)$ & $8(17.4 \%)$ & $32(13.9 \%)$ & $51(21.3 \%)$ & \\
\hline Unknown & 52 (10.1\%) & $8(17.4 \%)$ & 28 (12.2\%) & $16(6.7 \%)$ & \\
\hline \multicolumn{6}{|l|}{$\begin{array}{l}\text { Time from primary surgery to IBTR } \\
\text { diagnose (years) * }\end{array}$} \\
\hline Median (range) & $10.5(0.4-31.8)$ & $11.4(0.7-31.8)$ & $7.9(0.4-30.2)$ & $11.8(0.4-30.0)$ & $<0.001 \ddagger$ \\
\hline$<2$ years & $38(7.4 \%)$ & $2(4.3 \%)$ & $22(9.6 \% \%)$ & $14(5.9 \%)$ & 0.007 \\
\hline$\geq 2.0,<5.0$ & $94(18.3 \%)$ & $8(17.4 \%)$ & $49(21.4 \%)$ & $37(15.5 \%)$ & \\
\hline$\geq 5.0,<10.0$ & $117(22.8 \%)$ & $10(21.7 \%)$ & $63(27.5 \%)$ & 44 (18.4\%) & \\
\hline$\geq 10.0$ & $265(51.6 \%)$ & $26(56.5 \%)$ & $95(41.5 \%)$ & $144(60.3 \%)$ & \\
\hline Unknown & $1(0.2 \%)$ & $0(0.0 \%)$ & $1(0.4 \%)$ & $0(0.0 \%)$ & \\
\hline \multicolumn{6}{|l|}{ Age at IBTR (years) } \\
\hline Median (range) & $64.0(26-93)$ & $63.0(42-89)$ & $63.0(27-87)$ & $65.0(26-93)$ & $0.142 \ddagger$ \\
\hline$<35$ & $6(1.2 \%)$ & $0(0.0 \%)$ & $2(0.9 \%)$ & $4(1.7 \%)$ & 0.233 \\
\hline $35-59$ & $176(34.2 \%)$ & $20(43.5 \%)$ & $84(36.5 \%)$ & $72(30.1 \%)$ & \\
\hline $60-69$ & $178(34.6 \%)$ & $17(37.0 \%)$ & $81(35.2 \%)$ & $80(33.5 \%)$ & \\
\hline$\geq 70$ & $155(30.1 \%)$ & $63(27.4 \%)$ & $63(27.4 \%)$ & $83(34.7 \%)$ & \\
\hline Location of IBTR & & & & & $<0.001$ \\
\hline Breast & 454 (88.2\%) & 39 (84.8\%) & $188(81.7 \%)$ & 227 (95.0\%) & \\
\hline Mastectomy scar or chest wall & $61(11.8 \%)$ & $7(15.2 \%)$ & $42(18.3 \%)$ & $12(5.0 \%)$ & \\
\hline Aberrant location of SLN at rSLNB & & & & & $<0.001$ \\
\hline Yes & $126(24.5 \%)$ & $26(56.5 \%)$ & $100(43.5 \%)$ & $0(0.0 \%)$ & \\
\hline No & $148(28.7 \%)$ & 20 (43.5\%) & $128(55.7 \%)$ & $0(0.0 \%)$ & \\
\hline Unknown & $2(0.4 \%)$ & $0(0.0 \%)$ & $2(0.9 \%)$ & $0(0.0 \%)$ & \\
\hline Unsuccessful rSLNB & $239(46.4 \%)$ & $0(0.0 \%)$ & $0(0.0 \%)$ & $239(100 \%)$ & \\
\hline Final axillary surgery at IBTR & & & & & $<0.001$ \\
\hline Unsuccessful rSLNB & $179(34.8 \%)$ & $0(0.0 \%)$ & $0(0.0 \%)$ & 179 (74.9\%) & \\
\hline (c)ALND & $104(20.2 \%)$ & $15(32.6 \%)$ & $29(12.6 \%)$ & $60(25.1 \%)$ & \\
\hline rSLNB & $232(45.0 \%)$ & $31(67.4 \%)$ & $201(87.4 \%)$ & $0(0.0 \%)$ & \\
\hline Lesion size of IBTR $(\mathrm{cm})$ & & & & & 0.022 \\
\hline$\leq 2$ & $362(70.3 \%)$ & 32 (69.5\%) & 167 (72.6\%) & $163(68.2 \%)$ & \\
\hline$>2$ & $120(23.3 \%)$ & $14(30.4 \%)$ & $42(18.3 \%)$ & $64(26.8 \%)$ & \\
\hline Unknown & $33(6.4 \%)$ & $0(0.0 \%)$ & $21(9.1 \%)$ & $12(5.0 \%)$ & \\
\hline
\end{tabular}


Table 9.2 (continued)

\begin{tabular}{|c|c|c|c|c|c|}
\hline & $\begin{array}{l}\text { All patients } \\
(\mathrm{N}=515)\end{array}$ & $\begin{array}{l}\text { rSLNB- } \\
\text { positive } \\
(\mathrm{N}=46)\end{array}$ & $\begin{array}{c}\text { rSLNB- } \\
\text { negative } \\
(\mathrm{N}=230)\end{array}$ & $\begin{array}{c}\text { rSLNB } \\
\text { unsuccessful } \\
(\mathrm{N}=239)\end{array}$ & $P$-value ${ }^{\dagger}$ \\
\hline Tumour grade of IBTR & & & & & 0.745 \\
\hline 1 & $104(20.2 \%)$ & $7(15.2 \%)$ & $45(20.0 \%)$ & $52(21.8 \%)$ & \\
\hline II & 231 (44.9\%) & 25 (54.3\%) & $99(43.0 \%)$ & 107 (44.8\%) & \\
\hline III & $151(29.3 \%)$ & $11(23.9 \%)$ & $71(30.9 \%)$ & $69(28.9 \%)$ & \\
\hline Unknown & $29(5.6 \%)$ & $3(6.5 \%)$ & $15(6.5 \%)$ & $11(4.6 \%)$ & \\
\hline Receptor status of IBTR & & & & & 0.167 \\
\hline Triple-negative & $67(13.0 \%)$ & $2(4.3 \%)$ & $29(12.6 \%)$ & $36(15.1 \%)$ & \\
\hline HR-, HER-2+ & $18(3.5 \%)$ & $2(4.3 \%)$ & $7(3.0 \%)$ & $9(3.8 \%)$ & \\
\hline $\mathrm{HR}+$,HER-2+ & $33(6.4 \%)$ & $4(8.7 \%)$ & $14(6.1 \%)$ & $15(6.3 \%)$ & \\
\hline HR+, HER-2- & $345(67.0 \%)$ & $36(78.3 \%)$ & $148(64.3 \%)$ & $161(67.4 \%)$ & \\
\hline Unknown & $52(10.1 \%)$ & $2(4.3 \%)$ & 32 (13.9\%) & $18(7.5 \%)$ & \\
\hline Systemic therapy after IBTR & & & & & $<0.001$ \\
\hline Yes & $354(68.7 \%)$ & 45 (97.8\%) & $149(64.8 \%)$ & 160 (66.9\%) & \\
\hline No & $161(31.3 \%)$ & $1(2.2 \%)$ & $81(35.2 \%)$ & $79(33.1 \%)$ & \\
\hline Endocrine therapy after IBTR & & & & & $<0.001$ \\
\hline Yes & $315(61.2 \%)$ & $42(91.3 \%)$ & $133(57.8 \%)$ & $140(58.6 \%)$ & \\
\hline No & $200(38.8 \%)$ & $4(8.7 \%)$ & $97(42.2 \%)$ & $99(41.4 \%)$ & \\
\hline Chemotherapy after IBTR & & & & & $<0.001$ \\
\hline Yes & $125(24.3 \%)$ & $23(50.0 \%)$ & $47(20.7 \%)$ & $55(23.0 \%)$ & \\
\hline No & $390(75.7 \%)$ & $23(50.0 \%)$ & $183(79.6 \%)$ & $184(77.0 \%)$ & \\
\hline
\end{tabular}

Values in parentheses are percentages unless indicated otherwise. * Primary refers to the time of primary breast cancer treatment before the recurrence. (r)SLNB (repeat) sentinel lymph node biopsy, (c)ALND (completion) axillary lymph node dissection, IBTR ipsilateral breast tumour recurrence, SLN sentinel lymph node, HR hormone receptor, HER-2 human epidermal growth receptor 2. + Pearson $\chi 2$ test, except $¥$ MannWhitney $\mathrm{U}$ test

\section{Patterns of recurrence after curative treatment of ipsilateral breast tumour recurrence}

The median follow-up for patients still alive after treatment of IBTR was 5.1 (range, 1.1-13.2) years. After treatment of IBTR, 115 patients (22.3\%) developed a recurrence. The risk of developing another recurrence was highest in the third year following treatment for IBTR (5.9 ( $95 \% \mathrm{Cl} .5 .1$ to 6.7) per cent). LRR was observed in 20 patients (3.9\%), RR occurred in 18 patients (3.5\%), and 77 patients (15.0\%) developed DR as first event after IBTR (Figure 9.1). There was no significant difference in the occurrence of RRs between patients with a tumour-positive rSLNB (1 patient, 2.2\%), a tumournegative rSLNB $(10,4.3 \%)$ and those with an unsuccessful rSLNB $(7,2.9 \%)(P=0.618)$.

The 5-year overall recurrence-free survival rate after IBTR was $79.1 \%$ (95\% $\mathrm{Cl} 75.2$ to 83.0). No significant difference in 5-year recurrence-free survival was observed between patients with an unsuccessful rSLNB, tumour-positive or tumour-negative rSLNB ( $P=0.543)$. 
Thirteen of the 38 patients with LRR or RR developed another recurrence (Figure 9.1). Seventy-eight of the 515 patients (15.1\%) patients died during follow-up after IBTR, 60 (77\%) from breast-cancer related causes.

A total of 88 patients (17.1\%) developed DR, 77 (88\%) as a first event after treatment of IBTR and 11 (12\%) after diagnosis of LRR or RR following IBTR (Figure 9.1). The site of first distant metastases were bone (26 patients), lung (16), liver (10), brain (7) and other sites (12). In 17 patients DRs were diagnosed at multiple sites at the same time. The 5-year DRFS was $84.2 \%$ (95\% Cl. 80.7 to 87.7 ).

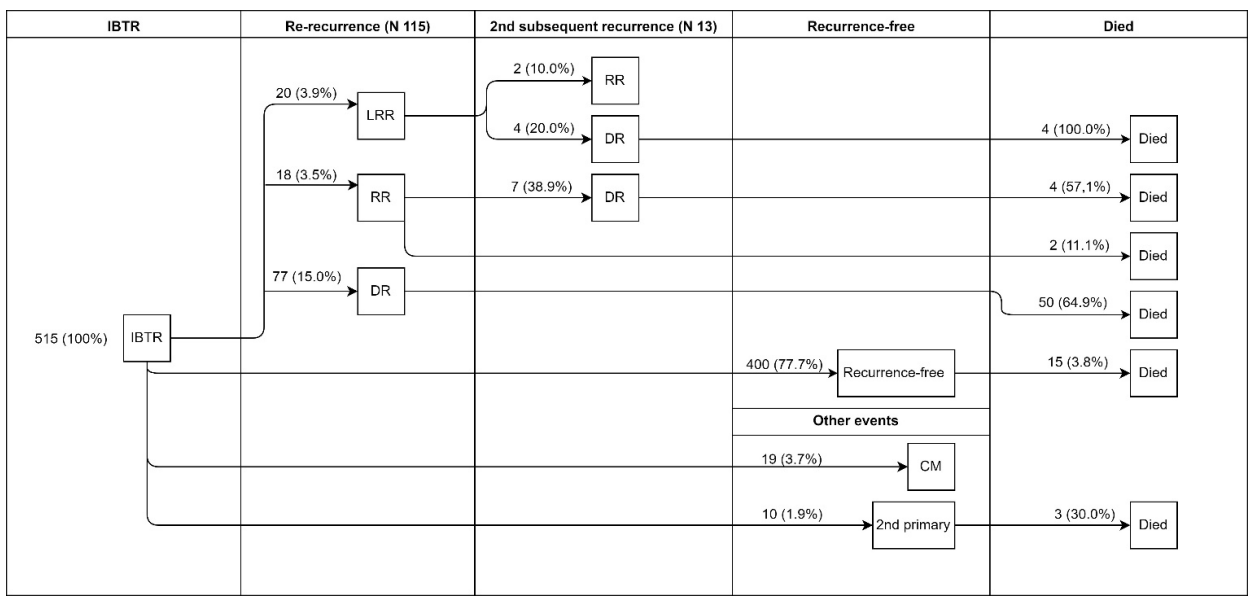

Figure 9.1 Patterns of recurrence after curative treatment of ipsilateral breast tumour recurrence in 515 patients. IBTR: ipsilateral breast tumour recurrence; LRR: local re-recurrence; RR: regional recurrence; $\mathrm{DR}$ : distant recurrence; $\mathrm{CM}$ : contralateral metastases

\section{Prognostic factors for distant recurrence-free survival}

Univariable analysis showed that the primary nodal status (ALND and/or SLNB) at the time of primary surgery and the DFI between primary breast cancer surgery and diagnosis of IBTR were significantly related to a higher risk of DR (Table 9.3). After inclusion of the predefined factors in a multivariable Cox regression analysis, the most important prognostic factors for the occurrence of DR were a DFI less than 2 years, a triple negative IBTR and the absence of adjuvant chemotherapy after IBTR (Table 9.4). 
Table 9.3 Univariable analysis of clinicopathological characteristics related to distant recurrence-free survival after curative treatment of ipsilateral breast tumour recurrence

\begin{tabular}{|c|c|c|c|c|}
\hline & $\begin{array}{l}\text { All patients } \\
(\mathrm{N}=515)\end{array}$ & $\begin{array}{l}\text { Patients with DR or } \\
\text { breast cancer- } \\
\text { related death } \\
(\mathrm{N}=90)\end{array}$ & $\begin{array}{c}\text { 5-year } \\
\text { DRFS (\%) }\end{array}$ & $P$-value \\
\hline Final status of primary axillary surgery * & & & & 0.700 \\
\hline No axillary staging & $34(6.6 \%)$ & 4 & 86.2 & \\
\hline SLNB & $203(39.4 \%)$ & 31 & 87.6 & \\
\hline (c)ALND & $278(54.0 \%)$ & 55 & 81.9 & \\
\hline Primary nodal status * & & & & 0.016 \\
\hline Negative & $372(72.2 \%)$ & 61 & 85.5 & \\
\hline Positive & $91(17.7 \%)$ & 25 & 75.1 & \\
\hline Unknown & $52(10.1 \%)$ & 4 & 91.5 & \\
\hline Time primary surgery to IBTR diagnosis (years)* & & & & 0.025 \\
\hline$<2.0$ & $38(7.4 \%)$ & 12 & 68.7 & \\
\hline$\geq 2.0,<5.0$ & $94(18.3 \%)$ & 14 & 85.0 & \\
\hline$\geq 5.0,<10.0$ & $117(22.7 \%)$ & 18 & 90.2 & \\
\hline$\geq 10.0$ & $265(51.5 \%)$ & 46 & 83.5 & \\
\hline Age at IBTR (years) & & & & 0.251 \\
\hline$<35$ & $6(1.2 \%)$ & 2 & 66.7 & \\
\hline $35-59$ & $176(34.2 \%)$ & 27 & 87.1 & \\
\hline $60-69$ & $178(34.6 \%)$ & 31 & 84.4 & \\
\hline$\geq 70$ & $155(30.1 \%)$ & 30 & 81.2 & \\
\hline Location of IBTR & & & & 0.672 \\
\hline Breast & $454(88.2 \%)$ & 79 & 84.5 & \\
\hline Mastectomy scar or chest wall & $61(11.8 \%)$ & 11 & 82.5 & \\
\hline Result of rSLNB & & & & 0.682 \\
\hline Negative & $230(44.7 \%)$ & 35 & 85.4 & \\
\hline Positive & $46(23.7 \%)$ & 10 & 76.3 & \\
\hline Unsuccessful & $239(46.4 \%)$ & 45 & 84.7 & \\
\hline Aberrant location of SLN on rSLNB & & & & 0.956 \\
\hline Yes & $126(24.5 \%)$ & 22 & 83.7 & \\
\hline No & $150(29.1 \%)$ & 23 & 83.8 & \\
\hline Unsuccessful rSLNB & $239(46.4 \%)$ & 45 & 84.5 & \\
\hline Final axillary surgery at IBTR & & & & 0.960 \\
\hline Unsuccessful rSLNB & $179(34.8 \%)$ & 33 & 83.8 & \\
\hline rSLNB & $232(45.0 \%)$ & 36 & 82.8 & \\
\hline (c)ALND & $104(20.2 \%)$ & 21 & 86.1 & \\
\hline IBTR nodal status & & & & 0.713 \\
\hline Negative & $279(54.2 \%)$ & 45 & 86.0 & \\
\hline Positive & $57(11.1 \%)$ & 12 & 77.0 & \\
\hline Unknown & $179(34.8 \%)$ & 33 & 83.8 & \\
\hline Lesion size of IBTR $(\mathrm{cm})$ & & & & 0.086 \\
\hline$\leq 2$ & $362(70.3 \%)$ & 60 & 85.1 & \\
\hline$>2$ & $120(23.3 \%)$ & 28 & 77.8 & \\
\hline Unknown & $33(6.4 \%)$ & 2 & 97.0 & \\
\hline Tumour grade of IBTR & & & & 0.089 \\
\hline 1 & $104(20.2 \%)$ & 11 & 90.0 & \\
\hline II & 231 (44.9\%) & 43 & 83.8 & \\
\hline III & $151(29.3 \%)$ & 28 & 82.8 & \\
\hline Unknown & $29(5.6 \%)$ & 8 & 74.0 & \\
\hline
\end{tabular}




\begin{tabular}{lccc}
\hline & All patients & $\begin{array}{c}\text { Patients with DR or } \\
\text { breast cancer- } \\
\text { related death } \\
\text { (N=90) }\end{array}$ & $\begin{array}{c}\text { 5-year } \\
\text { DRFS (\%) }\end{array}$ \\
P-value
\end{tabular}

Values in parentheses are percentages unless indicated otherwise. * Primary refers to the time of primary breast cancer treatment before the recurrence. DR distant recurrence, DRFS distant recurrence-free survival, (r)SLNB (repeat) sentinel lymph node biopsy, (c)ALND (completion) axillary lymph node dissection, IBTR ipsilateral breast tumour recurrence, SLN sentinel lymph node, HR hormone receptor, HER-2 human epidermal growth receptor $2 .+$ Log rank rest

The DRFI was longer for patients who received adjuvant chemotherapy following the IBTR, with a 5-year DRFS rate of $89.5 \%$ (95\% Cl 83.4 to 95.6$)$, compared with $82.6 \%$ (95\% Cl. 78.5 to-86.7) per cent for those treated without adjuvant chemotherapy (Table 9.3). In multivariable analysis, patients with IBTR who had adjuvant chemotherapy had a lower risk of developing DR (hazard ratio $0.46,95 \% \mathrm{Cl} 0.25$ to $0.83 ; P=0.010$ ) (Table 9.4). The beneficial effect of adjuvant chemotherapy on DRFS was significantly more pronounced in patients with an oestrogen receptor (ER)-negative IBTR (hazard ratio $0.21,95 \% \mathrm{Cl} 0.06$ to 0.74 ) (Table 9.5).

For patients in the negative rSLNB group, the 5-year DRFS was $85.4 \%(95 \% \mathrm{Cl} 80.5$ to 90.3 ), compared with $76 \%$ (95\% $\mathrm{Cl} 60$ to 92 ) in the positive rSLNB group and $84.7 \%$ (95\% Cl 79.8 to 90.3$)$ in the unsuccessful-rSLNB group $(P=0.682)$ (Table 9.3). Survival plots in relation to the outcome of rSLNB are shown in Figure 9.2. The outcome of rSLNB was not a statistically significant prognostic factor, either in the univariable or in the multivariable analysis (Table 9.4). 
Table 9.4 Univariable and multivariable Cox proportional hazards regression model of distant recurrencefree survival after curative treatment of ipsilateral breast tumour recurrence

\begin{tabular}{|c|c|c|c|c|c|c|}
\hline & \multicolumn{6}{|c|}{ Distance recurrence-free survival $(n=90)$} \\
\hline & \multicolumn{3}{|c|}{ Univariable analysis } & \multicolumn{3}{|c|}{ Multivariable analysis } \\
\hline & Hazard ratio & $95 \% \mathrm{Cl}$ & $P$ & Hazard ratio & $95 \% \mathrm{Cl}$ & $P$ \\
\hline \multicolumn{7}{|c|}{ Primary nodal status * } \\
\hline Negative & 1.00 (reference) & & & 1.00 (reference) & & \\
\hline Positive & 1.70 & $1.07-2.71$ & 0.025 & 1.52 & $0.94-2.45$ & 0.086 \\
\hline Unknown & 0.49 & $0.18-1.34$ & 0.165 & 0.48 & $0.17-1.34$ & 0.161 \\
\hline \multicolumn{7}{|c|}{$\begin{array}{l}\text { Time from primary surgery } \\
\text { to IBTR diagnosis (years) * }\end{array}$} \\
\hline$<2.0$ & 2.25 & $1.19-4.25$ & 0.012 & 2.54 & $1.17-5.53$ & 0.018 \\
\hline$\geq 2.0,<5.0$ & 0.82 & $0.45-1.49$ & 0.507 & 0.94 & $0.51-1.74$ & 0.845 \\
\hline$\geq 5.0,<10.0$ & 0.84 & $0.49-1.46$ & 0.541 & 0.88 & $0.51-1.54$ & 0.657 \\
\hline$\geq 10.0$ & 1.00 (reference) & & & 1.00 (reference) & & \\
\hline \multicolumn{7}{|l|}{ Location of IBTR } \\
\hline Breast & 1.00 (reference) & & & 1.00 (reference) & & \\
\hline Chest wall & 1.15 & $0.61-2.15$ & 0.672 & 0.73 & $0.34-1.54$ & 0.401 \\
\hline \multicolumn{7}{|c|}{ Receptor status of IBTR } \\
\hline HR+, HER-2- & 1.00 (reference) & & & 1.00 (reference) & & \\
\hline Triple-negative & 1.65 & $0.97-2.80$ & 0.063 & 1.82 & $1.04-3.26$ & 0.045 \\
\hline HR-, HER-2+ & 0.56 & $0.14-2.30$ & 0.422 & 0.84 & $0.20-3.51$ & 0.810 \\
\hline HR+, HER-2+ & 0.90 & $0.36-2.25$ & 0.822 & 1.05 & $0.41-2.66$ & 0.921 \\
\hline Unknown & 0.70 & $0.30-1.61$ & 0.398 & 0.88 & $0.36-2.15$ & 0.771 \\
\hline \multicolumn{7}{|c|}{ Lesion size of IBTR $(\mathrm{cm})$} \\
\hline$\leq 2$ & 1.00 (reference) & & & 1.00 (reference) & & \\
\hline$>2$ & 1.41 & $0.90-2.20$ & 0.137 & 1.57 & $0.99-2.50$ & 0.056 \\
\hline Unknown & 0.37 & $0.09-1.51$ & 0.165 & 0.35 & $0.08-1.59$ & 0.175 \\
\hline \multicolumn{7}{|c|}{ Chemotherapy after IBTR } \\
\hline No & 1.00 (reference) & & & 1.00 (reference) & & \\
\hline Yes & 0.61 & $0.35-1.04$ & 0.070 & 0.46 & $0.25-0.83$ & 0.010 \\
\hline \multicolumn{7}{|l|}{$\begin{array}{l}\text { Outcome of rSLNB } \\
\text { procedure }\end{array}$} \\
\hline Negative & 1.00 (reference) & & & 1.00 (reference) & & \\
\hline Positive & 1.35 & $0.67-2.72$ & 0.403 & 1.69 & $0.81-3.51$ & 0.163 \\
\hline Unsuccessful & 1.13 & $0.72-1.76$ & 0.596 & 1.05 & $0.66-1.66$ & 0.840 \\
\hline
\end{tabular}

Values in parentheses are 95 per cent confidence intervals. *Primary refers to the time of primary breast cancer treatment before the recurrence. IBTR ipsilateral breast tumour recurrence, HR hormone receptor, HER-2 human epidermal growth receptor 2, rSLNB repeat sentinel lymph node biopsy

Table 9.5 Multivariate Cox proportional hazards regression analysis of distant recurrence-freesurvival for patients with ipsilateral breast tumour recurrence, testing the interaction between adjuvant chemotherapy and oestrogen receptor status

\begin{tabular}{|c|c|c|c|c|}
\hline & \multicolumn{2}{|c|}{$\begin{array}{l}\text { Model with ER-negative } \\
\text { patients } \\
(n=89)^{*}\end{array}$} & \multicolumn{2}{|c|}{$\begin{array}{c}\text { Model with ER-positive } \\
\text { patients } \\
(n=386)\end{array}$} \\
\hline & Hazard ratio & $P$-value & Hazard ratio & $P$-value \\
\hline Adjuvant chemotherapy & $0.21(0.06-0.74)$ & 0.015 & $0.59(0.30-1.17)$ & 0.130 \\
\hline No adjuvant chemotherapy & $4.66(1.35-16.07)$ & 0.015 & $1.69(0.86-3.33)$ & 0.130 \\
\hline
\end{tabular}

Values in parentheses are 95 per cent confidence intervals. ER, oestrogen receptor. *Adjusted for $\mathrm{pN}$ status of primary tumour, disease-free interval, ipsilateral breast tumour recurrence location, tumour size and outcome of repeat sentinel lymph node biopsy 


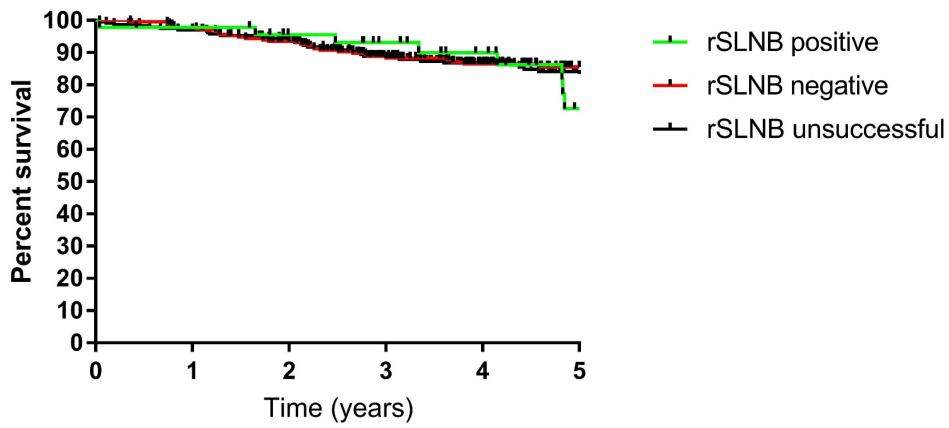

No. at risk

$\begin{array}{lcccccc}\text { rSLNB-positive } & 46 & 44 & 40 & 35 & 28 & 16 \\ \text { rSLNB-negative } & 230 & 226 & 210 & 172 & 130 & 89 \\ \text { rSLNB unsuccessful } & 239 & 228 & 212 & 182 & 151 & 117\end{array}$

rSLNB, repeat sentinel lymph node biopsy; IBTR, ipsilateral breast tumour recurrence

Figure 9.2 Kaplan-Meier curve showing distant recurrence-free survival after curative treatment for ipsilateral breast tumour recurrence, according to the outcome of repeat sentinel lymph node biopsy

\section{Discussion}

In this large cohort of 515 patients with IBTR, who all underwent rSLNB, the 5 -year DRFS was $84.2 \%$. Prognosis was significantly worse for patients with an interval of less than 2 years between primary breast cancer treatment and an IBTR, triple-negative IBTR or absence of treatment with adjuvant chemotherapy after IBTR. No statistically significant differences in outcomes (RR, DR) were found in comparisons of patients with a tumour-positive, tumour-negative or unsuccessful rSLNB.

Studies of the incidence of locoregional or DR after IBTR have reported rates ranging from 15 to $71 \% .^{9,24,25}$ Voogd and colleagues reported a 5-year DR rate of 55.8 per cent in a cohort patients with IBTR, initially treated between 1980 and $1992 .{ }^{9}$ That rate is much higher than the 5-year DR rate of $15.8 \%$ reported in the present SNARB cohort treated between 2002 and 2014. Advances in the diagnosis and treatment of breast cancer in recent years, might explain this difference. Furthermore, patients in the SNARB cohort had a more favourable prognosis as they were all clinically nodenegative.

Follow-up data of patients with ipsilateral locoregional recurrences in the CALOR trial were reported recently: $9.3 \%$ of patients developed an isolated locoregional rerecurrence after 5 years and 23\% developed DR ${ }^{3}$. However, the CALOR trial included patients with an isolated IBTR as well as those with regional disease. The present cohort 
included only patients with IBTR who had no clinical evidence of involved regional lymph nodes. Unfortunately, as other studies on prognosis after IBTR did not report on axillary staging methods, no comparison could be made of the results regarding the impact of rSLNB on outcome after IBTR.

Lymph node status is a known prognostic factor in primary breast cancer ${ }^{26}$. Therefore, it was hypothesized that lymph node status determined by rSLNB could have the same role in patients with IBTR. In an earlier study, a low regional relapse rate for rSLNBnegative patients treated without ALND suggested that omitting ipsilateral ALND was safe, and it was proposed that rSLNB should be adopted as standard of care in IBTR ${ }^{17}$. Going further, the present study analysed the impact of any axillary staging in patients with IBTR. No significant difference in the occurrence of DR after curative treatment for IBTR was found for patients with a tumour-positive, tumour-negative or unsuccessful rSLNB, in either univariable or multivariable analyses. This finding gives rise to several clinical questions and possible consequences regarding the value of surgical interventions in the axilla in patients with IBTR.

The value of rSLNB in clinically node-negative patients with IBTR might be disputed overall, as the outcome of the procedure appears to have minor impact on the prognosis. In addition, the rate of unsuccessful rSLNB procedures (46.4\%) was quite high here, although comparable with that in other studies ${ }^{27,28}$ reporting on rSLNB in patients with similar characteristics. Despite these findings, rSLNB could still be considered as a regional therapeutic procedure (preventing RR). Because the SNARB study did not collect data for patients with no axillary staging attempt at the time of IBTR, the therapeutic impact of the SNARB procedure could only be estimated from other observational studies. In a meta-analysis, the reported false-negative rate of rSLNB was $4.1 \%{ }^{13}$ The clinical ipsilateral recurrence rate after a negative rSLNB is 1.0 per cent after a follow-up of 5.1 years. ${ }^{17}$ Thus, a false-negative rSLNB seemed to be associated with clinical manifest recurrence in around $25 \mathrm{pr}$ cent of patients $(1.0 \% / 4.1 \%$ $\times 100$ ). In the total SNARB cohort, $8.9 \%$ of the patients had a positive rSLNB. These positive metastatic lymph nodes would be left behind if rSLNB were omitted, and RR would be expected to occur in more than $2 \%$ of the patients $(8.9 \% \times 24.4$ per cent/100) after 5.1 years of follow-up. In other words, $100 \mathrm{rSLNBs}$ would have to be performed to prevent two RRs. It is debatable whether fd-2 status only started in 2005; before that time, the HER-2 status of the primary tumour was generally not reported and this variable was therefore not included in the analysis. The number of rSLNB-positive patients in the SNARB study was relatively small, so a clinically relevant difference cannot be ruled out. Furthermore, a type II error owing to the low incidence of recurrence after IBTR cannot be excluded. An randomized controlled trial comparing patients who undergo rSLNB versus patients without any axillary interventions would be preferable to determine the impact on the occurrence of events after IBTR. However, such a trial would most probably be underpowered because of the low incidence of IBTR, and LR, RR, and DR after IBTR. 
Despite these limitations, the SNARB study represents a large cohort of patients with IBTR undergoing rSLNB with a median follow-up of more than 5 years. Furthermore, the inclusion of unselected patients in different types of hospitals in the Netherlands appears representative of the majority of patients with IBTR encounterd in daily practice. Based on the present findings, use of rSLNB as primary staging tool in patients with IBTR is disputable as it does not seem to provide important prognostic information. 


\section{References}

1. Taghian A, Jeong JH, Mamounas E, Anderson S, Bryant J, Deutsch M, et al. Patterns of locoregional failure in patients with operable breast cancer treated by mastectomy and adjuvant chemotherapy with or without tamoxifen and without radiotherapy: results from five National Surgical Adjuvant Breast and Bowel Project randomized clinical trials. J Clin Oncol. 2004;22(21):4247-4254.

2. van der Sangen MJ, van de Poll-Franse LV, Roumen RM, Rutten HJ, Coebergh JW, Vreugdenhil G, et al. The prognosis of patients with local recurrence more than five years after breast conservation therapy for invasive breast carcinoma. Eur J Surg Oncol. 2006;32(1):34-38.

3. Wapnir IL, Gelber S, Anderson SJ, Mamounas EP, Robidoux A, Martin M, et al. Poor Prognosis After Second Locoregional Recurrences in the CALOR Trial. Ann Surg Oncol. 2017;24(2):398-406.

4. Anderson SJ, Wapnir I, Dignam JJ, Fisher B, Mamounas EP, Jeong JH, et al. Prognosis after ipsilateral breast tumor recurrence and locoregional recurrences in patients treated by breast-conserving therapy in five National Surgical Adjuvant Breast and Bowel Project protocols of node-negative breast cancer. J Clin Oncol. 2009;27(15):2466-2473.

5. Alpert TE, Kuerer HM, Arthur DW, Lannin DR, Haffty BG. Ipsilateral breast tumor recurrence after breast conservation therapy: outcomes of salvage mastectomy vs. salvage breast-conserving surgery and prognostic factors for salvage breast preservation. Int J Radiat Oncol Biol Phys. 2005;63(3):845-851.

6. Galper S, Blood E, Gelman R, Abner A, Recht A, Kohli A, et al. Prognosis after local recurrence after conservative surgery and radiation for early-stage breast cancer. Int $\mathrm{J}$ Radiat Oncol Biol Phys. 2005;61(2):348-357.

7. Wadasadawala T, Vadgaonkar R, Bajpai J. Management of Isolated Locoregional Recurrences in Breast Cancer: A Review of Local and Systemic Modalities. Clin Breast Cancer. 2017;17(7):493-502.

8. Geurts YM, Witteveen A, Bretveld R, Poortmans PM, Sonke GS, Strobbe LJA, et al. Patterns and predictors of first and subsequent recurrence in women with early breast cancer. Breast Cancer Res Treat. 2017;165(3):709-720.

9. Voogd AC, van Oost FJ, Rutgers EJ, Elkhuizen PH, van Geel AN, Scheijmans LJ, et al. Long-term prognosis of patients with local recurrence after conservative surgery and radiotherapy for early breast cancer. Eur J Cancer. 2005;41(17):2637-2644.

10. Chand AR, Ziauddin MF, Tang SC. Can Locoregionally Recurrent Breast Cancer Be Cured? Clin Breast Cancer. 2017;17(5):326-335.

11. Siglin J, Champ CE, Vakhnenko Y, Anne PR, Simone NL. Radiation therapy for locally recurrent breast cancer. Int J Breast Cancer. 2012;2012:571946.

12. Hannoun-Levi JM, Ihrai T, Courdi A. Local treatment options for ipsilateral breast tumour recurrence. Cancer treatment reviews. 2013;39(7):737-741.

13. Poodt IGM, Vugts G, Schipper RJ, Nieuwenhuijzen GAP. Repeat sentinel lymph node biopsy for ipsilateral breast tumor recurrence: A systematic review of the results and impact on prognosis. Ann Surg Oncol. 2018;25(5):1329-1339.

14. Maaskant-Braat AJ, Voogd AC, Roumen RM, Nieuwenhuijzen GA. Repeat sentinel node biopsy in patients with locally recurrent breast cancer: a systematic review and meta-analysis of the literature. Breast Cancer Res Treat. 2013;138(1):13-20.

15. Vugts G, Maaskant-Braat AJ, Voogd AC, van Riet YE, Luiten EJ, Rutgers EJ, et al. Repeat sentinel node biopsy should be considered in patients with locally recurrent breast cancer. Breast Cancer Res Treat. 2015;153(3):549-556.

16. Intra M, Viale G, Vila J, Grana CM, Toesca A, Gentilini O, et al. Second Axillary Sentinel Lymph Node Biopsy for Breast Tumor Recurrence: Experience of the European Institute of Oncology. Ann Surg Oncol. 2015;22(7):2372-2377.

17. Poodt IGM, Vugts G, Maaskant-Braat AJG, Schipper RJ, Voogd AC, Nieuwenhuijzen GAP, et al. Risk of regional recurrence after negative repeat sentinel lymph node biopsy in patients with ipsilateral breast tumor recurrence. Ann Surg Oncol. 2018;25(5):1312-1321.

18. Vugts G, Maaskant-Braat AJG, Voogd AC, van Riet YEA, Roumen RMH, Luiten EJT, et al. Improving the Success Rate of Repeat Sentinel Node Biopsy in Recurrent Breast Cancer. Ann Surg Oncol. 2015;22: 529-535. 
19. Edge SB, Compton CC. The American Joint Committee on Cancer: the 7th edition of the AJCC cancer staging manual and the future of TNM. Ann Surg Oncol. 2010;17(6):1471-1474.

20. Moossdorff M, Vugts G, Maaskant-Braat AJ, Strobbe LJ, Voogd AC, Smidt ML, et al. Contralateral lymph node recurrence in breast cancer: Regional event rather than distant metastatic disease. A systematic review of the literature. Eur J Surg Oncol. 2015;41(9):1128-1136.

21. Gourgou-Bourgade S, Cameron D, Poortmans P, Asselain B, Azria D, Cardoso F, et al. Guidelines for time-to-event end point definitions in breast cancer trials: results of the DATECAN initiative (Definition for the Assessment of Time-to-event Endpoints in CANcer trials). Ann Oncol. 2015;26(12):2505-2506.

22. Hudis CA, Barlow WE, Costantino JP, Gray RJ, Pritchard KI, Chapman JA, et al. Proposal for standardized definitions for efficacy end points in adjuvant breast cancer trials: the STEEP system. J Clin Oncol. 2007;25(15):2127-2132.

23. Aebi S, Gelber S, Anderson SJ, Lang I, Robidoux A, Martin M, et al. Chemotherapy for isolated locoregional recurrence of breast cancer (CALOR): a randomised trial. Lancet Oncol. 2014;15(2): 156-163.

24. Gentilini O, Botteri E, Veronesi P, Sangalli C, Del Castillo A, Ballardini B, et al. Repeating conservative surgery after ipsilateral breast tumor reappearance: criteria for selecting the best candidates. Ann Surg Oncol. 2012;19(12):3771-3776.

25. Verheuvel NC, Voogd AC, Tjan-Heijnen VCG, Siesling S, Roumen RMH. Non-visualized sentinel nodes in breast cancer patients; prevalence, risk factors, and prognosis. Breast Cancer Res Treat. 2018;167(1):147-156.

26. Jatoi I, Benson JR, Toi M. De-escalation of axillary surgery in early breast cancer. Lancet Oncol. 2016;17(10):e430-e441.

27. Port ER, Garcia-Etienne CA, Park J, Fey J, Borgen PI, Cody IHS. Reoperative sentinel lymph node biopsy: A new frontier in the management of ipsilateral breast tumor recurrence. Annals of Surgical Oncology. 2007;14(8):2209-2214.

28. Uth CC, Christensen MH, Oldenbourg MH, Kjaer C, Garne JP, Teilum D, et al. Sentinel Lymph Node Dissection in Locally Recurrent Breast Cancer. Ann Surg Oncol. 2015;22(8):2526-2531. 


PART III 



\section{Chapter 10}

Summary, discussion and recommendations 


\section{Summary, discussion and recommendations}

The objective of this thesis was to explore the de-escalation of axillary management in primary and recurrent breast cancer. The first part presents trends of de-escalation of axillary surgery in primary breast cancer patients in the Netherlands and reports on the impact of these trends on the administration of systemic therapy. Furthermore, the impact on survival of incomplete nodal staging in elderly is reported. The second part relates to the use of different imaging modalities for pre-operative staging patients with ipsilateral recurrent breast cancer and explores the prognostic impact of repeat sentinel lymph node biopsy ( $r S L N B$ ) in patients with ipsilateral breast tumor recurrence (IBTR). All findings of this thesis are summarized and discussed in the following chapter.

\section{Part I: De-escalation of axillary management in de the primary setting}

Axillary lymph node management has changed dramatically in the past decades, ${ }^{1}$ mostly due to prior research questioning the extent of axillary surgery for early stage breast cancer; i.e. the NSABP B-04, ${ }^{2}$ ACOSOG-Z0011, ${ }^{3}$ IBSCG 23-01, ${ }^{4}$ OTOASOR trial ${ }^{5}$ and AMAROS trial. ${ }^{6}$ At first, the NSABP B-04 (accrual 1971-1974, published 2002) revealed after 25 years follow up, that the performance of a delayed axillary lymph node dissection (ALND) in case of occult positive lymph nodes, did not affect survival in, clinical node negative, primary breast cancer patients treated without systemic treatment or radiotherapy ${ }^{2}$. More recently, the ACOSOG-Z0011 trial (accrual 19992004, published 2011), exposed that completion ALND (CALND) could be safely omitted in cT1-2 clinically node negative breast cancer patient with a maximum of two positive sentinel lymph nodes (SLNs), if treated with breast conserving therapy (BCT) and adjuvant systemic therapy. ${ }^{3,7}$ Furthermore, the IBCSG 23-01 (accrual 2001-2010, published 2014) revealed that cALND could be safely avoided in patients with sentinel node (SN)-micro metastasis and treated with mastectomy (4.9\%) or BCT. ${ }^{4,8}$ Exploring the oncological safety of axillary irradiation, the OTOASOR trial (accrual 2002-2009, published 2013), found in early stage breast cancer patients, cT $<3 \mathrm{~cm}, \mathrm{pN} 1(\mathrm{SN})$, treated with BCT or mastectomy ( $16 \%$ of patients), and treated with cALND compared with regional nodal irradiation, no difference in the risk of axillary failure. ${ }^{5,9}$ The AMAROS trial (accrual 2001-2010, published 2014) revealed no additional benefit of cALND compared with axillary radiotherapy in cT1-2N0 breast cancer patients with 1 to 2 (and $5 \%>2$ ) positive sentinel lymph nodes, treated with BCT or mastectomy ( $18 \%$ of patients). ${ }^{6}$

To explore the impact of the aforementioned trials, the first study in this thesis (chapter 2) described trends in axillary management in 37,520 patients diagnosed with cT1-4NOM0 invasive, primary, breast cancer between 2011 and 2015 in the Netherlands. This study showed a trend towards less extensive axillary surgery, illustrated by an overall increase of sentinel lymph node biopsy from $72 \%$ to $93 \%$, and 
decrease in the use of cALND from $75 \%$ to $17 \%$ in cT1-2NO SN-positive patients. These trends reflected the implementation of previous mentioned randomizes trials in the Netherlands, and thereby confirm the de-escalation of axillary surgery in the primary setting. ${ }^{10}$ However, variations in patterns of care in axillary surgery between different types of hospitals in the Netherlands were noticed, revealing the presence of early and late adaptors. While no randomized trials were published to justify less extensive therapy in cT3-4 SN-positive patients, cALND was also selectively omitted in this group of patients. ${ }^{10}$ Since it was not yet clear whether or not a cALND could be omitted in primary breast cancer patients with $\mathrm{SN}$-macro metastasis, undergoing a mastectomy (and thus were not irradiated to the axilla), the BOOG-2013-07 was initiated. ${ }^{11}$ Because of slow accrual, the study was closed prematurely. It seems that clinical practice had caught up science and the omission of ALND was already implanted in clinical practice. A reduction in the percentage of cALND in patients treated with mastectomy was observed in our study. These results reflect the confidence of physicians in the concept that not every positive axillary lymph node will develop into clinically detectable axillary disease. ${ }^{2,3}$ Further data must determine, whether the conservative axillary surgery approach in cT3-4 patients in patient treated with mastectomy was expeditiousness.

For patients with clinically node positive disease extensive axillary treatment was often still indicated in order to provide regional oncological control. An ALND was routinely performed in all clinical node positive patients, also in those patients treated with neoadjuvant systemic therapy (NST), irrespective of the axillary response to NST. Increased use of NST, resulted in significant number of patients with axillary pathologic complete response and urges the need for also a less invasive procedure for axillary staging after NST. ${ }^{12}$ A wide variation of less invasive staging procedures, such as SLNB, removal of a marked axillary lymph node with radioactive iodine seed (MARI), or a combination of these two procedures (e.g. targeted axillary dissection) have been merged in clinical practice. A review from Simons and colleagues reported that axillary staging by a combination procedure consisting of SLNB and excision of a pre-NST marked positive lymph node (MARI) appeared to be the most accurate for axillary staging after NST. ${ }^{12}$

The increased use of adjuvant therapy like regional irradiation, chemo(-immuno) therapy, and/or hormonal therapy, also played a significant role in the shift to a more conservative approach of the axilla. The presence of axillary lymph node metastases used to be an important prognostic factor for the administration of adjuvant treatments. In the Dutch Breast Cancer Guidelines, adjuvant chemotherapy was recommended for all patients (<70 years) with lymph node positive tumors. However, more recent internal guidelines (St. Gallen) recommended adjuvant chemotherapy for hormone receptor positive, HER2-negative tumor (i.e. luminal A-like phenotype), only in case of more than three metastatic lymph nodes. A cALND may detect additional nodal involvement that upstages the pathologic nodal status and according to the guidelines, could thus influence systemic treatment. A point of discussion regarding the 
de-escalation of axillary surgery is the lack of information on the extent of nodal involvement. Axillary nodal involvement has always been an important factor for tumor staging, tailoring adjuvant chemotherapy plans and an important predictor for breast cancer recurrence. ${ }^{13}$ Loss of information regarding the total axillary tumor burden could thus lead to difficulties regarding these topics. Some hypothesized that the knowledge on the SN tumor burden would be enough in clinical decision-making for adjuvant chemotherapy in clinically node negative patients. ${ }^{14}$ However, others assumed that SNpositive patients treated without extensive axillary surgery should be treated with adjuvant chemotherapy, in order to manage possible occult metastases in the remaining axillary lymph nodes. ${ }^{15}$ In Chapter 3, exploring the impact of omitting CALND in sentinel node positive patients $(n=4331)$ on the administration of adjuvant chemo(immuno)therapy, $57 \%$ of patients treated with SLNB alone received chemo(immuno)therapy, compared with $75 \%$ of patients treated with cALND. ${ }^{16}$ Even after adjustment for potential confounding factors like patient age, lymph nodal status (pN1 and $\geq \mathrm{pN} 2$ ) and the hormone receptor (HR)-status, the performance of cALND had a positive impact on the administration of adjuvant chemo-(immuno)therapy. ${ }^{16}$ Intriguingly, not the extent of nodal involvement, but the performance of cALND by itself had a great impact on the administration of adjuvant chemo-(immuno)therapy. It is debatable that treatment choices were not solely based on guidelines, but also influenced by patients and physicians' opinions regarding comorbidities, fragility, and health related quality of life. Since the administration of adjuvant chemo(immuno)therapy was not only based on the lymph nodal status (pN1 or $\geq p N 2$ ), the discussion regarding loss of information on the final axillary tumor burden seems less important.

In the past decades, the use of adjuvant chemotherapy has considerably improved the prognosis of breast cancer patients. ${ }^{17}$ Though, there is also a growing awareness that not all breast cancer patients, especially estrogen receptor positive patients, derive benefit from chemotherapy. ${ }^{18}$ Furthermore, toxicity of systemic therapies, warrant an effective use indeed. ${ }^{19}$ The standard administration of adjuvant chemotherapy increases the risk of overtreatment as the threshold to use chemotherapy is hard to determine. ${ }^{20}$ In addition to the already known prognostic information of several patient and tumor factors, gene expression profiles were developed and investigated. The Dutch Breast Cancer Guideline presented in 2012, suggested that the use of gene expressing profiling in patients who benefited from chemotherapy was uncertain based on traditional prognostic factors. ${ }^{20}$

In chapter 3, we described a decrease in the administration of adjuvant chemo (-immuno) from 68\% to 55\% between 2011 and 2015 in the Netherlands. Possibly, due to the emerge of molecular biomarkers with powerful prognostic and predictive capacities as well as gene-expressing profiling techniques as forecasters for clinical decision making. ${ }^{15}$ Unfortunately, in chapter $\mathbf{3}$ information was missing regarding the 
use of gene-expression profiling. Schreuder and colleagues did investigated the use of gene-expressing profiling in the Netherlands and presented that only $7.5 \%$ of high risk patients ( among other things, all patients with metastatic lymph node involvement) received gene expressing profiling in the period 2011-2014. ${ }^{20}$ Among those high-risk patients, half were node positive and only $6.0 \%$ of the node positive patients received gene expressing profiling. Metastatic lymph node involvement was independently associated with an increased risk of chemotherapy administration in clinical high-risk patients with a low-risk gene expressing profile.

In the elderly breast cancer patient physicians already refrained from extensive axillary therapy, due to patient preferences, reduced health status, fragility and comorbidities. $^{21,22}$ Since elderly patients are often excluded from clinical trials, ${ }^{23,24}$ little evidence on the impact of such conservative treatments in the elderly population have been reported. The study presented in Chapter 4, compared in a cohort of primary elderly ( $\geq 75$ years) breast cancer patients; a group who received cALND in case of a positive SLN or who underwent ALND directly; and with a group of elderly who underwent no axillary staging procedures at all (no SLNB nor (c)ALND) or who received no CALND after a positive-SN (deviating from the standard axillary management those days (2001-2008)). ${ }^{25}$ The last group was considered to be the "incomplete staging group". Comparing those groups, this study showed no apparent impact of an "incomplete staging" on regional control and 10-year overall survival of elderly patients. ${ }^{25}$ Since most of the patients died from non-breast-cancer-related causes, elderly patients might be a group of patients for whom the assumed benefits of surgical treatment of the axilla do not outweigh the burden. Presently, omitting such cALND, had become standard of care in selected primary breast cancer patients; as we presented earlier with the increasing trend of omitting cALND in selected SN-positive patients. ${ }^{10}$ However, in the period the participating patients were treated (2001-2008), omitting cALND after a positive-SN was inconceivable. The extrapolation of the concept of no axillary staging in the elderly patient, now has been subject of several trials in a larger group of breast cancer patients. Following the de-escalating trend in axillary primary management, interest is raised in omitting all axillary surgical treatments, ${ }^{26}$ thereby sparing patients the morbidity related to axillary surgery and minimizing the impact of those treatments on the qualitive of life of breast cancer survivors. The SOUND, POSNOC and BOOG 2013-08 trials are currently exploring differences in outcome between patients staged with SLNB compared to no axillary surgery at all. The study results must be awaited. ${ }^{27-29}$

\section{Part II: Preoperative staging and de-escalation of axillary management in} patients with ipsilateral breast tumor recurrence (IBTR)

Within 10-years, approximately $2-5 \%$ of all primary breast cancer patients will experience an IBTR. ${ }^{30,31}$ New challenges belie the distinction of IBTR into true local recurrences and new ipsilateral primary tumors. Studies showed that patients with new primary tumors generally have a favorable long-term prognosis. ${ }^{32}$ Therapeutic decisions 
regarding systemic therapy in new primaries, could thus be similar to those used for patients with primary breast cancers. The distinction between new primaries and true recurrences may thus have important implications for the clinical management of patients with IBTR. However, accurate methods establishing the type of IBTR have proven difficult to reproduce ${ }^{33}$ and to date no consensus exist regarding the best method to differentiate.

In patients with IBTR, the detection and if present, the extent of distant metastases determines the curative or palliative intent of treatment. ${ }^{34}$ Therefore, adequate preoperative staging seems to be imperative for optimal treatment planning. Synchronous distant metastases are reported in up to $15-30 \%$ of patients with an IBTR and up to $35 \%$ of patients with isolated lymph node recurrence. ${ }^{35}$ Factors found to be associated with the presence of synchronous metastases are the TNM stage of the primary tumor, with patients with more advanced stages having a higher risk, ${ }^{36}$ and the type of locoregional recurrence, with patients with lymph node recurrences having a higher risk compared to patients with IBTR. ${ }^{35}$

In the last decades, besides conventional imaging techniques, ${ }^{18}$ F-FDG PET-CT has been shown to have a potential role in staging of IBTR patients. Chapter $\mathbf{5}$ assessed the use of different imaging modalities over time and investigated the long term impact of a specific preoperative staging procedure on the development of distant recurrences in patients diagnosed with IBTR. It was hypothesized when a staging method would be more sensitive, less occult metastases would develop to overt clinical metastases. Of all patients, $46.3 \%$ were preoperatively staged with conventional imaging, 19.8\% with ${ }^{18}$ F-FDG PET-CT, and $33.9 \%$ received no preoperative imaging at all. This wide spectrum in the use of conventional imaging, ${ }^{18}$ F-FDG PET-CT or no imaging at all to stage IBTR patients in the Netherlands, revealed a lack of concordance in guidelines. Over time, the use of ${ }^{18} \mathrm{~F}$-FDG PET-CT increased from $7 \%$ to $25 \%$, reflecting the confidence of physicians in the use of ${ }^{18} \mathrm{~F}$-FDG PET-CT, even though the clinical role of ${ }^{18} \mathrm{~F}$-FDG PET-CT remains controversial, ${ }^{37}$ since there is no evidence of the impact of ${ }^{18}$ F-FDG PET-CT on patients' outcomes.

Conventional imaging modalities have shown to be less sensitive and specific than ${ }^{18}$ F-FDG PET-CT. ${ }^{38,39}$ Theoretically, occult metastases could be present at time of diagnosis of IBTR, though too small for detection on conventional imaging modalities. Staging using a more sensitive staging strategy, i.e. ${ }^{18}$ F-FDG PET-CT could prevent false negative outcomes, by detecting otherwise occult distant metastases. Synchronous occult metastases missed at time of IBTR could continue to grow and could become clinical overt during follow-up. Thereby, ${ }^{18}$ F-FDG PET-CT is deemed to be especially valuable in the detection of extra-axillary nodal metastases. ${ }^{38,39}$ In chapter $\mathbf{5}$ however, no difference in the likelihood of, and time to, developing distant recurrences after curative treatment of IBTR, according to the distant staging strategy used at time of IBTR, was observed. Furthermore, patients screened with conventional imaging had a 
6-year regional recurrence free rate of $96.4 \%$, compared to $96.2 \%$ and $95.3 \%$ for patients with no imaging and ${ }^{18}$ F-FDG PET-CT, respectively. Therefore, a preferred distant screening strategy could not be recommended. Further studies are needed to define the long term consequences of ${ }^{18} \mathrm{~F}$-FDG PET-CT in preoperative stage patients with IBTR and to create consensus in guidelines. A randomized controlled trial comparing patients staged with conventional imaging versus patients staged with ${ }^{18}$ F-FDG PET-CT versus patients not staged at all would be preferable. However, such a trial would most probably be underpowered because of the low incidence of IBTR, and distant recurrences after IBTR.

The management of the lymph nodes in patients with IBTR is not standardized and largely not addressed by current guidelines. ${ }^{40}$ Historically, the performance of an ipsilateral ALND was a standard procedure in all patients with IBTR, aiming to achieve maximum regional disease control. Fortunately, in the recurrent setting the deescalation of axillary management has also been an ongoing trend. The rationale of performing a standard ipsilateral ALND has become questionable for several reasons. First, the prognostic impact of the nodal status at time of IBTR is unclear. Second, the staging accuracy of ipsilateral ALND is debatable, since aberrant lymphatic drainage patterns are reported frequently in IBTR patients. ${ }^{41}$ Last, exposing patients with IBTR to the risks of morbidity associated with ALND is disputed. Several studies have evaluated the concept of rSLNB in patients with IBTR and an increased number of patients with IBTR have undergone this procedure. The feasibility of rSLNB has been confirmed in the Dutch nationwide "Sentinel Node And Recurrent Breast cancer (SNARB)" registration study, which is the largest study regarding this subject, so far $(\mathrm{N}=536) .{ }^{41,42} \mathrm{~A}$ rSLN was identified in $62.1 \%$ of the patients and appeared to be tumor-negative in $80.1 \%$, justifying the omission of a completion ALND and sparing those patients' related morbidity. ${ }^{41}$ Extra-axillary SLNs or aberrant SLNs were reported in $54.1 \%$ of patients with successful surgical harvested rSLN, nodes whom would not be noticed with a standard ipsilateral ALND. Furthermore, the rSLNB appeared to have a role in tailoring adjuvant treatment plans. ${ }^{41,43}$ Though, the impact of the outcome of rSLNB on regional recurrence and overall survival of IBTR patients remained unclear until recently. For rSLNB to become an equivalent standard of care in the IBTR setting, it was imperative to ensure a high regional disease control and to investigate the impact of rSLNB on prognosis.

At first, an up to date systematic review was conducted to identify all current knowledge on rSLNB in patients with IBTR (Chapter 6). A rSLNB was successfully identified in $64 \%$ of the patients, and this rate was significantly higher for patients previous treated with SLNB alone compared to those who previous underwent ALND. ${ }^{44}$ With a negative predictive value of $96.5 \%$ rSLNB seemed to be highly specific. Unfortunately, the included studies revealed too little data to elucidate the prognostic value of rSLNB. The safety in terms of regional disease control after rSLNB was still 
unclear. Hence, follow-up data of all the SNARB patients were collected. Chapter 7 revealed a 5-year risk of developing regional recurrences after a negative rSLNB in patients treated without subsequent ALND of $4.6 \%$. Only $1 \%$ of these regional recurrences were located in the ipsilateral axilla. ${ }^{45}$ During the introduction of SLNB in the primary setting, an ipsilateral axillary recurrence rate of $5 \%$ was accepted to replace CALND by SLNB as a standard axillary staging tool. ${ }^{46}$ Analogous to these rates, it seems acceptable that the $1.0 \%$ reported in chapter 7 herein justified the replacement of an ipsilateral ALND by rSLNB in case of clinically node-negative recurrent disease.

IBTR patients have a higher risk of non-visualization of sentinel nodes and/or no successful surgical harvesting of sentinel nodes, due to previous treatments. As reported in chapter 6, a rSLN was harvested in approximately $64 \%$ of the IBTR patients. ${ }^{44}$ For the remaining patients the rSLNB procedure was unsuccessful, which meant that no sentinel lymph node could be harvested. One could speculate that in patients with unsuccessful rSLNB, positive sentinel nodes may have been left behind which could develop into clinically detectable diseases. Chapter 8 revealed a 5-year regional recurrence rate of only $3.7 \%$ in patients with such unsuccessful rSLNB treated without completion ALND. A quite similar rate compared with the $4.6 \%$ found in the group of patients with successfully harvested negative rSLNs, ${ }^{46}$ signifying no need for additional treatment of the axilla after an unsuccessful rSLNB. Present results fuel the discussion on the impact of any surgical axillary staging method in patients with IBTR. Recently, Ugras and colleagues, already questioned whether axillary staging with rSLNB was even worthwhile. They found a comparable regional recurrence rate between patients staged with rSLNB and patients with no axillary staging. ${ }^{47}$ The low regional recurrence rate in patients with unsuccessful rSLNB is in line with the results presented by Ugras and co-workers. Furthermore, with improving non-invasive diagnostic options as ${ }^{18}$ F-FDG PET-CT, the rationale seems to be even more questionable. Since no studies reported on the risk of distant recurrences and the impact of rSLNB on prognosis in patients with IBTR, it was speculated that rSLNB in clinically node negative IBTR patients might be of limited value. Chapter 9 showed a 5-year distant recurrence free survival of $84 \%$ in patients with IBTR. Prognosis was significantly worse for patients with an interval of less than 2 years between primary treatment and IBTR, a triple-negative IBTR and absence of adjuvant chemotherapy following IBTR. Moreover, no differences were found on the regional and distant recurrences rate comparing patients with a tumor positive, tumor negative or unsuccessful rSLNB. The outcome of the rSLNB procedure appeared to have minor impact on the prognosis, and therefore the value of performing rSLNB in clinically node negative IBTR patients might be disputed overall.

Still others consider rSLNB as a regional therapeutic procedure, since removal of the $\mathrm{SN}(\mathrm{s})$ could possibly prevent regional recurrences. The SNARB study did not include patients with no axillary surgical staging attempt at the time of IBTR and therefore the therapeutic impact of rSLNB could only be estimated from other observational studies. 
As reported in Chapter 9, the calculated therapeutic impact yielded only $2 \%$. In other words, 100 rSLNBs have to be performed to prevent two regional recurrences. It is debatable whether the standard performance of a rSLNB is justified with these numbers. As mentioned before, Ugras and colleagues already compared a group of IBTR patients with rSLNB with a group of IBTR patients with no axillary staging and found no differences in axillary recurrences rate between both groups. ${ }^{47}$ In the primary setting, several studies comparing CALND with SLNB alone reported that pathologically involved lymph nodes were found in $27-39 \%$ of patients undergoing ALND, ${ }^{3,6,9}$ while no difference was found in the axillary recurrence rate between both groups. Apparently, only a limited part of all axillary involved lymph nodes have the potential to cause regional problems, which appears to be the same in the recurrent setting. Furthermore, adjuvant systemic therapy and whole breast radiotherapy are factors that most likely diminish the risk that possible metastases left in situ will develop into clinically detectable lymph nodes.

A randomized controlled trial comparing patients treated with rSLNB versus patients treated without any axillary interventions would be preferable to identify the impact. However, as a randomized controlled trial is not feasible due to the low incidence of IBTR and recurrences after IBTR, it is reassuring that the SNARB study is the largest study published to date on the prognostic impact of rSLNB in clinically node negative patients.

The National Surgical Adjuvant Breast and Bowel Project (NSABP) trial revealed in two reports for node-positive and node-negative primary disease, all undergoing ALND, the overall survival rates after IBTR. ${ }^{48,49}$ However, the treatment strategies used after IBTR, including axillary management, were not described. The reported 5-year mortality risk after IBTR for primary node-negative and node-positive patients of $33 \%$ and $49 \%,{ }^{48,49}$ respectively, justified the use of systemic therapy for all patients with locoregional recurrence regardless of their nodal status at that time. ${ }^{47}$ The CALOR trial underlined this statement and revealed that the use of adjuvant chemotherapy in all IBTR patient is supported, especially in the ER-negative subgroup. ${ }^{50}$ Since the result of rSLNB did not have a prognostic value, a rSLNB will probably not change the indication for adjuvant systemic therapy.

Another subject for debate is the differentiation of IBTRs into "true" recurrences or new primary tumors in which the latter appeared to have a better survival rate. ${ }^{32,51} \mathrm{~A}$ new primary tumor could be regarded as a primary breast cancer tumor, treated as such and therefore having a great impact on clinical decision making. The distinction could be made based on tumor characteristics, such as tumor type, disease free interval, location, involved margins after primary surgery and receptor status. Others use molecular analysis to investigate the clonality between the primary tumor and IBTR. ${ }^{33}$ Accurate methods establishing the type of IBTR have been proven difficult to reproduce. $^{33}$ To date no consensus exist regarding the best method to differentiate. 
Furthermore, studies comparing recurrence free survival between true recurrences and new primaries are lacking.

\section{Conclusion and recommendations}

The main aim of this thesis was to describe the de-escalation of axillary management in the primary and recurrent setting of breast cancer, thereby diminishing the risk for complications, while maintaining regional control and overall survival. The role of surgery in breast cancer treatment and axillary management has changed and over the years extensive axillary surgery has gradually been replaced by less invasive techniques such as the sentinel lymph node procedure. SN-positive patients treated with cALND showed a higher independent probability for receiving adjuvant chemo (-immuno) therapy compared to patients treated with SLNB only. For elderly patients ( 75 years or older), the omission of any axillary staging or the omission of CALND after a positive SLNB had no apparent impact on regional control and 10 -year overall survival. Hence, ALND is no longer the standard approach for the management of all breast cancer patients with metastases in the SLNs. Further research is needed to explore the need for extensive surgery in the axilla of patients with high stage disease (cT3-4NO) and in clinically node-positive patients. Perhaps there will be an even greater role for (neo)adjuvant systemic therapies and radiotherapy to control locoregional disease. The axillary nodal status has been shown to be the most important prognostic factor in primary breast cancer, but molecular biomarkers with prognostic and predictive capacity have an emerging role in clinical decision making. ${ }^{15}$

Subsequent to changes in the primary setting, the axillary management of patients with IBTR changed and the concept of a repeat SLNB was implemented in the recurrent setting. A systematic review revealed an identification rate of $64 \%$ for rSLNB and with a negative predictive value of $96.5 \%$ rSLNB appeared to be highly specific. Furthermore, the risk of developing regional recurrence after negative rSLNB was low, supporting the safety of rSLNB. For patients with an unsuccessful rSLNB, there was no need for additional surgical treatment, since the regional recurrence risk is negligible. The overall distant recurrence free survival rate for all the SNARB patients was $84.2 \%$. An interval of less than two years between primary breast cancer treatment and ipsilateral recurrence, a triple-negative IBTR and absence of adjuvant chemotherapy after IBTR were independently associated with poor distant recurrence- free survival. The association between the outcome of rSLNB (positive $r S L N$, negative rSLN or unsuccessful rSLNB) and distant-recurrence free survival was not statistically significant. Further, it seems to be useful to stage all patients diagnosed with IBTR for distant metastases, though no preference was found to stage with conventional imaging or ${ }^{18}$ F-FDG PET-CT. 
In conclusion, this thesis confirmed the de-escalation of axillary management in the primary and recurrent setting. The nationwide SNARB study confirmed the feasibility, validity and safety of repeated SLNB in case of locally recurrent breast cancer and thereby eliminated the need for ALND and its associated morbidity. Minimizing the risk of severe morbidity related to extensive surgery, and improving the quality of life of breast cancer survivors. Going forward, since the outcome of rSLNB was not an important prognostic factor for distant recurrence, its value as staging tool seems disputable. In our opinion, these results warrant a change in the axillary management of patients with IBTR; to certainly withdraw from ALND and to consider that rSLNB is of limited value, if any.

\section{Future perspectives}

This thesis provides a next step towards less extensive axillary surgery for breast cancer patients. Although SLNB is a minimally invasive procedure it is still associated with some morbidity, including a 5-year risk of lymphedema up to $5 \% .{ }^{52}$ Against the background of improvements in breast cancer survival and the substantial reduction in the extent of axillary node surgery, the value of any surgical intervention of the axilla in primary as well as in IBTR patients is argued. In this era dominated by a growing knowledge of tumor biology, molecular biomarkers, gene expressing profiling techniques, non-invasive diagnostic options and effective adjuvant therapies, the role for axillary surgery either as a therapeutic and/or as a staging procedure is further decreasing.

Eligibility for adjuvant systemic therapy is increasingly based on the primary tumor biomarkers, and not solely on the nodal status. ${ }^{15}$ In the primary setting results have to be awaited from the SOUND, POSNOC and BOOG 2013-08 trials. ${ }^{27-29}$ The results of these trails will influence the perceptions on the value and purpose of SLNB. Further research in molecular biology and genetics, as well as the development of highly accurate non-invasive techniques such as imaging guided treatments, will change the future status of cancer treatment and ultimately that of breast cancer surgery. Research on these topics are encouraging and will potentially further minimize axillary surgery to the extent that in the future axillary surgery might only be considered for patients with regional failure after non-surgical management of the regional lymph nodes. In doing so, axillary surgery might become the adjuvant treatment of axillary management in general.

A reliable categorization between true recurrences and de novo transformation can be of great value since these new primary tumors may be regarded as primary tumors and therefore be treated as such. In the future, it could be useful to include determination of tumor characteristics and for instance molecular analysis to investigate the clonality between tumors ${ }^{53}$ (i.e. LOH-comparison) in the evaluation of IBTR patients. 
Following the de-escalating trend in the management of breast cancer, questions were raised regarding the surgical standard of a salvage mastectomy for all patients with an IBTR, previously treated with BCT. In the primary treatment setting, the inferiority of mastectomy compared with BCT, regarding cosmesis, perioperative risks and quality of life, has been evaluated extensively. ${ }^{54,55}$ With the improved survival of patients with IBTR, attention is warranted regarding these topics in patients with IBTR as well. Now, approaches that use repeated lumpectomy and repeated partial breast radiation are emerging. Several options have been lightly investigated such as repeated lumpectomy alone, or followed by, whole-breast external beam re-irradiation, partial breast reirradiation, e.g. external partial irradiation, brachytherapy or intra-operative radiotherapy. Walstra and colleagues, presented in a systematic review that repeated lumpectomy with or without radiotherapy seemed to be a reasonable alternative to salvage mastectomy in selected patients with IBTR. ${ }^{56}$ The oncological safety of this approach in terms of local control and overall survival seemed to improve with the addition of radiotherapy to repeated lumpectomy, without causing an unacceptable toxicity or worse cosmetic outcome. ${ }^{56}$ Furthermore, several advantages of intraoperative radiotherapy (IORT) over external beam were presented regarding patients' convenience, quality of life, cosmesis, and oncoplastic treatment options. ${ }^{56}$ Hence, following the trend of de-escalating management in breast cancer, future treatment strategies for patients with IBTR may include repeated lumpectomy with IORT.

Quality of life, shared decision making and less invasive techniques are now key values in axillary and breast management. Therefore, all (IBTR) patients should be discussed in a multi-disciplinary tumor board meeting to individualize treatment based on the expected risk-benefit of axillary staging. 


\section{References}

1. Rescigno J, Zampell JC, Axelrod D. Patterns of axillary surgical care for breast cancer in the era of sentinel lymph node biopsy. Ann Surg Oncol 2009;16:687-696.

2. Fisher $\mathrm{B}$, Jeong JH, Anderson $\mathrm{S}$, et al. Twenty-five-year follow-up of a randomized trial comparing radical mastectomy, total mastectomy, and total mastectomy followed by irradiation. $\mathrm{N}$ Engl J Med 2002;347:567-575.

3. Giuliano AE, Hunt KK, Ballman KV, et al. Axillary dissection vs no axillary dissection in women with invasive breast cancer and sentinel node metastasis: a randomized clinical trial. JAMA 2011;305: 569-575.

4. Galimberti V, Cole BF, Zurrida S, et al. Axillary dissection versus no axillary dissection in patients with sentinel-node micrometastases (IBCSG 23-01): a phase 3 randomised controlled trial. Lancet Oncol 2013;14:297-305.

5. Savolt A, Polgar C, Musonda $\mathrm{P}$, et al. Does the result of completion axillary lymph node dissection influence the recommendation for adjuvant treatment in sentinel lymph node-positive patients? Clin Breast Cancer 2013;13:364-370

6. Donker M, van Tienhoven G, Straver ME, et al. Radiotherapy or surgery of the axilla after a positive sentinel node in breast cancer (EORTC 10981-22023 AMAROS): a randomised, multicentre, open-label, phase 3 non-inferiority trial. Lancet Oncol 2014;15:1303-1310.

7. Giuliano AE, Ballman KV, McCall L, et al. Effect of Axillary Dissection vs No Axillary Dissection on 10-Year Overall Survival Among Women With Invasive Breast Cancer and Sentinel Node Metastasis: The ACOSOG Z0011 (Alliance) Randomized Clinical Trial. JAMA 2017;318:918-926.

8. Galimberti V, Cole BF, Viale G, et al. Axillary dissection versus no axillary dissection in patients with breast cancer and sentinel-node micrometastases (IBCSG 23-01): 10-year follow-up of a randomised, controlled phase 3 trial. Lancet Oncol 2018;19:1385-1393.

9. Savolt A, Peley G, Polgar C, et al. Eight-year follow up result of the OTOASOR trial: The Optimal Treatment Of the Axilla - Surgery Or Radiotherapy after positive sentinel lymph node biopsy in earlystage breast cancer: A randomized, single centre, phase III, non-inferiority trial. Eur J Surg Oncol 2017; 43:672-679.

10. Poodt IGM, Spronk PER, Vugts G, et al. Trends on Axillary Surgery in Nondistant Metastatic Breast Cancer Patients Treated Between 2011 and 2015: A Dutch Population-based Study in the ACOSOGZ0011 and AMAROS Era. Ann Surg 2018;268:1084-1090.

11. van Roozendaal LM, de Wilt JH, van Dalen T, et al. The value of completion axillary treatment in sentinel node positive breast cancer patients undergoing a mastectomy: a Dutch randomized controlled multicentre trial (BOOG 2013-07). BMC Cancer 2015;15:610.

12. Simons JM, van Nijnatten TJA, van der Pol CC, et al. Diagnostic Accuracy of Different Surgical Procedures for Axillary Staging After Neoadjuvant Systemic Therapy in Node-positive Breast Cancer: A Systematic Review and Meta-analysis. Ann Surg 2019;269:432-442.

13. Carter $\mathrm{CL}$, Allen C, Henson DE. Relation of tumor size, lymph node status, and survival in 24,740 breast cancer cases. Cancer 1989;63:181-187.

14. Ponzone R, Ruatta F, Gatti M, et al. Omission of axillary dissection after a positive sentinel lymph-node: Implications in the multidisciplinary treatment of operable breast cancer. Cancer Treat Rev 2016;48:1-7.

15. Jatoi I, Benson JR, Toi M. De-escalation of axillary surgery in early breast cancer. Lancet Oncol 2016;17: e430-e441.

16. Poodt IGM, Rots ML, Vugts G, et al. The administration of adjuvant chemo(-immuno) therapy in the post ACOSOG-Z0011 era; a population based study. Eur J Surg Oncol 2018;44:1151-1156.

17. Early Breast Cancer Trialists' Collaborative G. Effects of chemotherapy and hormonal therapy for early breast cancer on recurrence and 15-year survival: an overview of the randomised trials. Lancet 2005;365:1687-1717.

18. Paik S, Tang G, Shak S, et al. Gene expression and benefit of chemotherapy in women with nodenegative, estrogen receptor-positive breast cancer. J Clin Oncol 2006;24:3726-3734.

19. Beisecker A, Cook MR, Ashworth J, et al. Side effects of adjuvant chemotherapy: perceptions of nodenegative breast cancer patients. Psychooncology 1997;6:85-93. 
20. Schreuder K, Kuijer A, Rutgers EJT, et al. Impact of gene-expression profiling in patients with early breast cancer when applied outside the guideline directed indication area. Eur J Cancer 2017;84:270-277.

21. Velanovich V, Gabel M, Walker EM, et al. Causes for the undertreatment of elderly breast cancer patients: tailoring treatments to individual patients. J Am Coll Surg 2002;194:8-13.

22. Wyld L, Garg DK, Kumar ID, et al. Stage and treatment variation with age in postmenopausal women with breast cancer: compliance with guidelines. Br J Cancer 2004;90:1486-1491.

23. Biganzoli L, Wildiers $\mathrm{H}$, Oakman $\mathrm{C}$, et al. Management of elderly patients with breast cancer: updated recommendations of the International Society of Geriatric Oncology (SIOG) and European Society of Breast Cancer Specialists (EUSOMA). Lancet Oncol 2012;13:e148-160.

24. Wildiers H, Kunkler I, Biganzoli L, et al. Management of breast cancer in elderly individuals: recommendations of the International Society of Geriatric Oncology. Lancet Oncol 2007;8:1101-1115.

25. Poodt IGM, Schipper RJ, Vugts G, et al. The rationale for and long-term outcome of incomplete axillary staging in elderly women with primary breast cancer. Eur J Surg Oncol 2018;44:1714-1719.

26. Martelli G, Boracchi P, Orenti A, et al. Axillary dissection versus no axillary dissection in older T1NO breast cancer patients: 15-year results of trial and out-trial patients. Eur J Surg Oncol 2014;40:805-812.

27. Gentilini O, Veronesi U. Abandoning sentinel lymph node biopsy in early breast cancer? A new trial in progress at the European Institute of Oncology of Milan (SOUND: Sentinel node vs Observation after axillary UltraSouND). Breast 2012;21:678-681.

28. Goyal A, Dodwell D: POSNOC. A Randomised Trial Looking at Axillary Treatment in Women with One or Two Sentinel Nodes with Macrometastases. Clin Oncol (R Coll Radiol) 2015;27:692-695.

29. van Roozendaal LM, Vane MLG, van Dalen T, et al. Clinically node negative breast cancer patients undergoing breast conserving therapy, sentinel lymph node procedure versus follow-up: a Dutch randomized controlled multicentre trial (BOOG 2013-08). BMC Cancer 2017;17:459.

30. Geurts YM, Witteveen A, Bretveld R, et al. Patterns and predictors of first and subsequent recurrence in women with early breast cancer. Breast Cancer Res Treat 2017;165:709-720.

31. Bosma SC, van der Leij F, van Werkhoven E, et al. Very low local recurrence rates after breast-conserving therapy: analysis of 8485 patients treated over a 28-year period. Breast Cancer Res Treat 2016;156: 391-400.

32. Huang E, Buchholz TA, Meric F, et al. Classifying local disease recurrences after breast conservation therapy based on location and histology: new primary tumors have more favorable outcomes than true local disease recurrences. Cancer 2002;95:2059-2067.

33. McGrath S, Antonucci J, Goldstein N, et al. Long-term patterns of in-breast failure in patients with early stage breast cancer treated with breast-conserving therapy: a molecular based clonality evaluation. Am J Clin Oncol 2010;33:17-22.

34. Trovo M, Furlan C, Polesel J, et al. Radical radiation therapy for oligometastatic breast cancer: Results of a prospective phase II trial. Radiother Oncol 2018;126:177-180.

35. Neuman HB, Schumacher JR, Francescatti AB, et al. Risk of Synchronous Distant Recurrence at Time of Locoregional Recurrence in Patients With Stage II and III Breast Cancer (AFT-01). J Clin Oncol 2018;36: 975-980.

36. Singletary SE, Allred C, Ashley P, et al. Revision of the American Joint Committee on Cancer staging system for breast cancer. J Clin Oncol 2002;20:3628-3636.

37. Krammer J, Schnitzer A, Kaiser CG, et al. (18) F-FDG PET/CT for initial staging in breast cancer patients Is there a relevant impact on treatment planning compared to conventional staging modalities? Eur Radiol 2015;25:2460-2469.

38. Eubank WB, Mankoff DA, Takasugi J, et al. 18fluorodeoxyglucose positron emission tomography to detect mediastinal or internal mammary metastases in breast cancer. J Clin Oncol 2001;19:3516-3523.

39. Jager JJ, Keymeulen K, Beets-Tan RG, et al. FDG-PET-CT for staging of high-risk breast cancer patients reduces the number of further examinations: A pilot study. Acta Oncol 2010;49:185-191.

40. Derkx F, Maaskant-Braat AJ, van der Sangen MJ, et al. Staging and management of axillary lymph nodes in patients with local recurrence in the breast or chest wall after a previous negative sentinel node procedure. Eur J Surg Oncol 2010;36:646-651.

41. Vugts G, Maaskant-Braat AJ, Voogd AC, et al. Repeat sentinel node biopsy should be considered in patients with locally recurrent breast cancer. Breast Cancer Res Treat 2015;153:549-556.

42. Maaskant-Braat AJ, Roumen RM, Voogd AC, et al. Sentinel Node and Recurrent Breast Cancer (SNARB): results of a nationwide registration study. Ann Surg Oncol 2013;20:620-626. 
43. Maaskant-Braat AJ, Voogd AC, Roumen RM, et al. Repeat sentinel node biopsy in patients with locally recurrent breast cancer: a systematic review and meta-analysis of the literature. Breast Cancer Res Treat 2013;138:13-20.

44. Poodt IGM, Vugts G, Schipper RJ, et al. Repeat Sentinel Lymph Node Biopsy for Ipsilateral Breast Tumor Recurrence: A Systematic Review of the Results and Impact on Prognosis. Ann Surg Oncol 2018;25: 1329-1339.

45. Poodt IGM, Vugts G, Maaskant-Braat AJG, et al. Risk of Regional Recurrence After Negative Repeat Sentinel Lymph Node Biopsy in Patients with Ipsilateral Breast Tumor Recurrence. Ann Surg Oncol 2018;25:1312-1321.

46. de Kanter AY, Menke-Pluymers MM, Wouters MW, et al. 5-Year follow-up of sentinel node negative breast cancer patients. Eur J Surg Oncol 2006;32:282-286.

47. Ugras S, Matsen C, Eaton A, et al. Reoperative Sentinel Lymph Node Biopsy is Feasible for Locally Recurrent Breast Cancer, But is it Worthwhile? Ann Surg Oncol 2016;23:744-748.

48. Anderson SJ, Wapnir I, Dignam JJ, et al. Prognosis after ipsilateral breast tumor recurrence and locoregional recurrences in patients treated by breast-conserving therapy in five National Surgical Adjuvant Breast and Bowel Project protocols of node-negative breast cancer. J Clin Oncol 2009;27: 2466-2473.

49. Wapnir IL, Anderson SJ, Mamounas EP, et al. Prognosis after ipsilateral breast tumor recurrence and locoregional recurrences in five National Surgical Adjuvant Breast and Bowel Project node-positive adjuvant breast cancer trials. J Clin Oncol 2006;24:2028-2037.

50. Wapnir IL, Price KN, Anderson SJ, et al. Efficacy of Chemotherapy for ER-Negative and ER-Positive Isolated Locoregional Recurrence of Breast Cancer: Final Analysis of the CALOR Trial. J Clin Oncol 2018; 36(11):1073-1079.

51. Smith TE, Lee D, Turner BC, et al. True recurrence vs. new primary ipsilateral breast tumor relapse: an analysis of clinical and pathologic differences and their implications in natural history, prognoses, and therapeutic management. Int J Radiat Oncol Biol Phys 2000;48:1281-1289.

52. McLaughlin SA, Wright MJ, Morris KT, et al. Prevalence of lymphedema in women with breast cancer 5 years after sentinel lymph node biopsy or axillary dissection: objective measurements. J Clin Oncol 2008;26:5213-5219.

53. Goldstein NS, Vicini FA, Hunter S, et al. Molecular clonality determination of ipsilateral recurrence of invasive breast carcinomas after breast-conserving therapy: comparison with clinical and biologic factors. Am J Clin Pathol 2005;123:679-689.

54. Chatterjee A, Pyfer B, Czerniecki B, et al. Early postoperative outcomes in lumpectomy versus simple mastectomy. J Surg Res 2015;198:143-148.

55. Chow R, Pulenzas N, Zhang L, et al. Quality of life and symptom burden in patients with breast cancer treated with mastectomy and lumpectomy. Support Care Cancer 2016;24:2191-2199.

56. Walstra C, Schipper RJ, Poodt IGM, et al. Repeat breast-conserving therapy for ipsilateral breast cancer recurrence: A systematic review. Eur J Surg Oncol 2019;45(8):1317-1327 

Nederlandse samenvatting, discussie en aanbevelingen 


\section{Nederlandse samenvatting, discussie en aanbevelingen}

Dit proefschrift evalueert de trends met betrekking tot de axillaire lymfeklier chirurgie bij patiënten met primair en recidief borstkanker en de impact van de trend van minder opereren (de-escalatie) op de uitgebreidheid van aanvullende behandelingen, de kansen op terugkeer van ziekte, en de invloed van deze veranderingen op de overleving van borstkanker patiënten. In het eerste gedeelte van dit proefschrift worden trends gepresenteerd over de de-escalatie in axillaire lymfeklier chirurgie bij patiënten met primair borstkanker in Nederland. Tevens wordt er gerapporteerd over de impact van deze de-escalerende trend op het geven van systemische therapie. Vervolgens wordt het effect van een incomplete axillaire stadiëring op de overleving van ouderen met primair borstkanker gerapporteerd. Het tweede deel van dit proefschrift beschrijft het gebruik van verschillende soorten van beeldvormend onderzoek voor de preoperatieve stadiëring van patiënten met een ipsilateraal borsttumor recidief (IBTR). Als laatste wordt de prognostische impact van een herhaalde uitvoering (repeat) van een schildwachtklierbiopsie (SWK-biopsie) bij patiënten met een IBTR onderzocht. Alle bevindingen van dit proefschrift worden samengevat en besproken in dit hoofdstuk.

\section{Deel I: De-escalatie van axillaire lymfeklier chirurgie bij primair borstkanker}

Axillaire lymfeklier diagnostiek en de chirurgische uitgebreidheid hiervan zijn drastisch veranderd in de afgelopen decennia. ${ }^{1}$ Studies zoals o.a. de NSABP B-04 ${ }^{2}$, ACOSOGZ0011 ${ }^{3}$, IBSCG 23-01 ${ }^{4}$, OTOASOR ${ }^{5}$ en AMAROS $^{6}$, bediscussiëren de uitgebreidheid en impact van axillaire chirurgie bij laag stadium borstkanker patiënten. Als eerste toont de NSABP B-04 studie (inclusie 1971-1974, gepubliceerd in 2002) na 25 jaar follow-up aan, dat het enkel uitvoeren van een okselklierdissectie (OKD) in het geval van klinisch manifeste axillaire lymfeklieren, vergeleken met het standaard uitvoeren van een OKD bij diagnose, geen invloed heeft op de overleving van patiënten met primair borstkanker. Alle in deze studie geïncludeerde patiënten ontvingen geen systemische therapie of radiotherapie. ${ }^{2}$ Meer recentelijk, toont de ACOSOG-Z0011 studie aan (inclusie 1999-2004, gepubliceerd in 2011), dat een complementerende OKD (cOKD) veilig achter wegen gelaten kon worden bij cT1-2 klinisch lymfeklier negatieve borstkanker patiënten met maximaal twee positieve SWK-en, indien zij worden behandeld met een borstsparende techniek en adjuvante systemische therapie., Vervolgens blijkt uit de IBCSG 23-01 studie (inclusie 2001-2010, gepubliceerd in 2014) dat een COKD tevens veilig achterwege gelaten kon worden bij patiënten met micrometastasen in de SWK(-en), behandeld met een mastectomie ( $9 \%$ van de geïncludeerde patiënten) of middels een borstsparende techniek. ${ }^{4,8}$ Vervolgens werd de oncologische veiligheid van radiotherapie op de oksel onderzocht. De OTOASOR studie (inclusie 2002-2009, gepubliceerd in 2013), toont geen verschil aan in het ontwikkelen van een axillair recidief tussen patiënten behandelend met een cOKD of 
met enkel radiotherapie op de oksel., ${ }^{5,9}$ De geïncludeerde patiënten zijn allemaal primaire borstkankerpatiënten, met $\mathrm{cT} \leq 3 \mathrm{~cm}$ tumoren, $\mathrm{pN} 1$ op basis van een SWKbiopsie, behandeld met een borstsparende techniek of een mastectomie ( $16 \%$ van de patiënten). Daarop aansluitend, toont de AMAROS-studie (inclusie 2001-2010, gepubliceerd in 2014) geen verschil aan tussen een cOKD en axillaire radiotherapie aan, bij cT1-2NO borstkankerpatiënten met 1 tot 2 (en $5 \%>2$ ) positieve SWK-en, behandeld met een borstsparende techniek of met een mastectomie (18\% van de patiënten). ${ }^{6}$

De eerste studie van dit proefschrift (hoofdstuk 2) evalueert de impact van bovenstaande trials op axillaire lymfeklier chirurgie in 37.520 patiënten gediagnosticeerd met cT1-4NOM0 primair borstkanker in Nederland tussen 2011-2015. Hoofdstuk 2 laat een trend zien naar minder uitgebreide axillaire chirurgie in cT1-2NO SWK-positieve patiënten, weergegeven door een toename in het gebruik van de SWKprocedure van $72 \%$ tot $93 \%$, en een afname van de meer uitgebreide cOKD van $75 \%$ tot 17\%. Deze trends weerspiegelen de implementatie van eerder genoemde gerandomiseerde studies in Nederland en bevestigen daarmee de de-escalatie van axillaire chirurgie in de primaire borstkanker setting in Nederland. ${ }^{10}$ Echter, specifieker kijkend naar ziekenhuizen, worden er variaties opgemerkt in de uitgebreidheid van axillaire chirurgie tussen verschillende soorten ziekenhuizen in Nederland. Dit brengt de aanwezigheid van vroeg en laat implementerende ziekenhuizen aan het licht. Wat verder opvalt is, dat ondanks nog geen gerandomiseerde studies de veiligheid van minder uitgebreide axillaire chirurgie bij cT3-4 SWK-positieve patiënten heeft aangetoond, ook in deze groep patiënten al selectief de cOKD achterwege wordt gelaten. $^{10}$

Gezien er nog onduidelijkheid bestond of een cOKD ook veilig achterwege gelaten kon worden bij primaire borstkankerpatiënten met een positieve SWK-biopsie, behandeld met een mastectomie (waardoor hoogstwaarschijnlijk niet behandeld met radiotherapie op de oksel), werd de BOOG-2013-07 studie opgezet. ${ }^{11}$ Vanwege een te langzame inclusie van patiënten werd het onderzoek helaas vroegtijdig gesloten. Het lijkt erop dat de praktijk de wetenschap reeds heeft ingehaald en het achterwege laten van een COKD in deze groep patiënten al reeds in de kliniek is geïmplanteerd. Een afname van het aantal uitgevoerde cOKDs bij patiënten behandeld met een mastectomie wordt ook in hoofdstuk $\mathbf{2}$ waargenomen. Al deze resultaten weerspiegelen het vertrouwen van artsen in het concept dat niet elke positieve axillaire lymfeklier zich zal ontwikkelen tot klinisch detecteerbare axillaire ziekte., ${ }^{2,3}$ Vervolgonderzoek moet laten zien, of een minder uitgebreide axillair chirurgische aanpak in cT3-4 patiënten, als ook in patiënten behandeld met een mastectomie, gerechtvaardigd is.

Voor patiënten met klinisch lymfeklier positieve ziekte $(\mathrm{cN}+)$, is een uitgebreide axillaire behandeling vaak nog geïndiceerd. Een OKD werd routinematig uitgevoerd bij alle 
klinisch lymfeklier positieve patiënten, ook bij die patiënten die werden behandeld met neo-adjuvante systemische therapie (NST), ongeacht de lymfeklierstatus en dus de respons na NST. Toename in het gebruikt van NST, resulteert in een significant aantal patiënten met axillair volledige respons. ${ }^{12}$ Dit roept mogelijkheden op voor een minder uitgebreide okselklier procedure na NST. Verschillende mogelijkheden van minder invasieve procedures, zoals de SWK-biopsie, de verwijdering van een voorafgaande aan NST gemarkeerde axillaire lymfeklier met radioactief jodium zaad (MARI-procedure), of een combinatie van deze twee procedures (bijv. een gerichte axillaire dissectie) worden tegenwoordig uitgevoerd. Een review van Simons en collega's laat zien dat axillaire chirurgie, doormiddel van een combinatie procedure bestaande uit een SWK-biopsie en excisie van een pre-NST gemarkeerde positieve lymfeklier (MARI-klier) de meest nauwkeurige procedure blijkt te zijn voor axillaire stadiëring na NST. ${ }^{12}$

Toename in het gebruik van adjuvante therapieën, zoals (regionale) radiotherapie, chemo (-immuno) therapie en/of hormonale therapieën, spelen ook een belangrijke rol in de verschuiving naar minder uitgebreide axillaire chirurgie. De aanwezigheid van axillaire lymfeklier metastasen was vroeger een belangrijke prognostische factor voor het geven van adjuvante therapieën. In de Nederlandse richtlijn voor borstkanker werd adjuvante chemotherapie aanbevolen voor alle patiënten ( $<70$ jaar) met een positieve lymfeklier. Echter, een recente internationale richtlijn (St. Gallen) raadt adjuvante chemotherapie aan voor patiënten met een bepaald tumortype borstkanker, namelijk de hormoonreceptor-positieve, HER2-negatieve tumoren (ook wel luminal A-achtige fenotype), enkel in de aanwezigheid van meer dan drie positieve lymfeklieren. Een uitgebreide OKD kan meerdere positieve lymfeklieren detecteren, waardoor de pathologische klierstatus verandert en zo mogelijk ook de inzet van een systemische behandeling. Hiermee wordt meteen een punt van discussie aangesneden betreffende de de-escalatie van axillaire chirurgie; het gebrek aan informatie over de uitgebreidheid van lymfeklier metastasen in de axilla. Axillaire lymfeklier betrokkenheid is altijd een belangrijke factor geweest voor tumor stadiëring, inzet van adjuvante chemotherapie en een belangrijke voorspeller voor borstkanker recidief. ${ }^{13}$ Verlies van informatie over de totale axillaire tumorlast kan dus leiden tot onduidelijkheden met betrekking tot deze onderwerpen. Enkele artsen veronderstellen dat de uitslag van de SWK-biopsie genoeg zal zijn voor de klinische besluitvorming t.a.v. adjuvante chemotherapie in klinisch lymfeklier-negatieve patiënten. ${ }^{14}$ Andere artsen gaan ervan uit dat alle SWKpositieve patiënten, zonder aanvullend axillaire chirurgie, behandeld dienen te worden met adjuvante chemotherapie, om zo mogelijke occulte metastasen in de resterende axillaire lymfeklieren te bestrijden. ${ }^{15}$ Hoofdstuk 3 beschrijft de impact van het achterwege laten van een cOKD in SWK-positieve patiënten ( $\mathrm{N}=4331)$ op de toediening van adjuvante chemo-(immuno) therapie. Van de patiënten die enkel een SKW-biopsie ondergaan word $57 \%$ behandeld met chemo-(immuno) therapie, vergeleken met $75 \%$ van de patiënten behandeld met een cOKD. ${ }^{16}$ Zelfs na correctie voor andere factoren, zoals leeftijd, pathologische lymfeklierstatus ( $p N 1$ en $\geq p N 2$ ) en de hormoonreceptor 
(HR)-status, heeft het uitvoeren van een cOKD een grotere invloed op behandeling met adjuvante chemo-(immuno) therapie in vergelijking met het uitvoeren van SWKbiopsie. ${ }^{16}$ Intrigerend, dat niet de mate van lymfeklier betrokkenheid (zoals $\mathrm{pN}$ status), maar het uitvoeren van een COKD, an sich, een grotere invloed heeft op behandeling met adjuvante chemo-(immuno) therapie. Behandelplannen worden niet uitsluitend opgesteld aan de hand van de richtlijnen, maar ook beïnvloed door de mening van patiënten en artsen. Hierbij rekening houdend met mogelijke comorbiditeit, complicaties, kwaliteit van leven en de invloed van chemo- (immuno) therapieën hierop. Aangezien de toediening van adjuvante chemo-(immuno) therapie niet alleen gebaseerd wordt op de pathologische lymfeklierstatus ( $\mathrm{pN1}$ of $\geq \mathrm{pN2}$ ), lijkt de discussie over het verlies van informatie over de uiteindelijke axillaire tumorlast, door het minder uitvoeren van cOKDs, minder belangrijk.

In de laatste decennia, heeft het gebruik van adjuvante chemotherapie de prognose van borstkankerpatiënten aanzienlijk verbeterd. ${ }^{17}$ Tegenwoordig is er een groeiend besef dat niet alle borstkankerpatiënten, vooral de oestrogeen receptor positieve patiënten, standaard baat hebben van chemotherapie. ${ }^{18}$ Bekende bijwerkingen van systemische therapieën laten zien dat een efficiënt gebruik van chemotherapie nodig is. ${ }^{19}$ Naast de reeds bekende prognostische patiënt- en tumor-factoren, zijn de laatste tijd ook bepaalde genexpressie profielen onderzocht en ontwikkeld. De Nederlandse richtlijn voor borstkanker uit 2012, rapporteert dat genexpressie profielen geïndiceerd zijn, in het bijzonder bij oestrogeen receptor positieve patiënten, indien er op basis van de klassieke prognostische factoren twijfel bestaat over de toegevoegde waarde van adjuvante chemotherapie. ${ }^{20}$

Hoofdstuk 3 laat een daling zien in het gebruik van adjuvante chemotherapie (immuno) in Nederland van $68 \%$ in 2011 tot 55\% in 2015. Mogelijk is deze daling toe te schrijven aan de opkomst van moleculaire bio markers met goede prognostische en voorspellende capaciteiten, als ook de opkomst van genexpressie profilering in borstkanker. ${ }^{15}$ Helaas ontbreekt er in hoofdstuk 3 informatie over het gebruik van genexpressie profilering bij de geïncludeerde patiënten. Schreuder en collega's evalueren in hun studie het gebruik van genexpressie profilering in Nederland en rapporteren dat slechts $7,5 \%$ van de patiënten met een hoog risico profiel (waaronder patiënten met positieve lymfeklieren) genexpressie profilering ontvingen in de periode 2011-2014. ${ }^{20}$ Onder de patiënten met een hoog risico profiel, is 50\% lymfeklier positief en slechts $6,0 \%$ van deze lymfeklier positieve patiënten ontving genexpressie profilering. De betrokkenheid van gemetastaseerde lymfeklieren is onafhankelijk geassocieerd met een verhoogd risico op het krijgen van chemotherapie bij klinisch hoog-risicopatiënten met een laag risico-gen expressie profiel. De conclusie luidt dan ook dat de inzet van chemotherapie als adjuvante behandeling, destijds nog niet werd aangepast o.b.v. het genexpressie profiel. 
Bij de oudere borstkanker patiënt wijken artsen al langer af van dat wat standaard is. De oudere patiënt wordt al langer minder uitgebreide behandeld in de axilla. Dit komt onder andere door voorkeuren van de patiënt zelf, door een verminderde gezondheidstoestand, door mogelijke fragiliteit en comorbiditeit. ${ }^{21,22}$ Omdat oudere patiënten vaak uitgesloten worden van klinische onderzoeken ${ }^{23,24}$, is er weinig data gepubliceerd over de impact van een dergelijk de-escalerende behandeling bij ouderen. In hoofdstuk 4 worden twee groepen oudere borstkanker patiënten ( $\geq 75$ jaar) met elkaar vergeleken. De ene groep bestaat uit oudere patiënten die een cOKD ondergaan in het geval van een positieve-SWK en patiënten die direct een OKD ondergaan zonder een voorafgaand SWK-biopsie. De tweede groep bestaat uit een groep oudere patiënten die geen axillaire chirurgie ondergaan (geen SWK-biopsie of (c)OKD) en patiënten die geen cOKD ondergaan in het geval van een positieve-SWK. De tweede groep wordt gezien als de afwijkende groep, gezien die groep patiënten niet de standaard axillaire behandeling ondergingen van destijds (2001-2008). ${ }^{25}$ Deze groep wordt beschouwd als de "onvolledige stadiërings-groep". Bij het vergelijken van beide groepen, laat deze studie geen impact zien van "onvolledige stadiëring" op het ontwikkelen van regionale recidieven en de 10-jaars overleving van oudere patiënten. ${ }^{25}$ Omdat het merendeel van de patiënten stierf aan niet-borstkanker gerelateerde oorzaken, zijn oudere borstkanker patiënten wellicht een groep patiënten waarbij de veronderstelde voordelen van een axillaire chirurgie niet opwegen tegen de last. Tegenwoordig, is het achterwege laten van dergelijke COKD, standaard behandeling geworden bij geselecteerde borstkanker patiënten met een primaire tumor. Deze trend wordt ook gezien in hoofdstuk 2 met een stijgend percentage over de tijd in het achterwege laten van een COKD in geselecteerde SWK-positieve patiënten. ${ }^{10}$ Destijds (2001-2008) was het standaard achterwege laten van een cOKD na een positief-SWK zeer ongebruikelijk. Het concept, dat toen ook al werd uitgevoerd bij de oudere patiënt, namelijk het helemaal achterwege laten van een axillair chirurgische behandeling, is nu het onderwerp van verschillende studies in grotere groepen borstkankerpatiënten. Aansluitend aan de de-escalerende trend in axillaire chirurgie in de primaire setting, gaat nu dus ook de aandacht uit naar het helemaal achterwege laten van axillair chirurgische behandelingen. ${ }^{26}$ Hierdoor wordt patiënten de morbiditeit met betrekking tot axillaire chirurgie bespaart en de impact van deze behandelingen en mogelijke complicaties op de kwaliteit van leven geminimaliseerd. De SOUND, POSNOC en BOOG 2013-08 studies, onderzoeken momenteel de verschillen in uitkomst tussen patiënten die een SWK-biopsie ondergaan in vergelijking met patiënten die geen axillaire chirurgie ondergaan. De studieresultaten laten tot nu toe nog op zich wachten. ${ }^{27-29}$

\section{Deel II: preoperatief stadiëring en de-escalatie van axillaire chirurgie bij patiënten met een ipsilateraal borsttumor recidief}

Binnen 10 jaar worden tussen de 2-5\% van alle borstkankerpatiënten met een primaire borstkanker geconfronteerd met een IBTR. ${ }^{30,31}$ Nieuwe uitdagingen liggen daar in het 
onderscheiden van IBTRs; de "echt" lokaal recidieven en nieuwe ipsilaterale borstkankers (nieuwe primaire borstkankers). Studies hebben aangetoond dat patiënten met een nieuwe primaire borstkanker over het algemeen een gunstigere lange termijn prognose hebben. ${ }^{32}$ Therapeutische beslissingen met betrekking tot systemische therapie voor patiënten met een nieuwe primaire borstkanker kunnen vergelijkbaar zijn met die voor patiënten met een in eerste instantie primaire borstkanker. Het onderscheid tussen een nieuwe primaire borstkanker en een echt lokaal recidief kan dus belangrijke gevolgen hebben voor het klinisch beleid van patiënten met een IBTR. Het ontwikkelen van accurate methoden voor het bepalen van het type IBTR $^{33}$ blijkt moeilijk te zijn en tot op heden bestaat er geen consensus over wat de beste methode is om te kunnen differentiëren.

Bij patiënten met een IBTR bepaalt de detectie en indien aanwezig de uitgebreidheid van afstandsmetastasen de curatieve of palliatieve inzet van behandeling. ${ }^{34}$ Daarom is een adequate preoperatieve stadiëring noodzakelijk voor het opstellen van het optimale behandelplan. Synchrone metastasen op afstand worden gerapporteerd bij maximaal $15-30 \%$ van de patiënten met een IBTR en tot $35 \%$ van de patiënten met een geïsoleerde lymfeklier recidief. ${ }^{35}$ Factoren die worden geassocieerd met de aanwezigheid van synchrone metastasen zijn de TNM-classificatie van de primaire tumor, waarbij patiënten met vergevorderde stadia een hoger risico hebben ${ }^{36}$, en het type locoregionale recidief, waarbij patiënten met lymfeklier recidieven een hoger risico hebben in vergelijking met patiënten met een IBTR. ${ }^{35}$

In de laatste decennia, blijkt dat naast conventionele beeldvorming, ${ }^{18} \mathrm{~F}-\mathrm{FDG}$ PET-CT een potentiële rol heeft in de stadiëring van IBTR-patiënten. Hoofdstuk 5 evalueert het gebruik van verschillende beeldvormende modaliteiten over de tijd (2008-2014) en onderzoekt de lange termijn effecten van een bepaalde preoperatieve stadiëring techniek op de ontwikkeling van lange afstandsmetastasen bij patiënten gediagnosticeerd met een IBTR. Er werd verondersteld dat bij het gebruik van een meer sensitieve beeldvormende techniek, minder occulte metastasen zich zouden ontwikkelen tot klinische detecteerbare metastasen. Van alle patiënten, worden $46,3 \%$ preoperatief gestadieerd middels conventionele beeldvorming, 19,8\% met ${ }^{18}$ F-FDG PET$\mathrm{CT}$, en $33,9 \%$ worden niet preoperatief gestadieerd. Het verschil in het gebruik van conventionele beeldvorming, ${ }^{18}$ F-FDG PET-CT of helemaal geen beeldvorming weerspiegelt een gebrek aan eenduidigheid in de richtlijnen. In de loop van de tijd stijgt het gebruik van ${ }^{18}$ F-FDG PET-CT van $7 \%$ naar $25 \%$, wat het vertrouwen van artsen in het gebruik ${ }^{18}$ F-FDG PET-CT weerspiegelt. Toch blijft de klinische rol van ${ }^{18}$ F-FDG PET-CT controversieel $^{37}$, omdat er tot op heden geen bewijs is van de impact van ${ }^{18}$ F-FDG PETCT op de uitkomst van patiënten.

Conventionele beeldvorming blijkt minder sensitief en minder specifiek te zijn dan ${ }^{18} \mathrm{~F}$ FDG PET-CT ${ }^{38,39}$ Theoretisch gezien kunnen occulte metastasen aanwezig zijn op het moment van stadiëring, maar te klein voor detectie op conventionele beeldvorming 
modaliteiten. Stadiëring met behulp van een meer sensitievere strategie, zoals ${ }^{18} \mathrm{~F}$-FDG PET-CT, kan vals negatieve uitkomsten voorkomen, door het detecteren van anderszins occulte afstandsmetastasen. Synchrone occulte metastasen, gemist op het moment van IBTR, kunnen blijven groeien en klinische zichtbaar worden gedurende follow-up. Daarnaast wordt ${ }^{18}$ F-FDG PET-CT bijzonder waardevol geacht bij de opsporing van extra-axillaire lymfeklier metastasen. ${ }^{38,39}$ In hoofdstuk $\mathbf{5}$ wordt echter geen verschil gezien in de ontwikkeling van, en tijd tot ontwikkeling van, afstandsmetastasen na de curatieve behandeling van een IBTR, tussen de drie verschillende groepen. Daarbij hebben patiënten die gescreend worden met conventionele beeldvorming een 6-jaar regionaal recidiefpercentage van $96,4 \%$, vergeleken met $96,2 \%$ en $95,3 \%$ voor patiënten zonder enige beeldvorming en ${ }^{18} \mathrm{~F}$-FDG PET-CT, respectievelijk. Daarom kan aan de hand van deze studie geen geprefereerde stadiëring techniek voor afstandsmetastasen worden aanbevolen. Verdere studies zijn nodig om de lange termijn gevolgen van ${ }^{18} \mathrm{~F}$-FDG PET-CT in de preoperatieve stadiëring van patiënten met IBTR te definiëren en om consensus in de richtlijnen te creëren. Een gerandomiseerde trial waarin conventionele beeldvorming versus ${ }^{18}$ F-FDG PET-CT versus geen beeldvorming wordt vergeleken, zou de voorkeur hebben. Een dergelijke studie zal helaas waarschijnlijk te wensen overlaten, vanwege de lage incidentie van IBTRs, en het aantal afstandsmetastasen na IBTR.

Voor patiënten met een IBTR is ook de axillair chirurgische aanpak niet gestandaardiseerd in de huidige richtlijnen. ${ }^{40}$ Vroeger was een ipsilaterale OKD de standaardprocedure bij alle patiënten met een IBTR, gericht op het bereiken van een maximale locoregionale tumorcontrole. Gelukkig is de de-escalatie van axillaire chirurgie ook in de recidief setting een voortdurende trend geweest. Het standaard uitvoeren van een ipsilaterale OKD is door verschillende redenen twijfelachtig geworden. Ten eerste, is de prognostische impact van de lymfeklierstatus op het moment van IBTR onduidelijk. Ten tweede, is de stadiëring nauwkeurigheid van een ipsilaterale OKD discutabel, aangezien afwijkende lymfatische drainage patronen frequent worden gerapporteerd bij IBTR-patiënten. ${ }^{41}$ Ten slotte, wordt het betwist of het nodig is om patiënten met een IBTR standaard bloot te stellen aan de morbiditeit geassocieerd met een OKD. Verschillende studies hebben het concept van een herhaalde/repeat SWK-biopsie (rSWK-biopsie) geëvalueerd bij patiënten met een IBTR. Over de tijd heeft een toenemend aantal patiënten met een IBTR deze procedure ondergaan. Het identificatiepercentage van een rSWK-biopsie is reeds bevestigd in de Nederlandse "Sentinel node en recidiverende borstkanker"(SNARB) landelijke studie. De grootste studie betreffende dit onderwerp tot nu toe $(N=536)^{.41,42}$ Een rSWK wordt geïdentificeerd bij $62,1 \%$ van de patiënten en blijkt tumor-negatief te zijn in $80,1 \%$. Dit rechtvaardigt het achterwege laten van een cOKD bij deze patiënten, waarmee voor hen de morbiditeit geassocieerd met een OKD bespaard wordt. ${ }^{41}$ Extra-axillaire SWK-en worden gerapporteerd bij 54,1\% van de patiënten met een succesvolle chirurgisch verkregen rSWK. De extra axillaire lymfeklieren zijn klieren die niet worden opgemerkt 
met een standaard ipsilaterale OKD. Bovendien blijkt een rSWK een rol te spelen in het afstemmen van adjuvante behandelingsplannen. ${ }^{41,43}$ Alleen, was de impact van een rSWK op het ontwikkelen van een regionaal recidief en de algehele overleving van IBTRpatiënten tot op heden onduidelijk. Om ervoor te zorgen dat rSWK-biopsie een gelijkwaardige standaard wordt in de zorg voor IBTR patiënten, was het noodzakelijk om een hoge regionale ziektecontrole te waarborgen en om de impact van rSWK op de prognose te onderzoeken. De volgende hoofstukken in dit proefschrift geven hier antwoord op.

Als eerste werd er een up-to-date systematische review uitgevoerd om alle huidige kennis over rSWK-biopsie bij patiënten met een IBTR te identificeren (hoofdstuk 6). Een rSWK wordt met succes geïdentificeerd bij $64 \%$ van alle geïncludeerde patiënten. Dit percentage is significant hoger voor patiënten die eerder behandeld zijn met enkel een SWK-biopsie in vergelijking met de patiënten die eerder een OKD ondergaan. ${ }^{44}$ Met een negatief voorspellende waarde van 96,5\%, blijkt rSWK-biopsie een zeer specifieke procedure. Helaas, rapporteren de geïncludeerde studies te weinig tot geen data om de prognostische waarde van rSWK-biopsie te kunnen onderzoeken en blijft de regionale ziektecontrole na rSWK-biopsie nog steeds onduidelijk. Vandaar zijn voor de opzet van de volgende hoofdstukken de follow-up gegevens van alle SNARB-patiënten verzameld.

Hoofdstuk 7 rapporteert een 5-jaars risico op het ontwikkelen van regionale recidieven na een negatieve-rSWK bij patiënten behandeld zonder COKD, van $4.6 \%$. Slechts $1 \%$ van deze regionale recidieven worden gevonden in de ipsilaterale axilla. ${ }^{45}$ Tijdens de introductie van de SWK-biopsie in de primaire setting werd een ipsilateraal axillaire recidief percentage van $5 \%$ geaccepteerd. Bij dit percentage kon een cOKD veilig worden vervangen door een SWK-biopsie als standaard axillaire stadiëring. ${ }^{46}$ Analoog aan deze percentages, lijkt het aanvaardbaar dat de 1,0\% gerapporteerd in hoofdstuk 7 hierin de vervanging rechtvaardigt van een standaard ipsilateraal COKD door een rSWKbiopsie in het geval van klinisch lymfeklier-negatieve recidief ziekte.

Patiënten met een IBTR hebben, als gevolg van eerdere behandelingen, een hoger risico op het niet identificeren van SWK-en en/of een niet succesvolle chirurgische excisie van SWK-en. Zoals gerapporteerd in hoofdstuk 6, word een rSWK geïdentificeerd in ongeveer $64 \%$ van de IBTR-patiënten. ${ }^{44}$ Voor de overige patiënten is de rSWK-procedure niet succesvol, wat betekendt dat er geen SWK word verkregen. Men zou kunnen zeggen dat bij patiënten met een onsuccesvolle rSWK-biopsie, mogelijk positieve lymfeklieren achterblijven die zich kunnen ontwikkelen tot klinisch detecteerbare lymfeklieren. Hoofdstuk 8 toont een 5 -jaar regionaal recidief percentage van slechts 3,7\% bij patiënten met een dergelijke niet-succesvolle rSWK-biopsie, behandeld zonder cOKD. Een vergelijkbaar percentage met de $4.6 \%$ gevonden in de groep patiënten met succesvol geëxcideerde negatieve rSWK-en. ${ }^{46}$ Dit zou kunnen betekenen dat er, na een niet succesvolle rSWK-biopsie, geen aanvullende behandeling 
van de axilla benodigd is. Huidige resultaten zijn voer voor discussie over de impact van überhaupt enig axillair chirurgisch ingrijpen bij patiënten met een IBTR. Onlangs vroegen Ugras en collega's zich in hun studie al af, of axillaire stadiëring in de vorm van rSWK-biopsie nog wel de moeite waard was. Zij beschrijven een vergelijkbare regionale recidief kans tussen patiënten die een rSWK-biopsie ondergaan met patiënten die geen chirurgisch axillaire stadiëring ondergaan. ${ }^{47}$ Het lage regionale recidiefpercentage van $3.7 \%$ bij patiënten met een niet succesvolle rSWK-biopsie komt overeen met de resultaten die worden gepresenteerd door Ugras et al. Bovendien, met het verbeteren en de opkomst van niet-invasieve diagnostische mogelijkheden als bijvoorbeeld de ${ }^{18} \mathrm{~F}$ FDG PET-CT, lijkt het concept van invasieve stadiëring nog discutabeler.

Weinig tot geen studies hebben tot nu toe gerapporteerd over het risico op afstandsmetastasen en de impact van de status van de rSWK op de prognose van patiënten met een IBTR. Wellicht is rSWK-biopsie inderdaad van beperkte waarde voor patiënten met klinisch lymfeklier negatieve ziekte. Hoofdstuk 9 toont een 5-jaars afstandsmetastasen vrije overleving van $84 \%$ bij patiënten met een IBTR. De prognose is significant slechter voor patiënten met een interval van minder dan 2 jaar tussen de primaire behandeling en de diagnose van IBTR, voor patiënten met een triple-negatieve tumor, en voor patiënten die niet worden behandelend met adjuvante chemotherapie na de diagnose van een IBTR. Maar bovenal word er geen verschil ontdekt in het ontwikkelen van regionale recidieven en/of afstandsmetastasen na IBTR, tussen patiënten met een tumor positief, tumor negatief of niet succesvolle rSWK. De uitkomst van de rSWK-procedure lijkt geen invloed te hebben op de prognose van IBTR patiënten en daarom kan de invloed van een rSWK in klinisch lymfeklier negatieve IBTR-patiënten worden betwist.

Andere artsen beschouwen de procedure van de rSWK als een regionaal therapeutische procedure, omdat het verwijderen van de SWK(en) mogelijk regionale recidieven zou kunnen voorkomen. De SNARB-studie heeft geen patiënten geïncludeerd waarbij geen rSWK-biopsie werd gepoogd ten tijde van IBTR. Daarom kan de therapeutische impact van rSWK-biopsie alleen worden geschat op basis van andere reeds uitgevoerde observationele studies. Zoals gerapporteerd in hoofdstuk 9, is de berekende therapeutische impact slechts $2 \%$. Met andere woorden, 100 rSWK-biopsies moeten worden uitgevoerd om twee regionale recidieven te voorkomen. Het is wederom betwistbaar of de standaard uitvoering van een rSWK-biopsie met deze lage getallen gerechtvaardigd is. Zoals eerder vermeldt, hebben Ugras en collega's al een groep IBTRpatiënten, die een rSWK-biopsie ondergaan vergeleken met een groep IBTR-patiënten die geen chirurgisch axillair procedure ondergaan. Zij vinden geen verschil in het aantal axillaire recidieven tussen beide groepen. ${ }^{47}$ In de primaire setting, rapporteren verschillende studies dat pathologisch positieve lymfeklieren worden gevonden in 27-39\% van de patiënten die een OKD ondergaan. ${ }^{3,6,9}$ Een hoog percentage, terwijl er geen verschil word gevonden in de aantallen van axillaire recidieven tussen patiënten 
met SWK-biopsie en COKD. Blijkbaar, heeft slechts een beperkt deel van alle betrokken positieve axillaire lymfeklieren, de potentie om regionale problemen te veroorzaken. Dit lijkt ook zo te zijn in de recidief setting. Daarbij zorgen adjuvante systemische therapieën en radiotherapie er waarschijnlijk voor dat het risico dat achtergebleven lymfeklieren zich ontwikkelen tot klinisch detecteerbare lymfklieren nog meer wordt verminderd.

Een gerandomiseerde gecontroleerde trial waarin patiënten die een rSWK-biopsie ondergaan worden vergeleken met patiënten zonder axillair chirurgische interventies, zou de voorkeur hebben om de impact van rSWK-biopsie te kunnen beschrijven. Echter, is zo'n randomiseerde gecontroleerde trial waarschijnlijk niet haalbaar, gezien de relatief lage incidentie van IBTR en recidieven na IBTR. Daarentegen is de SNARB-studie de grootste studie tot nu toe, rapporterend over de prognostische impact van rSWKbiopsie in klinisch lymfeklier negatieve patiënten gediagnosticeerd met een IBTR.

Het "National Surgical Adjuvant Breast and Bowel Project" (NSABP B-13 t/m 16, B-18 $\mathrm{t} / \mathrm{m}$ 20, B-22, B-23, and B-25) onderzoek onthulde in twee studies over lymfeklier positieve en lymfeklier negatieve primaire borstkanker patiënten, die allen een OKD ondergingen, de algehele overleving cijfers na IBTR. ${ }^{48,49}$ De axillaire stadiëring procedure ten tijde van IBTR worden in deze studie niet beschreven. Deze studies rapporteren een 5 -jaars overlijdensrisico na IBTR voor primair lymfeklier-negatieve en lymfeklier-positieve patiënten van respectievelijk $33 \%$ en $49 \%{ }^{48,49}$ Deze hoge percentages rechtvaardigen, volgens hen, de aanbeveling om alle patiënten met een locoregionaal recidief te behandelen met systemische therapie, ongeacht de lymfeklier status op dat moment. ${ }^{47}$ De CALOR-studie onderstreept deze uitspraak en adviseert adjuvante chemotherapie voor alle IBTR-patiënten, vooral voor de ER-negatieve groep patiënten. ${ }^{50}$ Aangezien het resultaat van rSWK-biopsie geen prognostische waarde blijkt te hebben, zal een rSWK-biopsie waarschijnlijk de indicatie voor adjuvante systemische ook niet veranderen.

Zoals al eerder aangehaald, is de differentiatie van IBTRs in "echte" borstkanker recidieven en nieuwe primaire borstkanker een onderwerp van discussie. ${ }^{32,51}$ Een nieuwe primaire borstkanker kan worden beschouwd als een primaire borstkanker tumor, en dus ook als zodanig worden behandeld. Vandaar dat de differentiatie van IBTR's een grote invloed heeft op de klinische besluitvorming. Het onderscheid kan worden gemaakt op basis van bepaalde tumor kenmerken, zoals het tumortype, de duur van het ziektevrije interval, de locatie, de betrokken marges na primaire chirurgie en de receptor status. Sommige artsen zijn overtuigd van moleculaire analyses om de clonaliteit tussen de primaire borstkanker en IBTR te onderzoeken. ${ }^{33}$ Echter, nauwkeurige methoden voor het vaststellen van het type IBTR zijn er helaas nog niet. ${ }^{33}$ Bovendien, ontbreken er studies die een vergelijking maken tussen een echt recidief en een nieuwe primaire borstkanker op de recidief vrije overleving. De toekomst zal het ons hopelijk leren. 


\section{Conclusie en aanbevelingen}

De belangrijkste doelen van dit proefschrift zijn het evalueren van de de-escalatie van axillair lymfeklier chirurgie in de primaire en recidief setting van borstkanker. Door de de-escalatie wordt het risico op complicaties minder, zonder dat dit ten koste gaat van de regionale ziekte controle en overleving. De rol van de chirurgie bij de behandeling van borstkanker en hierbij ook de axillaire lymfeklieren is in de loop der jaren sterk verandert, waarbij uitgebreide axillaire chirurgie geleidelijk vervangen is door minder invasieve technieken zoals de schildwachtklier-procedure. De de-escalatie van borstkanker chirurgie wordt benadrukt in dit proefschrift.

Verder toont dit proefschrift onder andere aan, dat SWK-positieve patiënten behandeld met een COKD, een hogere onafhankelijke kans hebben op het krijgen van adjuvante chemotherapie (-immuno) vergeleken met patiënten die enkel een SWK-biopsie ondergaan. Voor oudere patiënten (75 jaar of ouder) heeft het achterwege laten van een cOKD na een positieve SWK-biopsie, als ook het achterwege laten van überhaupt een axillaire chirurgische procedure, geen impact op de regionale recidief kans en 10jaars overleving. Een OKD is tegenwoordig niet langer de standaardbehandeling voor alle borstkankerpatiënten met uitzaaiingen in de SWK(en). Verder onderzoek is nodig om de noodzaak van uitgebreide chirurgie in de axilla van patiënten met grotere tumoren (cT3-4NO) en van klinisch lymfeklier-positieve patiënten te onderzoeken. Wellicht is er (nog) een grotere rol weggelegd voor (neo) adjuvante systemische therapieën en radiotherapie om locoregionale ziekte aan te pakken. De axillaire lymfeklier status is een van de belangrijkste prognostische factoren bij primair borstkanker, waar moleculaire biomarkers met prognostische en voorspellende capaciteiten een opkomende rol innemen in de klinische besluitvorming. ${ }^{15}$

Als gevolg van de veranderingen in axillaire chirurgie in de primaire setting, worden deze veranderingen ook langzaam doorgevoerd bij patiënten gediagnosticeerd met een IBTR. Zo werd het concept van een rSWK-biopsie geïmplementeerd in de recidief setting. Een systematische review onthuld een identificatie percentage van de rSWKbiopsie van $64 \%$. Met een negatieve voorspellende waarde van $96,5 \%$ blijkt rSWKbiopsie zeer specifiek te zijn. Bovendien is het risico op het ontwikkelen van een regionaal recidief na een negatieve rSWK-biopsie laag. Dit resultaat onderstreept de veiligheid van het enkel uitvoeren van rSWK-biopsie in plaats van een COKD in geselecteerde patiënten. Voor patiënten met een niet-succesvolle rSWK-biopsie wordt er geen extra chirurgische behandeling aangeraden, aangezien het regionale recidief risico, na een niet-succesvolle rSWK-biopsie, verwaarloosbaar laag is. Het afstandsmetastasen vrije overlevingspercentage is voor alle SNARB patiënten $84,2 \%$. Een interval van minder dan twee jaar tussen de primaire borstkanker behandeling en de diagnose van het ipsilaterale recidief, een triple-negatieve recidief borstkanker en het niet behandelen met adjuvante chemotherapie zijn onafhankelijke factoren geassocieerd met een slechtere afstandsmetastasen vrije overleving. De associatie tussen de uitkomst van de rSWK-biopie (positieve rSWK, negatieve rSWK of 
onsuccesvolle rSWK-biopsie) en de afstandsmetastasen vrije overleving is statistisch niet significant. Ten slotte lijkt het nuttig om alle patiënten gediagnosticeerd met IBTR, pre-operatief te stadiëren op mogelijke afstandsmetastasen. Er word geen voorkeur gevonden voor de manier van stadiëring middels conventionele beeldvorming of ${ }^{18} \mathrm{~F}$ FDG PET-CT.

Concluderend bevestigt dit proefschrift de-escalatie van axillair lymfeklier chirurgie in de primaire en recidief setting. De landelijke SNARB-studie bevestigd de haalbaarheid, validiteit en veiligheid van een rSWK-biopsie in het geval van lokaal recidief borstkanker en elimineert daarmee de noodzaak van een standaard COKD en de daaraan geassocieerde morbiditeit. Het minimaliseren van het risico op ernstige morbiditeit gerelateerd aan uitgebreide chirurgie, zorgt voor verbetering van de kwaliteit van leven van overlevende borstkanker patiënten. Verder kijkend naar de toekomst; gezien de uitkomst van rSWK-biopsie geen belangrijke prognostische factor voor het ontwikkelen van afstandsmetastasen lijkt te zijn, is de waarde hiervan als stadiëring instrument discutabel. Naar onze mening rechtvaardigen deze resultaten een verandering in de axillaire aanpak van patiënten met IBTR. Een standaard OKD moet achterwegen worden gelaten. De uitvoering van een rSWK-biopsie moet goed worden overwogen en in ieder geval niet standaard worden uitgevoerd. Dit gezien de matige tot wellicht wel geen invloed van rSWK-biopsie op de prognose van patiënten met een IBTR.

\section{Toekomstperspectieven}

Dit proefschrift biedt een volgende stap in de weg naar minder uitgebreide axillaire chirurgie bij borstkankerpatiënten. Hoewel SWK-biopsie al een minimaal invasieve ingreep is, wordt ook deze ingreep geassocieerd met enige morbiditeit; onder andere een 5 -jaars risico tot $5 \%$ op het ontwikkelen van lymfeoedeem. ${ }^{52}$ Gezien de verbeteringen in de overleving van borstkanker patiënten en de aanzienlijke vermindering in de uitgebreidheid van axillaire lymfeklier chirurgie, wordt nu de waarde van überhaupt chirurgische ingrijpen in de oksel, bij zowel primaire als patiënten met een IBTR, bediscussieerd. In het huidige tijdperk, gekend door een

groeiende kennis van tumor biologie, moleculaire biomarkers, gen profileringstechnieken, niet-invasieve diagnostische opties en effectieve adjuvante therapieën, wordt de waarde van axillaire chirurgie als therapeutische en/of als stadiëring procedure steeds minder relevant geacht.

De inzetbaarheid van adjuvante systemische therapie wordt steeds vaker (ook) gebaseerd op primaire tumor biomarkers, en is dus niet enkel afhankelijk van de lymfeklierstatus $^{15}$. Nieuwe bevindingen met betrekking tot SWK-biopsie bij patiënten met een primaire tumor zullen volgen in de toekomst, en daarvoor wachten we met smart de resultaten van de SOUND, POSNOC en BOOG 2013-08 studies af. ${ }^{27-29}$ Deze resultaten zullen de perceptie van de waarde en het doel van lymfeklier biopsie mogelijk sterk beïnvloeden en daarmee ook doen veranderen. Verder onderzoek naar 
moleculaire biologie en genetica, evenals de ontwikkeling van nauwkeurige nietinvasieve technieken zoals behandelingen onder geleide van beeldvorming, zullen toekomstige kanker behandelingen en uiteindelijk die van borstkanker chirurgie veranderen. Onderzoek naar deze onderwerpen wordt aangemoedigd en zal de uitgebreidheid van axillaire chirurgie nog verder minimaliseren. Mogelijk, dat in de toekomst axillaire chirurgie alleen zal worden overwogen bij patiënten met een klinisch regionaal recidief. Daardoor zal er wellicht een verschuiving plaatsvinden in te toekomst, waarin axillaire chirurgie de adjuvante behandeling wordt in de aanpak van borstkanker.

Een betrouwbare manier om het onderscheid te maken tussen een waar recidief IBTR en een borstkanker de novo transformatie kan van grote waarde zijn, aangezien deze de novo borstkankers als primaire borstkankers kunnen worden beschouwd en daarom ook als zodanig kunnen worden behandeld. In de toekomst kan het nuttig zijn om borstkanker karakteristieken en bijvoorbeeld moleculaire analyses naar de clonaliteit tussen borstkankers (d.w.z. Loh-vergelijking) ${ }^{53}$ te onderzoeken in de workup van patiënten met een IBTR.

In navolging van de de-escalerende trend in de behandeling van borstkanker, worden er ook vraagtekens gezet bij de standaard chirurgische borst behandeling van patiënten met een borstkanker recidief. Met name voor die patiënten primair behandeld met een borstsparende therapie, die ten tijde van een IBTR een standaard een salvage mastectomie ondergaan. In de primaire setting is de verminderde uitkomst van een mastectomie in vergelijking met borstsparende therapie, met betrekking tot cosmetiek, perioperatieve risico's en kwaliteit van leven, uitgebreid geëvalueerd. ${ }^{54,55}$ Met het verbeteren van de overleving van patiënten met een IBTR, is aandacht voor deze onderwerpen ook gerechtvaardigd bij patiënten met een IBTR. Tegenwoordig, komen een tweede borstsparende operatie, als ook het voor de tweede keer bestralen van de borst steeds vaker voor. Verschillende behandelmogelijkheden zijn in kleine studies onderzocht, waaronder het uitvoeren van enkel een tweede borstsparende operatie, of een borstsparende operatie gevolgd door een tweede keer volledige borst bestraling, een tweede keer gedeeltelijke borst bestraling, of enkel (gedeeltelijke) tweede keer borst bestraling, brachytherapie of intra-operatieve radiotherapie. Walstra en collega's, presenteren in een systematische review dat een herhaalde borstsparende operatie met of zonder radiotherapie een te overwegen alternatief is in vergelijking met een salvage mastectomie bij geselecteerde patiënten met een IBTR. ${ }^{56}$ De oncologische veiligheid van een tweede borstsparende behandeling, in de zin van lokaal recidief controle en algehele overleving, lijkt te verbeteren indien patiënten ook na een tweede borstsparende operatie worden bestraald. Zo'n bestraling word niet geassocieerd met ernstige toxiciteit of een verminderd cosmetisch resultaat. ${ }^{56}$ Bovendien worden verschillende voordelen van intra-operatieve radiotherapie (IORT) ten op zichtte van adjuvante bestraling gepresenteerd. Met name met betrekking tot het gemak van de 
patiënt, kwaliteit van leven, cosmetisch resultaat en oncoplastische behandelingsopties. $^{56}$ In navolging van de de-escalerende trend in de behandeling van borstkanker, kunnen toekomstige behandelingsstrategieën voor patiënten met IBTR bestaan uit het uitvoeren van een tweede borstsparende operatie met IORT.

Kwaliteit van leven, gezamenlijke besluitvorming tussen patiënt en arts, en minder invasieve technieken zijn belangrijke punten in de aanpak van borstkanker patiënten. Alle primair en recidief borstkanker patiënten moeten worden besproken in een multidisciplinaire overleg, alwaar een geïndividualiseerde behandeling wordt opgesteld op basis van het verwachte risico-voordeel van axillaire lymfeklier- en borst-chirurgie. 


\section{References}

1. Rescigno J, Zampell JC, Axelrod D. Patterns of axillary surgical care for breast cancer in the era of sentinel lymph node biopsy. Ann Surg Oncol 2009;16:687-696.

2. Fisher $\mathrm{B}$, Jeong JH, Anderson $\mathrm{S}$, et al. Twenty-five-year follow-up of a randomized trial comparing radical mastectomy, total mastectomy, and total mastectomy followed by irradiation. N Engl J Med 2002; 347:567-575.

3. Giuliano AE, Hunt KK, Ballman KV, et al. Axillary dissection vs no axillary dissection in women with invasive breast cancer and sentinel node metastasis: a randomized clinical trial. JAMA 2011;305:569-75.

4. Galimberti V, Cole BF, Zurrida S, et al: Axillary dissection versus no axillary dissection in patients with sentinel-node micrometastases (IBCSG 23-01): a phase 3 randomised controlled trial. Lancet Oncol 2013;14:297-305.

5. Savolt A, Polgar C, Musonda P, et al. Does the result of completion axillary lymph node dissection influence the recommendation for adjuvant treatment in sentinel lymph node-positive patients? Clin Breast Cancer 2013;13:364-370.

6. Donker M, van Tienhoven G, Straver ME, et al. Radiotherapy or surgery of the axilla after a positive sentinel node in breast cancer (EORTC 10981-22023 AMAROS): a randomised, multicentre, open-label, phase 3 non-inferiority trial. Lancet Oncol 2014;15:1303-1310.

7. Giuliano AE, Ballman KV, McCall L, et al. Effect of Axillary Dissection vs No Axillary Dissection on 10-Year Overall Survival Among Women With Invasive Breast Cancer and Sentinel Node Metastasis: The ACOSOG Z0011 (Alliance) Randomized Clinical Trial. JAMA 2017;318:918-926.

8. Galimberti V, Cole BF, Viale G, et al. Axillary dissection versus no axillary dissection in patients with breast cancer and sentinel-node micrometastases (IBCSG 23-01): 10-year follow-up of a randomised, controlled phase 3 trial. Lancet Oncol 2018;19:1385-1393.

9. Savolt A, Peley G, Polgar C, et al. Eight-year follow up result of the OTOASOR trial: The Optimal Treatment Of the Axilla - Surgery Or Radiotherapy after positive sentinel lymph node biopsy in earlystage breast cancer: A randomized, single centre, phase III, non-inferiority trial. Eur J Surg Oncol 2017;43:672-679.

10. Poodt IGM, Spronk PER, Vugts G, et al. Trends on Axillary Surgery in Nondistant Metastatic Breast Cancer Patients Treated Between 2011 and 2015: A Dutch Population-based Study in the ACOSOGZ0011 and AMAROS Era. Ann Surg 2018;268:1084-1090.

11. van Roozendaal $\mathrm{LM}$, de Wilt JH, van Dalen $\mathrm{T}$, et al. The value of completion axillary treatment in sentinel node positive breast cancer patients undergoing a mastectomy: a Dutch randomized controlled multicentre trial (BOOG 2013-07). BMC Cancer 2015;15:610.

12. Simons JM, van Nijnatten TJA, van der Pol CC, et al. Diagnostic accuracy of different surgical procedures for axillary staging after neoadjuvant systemic therapy in node-positive breast cancer: a systematic review and meta-analysis. Ann Surg 2019;269:432-442.

13. Carter CL, Allen C, Henson DE. Relation of tumor size, lymph node status, and survival in 24,740 breast cancer cases. Cancer 1989;63:181-187.

14. Ponzone R, Ruatta F, Gatti M, et al. Omission of axillary dissection after a positive sentinel lymph-node: Implications in the multidisciplinary treatment of operable breast cancer. Cancer Treat Rev 2016;48:1-7.

15. Jatoi I, Benson JR, Toi M. De-escalation of axillary surgery in early breast cancer. Lancet Oncol 2016;17:e430-e441.

16. Poodt IGM, Rots ML, Vugts G, et al. The administration of adjuvant chemo(-immuno) therapy in the post ACOSOG-Z0011 era; a population based study. Eur J Surg Oncol 2018;44:1151-1156.

17. Early Breast Cancer Trialists' Collaborative G. Effects of chemotherapy and hormonal therapy for early breast cancer on recurrence and 15-year survival: an overview of the randomised trials. Lancet 2005;365:1687-1717.

18. Paik S, Tang G, Shak S, et al. Gene expression and benefit of chemotherapy in women with nodenegative, estrogen receptor-positive breast cancer. J Clin Oncol 2006;24:3726-3734.

19. Beisecker A, Cook MR, Ashworth J, et al. Side effects of adjuvant chemotherapy: perceptions of nodenegative breast cancer patients. Psychooncology 1997;6:85-93.

20. Schreuder K, Kuijer A, Rutgers EJT, et al. Impact of gene-expression profiling in patients with early breast cancer when applied outside the guideline directed indication area. Eur J Cancer 2017;84:270-277. 
21. Velanovich V, Gabel M, Walker EM, et al. Causes for the undertreatment of elderly breast cancer patients: tailoring treatments to individual patients. J Am Coll Surg 2002;194:8-13.

22. Wyld L, Garg DK, Kumar ID, et al. Stage and treatment variation with age in postmenopausal women with breast cancer: compliance with guidelines. Br J Cancer 2004;90:1486-1491.

23. Biganzoli L, Wildiers $\mathrm{H}$, Oakman $\mathrm{C}$, et al. Management of elderly patients with breast cancer: updated recommendations of the International Society of Geriatric Oncology (SIOG) and European Society of Breast Cancer Specialists (EUSOMA). Lancet Oncol 2012;13:e148-e160.

24. Wildiers $\mathrm{H}$, Kunkler I, Biganzoli $\mathrm{L}$, et al. Management of breast cancer in elderly individuals: recommendations of the International Society of Geriatric Oncology. Lancet Oncol 2007;8:1101-1115.

25. Poodt IGM, Schipper RJ, Vugts G, et al. The rationale for and long-term outcome of incomplete axillary staging in elderly women with primary breast cancer. Eur J Surg Oncol 2018;44:1714-1719.

26. Martelli G, Boracchi $P$, Orenti $A$, et al. Axillary dissection versus no axillary dissection in older T1NO breast cancer patients: 15-year results of trial and out-trial patients. Eur J Surg Oncol 2014;40:805-812.

27. Gentilini O, Veronesi U. Abandoning sentinel lymph node biopsy in early breast cancer? A new trial in progress at the European Institute of Oncology of Milan (SOUND: Sentinel node vs Observation after axillary UltraSouND). Breast 2012;21:678-681.

28. Goyal A, Dodwell D. POSNOC: A Randomised Trial Looking at Axillary Treatment in Women with One or Two Sentinel Nodes with Macrometastases. Clin Oncol (R Coll Radiol) 2015;27:692-695.

29. van Roozendaal LM, Vane MLG, van Dalen $T$, et al. Clinically node negative breast cancer patients undergoing breast conserving therapy, sentinel lymph node procedure versus follow-up: a Dutch randomized controlled multicentre trial (BOOG 2013-08). BMC Cancer 2017;17:459.

30. Geurts YM, Witteveen A, Bretveld R, et al. Patterns and predictors of first and subsequent recurrence in women with early breast cancer. Breast Cancer Res Treat 2017;165:709-720.

31. Bosma SC, van der Leij F, van Werkhoven E, et al. Very low local recurrence rates after breast-conserving therapy: analysis of 8485 patients treated over a 28-year period. Breast Cancer Res Treat 2016;156: 391-400.

32. Huang E, Buchholz TA, Meric F, et al. Classifying local disease recurrences after breast conservation therapy based on location and histology: new primary tumors have more favorable outcomes than true local disease recurrences. Cancer 2002;95:2059-2067.

33. McGrath S, Antonucci J, Goldstein N, et al. Long-term patterns of in-breast failure in patients with early stage breast cancer treated with breast-conserving therapy: a molecular based clonality evaluation. Am J Clin Oncol 2010;33:17-22.

34. Trovo M, Furlan C, Polesel J, et al. Radical radiation therapy for oligometastatic breast cancer: Results of a prospective phase II trial. Radiother Oncol 2018;126:177-180.

35. Neuman HB, Schumacher JR, Francescatti AB, et al. Risk of Synchronous Distant Recurrence at Time of Locoregional Recurrence in Patients With Stage II and III Breast Cancer (AFT-01). J Clin Oncol 2018;36: 975-980.

36. Singletary SE, Allred C, Ashley $\mathrm{P}$, et al. Revision of the American Joint Committee on Cancer staging system for breast cancer. J Clin Oncol 2002;20:3628-3636.

37. Krammer J, Schnitzer A, Kaiser CG, et al. (18) F-FDG PET/CT for initial staging in breast cancer patients Is there a relevant impact on treatment planning compared to conventional staging modalities? Eur Radiol 2015;25:2460-2469.

38. Eubank WB, Mankoff DA, Takasugi J, et al. 18fluorodeoxyglucose positron emission tomography to detect mediastinal or internal mammary metastases in breast cancer. J Clin Oncol 2001;19:3516-3523.

39. Jager JJ, Keymeulen K, Beets-Tan RG, et al. FDG-PET-CT for staging of high-risk breast cancer patients reduces the number of further examinations: A pilot study. Acta Oncol 2010;49:185-191.

40. Derkx F, Maaskant-Braat AJ, van der Sangen MJ, et al. Staging and management of axillary lymph nodes in patients with local recurrence in the breast or chest wall after a previous negative sentinel node procedure. Eur J Surg Oncol 2010;36:646-651.

41. Vugts G, Maaskant-Braat AJ, Voogd AC, et al. Repeat sentinel node biopsy should be considered in patients with locally recurrent breast cancer. Breast Cancer Res Treat 2015;153:549-556.

42. Maaskant-Braat AJ, Roumen RM, Voogd AC, et al. Sentinel Node and Recurrent Breast Cancer (SNARB): results of a nationwide registration study. Ann Surg Oncol 2013;20:620-626. 
43. Maaskant-Braat AJ, Voogd AC, Roumen RM, et al. Repeat sentinel node biopsy in patients with locally recurrent breast cancer: a systematic review and meta-analysis of the literature. Breast Cancer Res Treat 2013;138:13-20.

44. Poodt IGM, Vugts G, Schipper RJ, et al. Repeat Sentinel Lymph Node Biopsy for Ipsilateral Breast Tumor Recurrence: A Systematic Review of the Results and Impact on Prognosis. Ann Surg Oncol 2018;25: 1329-1339.

45. Poodt IGM, Vugts G, Maaskant-Braat AJG, et al. Risk of Regional Recurrence After Negative Repeat Sentinel Lymph Node Biopsy in Patients with Ipsilateral Breast Tumor Recurrence. Ann Surg Oncol 2018;25:1312-1321.

46. de Kanter AY, Menke-Pluymers MM, Wouters MW, et al. 5-Year follow-up of sentinel node negative breast cancer patients. Eur J Surg Oncol 2006;32:282-286.

47. Ugras S, Matsen C, Eaton A, et al. Reoperative Sentinel Lymph Node Biopsy is Feasible for Locally Recurrent Breast Cancer, But is it Worthwhile? Ann Surg Oncol 2016;23:744-748.

48. Anderson SJ, Wapnir I, Dignam JJ, et al. Prognosis after ipsilateral breast tumor recurrence and locoregional recurrences in patients treated by breast-conserving therapy in five National Surgical Adjuvant Breast and Bowel Project protocols of node-negative breast cancer. J Clin Oncol 2009;27: 2466-2473.

49. Wapnir IL, Anderson SJ, Mamounas EP, et al. Prognosis after ipsilateral breast tumor recurrence and locoregional recurrences in five National Surgical Adjuvant Breast and Bowel Project node-positive adjuvant breast cancer trials. J Clin Oncol 2006;24:2028-2037.

50. Wapnir IL, Price KN, Anderson SJ, et al. Efficacy of chemotherapy for ER-negative and ER-positive isolated locoregional recurrence of breast cancer: final analysis of the CALOR trial. J Clin Oncol 2018;36(11):1073-1079.

51. Smith TE, Lee D, Turner BC, et al. True recurrence vs. new primary ipsilateral breast tumor relapse: an analysis of clinical and pathologic differences and their implications in natural history, prognoses, and therapeutic management. Int J Radiat Oncol Biol Phys 2000;48:1281-1289.

52. McLaughlin SA, Wright MJ, Morris KT, et al. Prevalence of lymphedema in women with breast cancer 5 years after sentinel lymph node biopsy or axillary dissection: objective measurements. J Clin Oncol 2008;26:5213-5219.

53. Goldstein NS, Vicini FA, Hunter S, et al. Molecular clonality determination of ipsilateral recurrence of invasive breast carcinomas after breast-conserving therapy: comparison with clinical and biologic factors. Am J Clin Pathol 2005;123:679-689.

54. Chatterjee A, Pyfer B, Czerniecki B, et al. Early postoperative outcomes in lumpectomy versus simple mastectomy. J Surg Res 2015;198:143-148.

55. Chow R, Pulenzas N, Zhang L, et al. Quality of life and symptom burden in patients with breast cancer treated with mastectomy and lumpectomy. Support Care Cancer 2016;24:2191-2199.

56. Walstra C, Schipper RJ, Poodt IGM, et al. Repeat breast-conserving therapy for ipsilateral breast cancer recurrence: A systematic review. Eur J Surg Oncol 2019;45(8):1317-1327. 


\section{Appendix}

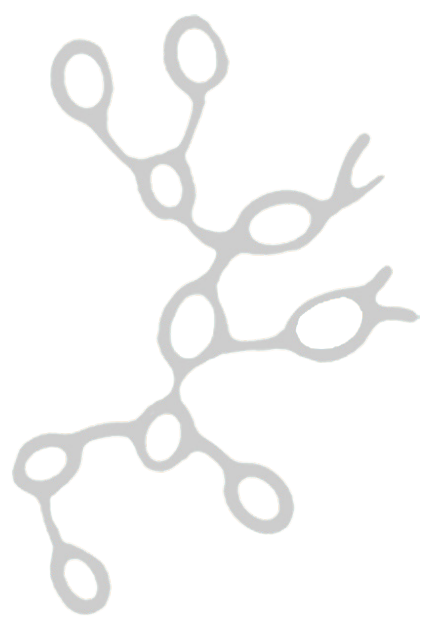

Valorisation

List of publications

Dankwoord

Curriculum Vitae 

Valorisation 


\section{Valorisation}

\section{Introduction}

Breast cancer is the most common form of cancer to affect women and the second most common cancer worldwide. It is a potentially curable disease if diagnosed and treated at an early stage. Survival rates are still increasing, with a current 5-year overall survival of $90 \%$. Treatment of breast cancer consists of excision of the tumor and one or more axillary lymph nodes, combined with (neo)adjuvant hormonal-, chemo-, immuno-, and/or radiotherapy in selected patients. Although survival rates and treatment modalities are improving, quality of life of breast cancer survivors is affected by the treatment associated morbidity. Due to its high incidence, breast cancer has an significant socio-economic impact. The majority of the costs concern healthcare costs followed by costs for productivity losses due to morbidity. Hence it is important to avoid exposure of patients to radical treatments that do not positively affect their survival, while causing lifetime morbidity.

Fortunately, breast cancer surgery has become less invasive over the years. The radical mastectomy described by Halsted has been replaced by the modified radical mastectomy and at present, the majority of breast cancer patients are now treated with breast conserving surgery. Axillary surgery has also become less invasive and the standard performance of an axillary lymph node dissection (ALND) has been replaced by the sentinel lymph node biopsy (SLNB) in clinically node negative breast cancer patients.

This shift towards less invasive treatment is also observed in patients with an ipsilateral breast tumor recurrence (IBTR). The general trend in breast and axillary management is to de-escalate, diminishing the risk of morbidity, while maintaining local and regional control and a high overall survival.

\section{Relevance of scientific results in this thesis}

This thesis addressed several topics of staging and management of the axillary lymph nodes in breast cancer patients with primary and recurrent disease. For a long time, an ALND was the standard procedure to assess the axillary lymph node status of all breast cancer patients. An ALND is associated with significant short- and long-term morbidity; such as upper extremity lymphedema in up to $20 \%$ of patients, seroma, shoulder dysfunction and nerve injury. Patients with ALND related lymphedema report a lower quality of life, higher level of depression and greater difficulty of functioning at work, socially and sexually compared to patients without lymphedema. Over the past years standard ALND was replaced by the less invasive SLNB as staging procedure. In SLNB, 1-2 axillary lymph nodes will be removed, while current benchmarks require at least 10 lymph nodes to be harvested during ALND. Complications associated with axillary surgery, still occur after SLNB, though less frequently and might me more associated 
with axillary radiotherapy. Severe lymphedema occurs in $5 \%$ after a follow-up of 5 years.

In the first part of this thesis, a trend towards less extensive axillary surgery in primary breast cancer patients is shown, illustrated by an overall increase of the use of SLNB and a decrease in the use of completion ALND (CALND) after a positive SLNB. This trend is not only noticed in patients with small tumors (cT1-T2), but also in cT3-T4 breast cancer patients, as well as for patients treated with mastectomy. This reflects the confidence of physicians in the concept that not every tumor-positive sentinel lymph node will develop into clinically detectable axillary disease over time. Notably, sentinel node positive patients who were treated with cALND had a higher independent probability to receive adjuvant chemo(-immuno) therapy, irrespective of the final lymph node status. So, these patients experience not only the morbidity associated with ALND, but also with adjuvant therapy. Over the last decade, there is a growing interest in shared decision-making, in which physicians and patients share treatment preferences together. During this shared-decision making process, it is important to explore the risk of overtreatment and the costs related to treatments.

After showing that the use of extensive axillary surgery is decreasing, in the next chapter of this thesis interest is raised in not using axillary surgery in selected patients. In a study in elderly breast cancer patients (>75 years) omission of complete axillary staging had no impact on regional control and most of the patients died from nonbreast-cancer-related causes. Therefore, even more restrictive axillary treatment might be indicated in this already vulnerable group of patients.

The second part of this thesis evaluates the de-escalation of axillary management in the recurrent breast cancer setting, aiming to prevent morbidity after axillary surgery even further Also, the impact of repeating the SLNB instead of standard ALND on recurrence rates and prognosis was investigated.

For patients with IBTR, adequate preoperative staging is imperative for tailoring optimal treatment plans. However, current guidelines do not provide a clear diagnostic path for this subgroup of patients. Within a large group of recurrent breast cancer patients, we showed a wide variation in the use of conventional imaging (chest X-ray, ultrasound of the liver, computed tomography scans of thorax and/or abdomen, skeletal scintigraphy), 18-F-FDG PET-CT or no preoperative imaging at all. Though, we did not observe a difference in the mean time to detection of distant recurrence, nor in the risk of regional recurrences after IBTR between the groups. Based on these results we cannot recommend a preferred type of preoperative staging. We do recommend to perform some kind of preoperative staging in every IBTR patient, because no staging could lead to unnecessary exposure to potentially harmful surgical and adjuvant treatments. 18-F-FDG PET-CT is one of the available staging modalities, but since 
superiority to other modalities was not proven in this setting, further studies are needed to explore i.e. the cost-effectiveness.

The "Sentinel Node and Recurrent Breast Cancer" (SNARB)-study revealed that a repeat sentinel lymph node biopsy (rSLNB) was a feasible procedure with a high negative predictive value. This warranted the oncological safety and a rapid implementation of the rSLNB was initiated in the recurrent setting. This thesis showed that the risk of developing regional recurrence after a negative rSLNB was low, which supports the safety of rSLNB as a primary nodal staging tool in IBTR patients. Unlike SLNB in the primary setting, performing a rSLNB in patients with IBTR is more challenging, because of previous treatments of the breast and axilla. For some patients the rSLNB was unsuccesfull, which means that no sentinel lymph node could be visualized and/or harvested. Some assumed that in those patients possible positive sentinel lymph nodes would be left behind, which could develop into clinically detectable disease. This thesis reported that the risk of developing regional recurrences after an unsuccesfull rSLNB is low and showed that there is no need for additional axillary treatments. This may indicate that the value of rSLNB in clinically node-negative patients with IBTR might be disputed overall. Especially, since we showed that the outcome of rSLNB appears to have minor impact on the prognosis of patients with IBTR.

Therefore, the detection and removal of every metastatic lymph node might not be mandatory any longer. This creates new opportunities to further de-escalate axillary management, by omitting even the less invasive ( $r$ )SLNB procedure in patients with clinically node negative disease.

\section{Target population}

The results of this thesis are relevant for breast cancer patients with primary breast cancer and with an ipsilateral breast tumor recurrence, because it offers more information about axillary nodal staging and treatment in the primary and recurrent setting, the impact of axillary surgery on the use of adjuvant chemo (-immuno) therapy and the use of different pre-operative imaging modalities. Therefore, it is especially of interest for clinicians involved in multidisciplinary breast cancer treatment.

Lastly, the contents of this thesis are relevant for expert panels, which are responsible for the development of the national and international guidelines in breast cancer treatment.

\section{Innovation and future}

The de-escalation of breast and axillary surgery is a topic of debate in breast cancer treatment. This thesis provides next steps towards less invasive axillary surgery and towards possibly no surgical intervention in the axilla of breast cancer patients. To perform a standard ALND in clinically node negative (primary and recurrent) breast cancer patients is nowadays obsolete. Furthermore, since the outcome of rSLNB was 
not an important prognostic factor, its value as a staging tool in IBTR-patients appears also to be disputable. The de-escalation of axillary surgery could theoretically increase the risk of regional recurrences, yet this disadvantage can be well balanced against the treatment associated morbidity of SLNB and ALND.

Ongoing studies are determining the value of SLNB versus no SLNB in the primary setting and results have to be awaited. In the recurrent setting, a randomized control trial would also be preferable, however such a trial is not feasible due to the low incidence of IBTR and recurrences after IBTR. The SNARB study is the largest study published on rSLNB, though did not include patients without an attempt of rSLNB. A multi-center prospective trial, including patients with rSLNB and without rSLNB, can be set up to evaluate and emphasize whether it is oncological safe to omit rSLNB in the recurrent setting. Though, due to a possible low accrual, such trials are frequently unable to inform clinical practice or benefit patients.

Highly accurate noninvasive techniques, such as axillary MRI and 18-FDG-PET-CT, are being evaluated for their ability to identify axillary tumor burden in clinically node negative patients. In the future, this might replace the relatively invasive SLNB. Research on these modalities in primary breast cancer is encouraging and trials should be conducted to confirm the use and cost-effectiveness of these techniques in the primary and recurrent setting. In the future axillary surgery might become the adjuvant treatment in the setting of breast cancer treatment.

Last, following the trend to de-escalate, the omission of a standard salvage mastectomy for all patients with an IBTR could be the next step. A prospective clinical trial investigating the feasibility of repeat breast conserving therapy for patients with an IBTR is currently designed. 

List of publications 


\section{List of publications}

Poodt IGM, Walstra CJEF, Vugts G, Maaskant-Braat AJG, Voogd AC, Schipper RJ, Nieuwenhuijzen GAP; Sentinel Node And Recurrent Breast Cancer (SNARB) study group. Low Risk of Development of a Regional Recurrence After an Unsuccessful Repeat Sentinel Lymph Node Biopsy in Patients with Ipsilateral Breast Tumor Recurrence. Ann Surg Oncol. 2019 Aug;26(8):2417-2427

Poodt IGM, Schipper RJ, de Greef BTA, Vugts G, Maaskant-Braat AJG, Jansen FH, Wyndaele DNJ, Voogd AC, Nieuwenhuijzen GAP; Sentinel Node And Recurrent Breast Cancer (SNARB) Research Group. Screening for distant metastases in patients with ipsilateral breast tumor recurrence: the impact of different imaging modalities on distant recurrence-free interval. Breast Cancer Res Treat. 2019 Jun;175(2):419-428

Poodt IGM, Vugts G, Schipper RJ, Roumen RMH, Rutten HJT, Maaskant-Braat AJG, Voogd AC, Nieuwenhuijzen GAP; Sentinel Node and Recurrent Breast Cancer (SNARB) study group. Prognostic impact of repeat sentinel lymph node biopsy in patients with ipsilateral breast tumour recurrence. Br J Surg. 2019 Apr;106(5):574-585

Poodt IGM* Spronk PER, Vugts G, van Dalen T, Peeters MTFDV, Rots ML, Kuijer A, Nieuwenhuijzen GAP, Schipper RJ. Trends on Axillary Surgery in Nondistant Metastatic Breast Cancer Patients Treated Between 2011 and 2015: A Dutch Population-based Study in the ACOSOG-Z0011 and AMAROS Era._Ann Surg. 2018 Dec;268(6):1084-1090

* :both authors contributed equally and should be considered first author

Poodt IGM, Schipper RJ, Vugts G, Woensdregt K, van der Sangen M, Voogd AC, Nieuwenhuijzen GAP. The rationale for and long-term outcome of incomplete axillary staging in elderly women with primary breast cancer. Eur J Surg Oncol. 2018 Nov;44(11):1714-1719

Poodt IGM, Rots ML, Vugts G, van Dalen T, Kuijer A, Vriens BEPJ, Nieuwenhuijzen GAP, Schipper RJ. The administration of adjuvant chemo(-immuno) therapy in the post ACOSOG-Z0011 era; a population based study. Eur J Surg Oncol. 2018 Aug;44(8):11511156

Poodt IGM, Vugts G, Schipper RJ, Nieuwenhuijzen GAP. Repeat Sentinel Lymph Node Biopsy for Ipsilateral Breast Tumor Recurrence: A Systematic Review of the Results and Impact on Prognosis. Eur J Surg Oncol. 2018 Aug;44(8):1151-1156 
Poodt IGM, Vugts G, Maaskant-Braat AJG, Schipper RJ, Voogd AC, Nieuwenhuijzen GAP; Sentinel Node and Recurrent Breast Cancer (SNARB) study group. Risk of Regional Recurrence After Negative Repeat Sentinel Lymph Node Biopsy in Patients with Ipsilateral Breast Tumor Recurrence. Ann Surg Oncol. 2018 May;25(5):1312-1321

Walstra CJEF, Schipper RJ, Poodt IGM, van Riet YE, Voogd AC, van der Sangen MJC, Nieuwenhuijzen GAP. Repeat breast-conserving therapy for ipsilateral breast cancer recurrence: A systematic review. Eur J Surg Oncol. 2019 Aug;45(8):1317-1327

Poodt IG, van Dijk MM, Klein S, Hoogbergen MM. Complications of Lower Body Lift Surgery in Postbariatric Patients. Plast Reconstr Surg Glob Open. 2016 Sep 29;4(9): e1030 

Dankwoord 


\section{Dankwoord}

Dit proefschrift was nooit tot stand gekomen zonder de hulp, inzet en aanmoedigingen van vele collega's, patiënten, vrienden en familie. Enkelen van hen wil ik op deze plaats in het bijzonder bedanken.

Allereerst mijn promotor, prof. dr. Harm Rutten. Bedankt voor uw begeleiding tijdens dit promotietraject en het vertrouwen dat u mij altijd geeft. Ik was vereerd toen ik in uw mailconversatie las dat u het had over een "shooting star". Ik hoop dat ik op wetenschappelijk als op chirurgisch technisch gebied nog veel van u mag leren.

Vervolgens mijn copromotores, Grard Nieuwenhuijzen, Robert-Jan Schipper en Guusje Vugts.

Grard, vanaf moment 1 was jij mijn directe onderzoeksbegeleider en stond jij altijd klaar voor vragen, suggesties of adviezen. Jouw enthousiasme en energie zijn een grote inspiratie bron en hebben mij er toe gezet om dit promotietraject vlot af te ronden, als ook om aan de slag te gaan als ANIOS IC en later chirurgie. Niet alleen op wetenschappelijk, maar ook op chirurgisch, als ook op persoonlijk gebied heb je me altijd van goeie adviezen voorzien. Jij geeft mij vertrouwen en het gevoel dat je achter me staat. Buiten dit kan ik ook ontzettend met je lachen, je bent een levensgenieter en dat breng je over op mensen. Hopelijk kan ik nog vaak luisteren naar jouw mooie verhalen en genieten van een borrel op een feest of op de wintersport. Bedankt voor alle inspiratie die je mij hebt gegeven en ik hoop nog veel van jouw kennis en kunde mee te kunnen pikken.

Lieve Robert-Jan en Guusje, wat bijzonder dat niet alleen twee collega's, maar ook twee goede vrienden copromotores zijn. Super knap hoe jullie aan het begin van jullie carrière al zoveel bereikt hebben. Schipper, jij kwam als eerste met het voorstel voor mij om dit promotietraject in Eindhoven te gaan doen. Dat terwijl ik toen nog in Rotterdam woonde en wij beide die stad en Feyenoord fantastisch vinden. Wat hebben we daar plezier gemaakt in De fontein en café Ari! We kunnen samen goed feest vieren, maar we hebben samen ook veel uren aan de wetenschap gespendeerd. Ik sta er altijd weer van versteld hoe jij uit je hoofd elk artikel oprakelt, welke ik dan weer goed kon gebruiken als referentie. Je onuitputtelijke ideeën voor nieuwe onderzoeksvragen en discussies. Met jouw kennis en vastberadenheid weet ik zeker dat ik ooit sta te luisteren naar jouw oratie. Super bedankt voor alle uren die je in mijn proefschrift heb gestopt en ook zeker alle gezellige momenten. Wintersport houden we er in, fel zijn en plezier maken!

Lieve Guusje, ik stapte de SNARB trein op, die jij erg netjes had achter gelaten. Dit resulteerde er in dat ik direct aan de slag kon gaan en me de SNARB-data eigen kon maken. Bij vragen en problemen kan ik altijd snel bij je terecht om met een goed advies 
en wat wijntjes later weer weg te gaan. Bedankt voor je betrokkenheid en alle mooie momenten ook buiten werk. Dat ene weekend dat we samen uit een vliegtuig sprongen zal ik nooit vergeten, wat een kick was dat! Ik kan me vaag herinneren dat we dit nog een keer zouden herhalen met Grard en Robert-Jan wanneer ik gepromoveerd zou zijn? Guus, ik vind het ontzettend knap hoe jij alles kunt combineren en nu ook nog eens de lieve mama bent van Hila. Op naar vele lunches, sushi en wijntjes. En, ik heb heel veel zin om dadelijk je vaste oppas te zijn als buurvrouw in Den Bosch!

Natuurlijk wil ik ook de leden van de beoordelingscommissie, prof. dr. V.C.G. TjanHeijnen, prof. dr. L.J. Boersma, prof. dr. J.A. Roukema, prof. dr. E.J.Th. Rutgers en dr. M.L. Smidt, bedanken voor het aanvaarden van de positie in de beoordelingscommissie. Veel dank voor uw interesse en het beoordelen van dit proefschrift. Tevens wil ik de overige leden bedanken voor het optreden als opponent tijdens mijn verdediging. Ik kijk er naar uit om met $u$ van gedachten te wisselen tijdens de verdediging.

Adri, bedankt voor al je hulp, waardevolle aanvullingen en commentaar op een aantal stukken in dit proefschrift. Jouw kennis van de literatuur en de wetenschappelijke Engelse taal bracht elk manuscript naar een hoger niveau. Daarnaast wil ik je bedanken voor altijd die persoonlijke noot. Hoe druk je ook was, in elk bericht bleek je oprechte interesse.

Voor zover nog niet benoemd, dank aan alle coauteurs van de verschillende hoofdstukken in dit proefschrift. Jullie kritische blik, analyses en aanvullingen hebben de manuscripten van meer kwaliteit voorzien.

Speciale dank gaat uit naar alle collega's chirurgie; chirurgen en arts-assistenten in het Catharina Ziekenhuis in Eindhoven. Het "Cathrien" is een ziekenhuis waar ik altijd met veel plezier naar toe ga en waar ik vele vriendschappen gesloten heb. Hier heb ik mijn eerste stappen op medisch, wetenschappelijk en chirurgisch gebied gezet. Bedankt voor een mooie tijd, waarin ik veel geleerd heb, maar ook zeker ruimte was voor gezelligheid. Heerlijk hoe de Brabantse gezelligheid ook tot zijn recht komt in een ziekenhuis en in de omgang met collega's, verpleegkundige, bazen en andere specialisten.

IC collega's, ook jullie bedankt voor de leuke en leerzame tijd. Tijdens mijn tijd op de IC heb ik weer kunnen ervaren hoe leuk het is om in de kliniek te werken en daarbij nog veel werk kunnen verzetten aan mijn proefschrift. Jullie hebben mijn chirurgische blik weten te verbreden. Lieve IC chickies, die maandelijkse etentjes houden we er zeker in.

Graag wil ik ook alle mensen op "zolder" bedanken. Onderzoek doen kan soms saai zijn als je dagen lang achter je computer zit, maar wat hebben wij daar een lol gehad. Bedankt voor alle gouden uitspraken, de gesmolten ontbijt koek op de wc, lelijke foto's 
aan de muur, vele festivals, de tourpoule, eindeloze bestellingen koffiecups, laven, nassen, slurpen, Sal grasse, en de plezierlijst aan hitjes. Hopelijk kunnen we nog lang met elkaar samenwerken.

Oranje rood dames 4, wat ben ik blij dat Sas me overtuigd heeft om weer te gaan hockeyen. Bij jullie in het team werd ik direct met open armen ontvangen en heb ik me altijd fijn gevoeld! Bedankt voor de goede momenten van ontspanning na het werk, het lekkere potje hockey dat we nog steeds laten zien, de hoofdpijntjes op maandagochtend en de gezelligheid naast het veld. Ron dat zondagse speciaal biertje om het af te leren, blijft toch heerlijk he.

Dwarsjes, "Die wie altijd rebels zijn". Wat een mooie studententijd hebben wij in het Maastrichtse gehad en wat worden we nu volwassen. Trouwerij, samenwonen, baby's krijgen en emigreren, wat ben ik stuk voor stuk trots op jullie! Die ranking lijst moet toch echt weer een keer boven tafel komen, want wie had dit allemaal van te voren bedacht!

Lieve Annie, helaas moeten we jou vaker missen. Jij hebt als enige gedurfd je spullen te pakken en naar het buitenland te vertrekken. En niet zomaar op vakantie, maar aan het werk voor artsen zonder grenzen in Ethiopië. De verhalen die je stuurt zijn soms beangstigend, is het daar wel veilig genoeg? Vaak dapper, heftig en vindingrijk. Super knap hoe je orde in de chaos creëert en na tegenslagen je zelf weer enthousiast krijgt. Ik ben ongelofelijk trots, zet om Dekker!

Oud Dames 1 Weert; Gene, Jenna, Bien, Lau aka scheetje mob, Ali, Annie en Lies. Dat we toch nog steeds geen creatievere naam hebben verzonnen voor ons stel gekkies, is toch raar. Lieve meiden, we kennen elkaar al sinds kleins af met een stick in de hand op het hockeyveld. Samen hebben we veel strijd geleverd op het veld; kapotte knieën, tanden, gebroken handen en benen. Daarnaast hebben we ook veel strijd geleverd naast het veld. Ik weet nog steeds niet waar we beter in zijn op of naast het veld. De jaarlijkse uitjes als, het Paasweekend met schnappie op wintersport, de hilarische sinterklaasgedichten, de Secends, carnaval en kamelenrace op de kermis, blijven iets om naar uit te kijken. Ons kennende staan we over 50jaar nog steeds te kamelen racen! Op naar weer een jaar met tageshit, vliegende herten, aubergines en trouwringen.

Lies speciale dank voor jou voor het ontwerpen van de voorkant van dit boekje, ik had het me niet mooier kunnen voorstellen!

Bedankt maatjes, Mad, Mol (mijn geweten), en An (biertje) voor al die mooie momenten in Maastricht. Als kroeg meubilair hebben wij de grootste omzet gedraaid, gouden tijden voor de vereniging. De zondag is de nieuwe maandag, leeg is nieuw, alle danspasjes in de alla, het bourgondische leventje wat voor ons gemaakt is, Orlando and Bloom?, can I have a word with you? Ik ben blij dat we nu weer wat meer tijd hebben gevonden om elkaar vaker te zien, want dit blijven gouden momenten. 
JOEHOE family, big summer blowout! Ik lig weer plat. Lieve, gekke, fantastische, soms botte, grappige, betrouwbare, altijd genietende, dikke vriendinnen van me aka Slytherin. Wat hebben wij de afgelopen jaren al veel avonturen met elkaar beleefd. Van Maastricht nu uitgewaaid over Nederland, maar gelukkig is afstand voor ons geen issue. Wij kunnen bij elkaar heerlijk onszelf zijn en meer dan dat is niet nodig. Londen, Ibiza, Dublin, Kopenhagen, de Balkan en ga maar door. Ik heb zin om weer op avontuur te gaan, wat jullie?

Lieve Val en Juul, Maison Minion was fantastisch. Ik ben blij dat alle toevalligheden toen op het juiste moment bij elkaar kwamen en wij samen konden gaan wonen. Met Kief als huisdier erbij, maakte dit het plaatje compleet.

Lieve Cumbo's wat hebben wij een fantastische club; meliorem voor de toekomst daarop heffen wij het glas en over vele jaren drinken wij nog steeds op hoe mooi het was!

Een speciaal woordje voor mijn beide paranimfen. Lieve Leanne Jannetje Provina Vaartjes. Ik kon het toch niet laten om deze geweldige naam nog eens volledig uit te schrijven. In Maastricht hebben we elkaar leren kennen, waar het al snel een match bleek te zijn. Heerlijk hoe jij kunt genieten om mensen op de kast te jagen, uit de tent te lokken en discussies aan te gaan. Jouw boeven streken en reisgierigheid, maakt het nooit saai om met jouw op pad te zijn. Naast deze streken ben je een fantastische vriendin, zo zorgzaam, betrouwbaar en loyaal ken ik er weinig. Waar we beide vaak genoeg twijfels hebben, kunnen we daar samen uren over praten en Jannie geloof het of niet, wij komen er wel ;). Lieve Jannie, het begon in Maastricht, de vele mooie avonden als tonspelers in de kroeg, het ene nachtje logeren wat resulteerde erin dat ik meer dan een jaar lang bij jou op de pallet heb gebivakkeerd, de waanzinnige ongelofelijke reis van Jannie en Poodt in Zuid-Afrika, tot het nu zijn van buren in Eindhoven. Wij hebben aan een half woord genoeg om te begrijpen wat er speelt. Samen gaan we, letterlijk en figuurlijk, nog zo veel ongelofelijke reizen maken en wat heb ik daar een zin zeg. Jannie je bent een super vriendin en ook al ga ik je verlaten als buurvrouw, onze deuren staan altijd voor elkaar open!

Lieve sas, het lijkt alsof ik je al van kinds af aan ken, maar voor ons begon het ook allemaal in Maastricht. Beide pas de derde keer ingeloot voor Geneeskunde, wat er toe leidde dat we gedurende onze opleiding nagenoeg alles samen deden en ons in de UB middels snoepringen verloofd hebben (Ri ik was eerder;)). Misschien maar goed dat we niet ook bij elkaar in de jaarclub en dispuut zaten. Tijdens de eerste jaren van gezondheidswetenschappen had $\mathrm{jij}$ al een betere ruggengraat om te gaan studeren. Mede dankzij jouw ruggengraat is dit boekje tot stand gekomen, want gelukkig heb jij mij tijdens ons soccie jaar en alle andere jaren naar de unie weten te slepen. Onze vriendschap is uitgegroeid tot iets onvoorwaardelijks op de Kruisstraat. Samen daar wonen was meer dan fantastisch; het trainen voor mud masters, om 6uur s'ochtends hardlopen in de sneeuw, van elke groente soep maken, de Woenselse markt, Flying 
Dutch vanaf het balkon, de soap rond jouw liefde met Ri (en kijk eens wat er van is gekomen, Luca zo'n mooi lief mannetje), de soap rond mijn escapades, het ontdekken van tinder, de hüttenkäse van de Lidl, Let it go, maar bovenal natuurlijk al onze balkon momentjes waarbij we zoveel hebben gelachen en besproken. Die balkonmomentjes zijn goud, en soms willen we daar graag weer even naar toe terug. Toen ik begon aan dit onderzoek hebben we nog vaak gegrapt wie de laatste persoon zou zijn in mijn dankwoord en dat dat toch echt jij ging zijn. Moet je nu eens zien wat er over afgelopen jaren weer allemaal veranderd is. Ik heb zowaar iemand anders die ik als laatste persoon benoem en jij een fantastisch gezin met Ri en Luca, die ook nog eens mijn beste maatjes zijn!! Ri jij bedank voor jouw vertrouwen, eeuwige felheid en plezier en dat jij mijn lieve vriendinnetje zo gelukkig maakt. Lieve sas, bedankt voor jouw onvoorwaardelijke vriendschap en energie, dat je me door en door kent, uit de goot trekt waar moet en altijd klaar staat voor me. Wat ben ik trots op jou, een fantastische vriendin, liefdevolle verloofde en bovenal allerleukste mamma!

Familie van Eck, gekke buurtjes. Bedankt voor een fantastische jeugd op de Rubenslaan en de niet te vergeten vakanties. De opvang van mij in Malawi en fantastische reis in Tanzania. Lieve Rita Corita, bedankt dat ik altijd bij je terecht kan, van vroeger toen ik bang was alleen thuis tot nu voor een knuffel, kop thee, wijntje en goed advies!

Lieve zussen, Aniet en San. Bedankt voor al het vertrouwen dat jullie me altijd hebben gegeven. Jullie hebben me heel wat levenslessen geleerd en nog steeds blijf ik veel van jullie leren. Als jongste van de drie was ik soms de roekeloze, egoïstische puber en student, en jullie hebben me ondanks die streken nooit laten vallen. Aniet ik zag jou als mijn tweede moeder en ik vond het dan ook verschrikkelijk toen je uit huig ging om te studeren. Wanneer je er weer was hing ik letterlijk aan je been. San, ik wordt op de SEH nu de kleine Poodt genoemd en wat ben ik daar trots op. Ik vergeet nooit de verwijzing van huisarts A. Poodt naar SEH-arts S. Poodt naar toen nog semi-arts I.Poodt.

Bedankt voor het feit dat als ik bij jullie ben, ik me meteen thuis voel en onderdeel ben van een fantastisch gezin. Lieve Aniet, Bas, Wout, Marit en Jasper, wat een mooie stap hebben jullie gemaakt naar een fantastisch huis. Heerlijk grote tuin, snoeien van de bomen, zelf maken van jam en appelmoes, en Wout, Marit en Jasper hebben alle ruimte om lekker te ravotten. Heel veel plezier in dit mooie huis en ik hoop vaak langs te komen met mijn wielrenfiets! Lieve San, Maarten, Tijn, Mink en Roef, als iemand moet leren hoe je een huis bouwt, verwijs ik ze door naar jullie. Ik vraag me nog steeds af hoe jullie het voor elkaar hebben gekregen om een huis te bouwen, naast jullie drukke banen en drie jongens. Ook bij jullie wordt ik altijd met een warm gevoel ontvangen en staat altijd de borrel klaar!

Lieve papa en mama. Jullie kleine meid, Ingiepingie, is dit proefschrift het bewijs dat ze nu dan eindelijk volwassen geworden? Wat hebben jullie je vaak zorgen gemaakt en gedacht wat gaat ze nu weer doen.. Ondanks dat, hebben jullie me altijd gesteund en 
vrij gelaten in mijn keuzes. Door jullie heb ik geleerd wat je kunt bereiken als je er maar achter staat, er voor vecht. Ik heb veel bewondering hoe jullie alles regelen en altijd hebben geregeld. Het wonen in Frankrijk, een gezin met drie meiden, de verhuizing terug naar Nederland waar papa nog langer in Frankrijk moest blijven. Jullie drukke levens naast het drukke werk, maar onvoorwaardelijke liefde voor ons. De ruimte die jullie creëren voor ons om alles te mogen ontdekken. Binnenkort zijn jullie beide met pensioen, kunnen jullie genieten en wat hebben jullie dat verdiend zeg. Maar dat genieten doen jullie eigenlijk altijd al, veel mooie reizen, bridgen, fietsen, zingen en natuurlijk de kleinkinderen. Het is fantastisch om te zien hoe jullie dolverliefd en gek met ze zijn. Jullie zijn bewonderingswaardige ouders met zoveel liefde en vertrouwen in ons en bovenal te gek, gave opa en oma, ontelbaar veel dank daarvoor!

Lieve Daan, je hebt erg veel geduld met me moeten hebben, maar kijk nu waar je staat, de laatste plek in mijn dankwoord! Wat ben ik blij dat de aanhouder wint, en jij een aanhouder bent. Ik ken je ongeveer net zolang als dat ik bezig ben met mijn promotie, want net toen ik jou leerde kennen vertrok ik eigenlijk weer naar Eindhoven, echte liefde dus...Toch bleven we elkaar zien en dat vond ik stiekem wel erg leuk. Nu inmiddels hebben we bewezen dat we op weinig vierkante meter elkaar niet gek maken en gaan we samen een super spannende maar leuke stap maken naar ons huisje in Den Bosch! Lieve Daan, bedankt dat je er altijd voor me bent en voor me zorgt. Dat je zo ondernemend bent en mij daarin meeneemt. Dat je me weet op te vrolijken als ik chagi of hangry ben en helpt als ik weer even iets niet helemaal goed gepland hebt. Ik heb super veel zin om samen nog zoveel van de wereld te gaan zien. Lief mannetje, witluf! 



\section{Curriculum Vitae}

Ingrid Gerdine Marthe Poodt was born on 19 June 1988 in Saint Doulchard, France, and raised in Weert, the Netherlands. In 2006 she graduated from the Bisschoppelijk College in Weert, the Netherlands. After her graduation, Ingrid first took a sabbatical year to work, volunteer and travel in Africa.

The third time she attented the national lottery for medical school, she was admitted and started medical school at the University of Maastricht (2010-2016). In this period she was a member of the student association Circumflex and participated in a couple of committees.

During her interships she spend a trimester in the Chulalongkorn Hospital in Bangkok, Thailand to study surgery and radiology and she followed her gynaecology \& obstetric internship at the Pretoria Academic Hospital, South Africa. Ingrid completed medical school with an elective in plastic surgery at the Catharina Hospital Eindhoven.

After obtaining her medial degree in 2016, she started to work at the Daniel den Hoed department of medical oncology at Erasmus MC, in Rotterdam. After a year she went back to Eindhoven, where she started as a PhD student under the supervision of Prof. dr. Rutten, dr. Nieuwenhuijzen, dr. Vugts and dr. Schipper. The main goal of this PhD project was to report on the de-escalation of axillary management in primary breast cancer, and to further reduce invasive lymph node surgery in the local recurrent setting. The results are discribed in this thesis.

In March 2018, she started to combine her research with working in the clinic and started as a resident in the ICU department. Soon after she switched to the Surgery department. Currently she is working at the department of Surgery at the Catharina Hospital, Eindhoven. 
